Portland State University

PDXScholar

$1-1-1982$

\title{
The articulation of formal and informal helping: the influence of organizational context on relationships between professional and lay caregivers
}

Priscilla J. Kimboko

Portland State University

Follow this and additional works at: https://pdxscholar.library.pdx.edu/open_access_etds Let us know how access to this document benefits you.

\section{Recommended Citation}

Kimboko, Priscilla J., "The articulation of formal and informal helping: the influence of organizational context on relationships between professional and lay caregivers" (1982). Dissertations and Theses. Paper 352.

https://doi.org/10.15760/etd.352

This Dissertation is brought to you for free and open access. It has been accepted for inclusion in Dissertations and Theses by an authorized administrator of PDXScholar. Please contact us if we can make this document more accessible: pdxscholar@pdx.edu. 
THE ARTICULATION OF FORMAL AND INFORMAL HET.PING:

THE INFLUENCE OF ORGANIZATIONAL CONTEXT ON REIATIONSHIPS

BETIEEN PROFESSIONAL AND LAY CAREGIVERS

by

PRISCIIIA J. KIMBOKO

A dissertation submitted in partial fulfillment of the requirements for the degree of

DOCTOR OF PHIIOSOPHY

in

URBAN STUDIES

Portland State University

1982 
TO THE OFFICE OF GRADUATE STUDIES AND RESEARCH:

The members of the Camittee approve the dissertation of Priscilla J. Kimboko presented July 28, 1982.
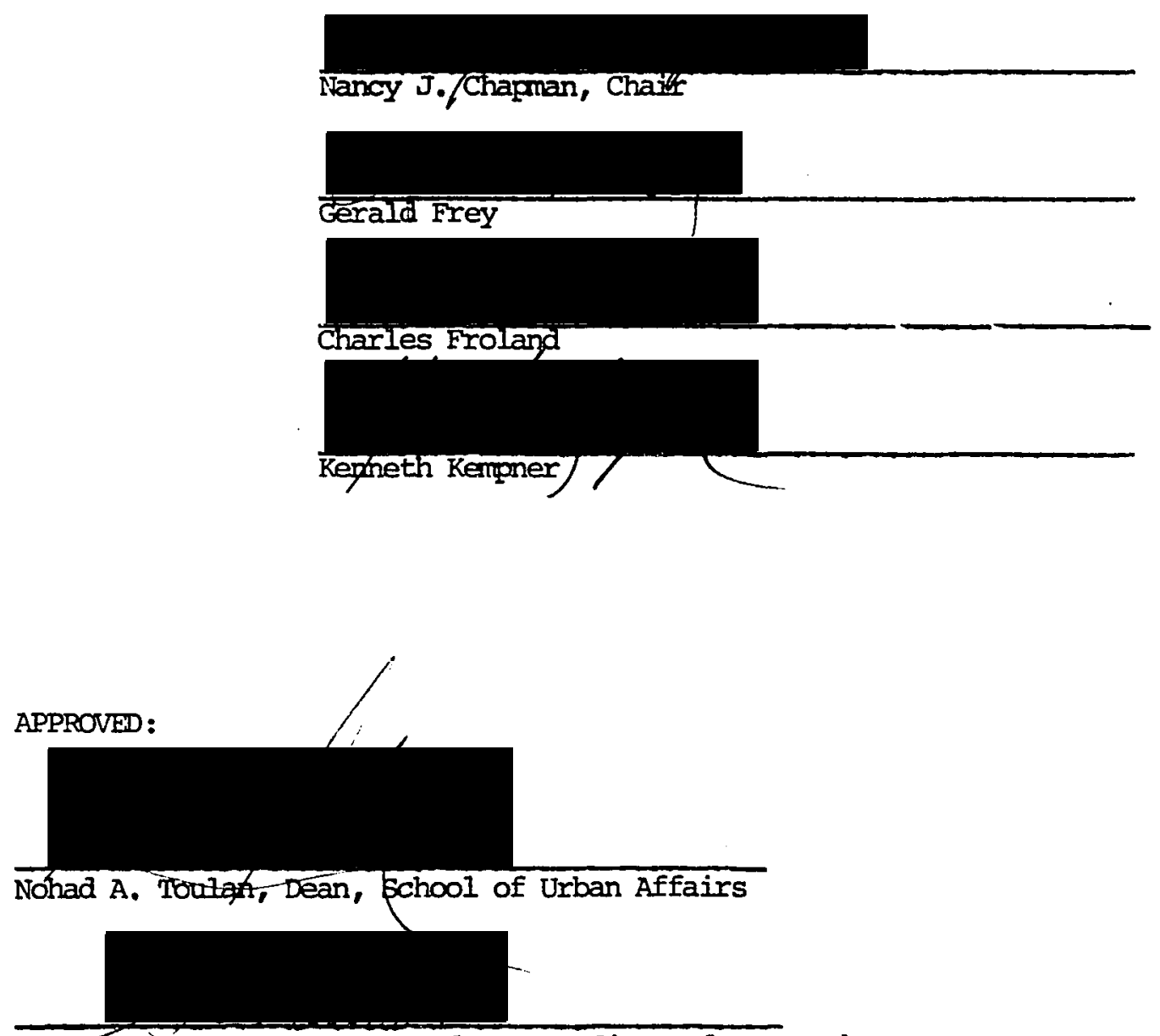

Stanley E. Rauch, Dean, Graduate Studies and Research 
AN ABSIRACT OF THE DISSERTATION OF Priscilla J. Kimboko for the Doctor of Philosophy in Urban Studies presented July 28, 1982.

Title: The Articulation of Formal and Informal Helping: The Influence of Organizational Context on Relationships Between Professional and Lay Caregivers

APPROVED BY MEMBERS OF THE DISSERTATION COMMITTEE:
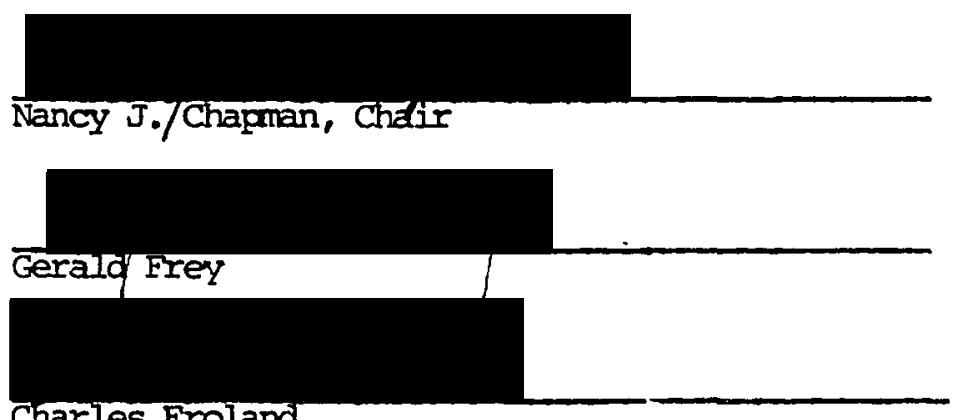

Charles Froland

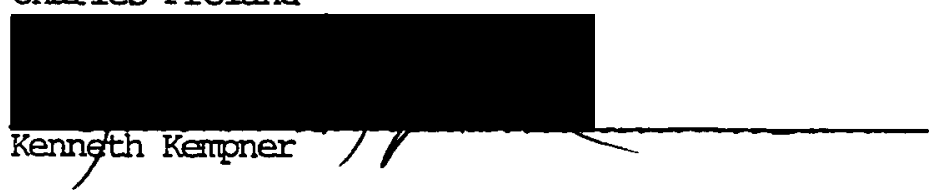

This research is an exploratory study of thirty human service agencies' programs to link their services to informal helpers in their camunities. The helpers were persons identified as important helping resources to persons in their own social networks, who were often also clients of the service agency. The thirty agencies were drawn from across the nation, and served several different types of client populations and needs.

Models fram practice and theory suggest that linkages between the 
formal and informal caregiving systems should be modeled aftor primary type relations, that is, those that are informal and personal in character. Other research and literature on organizations suggests, however, that the tendency of the formal service system is to impose its own standards on its linkages, in order to ensure its own control and accountability.

The primary question of this research was how agency context influenced the structure of the relationships between agency staff and informal caregivers. Specific questions asked were: (1) What organizational attributes act as barriers to, or facilitators of, informally structured relationships? (2) Does the perception of the program innovation moderate the influence of organizational attributes on the relationship structure?

Data on the agency programs were gathered through intensive site visits, using discussions, observations, and document reviews. These data were converted into case studies and content analyses. Pultiple item scales were constructed to measure different attributes of the agency context: structure, work climate, and environmental linkages; of the program innovation: perceived relevance, perceived riskiness and stage of program implementation; and of staff-helper relationship firmalization. In all the scales constructed the reliability ranged frax an alpha of .29 to .93. A conceptual model was proposed regarding the relationships among these variables, fram which seven hypotheses were derived.

Pearson correlations and partial correlations were used to test the hypotheses statistically. Case analyses and multiple regressions 
were used to gain further insights into the patterns of association among the variables.

The pattern of associations found in the study are more complex than initially proposed. The major organizational attribute associated with high formalization of the staff-helper relationship was a high degree of formalization of the roles and relationships among the staff in the program unit. The attribute most highly associated with the informal relationship between staff and helpers was a supportive work climate, including supportive leadership and peer support among the staff in the program. Program complexity was also associated with informal relationships, rather than with formalized relationships as was predicted. 


\section{ACKNOWLEDGEMENTS}

There are several people who have had vital roles in my life during the long effort to complete this dissertation. I wish to thank them all sincerely for their support and encouragement.

First, I want to thank each of my camittee members for their insights, advice, encouragement, ar:d patient support at several key points throughout the process, and for their willingness to read through the drafts of the dissertation without delay or complaint, despite their busy schedules. Each of them played an important role in keeping me on track and honest. Thanks also to Barbara Stewart, who worked with me in the early phases of the proposal and the analysis.

The Regional Research Institute for Human Services has been a hame to me for these recent ycars. It has been a good place to be while working on a serious piece of research, not only because of the technical resources it has to offer, but because of the work environment where research is a way of life and one is expected to do one's best. Thanks to Dr. Arthur Emlen for his interest and concern, to Darey Shell who helped me over the rough spots in the computer work, and to Margaret LaFaive, who patiently typed and retyped and corrected the manuscript.

I also want to acknowledge several friends who have demonstrated to me again and again the value of their friendship, as a source of both intellectual and emotional support. Each in her own way has has been a source of respite, reassurance, and belief that has stayed 
me on my course. Thanks to Carol, Colleen, Judy, Nancy B., Nancy C., and Diane, to name a few.

And last, but definitely not least, I want to thank my husband, Andre, and my daughters, Rachel and Nicole, for their truly remarkable patience and understanding, and for the love and encouragement that kept me going, and for pitching in when other tasks and responsibilities got neglected. I am proud of them and have shared their pride in me as I brought this dissertation to its finish.

The sense of accomplishment I feel on campleting this dissertation is shared with each of these others who have functioned as my personal social network of support, advice, information, and assistance. 
TABLE OF CONTENTS

PAGE

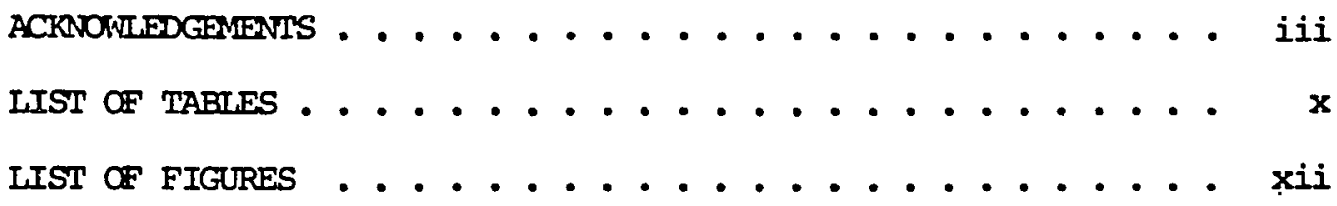

CHAPTER

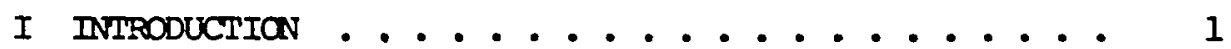

Overview of Research Problem ........... 1

Normative rodel ................... 4

Practice Models

Theoretical Mbdels

Current Research Problem . . . . . . . . 8

Purpose

Identification of the Research Problem

Definitions

Factors Affecting Programs

Significance of the Research Problem ....... 13

Service Society

Formal and Informal Caregiving Values

Recognition of Informal Care as a Resource

Urban Relevance

Organization of the Dissertation ....... 16

II LTIERRATURE REVIEW AND CONCEPTUAL FRAMEWORK . . . . 17

Contrasts Between Fonmal and Informal Relationships 19

Primary Relations

Primary Groups

Social Networks

Secondary Relations 
Implications of Contrasts Between Formal and Informal Relations

Organizations and Social Relations .......

Definitions of Organizations

Size

Complexity

Formalization

Performance Variables

Technology

hork Climate

Leadership Roles

ilork Group Norms

Interaction of Performance Variables

Contextual Variables

Organizations and Environments

General Environment

Organization-Set Environment

Implications of Organizational Influences on Social Relations

Program Innovations and Social Relations ..... 45

Conceptual :bdel . . . . . . . . . . . 4 48

Organizational Attributes as Predictor Variables Structure

ibrk Climate

Environmental Iinkage

Program Innovation Attributes as Mediating Variables

Perceived Relevance

Perceived Riskiness

Stage of Program Implementation

Staff-Helper Relationship Attributes as outcame Variable

Research Hypotheses . . . . . . . . . 54

III RESEARCH METHODOLOGY . . . . . . . . . 58

Sampling Procedures ........... 58

Sample Selection

Nonmative Criteria

First Stage 


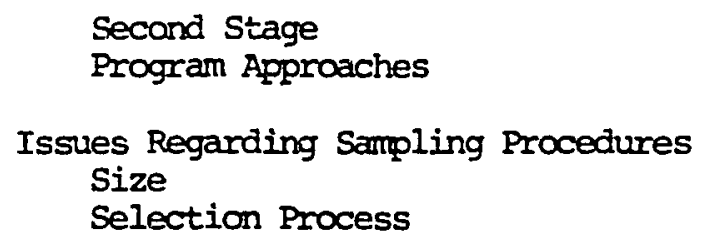

Types of Data Collected Discussion Guide Development

Reliability Controls on Data Collection Procedures

Data Reduction Procectures .......... 68

Case Studies

Content Analyses

Muitiple-Item Scale Construction ....... 70

Benefits of Ifultiple-Item Scales

Steps in Scale Construction

Missing Data

Constructing Weighted Scores

Reliabilities of Scales

Hypotheses Testing Procedures .......... 77

Pearson Correlations

Partial Correlations

Multiple Regression

Case Materials

IV RESULTS

Effects of Predictor Variables ......... 81

Size

Hypothesis 1

Case Illustrations

Surmary

Formalization and Complexity or Bureaucratization Hypothesis 2

Case Illustrations

Summary

riork Climate

Hypothesis 3

Case Illustrations

Summary 
viii

Environmental Iinkage

Hypothesis 4

Case Illustrations

Summary

Effects of Mediating Variables ..........

Perceived Relevance

Hypothesis 5

Sumary

Perceived Riskiness

Hypothesis 6

Stage of Program Implementation

Hypothesis 7

Sumary Regarding Effects of Program Innovation

Exploratory Procedures . . . . . . . . 124

Intercorrelations Among Variables Across Scales

Multiple Regressions With Predictor Categories

Agency Structure

Program Structure

Work Climate

Program Enviromental Linkage

Ifultiple Regression with Program Innovation as Predictors

Multiple Regression Using Combination of Organizational Attributes

Iultiple Regression With Porgram Strategies

overall summary ............. 141

Hypotheses Tests

Exploratory Findings

$\mathrm{V}$

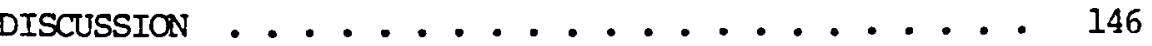

Theoretical Implications of the Research . . . . 147

Implications for Social Service Policy and Practice 153

Needs for Further Research . . . . . . . . 157

Sumary ............... 159

REFERERTE BIBLTOGRAPHY ................... 162 
APPENDIX
A DOCURIENTATION OF SARPLE IDENTIFICATION AND SELECTION
PROCESS . . . . . . . . . . . . . 172
B CASE STUDY DOCUMENIATION . . . . . . . . 180
C DISCUSSION GUIDE . . . . . . . . . . 252
D CONTENT ANALYSIS ITEM STERS ............ 265
E RESULTS OF TESTS FOR BIAS WTTH NUISANCE VARTABLES . . 289
F SCATE COASTIUUCIOII DPDCESSES 291 


\section{IIST OF TABTES}

TABLE

PAGE

I Operational Definition of Organizational Attributes . . 50

II Operational Definitions of Program Innovations . . . 53

III Operational Definitions of Staff-Helper Relationship Formalization ........... 55

IV Nomative Criteria for Sample Selection . . . . . 60

V Brief Case Descriptions .............. 64

VI Internal Consistency Reliabilities of Scales . . . 76

VII Correlations Between Predictor Heasures and overall Staff-Helper Relationship Fonmalization . . . . 83

VIII Correlations Between Mediating Measures of Program Innovation and Overall Staff-Helper Relationship Formali-

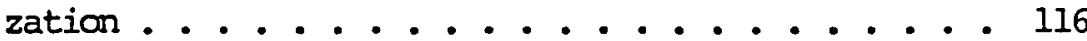

IX Partial Correlations Between Predictor Measures and Relationship Formalization Controlling for Innovation Measures .................. 118

X Significant Intercorrelations Among Subscales . . . . 127

XI Multiple Regressions With Separate Predictor Categories And Staff-Helper Relationship Formalization . . . 129

XII Itultiple Regression with Combined Organizational Attribute and Staff-Helper Relationship Formalization . . 135 XIII Iultiple Regression Using Program Approaches as Predictors of Staff-Helper Relationship Formalization . 138 
XIV Correlations Among Program Approaches and Relationship Formalization ............. 139

XV Overview of Program Approaches . . . . . . . . 140

XVI Sumary of Regressions to Explain Forralization of Staff-Lelper Relationships . . . . . . . . 144

XVII Randam Effects Analysis of Variance for Bias or Nuisance Effects ........... 290

XVIII Number of Items in Scales, Proposed to Final Form, By Steps . . . . . . . . . . . . 295

XIX Agency Structure subscales . . . . . . . . 296

XX Progran Structure Subscales . . . . . . . . 297

XXI Work Climate Subscales . . . . . . . . . 298

XXII Environmental Linitage Subscales . . . . . . . 299

XXIII Innovation Subscales ............. 300

XXIV Staff-Helper Relationship Subscales . . . . . . . 301 
LIST OF FIGURES

FIGURE

PAGE

1 Simple Conceptual :bodel ............. 18

2 Conceptual Model of Predicted Relationships Between Agency, Innovation, and Staff-Helper Relationship Attributes ................ 49 


\section{CHAPTER I}

\section{INTRODUCTION}

\section{OVERVIEW OF RESEARCH PROBLEM}

Most social welfare policy deals with ways to organize and evaluate the formal system of care offered by public and private human service organizations. However, in recent years some attention has shifted from the formal system of care to a wider range of caregiving resources and settings (President's Comission on Mental Health, 1978; National Cammission on Neighborhoods, 1979; Wingspread Report, 1972; Wolfenden Report, 1978). Attention has turned to the value and pervasiveness of informal sources of help such as often occur in everyday social relationships with family, friends, neighbors, or in voluntary mutual support groups. A perspective has emerged that extends the responsibility of the formal system to include giving support to such informal helping activities that benefit their clients (or potential clients). Arising fram this perspective there has been a call for partnerships between the formal and informal helping systems, which involves working relationships between professional staff and informal caregivers known to help the agency's clients (Collins \& Pancoast, 1976; Froland, 1980; Gottlieb \& Schroter, 1978; Lenrow \& Burch, 1981). Underlying this perspective is an assumption that this type of working relationship differs both in form and content from more conventional strategies used by human service agencies to engage public 
participation in agency decision-making and service delivery. For example, these partnerships differ fram the use of indigeneous cammunity members as paid paraprofessionals who perform nontechnical tasks under professional supervision. They also differ from programs which rely primarily on advice of influential citizens or clients on agency advisory groups. The lay helpers are looked upon as sharing more responsibility for the actual definition and delivery of care than either of these other approaches pernits. However, though most may agree on what should differ from other programs to involve clients and citizens, it is less clear how to develop relationships between the formal and informal, between professional and lay helper, what their respective roles will be, and what services are amenable to this type of linkage. It is to this issue of the nature of the linkage and the roles that the current research is directed. Underlying this research is a normative model for such relationships that derives from the practice literature, from social service theory, and, more generally, from social exchange theory.

However, before discussing in more detail the normative model for such relationships the broader research question will be discussed. The principal question in the current study is just how differences in agency context influence the type of partnership relationships that develop between professionals and lay helpers. Do differences in the formal agency context affect the way the relationships are structured, the roles of professionals and lay helpers? If so, what aspects of the formal agency context are more influential in shaping the way the relationships develop? Overall, is the partnership between formal and informal helping systems samething that can happen in only certain 
types of agencies or is it feasible for a broad range of human service agencies?

These questions are significant within the context of present social service practice for a number of reasons. Most social service agencies today are looking for ways to stem the ever-rising costs of social service delivery without drastic reductions in the level of services available. They are also seeking to ensure that their services are accessible and acceptable to their clients, and that they are available in the least restrictive environment, with an enphasis on community-based alternatives to institutional care. Each of these agency concerns may lead to an interest in achieving better linkages to the informal helping resources in the cormunity. Many agencies may see families, neighbors, or friends as sharing responsibility for caring for their clients. Not all, however, see it as their responsibility to directly involve themselves in assuring that there is continuity of care between the formal and the informal sectors.

Same make no effort to work with the informal caregivers of their clients. They may be unaware or unconcerned about how their own caregiving activities affect the infomal helping resources of their clients. Of those who attempt to develop linkages with informal helpers, some cite the contrast between "the world of the bureaucrat and the work of mothers" (Abrams, 1978), or the discontinuities in values, premises, and attitudes underlying the two types of caregiving (Froland, 1980; Lenrow \& Burch, 1981). This is done to caution against permitting either form of caregiving to undermine or distort the inherent character, worth, and effectiveness of the other. 
NORSATIVE MODEL

These concerns and cautions underline the significance of the relationship that develops when agencies do seek to create partnerships with informal helping systems. Such cautions are inherent in most models for such relationships emerging fram social service practice and theory, giving rise to a canmon philosophy and set of principles for action. This nomative approach assmes, first, that formal and informal sources of help are camplementary to each other. Each has different roles and potentials that can work together with the other to assure a continunum of helping resources available for persons in need.

A second assumption of this normative model is that the relationship between professional and lay helpers is most appropriately a collegial, collaborative one (rather than hierarchical or directive). The professional brings to the relationship knowledge and understanding of human behavior, organizational skills, knowledge of formal community resources. Informal helpers bring their opportunities for spontaneous helping, their knowledge and understanding of their own social network and its needs and preferences regarding helping services, and their willingness to help and/or reputation as a helper. These two sets of knowledge and skills are both essential to the success of the relationship.

These two assumptions, which are critical to this current study, derive as previously noted, both fram social service practice and theory. Each will be described briefly in the following sections. 
Practice Models

Due to the emerging nature of the effort for human service agencies to work with informal helpers, the practice models that evolved are frequently modifications of conventional service models. For example, Collins and Pancoast (1976) identify mental health consultation as one conventional service approach which lends itself to adaptation in work with informal caregivers, particularly those "central figures" who function as major sources of informal care within their own communities. The professional, as consultant, makes available his/her knowledge of human behavior and of community resources, and expresses a willingness to listen, and to advise, as requested by the lay helpers. The lay helpers are the ones who provide direct emotional and instrumental support to persons within their own social network. Consultants and lay helpers relate to one another as "friends and partners" (Collins \& Pancoast, 1976: 136). From their relationship each can expect to benefit and to address their mutual concerns, which are to serve the neds of those within the helper's network who are also actual or potential clients of the professional's agency.

Biegel and Naperstek (1979) offer a slightly different model for partnerships between professionals and community or lay helpers. They view neighborhoods, families, ethnic groups, and religious groups as "mediating structures" whereby many of the social and material needs of individuals are met. They advocate that these mediating structures receive support from the formal institutional caregivers. Thus, in a reversal of conventional community organization practice, they recammend that professionals seeking to enter a community find 
"natural sponsors" who have already determined their local needs, the services they find appropriate and acceptable, and their own resources. The community members can then seek the advice and assistance of professionals in developing programs and services that meet their own locally identified needs. Professionals, in this instance, work through the comminity helpers to assure that the needs of a local comminity, ethnic group, or other natural community are met.

Both of these service models propose relationships between formal and informal helper in which lay helpers have an equal (if not greater) responsibility for developing and delivering services with professionals. The professionals may initiate the relationship in order to expand or improve the services available to a specific client population. Yet both partners share the initiative and responsibility for the services that result. The relationship goes beyond cooperation, which has been defined as "partial incorporation of each other's needs and actions into the other's actions and activities" (Warner, Hutchison, et al., n.d.:18). It involves full collaboration, in that both are working together on a mutually defined project or task.

Theoretical Models

Litwak's work $(1978 \mathrm{a} ; 1978 \mathrm{~b})$ on coordination between two or more social service agencies, or between a social service agency and a cormunity group or collection of individuals is described as "balance theory." He stresses that the structure of the linkage or relationship between the two parties is a critical factor in the eventual success of such coordination efforts. In his balance theory he suggests that such relationships between highly formalized agencies and primary- 
type cormunity groups must remain as informal in structure as possible, so that they will be compatible with and non-dismptive to the primary relations. Such an informal structure should consist of face-to-face contact, positive affect, mutual trust and respect, and egalitarian or collegial role relationships. Litwak notes that such relationships are patterned after those of friends in everyday interpersonal relationships.

Lenrow (1976) and Lenrow and Burch (1981) argue for relationships between professionals and clients or self-help group members where power is equal. In order for professionals to "help" anyone they must recognize the basic interdependence of helper and helped in any type of helping relationship. They suggest that, once power is equal, both professionals and clients can more readily learn from each other and achieve their conmon goals. Lenrow's argument regarding interdependence and equalization of power is even more relevant in relationships between professionals and lay helpers. The helpers may have little interest or incentive to involve themselves in relationships with professionals if these relationships do not offer them benefits, such as power, support, trust, and an opportunity to share cammon interests and concerns.

These viewpoints from both practice and theory are cited because they underscore the importance of the structure of the relationship between formal and informal systems. Each view, fram a slightly different approach, points to a cormon underlying philosophy and norm for such relationships. They call for equal power, collegiality, trust, mutual benefit, and collaboration in a common effort. They suggest 
that the professionals and lay helpers are partners in joint endeavors. These are the characteristics of partnership programs which constitute the reference norm against which the specific relationships between professionals and helpers in different agency programs will be campared in the present research.

\section{CURRENT RESEARCH PROBLEM}

Purpose

The purpose of this research is to examine the structure of relationships between professionals and informal helpers in 30 different agencies. This research investigates the differences in the formal side of the relationship, that is, in the agencies sponsoring the programs. It also looks at how the agency differences are associated with differences in the structure of the relationship between agency staff and informal helpers. The research seeks to identify those agency attributes which appear to influence the ability of professional staff to structure relationships that fit the normative model of collaboration and collegiality.

\section{Identification of the Research Problem}

The initial impetus for this study came from observations by the author during work on a larger research project. ${ }^{1}$ The purpose of that

$I_{\text {The author was a research assistant on the project, "Natural }}$ Helping Networks and Service Delivery," funded by the Office of Human Development Services (\#18-P-00088), 1978-1980. 
study (Froland, Pancoast, Chapman, \& Kinthoko, 1980a, Executive Sunmary) was to:

identify and assess program strategies which human service agencies might adopt to strengthen and facilitate the use of informal sources of help in meeting the needs of such populations as the elderly, the developmentally and physically disabled, children, youth and families, as well as servicing preventive aims in the general comminity. (p. 1)

The larger project selected 30 agencies fram across the United States. Each of these agencies had established a program for working with informal helpers in its comminity. The research staff collected information from these agencies regarding the agency, the program, the community in which the agency and/or program operated, the client population served by agency and program, the informal helpers that the agency staff had identified, and the type of working relationships that agency staff had developed with the informal helpers. These data were collected through in-depth interviews and reviews of program documents and descriptive materials. Analysis of the data included case studies and content analyses of the materials.

The current research is based on the same sample of programs and the same data base as the larger Network project. In the early stages of the Network project, research staff recognized that it was possible that variations in the size and structure of the agencies adopting programs might be reflected in the types of relationships that developed between staff and lay helpers. Preliminary reviews of the organizational theory and research suggested other organizational factors as well that could influence the implementation of innovative programs such as these requiring professionals to work collaboratively with lay caregivers. 
The Network project adopted a normative model for the way programs for working with natural helpers should be structured. This model, previously described, was based on both a review of the literature and expert opinion. Certain key elements of that model are defined below to facilitate ease and clarity of cammunication throughout the remainder of this research study.

\section{Definitions}

A concept that is basic to this research is that of "informal helpers." Other terms used synonymously with informal helper are informal caregiver, community helper, natural helper, or lay helper. The first part of this expression, "informal," refers to relationships that grow out of personal, individual interactions in everyday contexts. The second part of the term refers to individuals whose activities constitute services or support to others within their own everyday personal network. By their actions and attitudes they offer either material, emotional, or referral services to others with whom they come in contact. Generally such help is voluntary, spontaneous, unpaid, and a natural outgrowth of the reciprocal give-and-take of primary, personal relationships. In this research informal helpers were were indivicuals or groups of individuals identified by agency staff for their helping activities that benefitted the clients of the agency in which the staff worked.

A second basic concept is that of a program offered by direct service agency in which agency staff work with informal helpers. Throughout this report these programs are referred to as "partnership programs." Partnership here refers to the implicit notion of 
collaboration, complementarity, and mutual benefit that underlie such

programs. Program refers to the fact that these efforts were systematic, agency-sanctioned efforts to work with natural helpers, rather than the ad hoc efforts of individual staff members acting on their own initiative. The assumption is that these programs will benefit the agency (by expanding or improving its services to clients) and that it will benefit the lay helpers (by sustaining and enhancing their helping activities). Throughout this paper all references to staff-helper relationships assume the existence of a partnership program.

\section{Factors Affecting Programs}

The normative model calls for programs in which the relationship between staff and helpers is collegial, collaborative, and in which there is mutual respect, cultural sensitivity on the part of the staff, and where there is joint or balanced responsibility for planning and delivery of services. However, the research staff of the Networks project and this author observed that not all the programs had developed these types of relationships with informal helpers. This was true, despite the fact that all the programs had assigned paid staff to work with informal helpers, and seemed to share a cormon philosophy that involved respect for the value of informal helping and selfreliance, and a commitment to empowerment. Several possible contributing factors arose as research staff sought to explain the differences observed in the programs:

(1) The agency in which the partnership program was established. Agencies varied in size, the degree to which they relied on formal structuring of rules, procedures, personnel selection and supervision, 
and decision-making hierarchies to coordinate staff activities. They also varied in the diversity of sites, functions, clients or communities served by the agency, in the types and sources of funding, and in their client populations.

(2) The models of social service practice that agency staff relied on to chart their relationships with informal helpers. These models varied in the goals for the partnership, and their compatibility with the overall agency goals and other programs offered by the larger agency (if the program was not a freestanding "agency"). In any event, there was the issue of how cormpatible the program was thought to be with "professional practice" by the staff who were directly involved, as well as by their peers.

(3) The attitudes of the individual staff members and of the group of staff members directly involved in the program about the relative value and purpose of their efforts. Staff attitudes varied in the level of enthusiasm or excitement and in the degree of carmitment of the individuals and of the entire work group toward the partnership program and toward the helpers with whom they were directly involved. These three broad factors were identified through an inductive process by the Network project researchers and confirmed by organizational theory and research as each potentially having significant impacts on the type of relationships that developed between agency staff and informal helpers. This research study reviews the literature relevant to this issue, then tests the relative contribution of each factor in explaining the types of relationships that were developed between the professionals and informal helpers in the 30 agencies in the study. 
SIGNIFICANCE OF THE RESEARCH PROBLEM

This research is significant for a number of reasons. It addresses an area of life that has taken on increased significance over the past 50 years, the service sector; it recognizes and expands upon the contrasts between formal and informal relations, between professional and non-professional bases for helping and their relative value; it provides new insights into the emerging social service strategy of trying to find a balance between lay and institutional responsibility for caring for dependent and needy populations; and it addresses problems and issues that affect urban as well as rural populations.

\section{Service Society}

Formal, institutionalized human services have been expanding both in number and in scope in the last generation. New services have been developed to respond to new needs as they have been identified by a growing cadre of professionally trained social service experts. New professional specialties have emerged to provide the new services. More than a third of society's resources have been devoted to services of various kinds, although not all of these are social welfare services (Hirschhorn, 1974). Certainly service activities have became a central element of modern society (Bell,1073). Institutionalization of the caregiving process is just one more step in the shift of functions from the primary group to the institutional level. Sociological theory supports this shift as a trend characteristic of urbanization and modernization. Classical theorists 
even suggested that the primary group would eventually lose all of its functions to formal institutions (Simmel, 1950; Wirth, 1938). Other theorists and researchers today have found, however, that with every shift of functions to the institutional level nes: functions arise for the primary or informal relationships. Thus, personal social ties that arise in family, friendship, and similar daily circumstances have vital importance to the well-being of individuals in modern society. These relationships are the source for information, advice, moral support, tangible support needed by individuals to cope with everyday problems or with major life crises (Gourash, 1978; Craven \& Wellman, 1973; Litwak \& Szelenyi, 1969; Wellman, 1979; Wellman, 1981).

Formal and Informal Caregiving Values

Many people rely solely on informal sources of support and help to deal with their problems or difficulties. Others seek out professional services as a matter of preference. Still others seek out professional services as a last resort, after their informal resources are exhausted, or after saneone in their informal personal network refers them to a specific agency or professional for help (Booth \& Babchuk, 1972; Kasl, Gore \& Cobb, 1975; Leutz, 1976). Studies have shown that people rate the help received from informal sources at least as high as they rate professional help (Gourash, 1978). They also associate different rights and obligations, or different expectations with each type of care, each of which may be deemed to be beneficial or detrimental by the intended recipient of care (Brown, 1978; Schreiber \& Glidewell, 1978). 
Recognition of Informal Care as a Resource

Social welfare professionals have begun to recognize the continuing importance of personal social ties as caregiving resources to individuals. Coupled with this recognition is an increasing awareness that often illness, distress, and other social personal problems are averted because of the informal system, and that many problems only reach the formal system because of referrals fram the informal system. This recognition has led to the development of the idea of working with certain types of informal caregivers. It has also led to the perplexing situation of trying to devise ways of bringing together these two types of caregiving which often differ radically in their basic premises and methods of giving help (Abrams, 1980). The significance of this research lies in the information it can provide that can facilitate the development of successful working relationships between the formal and informal helpers, and that can reduce the rate of failure and the distress that results for both the formal and informal helpers involved. More and better information will enable agencies and professionals to adapt their partnership programs to the realities of their own situation, and to adopt policies and procedures that minimize adverse consequences for both partners and for the agency's client population.

\section{Urban Relevance}

Partnership programs were found in urban, rural and suburban settings. This research will permit an assessment of potential differences arising from these comminity differences. Since urban environments tend to have high concentrations of social service 
agencies and clients the research is likely to benefit urban residents and social service professionals. Also since urban settings tend to have diverse populations this research will potentially demonstrate the value and significance for a number of different needy urban populations such as the chronically mentally ill, developmentally-disabled, the physically-disabled, and neighborhoods of lower-incame or working class ethnic groups.

\section{ORGANIZATION OF THE DISSERTATION}

The remainder of the research reported here will include a more detailed review of the literature of formal organizations, informal social relationships, and factors affecting their structure and their activities. Particular attention will be given to those factors that condition the success of organizations in implementing a new program or technology. Though the general literature on organizations is reviewed, primary attention is given to formal human service organizations and their functioning.

Following the review of the literature and research, the specific research questions and hypotheses to be addressed by this research are presented. This is followed by a discussion of the research design, methodology, and analysis.

Finally, the results of the research are discussed and conclusions and implications for policy and practice that can be drawn from it are presented. 
CHAPTER II

LITEERATURE REVIEW AND CONCEPTUAL FRAMENORK

A key concern in this research study is how to develop collaborative partnership programs between agency-based human service professionals and community-based informal helpers or helping systems. Current evidence fram the developing practice and theory in regard to formal/informal linkages suggests that, to succeed, they should be egalitarian, collaborative, flexible, and beneficial to both sides of the relationship.

In order to achieve this type of linkage the interpersonal relationships between agency staff and informal helpers are central. Their structure, it has been suggested, should be patterned after those characteristic of primary social relationships rather than of formal organizations. That is, the interpersonal relationships between staff and helpers require either loosening or abandoning agency measures of control such as hierarchies or authority, standardized and routinized procedures, and impersonal or objective approaches to interaction. However the ability of staff to develop such a collaborative linkage structure is potentially affected by the agency in which they work: its own structure of formal and infomal relationships, and other significant dimensions of the agency context.

The present chapter seeks to draw on the existing research, theory, and literature to examine these factors influencing the 
structure of linkages between formal and informal caregiving systems. Broadiy stated the question to be answered by this review is: which aspects of the organizational context are likely to facilitate and which will hinder the development of collaborative relationships between agency staff and informal helpers. This perspective is consciously one-sided; it would be equally reasonable to focus on the aspects of informal helping systems that prevent or facilitate collaboration. However, this research seeks to address the policy and program issues that may arise within a human service organization when proposals are made to develop a partnership program, to work with natural helpers.

Figure 1 presents a simple model of the factors that are to be discussed in this review. It is presented here as a guide to the reader, as this review mast necessarily draw on a diverse literature. At the end of the review the conceptual model is presented again in more detail.

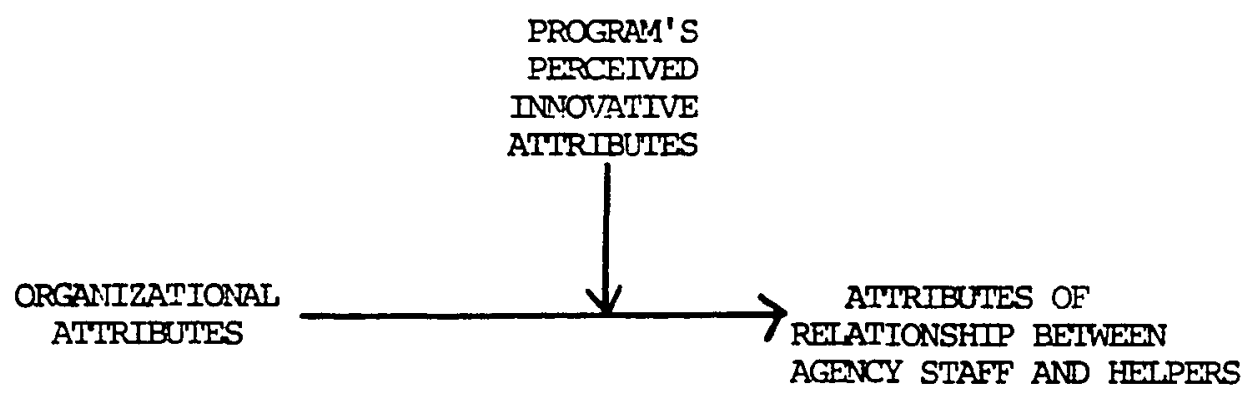

Figure 1. Simple conceptual model

Several major subjects are reviewed: (1) the contrasts between the formal and informal social systems and between primary and secondary 
social relationships; (2) explanations for the nature of social relations within formal organizations, from the perspectives of several major schools of thought; (3) effects of program innovations on arganizational behavior, in view of both the program design and agency context. Factors that arise specifically from the nature of human service organizations are included in each discussion section, as appropriate.

\section{CONIRASTS BETWEKN FORMAL AND TNFORMAL REIATIONSHIPS}

There are two key dimensions of social relationships that serve to focus the discussion of formal and informal relations. A social relationship may be thought of as existing whenever two or more persons interact or have the probability of interacting. However, relationships vary in the degree to which they engage the individual, that is, the extent to which the individual interacts as a total person rather than simply as an occupant of a role. As relationships move fram one end of the continuum to the other, there is a decrease in the affective or emotional effect on the persons involved (Anderson \& Carter, 1974). Relationships also vary in their relative emphasis on expressive or integrative behaviors or goal-directed or instrumental behaviors. That is, relationships range in their basic premises between sentiment and task orientations (Parsons, 1951). Relationships in which sentiment is the basis of interaction tend to have little articulation of purpose and vague or unspecific limits on the content of exchanges, while those in which goals and task-performance are the basis tend to be narrow and defined in purpose and clearly limited in terms of the appropriate content of exchanges (Homans, 1961; Broam \& Selznick, 1968; Cooley, 1902). 
Within classical sociology, sociai relationships have generally been studied in terms of their function within social organizations such as groups (Cooley,1902), bureaucracies (Weber, 1947), or communities (Simmel, 1950), or have been looked at less as relationships between persons than between the abstract patterns of social roles (Parsons, 1951).

In social relationships membership in a cormon collectivity the basis for the probability of interaction and the form the interaction will take (McCall, 1970). At one extreme, the collectivity which is the basis for interaction is a role relationship, which brings with it certain constraints (expectations, rights, and duties) that shape the form of the interaction. On the other extreme is the personal relationship in which knowledge of persons rather than roles shapes the interaction. The relationship based primarily on roles has also been referred to as formal or secondary, while that based on personal knowledge is referred to as personal, primary, or informal. Social relationships are characterized by McCall (1970) in terms of their substance or the bonds, structure, and culture. Bonds are the basic premises that hold people together in relationships. Bonding arises from such factors as ascription (ties that arise simply out of position in other social groups such as families, or occupation), commitment (1inking oneself with another for either moral or other reasons), attachment (building in specific other persons into one's own role-identify), investment (coming about because of time and resources being devoted to another), reward dependability (the other 
person has shown him or herself to be reliable as a source of moral and emotional support).

\section{Primary Relations}

Primary or informal relations involve individuals interacting with each other as total persons. Such relations have the broadest influence on the individual's affective functioning. They develop in situations where individuals have ongoing fact-to-face contact in everyday life such as family, work group, neighborhood, and other long-term voluntary associations. Primary relationships often emphasize expressive and emotional content more than task perfonmance. Primary relations may arise out of ascribed statuses such as leadership, but they are more likely, in the modern west, to be shaped by bonds of commitment, attachment, investment, and reward dependability. This is another way of saying that these relations are more likely to engage the total person, and to be affective and normative in content than are formal or secondary relations. Attachments are to specific persons, not to roles. Such attachments make one person vulnerable to the behaviors, and experiences of the other, and make the resulting relationship non-transferable. Once an individual has invested time, resources such as money and ideas, and shared life experiences with another in a specific relationship, it becomes difficult to replace that specific person. Within primary relations, norms of reciprocity tend to prevail (Gouldner, 1960) requiring of each partner consideration for the other's attachments and investments in the relationship. When one knows that another person is a reliable 
and dependable source of certain types of support, then he/she will usually work to make that relationship more durable.

Primary groups. Social psychologists have devoted considerable attention to the behavior of individuals within groups--either primary groups or small groups. Berelson and Steiner (1964) define the small group as:
an aggregate of people . . . who associate together in face-to-face relations over an extended period of time, who differentiate themselves in same regard fram others around them, who are mutually aware of their memberhsip in the groups, and whose personal relations are taken as an end in itself . . . all the members must be able to engage in direct personal relations at one time. (P. 326)

There are two broad types of groups, as of relationships. The first are groups with specific tasks to do, and the second, those with more diffuse or diverse purposes, such as social and emotional satisfactions. Regardless of the form or purposes of the group, they exhibit certain similarities of functioning and influence on individuals. Interaction within small groups is likely to involve patterned behaviors and shared expectations or norms. These expectations or norms increase the likelihood that members of a group are similar to each other in values and beliefs. Lazarfield and Thielens (1958) note that:

sharing of beliefs which are relevant to a group facilitates friendships among that group and . . - inversely, close personal contacts lead to a similarity of relevant attitudes. (p. 147)

Researchers have found that primary groups provide opportunities for interaction, which are also associated with similarity in activities, beliefs, and sentiments (Homans, 1950; Newcomb, 1959). Small groups exert strong influence on their members to conform to the values and 
behavioral standards shared by the group through the use of rewards such as reinforcement, encouragement, and security for proper behavior, and penalties such as expulsion, ridicule, shame, and punishment for improper behavior (Berelson \& Steiner, 1964).

Group norms can be particulary important in groups with specific tasks to accomplish, such as work groups. In such situations group norms can support or undermine the goals or norms of the larger collectivity (organization or community) of which the small group is a part (19ayo, 1945). In either event primary groups act as a major influence on individual behavior and social relations. There are both informal pressures and formal controls that serve to hold the individual to specific roles and relationships.

Social networks. While the "group concept" has long standing in sociology, a slightly different way of looking at social relationships has emerged in recent years. This approach looks at interpersonal relationships as "ties that cut across the boundaries of institutionalized groups or social categories" (Wellman, 1981) to form networks of inter-connected individuals. The focus of attention is on the regular patterns of interaction that underlie the groups or systems, not just the behaviors of the individuals directly involved. Interactions within these ties may be limited to one single type of exchange, as in secondary relations, or to multiple types of exchanges. Networks as a concept differs from "group" concept by not assuming either goaldirected behavior of the network or a sense of common identity among those individuals who are within the network. Thus, two acquaintances of a nodal individual may not know of each other, yet be connected 
indirectly to each other through the nodal individual, and thus both be members of the nodal individual's personal network. The personal network of any one person cuts across the many groups and settings which that person belongs to or participates in. It also reaches through indirect ties to persons and resources that are not directly available to the individual in his/her own face-to-face social relationships.

\section{Secondary Relations}

It has been a major tenet of sociological theory that the central trend of Western civilization is toward "impersonal and instrumental modes of sccial orgenization" (Brocm \& Selznick, 1968, p. 46). This is a move away from personal and affective relations to relations derived from specialized role relationships and social categories. The latter relationships are referred to variously as secondary relations or formal relations. The basic ethic underlying secondary relations is utility--one interacts with certain individuals because of their role, which is critical to one's own achievement of some purpose or satisfaction of some need (Simmel, 1950). Such interactions remain impersonal, that is, they involve little affective content, personal attachment, comitment or investment.

Formal relations within organizations or settings are usually expected to exhibit these principles of impersonal interpersonal relations, that is, specialization, division of labor (or roles), rationality, utilitarian values, and detachment. There are an infinite variety of organizations and settings in everyday life in which individuals interact with others in formal (role-defined, impersonal, secondary) 
relationships. Examples include the grocery store, the doctor's office, driving or riding to work, using the telephone operator, paying a bill, and so on. Formal relationships are the glue that holds together our modern, complex, institutionalized society (McCall, 1970).

Inplications of Contrasts Between Formal and Informal Relations

The two types of relations described here are polar types, in sharp contrast to each other. As noted, in informal relations there is sentiment, shared knowledge of the other, diffuse purposes, and personal identity that is closely tied to the others with whom one shares the relationship. Personal relationships of this type involve affect (which can be negatively or positively weighted), attachment, personal long-term commitments and investments, and a knowledge (based on experience) of what one can share with, get from, or depend on the other for. In formal relations there is a specific purpose for interaction, little sentiment or affect, no camitment or investment. In formal relations, where the roles are more important than the individuals involved, one person can easily replace another without significant consequences for the relationship. One bases one's expectations on what the relationship has to offer more on the roles involved than on the personal knowledge of the individuals playing the roles (McCall, 1970; Berelson \& Steiner, 1964).

The network of social relations of any individual at any given time involve relationships that vary in level of formality or informality. There are in reality many different levels of formality, rather than all or nothing types. When social relationships are informal or personal they have developed and been sustained through 
ongoing interaction, commitment, mutuality, trust and personal knowledge and may also be ascribed by common membership in a binding social relationship such as kinship, neighborhood residence, or so on. Formal social relationships are developed and sustained differently-generally through the development of explicit role definitions and role-set expectations for appropriate role performance, to which sanctions are attached. Standardization of roles, rules, and expectations takes the place of affect, personal knowledge, and trust in shaping the social relations.

These contrasts between formal and informal relations are reviewed in such detail here because of their implications for the types of programs this research study deals with. Partnership programs propose to link together agency staff, whose explicit purpose for the link derives from their role as "professional helpers," and informal helpers, who have no explicit purpose for linking with the agency staff but through their personal relations have developed a pattern of involvement, attachment, and comitment that is particularly helpful to specific other individuals. The normative model proposes that the most effective way for the professional staff to achieve their goals, that is, to support and enhance the help offered by informal helpers, is to develop a more informal relationship with individuals that is based on mutual respect and trust rather than a standardized, rolebased type of relationship. The question, then is to what extent the agency staff will be able to develop social relations that are infonmal and yet effective in meeting the agency's purposes. 
ORGANIZATIONS AND SOCIAL RELATIONS

One of the major factors shaping the nature of social relations that are developed between agency staff and informal helpers is the organization in which the staff are members, and the nature of social relations that occur within the organization. The types of roles, the expectations regarding role performance, the sanctions for poor performance, and the system of relationships within the organization through which the roles are established and enforced will all influence the formality of relations within the organization and the ability of the individual staff member to develop informal relations with the nonmember informal helper.

\section{Definition of Organizations}

Organizations, in contrast to primary groups or social networks, are "social units deliberately constructed to seek specific goals" (Parsons, 1960, p. 17). Thus the principal basis of association of individuals within organizations is goal-attainment, i.e., to carry out specific activities that will contribute to the achievement of the organization's goals. Social relationships or interactions within organizations are generally goal-oriented, instrumental, and functional. This cames about because, in order to acconplish its goals the organization has rules and procedures governing the behavior of its members. These rules and procedures are intended to make goal attainment a rational and efficient process.

The classical model of a rational, effective formal organization is the "bureaucracy" (Weber, 1947). It is presented as the most 
effective form of organization because of its rational use of individuals and of technical knowledge, and its ability to capitalize on econanies of large scale (Iitwak, 1978b). The basic principles identified by weber as governing social relations within bureaucracies are primarily structural, including: (1) a clear division of labor, with a high degree of specialization in tasks; (2) a pyramidal hierarchy of positions in which each role-occupant is under the control and supervision of a higher one, up to a single highest position of authority; (3) a system of abstract rules governing the coordination of tasks to assure unifonm work results and criteria for performance criteria; (4) impersonal interactions in relation to work perfonmance, governed by organizational rather than personal goals; (5) positions filled by persons having the appropriate levels of training and experience, or technical expertise; (6) transactions, criteria, and rules recorded in writing to make them explicit and clear.

Enpirical research has shown that organizations vary widely in the degree to which they adopt these principles of bureaucratic organization, that is, standardization, centralization, impersonal relations, merit, and large size (Hall, 1963). Same of the principles may be adhered to or present in an organization while others are ignored or absent. Hall concludes that each of the bureaucratic principles represents a separate dimension of the organizational structure, and that each can vary on a continuum from present to absent independently of the others. For exarmple, an organization may be small in size and still adopt written rules and procedures, rely on 
technical expertise and merit in hiring and promotion, and hierarichies of roles and authority.

The bureaucracy represents an extreme version of the way in which formal relations enable an organization to achieve its goals. In this model individuals are expected to interact only in tems of their organizationally-detemined roles. The content or behaviors and activities appropriate to each role are predetermined and standardized, and roles are specialized and arranged in hierarchical role-sets, such that the higher role has power to control the lower ones. Bureaucracy focuses its attention primarily on these structural positions and properties of roles. From this perspective on organizations, certain structural dimensions emerge that shape the social relations among organization members. They include the size and conplexity of the organization and the degree of formal definition and standardization cf roles and authority (Hage \& Aiken, 1967, Hall, 1977; Pugh, Hickson, Hinings, \& Tumer, 1968). The ways in which these structural dimensions influence social relations are explored in more detail below.

Size. In most organization research and literature, the size of the organization is the number of organization members. In enpirical research this has been narrowed to include only paid members or broadened to include the number of financial resources or assets or the number of clients (Hall, 1977). These types of measures are often hjghly intercorrelated, although Kimberley (1976) argues that they need not be. Increases in organization size have been found to be associated with problems in communication (Caplow, 1957), control (Weick, 1976), coordination and administration (Blau, 1973), with internal 
differentiation of functions and roles (Blau \& Scott, 1962; Blau \& Schoenherr, 1971), and with increased standardization of tasks and decreased centralization of decision-making authority (Pugh et al., 1968). This pattern of associations suggests that the degree of formality of social relations among organizational members will increase directly with the size of the organization, in an effort to achieve organization goals in an efficient, predictable manner. However, size alone is not sufficient to explain the level of formalization of social relations within an organization (Hall, 1977).

Complexity. Complexity of an organization is another structural dimension that can influence social relations. This concept refers to the extent of role-specialization and functional differentiation that exists within an organization, that is, the division of labor within the organization among specialized roles, functions, divisions, levels, or locations (Beyer \& Trice, 1979; Hall, 1977). In empirical research these elements have been clustered into three broad categories: horizontal differentiation, vertical differentiation, and spatial dispersion (Aiken \& Hage, 1968).

Horizontal differentiation refers to the number of different parallel divisions or roles at any given level. For example, in a hospital there may be separate units to deal with pediatrics, surgery, gynecology, emergencies, and so on.

Vertical differentiation refers to the number of levels of supervisory and administrative authority above the direct line employee (Pugh, 1966), and the degree of separation of administrative and 
production functions in a hierarchical manner (Litwak, 1978a). The unit used in determining the differentiation is the role.

Spatial dispersion refers to the extent to which the organization is made up of multiple units which are physically located at different sites.

When organizational tasks and/or roles are both physically and functionally separate there are at least two possible outcomes. The first is that each functional unit will develop its own set of formal prescriptions regarding roles, performance standards, procedures, and decision-making hierarchy that are appropriate to its specific tasks. This means that social relations may differ in formality within an organization fram one unit or division to another in response to differences in tasks. Complexity, in this type of situation, derives From the necessity of assuring adequate and appropriate conmunication and coordination at the higher levels within the organization so that all units will also contime to pursue agency-wide goals and objectives. The second possibility is that a uniform set of roles, procedures, and perfomance criteria will be applied across all units. This requires mechanisms of control and integration that shape social relations at every level of the organization, with the emphasis on internal administrative concerns (Andersen \& Warkov, 1961; Baldridge \& Burnham, 1979; Hall, 1977). In either event, higher complexity may be expected to be associated with higher formality of social relations at same level within the organization.

Formalization. The property of organizations that is most cammonly associated with bureaucracy (albeit negatively) is formalization. 
This term refers to ways explicity used by organizations to shape the behavior and social relations among members. It includes the written rules and regulations used by organizations to ensure the comparability and predictability of role performance, the hierarchy of roles that exist to ensure that these rules are observed, and the criteria and methods used to match person to organizational roles (Hage \& Aiken, 1967; Hall, 1963, 1977; Katz \& Kahn, 1966).

Same organizations strictly adhere to their formal rules and regulations while others use written rules and procedures primarily as guides to action (Child, 1973). When standards and procedures are written, then it is easier to replace any single role-occupant without serious threat to the relations or to the accomplisiment of the organization's goals. Written procedures and guidelines serve to document solutions to recurring problems and methods to be used in carrying out routine tasks, based on past organizational experience (Litwak, 1961). Within organizations, formalization serves two purposes: to ensure the predictability of individual behaviors and interpersonal relations, and to contribute to the production and maintenance functions of the organization, i.e. its stability and survival (Merton, 1957; Katz \& Kahn, 1966; Thampson, 1967).

critics of the bureaucratic model note a number of problems with the automatic adoption of formalization of social relations in organizations. Litwak (1961) argues that formalization is an efficiers, rational approach to arranging social relations only when the organization deals with one uniform, recurrent event which requires only the application of traditional knowledge. When there are many different 
types of events or situations which must be dealt with, when the situations are rapidly changing, or where social skills are an important job requirement, then formalization is no longer rational or efficient. Formalization encourages confonity and discourages individual initiative or the use of personal judgment (Hage \& Aiken, 1967).

In sum, then, it can be seen that each of the major dimensions of organization structure, if it approaches the high levels represented by the bureaucratic concept, acts to increase the level or necessity of formal or role-specific, impersonal relations.

While structural factors are seeningly major determinants of the types of social relations and the nature of interactions and exchanges among organization members there are at least two other types of properties of organizations that are used within the field of organization theory and research to explain such relations. They include what are referred to by Hage \& Aiken (1967) as performance variables and contextual variables. Those properties grouped together under performance variables are the task-structure or technology, and the work climate. Those properties included under contextual variables are the relationships between organizations and their environment and the nature of the general enviroment in which the organization is situated.

\section{Performance Variables}

Technology. The term technology refers to the skills and knowledge base relied on in carrying out the organization goals. Perrow (1967) and woodward (1970) showed that many of the structural and interpersonal properties within organizations are shaped by the 
properties of the tasks and the raw materials (things, symbols, or people) used in production. The technology or methods used in processing materials may be based on a knowledge base that is simple, reliable, well-developed and integrated, or ane that is complex, ill-defined, or only partially developed. Raw materials can be stable, predictable and uniform or highly reactive and variable. The social relations or positions in an organization are likely to be grouped to minimize coordination costs (Thompson, 1967). When technology is necessarily non-routine (because of the nature either of the raw materials or of the knowledge base or both), less formal relations are likely to be the most effective approach to carrying out the organization's goals (Hall, 1977; Litwak, 1978a). Enpirical studies also show that when there are intra-organizational variations in technology (e.g., between research and production tasks), there are variations in the types of social relations that are most common.

Litwak (1978a, 1978b) notes that technology is a critical factor in the types of relations relied on in human service organizations. Some human service organizations have relatively routine, repetitive or "uniform" tasks to perform, while others must deal with the variability and idiosyncracies of their primary raw material, individual human beings. Hasenfeld (1974) contrasts those human service organizations that have as their primary task people-processing with those that have people-changing goals. The technologies and structures of social relations differ between these two tasks. Both must deal with the variability and reactivity of human nature and personality. However, the knowledge base for people-processing, which is classifying 
and disposing social statuses on individuals (as in an admissions office, diagnostic clinic, credit bureau), is generally more standardized, routine, and repetitive than is people-changing knowledge base. The former is more likely to function effectively with a formal social relations structure than the latter.

Technology can be seen to have a potentially significant impact on the social relations in an organization by modifying the type of structure that is effective, and, as will be seen in the next section, on the type of leadership style that is most appropriate.

Work Climate. Pules and regulations prescribe the roles and relationships between roles within an organization. However, there are total persons occupying those roles; and when role-relationships continue over time and tasks require interdependence among roles, it is quite normal for the social relations among workers to take on the attributes of a primary or informal and personal nature. Ongoing, faceto-face contact leads to personal knowledge of the others involved and may lead to affect, attachment, and a sense of mutual obligation and dependency. It may also lead to the development of shared values and norms relative to the sork to be performed and to other matters of cammon concern and interest (Mayo, 1933; McCall, 1970). The interpersonal relations that occur in the work setting can be broadly classified into two types: those between superiors and subordinates, which in large part revolve around the style of leadership exercised by the person occupying the superior role, and those among peers, revolving around the work group norms and their compatibility with the formal rules and procedures prescribed by the organization. 
Leadership roles. Within hierarchy of roles, the person occupying the superior role is expected to exercise "leadership" vis-a-vis his/her subordinates. A good leader from the perspective of the organization is the individual who is able to develop and sustain effective work performance.

There are two sets of attitudes and behaviors that are consistently associated with effective leadership. On the one hand is the person who is critical, directive, autocratic, task-oriented, on the other the person who is democratic, permissive, supportive, and personoriented (Argyris, 1970; Etzioni, 1975; Fiedler, 1965; Lewin, 1952; Lippett \& White, 1965; Stogdill \& Coons, 1957). The more traditional bureaucratic approach supposes that a decisive, authoritative leader who impersonally coordinates, directs, and evaluates the actions of subordinate workers will be most effective. The human relations approach supposes a leader who has social skills as well as technical expertise and who is non-directive, democratic, and permissive will be more effective in part because subordinate workers can develop same attachment and positive affect for him/her.

There is contradictory evidence regarding which style of leadership is most likely to contribute to effective work perfonnance and to informal norms that support rather than undermine the formal purposes and goals of the organization. Fiedler (1965) proposes a contingency model of leadership in which the style of leadership that is most effective is contingent in large part on the task-structure that the work group must perform and also somewhat on the position of the leader 
in the role hierarchy. Structured tasks can be progranmed because of their recurring, routine, and repetitive nature. They are amenable to a leader who is directive, controlling, and task-oriented. Tasks that are relatively unstructured camot be programmed because of their uniqueness, the many possible solutions or procedures for dealing with them, or because solutions must be created. They will be most effectively carried out when the leader is accepting of his/her subordinates, permissive, considerate and person-oriented. While the directive leader can rely on the authority structure of the organization to enforce compliance with the directions issued, the permissive or supportive leader must be personally capable of inspiring and motivating subordinates and initiating a structure appropriate to their specific task (Fiedler, 1965; Stogdill \& Coons, 1957; Litwak, 1978a).

Leadership styles also have a direct influence on the performance, motivation, and satisfaction of individual organization members (Argyris, 1957; Likert, 1961; Katz \& Kahn, 1966). Directive leadership seeks to control the flow of communications through appropriate channels and to limit the content to task performance. Supportive leadership . not only permits but encourages open communication among organization members (Etzioni, 1975). The pattern of social relations that develops among organization members will be influenced by leadership style. The type of social relations that the individual has within an organization is an important influence on their role performance (Likert, 1961; Katz \& Kainn, 1966).

Work Group Norms. The formal structure of an organization provides official patterns of leadership authority, role-relationships, 
and communications. However, informal patterns of association and communication tend to develop fram the spontaneous exchanges and interactions among organization members. Friendships and small groups or cliques arise which lead to patterns of communication and association that cross or contravene the formal structure (Broan \& Selznick, 1968; Likert, 1961).

This happens in a very natural fashion because the individuals in the organizations are not only organization members; they have personal lives (family and friends), ties to other organizations and associations, and values and attitudes derived from their personal life experiences. Individuals prefer to be treated as persons rather than instruments. These factors act together to bring about the process of informal relations development within an organization. These personal, informal relations may develop with peers (who function basically at the same level of authority) or they may cross lines of authority. In the same manner, they may develop between members whose work-tasks are interdependent, or may cross functional divisions within the formal roles and activities of the organization (Cartwright \& Zander, 1968; Berelson \& Steiner, 1964).

As previously noted, primary groups tend to develop in contexts where individuals have ongoing, face-to-face contact. such groups develop shared norms and role expectations. Within the work context the norms of the work group may support or undermine the fommal arganizational norms and role expectations (Broom \& Selznick, 1968). There is an extensive literature in organizational and small group 
research which documents the overriding influence that work group norms have on individual role performance and organization effectiveness (Argyris, 1957; Bowers \& Seashore, 1966; Lerin, 1952; Katz \& Kahn, 1966; Whyte, 1956). Work group norms often prevail over individual or organizational norms (ilayo, 1945; Roethlisberger \& Dickson, 1939). The informal work group can often effectively mobilize its members to achieve organizational goals. On the other hand the group may undermine organization goals by setting other goals for individual performance.

Primary relations among individuals within work settings may result in an informal structure (including a socio-emotional and a task leader) and informal mechanisms of control over the behavior of individuals that are either positive (offering affection, respect, and inclusion) or negative (offering disapproval, shame, or expulsion) in valence. Primary relations are generally viewed by the human relations theorists in organizational research as essential to the effective functioning of an organization because they help inprove morale by reducing the impersonality of the formal system, inprove communication by adapting it to the specific situation and special vocabulary of the work groups, and operate as an alternative and powerful source of control over the behavior of members (Broam a Selznick, 1968; Argyris, 1957; Katz \& Kahn, 1966).

The role of the supportive work group is particularly important to the individual faced with carrying out tasks which are not clearly covered by the rules of the organization, such as occurs when the problems or situations to be dealt with are diverse and changing or 
novel. In such situations it is important for the individual to have trusted peers to call on if they are to perform effectively (Litwak, 1961; Hage \& Aiken, 1967). Litwak (1978a) even suggests that informal peer support and a democratic leader are essential for effective performance when tasks are non-routine or involve frontier areas of knowledge.

Interaction of Performance Variables. The three types of performance variables interact to have a significant influence on the types of social relations that develop among members of an organization. As indicated leadership style and work group norms are mutually interdependent and are both influenced by the technology or task structure with which both leader and workers are faced. Together they constitute a work climate that shapes the ability of the organization to engage its members in effectively carrying out its goals. Periods of innovation in procedures or tasks are particularly susceptible to uncertainty and to a need for individual innovation and creativity, for short lines of cormunication and spontaneity in problem-solving and decision-making, and for peer group norms that support asking for and giving help (Lippitt \& Wite, 1965; Aiken \& Hage, 1968).

\section{Contextual Variables}

Much of organizational theory and research focuses only on the internal workings of organizations, adopting a closed-systems perspective. However, in the past decade an open-systems perspective has developed that takes into account forces in the environment of an organization that set limits on its behavior, including the shape of social relations within it (Aldrich, 1979; Katz \& Kahn, 1966). 
From this perspective organizations are not only goal-directed activity systems (Parsons, 1956) but boundary-maintaining systems as well. The boundedness of organizations is reflected in the distinction that is made between members and non-members. Control over organizational boundaries is a central concern and activity of any organization (Aldrich, 1979).

Organizations and Environments. While the bureaucratic model assumes that organizational goals are known, it is possible for goals to be imposed on an organization by its environment, that is, by other organizations or groups that provide resources or obtain resources from a nodal organization (Thompson \& McEwen, 1958; Aldrich, 1979). It is also possible for changes in the environment to make the technology of an organization ineffective or irrelevant, requiring appropriate changes in the organization's technology if it is to survive. Most organizations are dependent on transactions with other organizations for resources which leads to a system or set of inter-organizational ties with associated degrees of interdependency (Levine \& White, 1961; Evans, 1966). Within these inter-organizational sets, dominant organizations (those in control of certain vital resources) may have a significant impact on the behavior (the structure, boundaries, technology, and social relations) of the other dependent organizations (Aldrich, 1975). In sum, the open-systems perspective reveals that organizations are affected by changes and variations in their environmental context at both a general level (i.e., the general availablility of both input and output resources, raw materials and consumers) and at the level of specific links they have to a set of organizations. 
General Environment. The commanity in which an organization is located constitutes an environment with indirect influence on the organization. This occurs through the conditions that exist and changes that occur in several spheres: technology, law, political values, economic conditions, demographics, ecology, local culture, and through their varied interconnections and interdependencies. Changes in any of these spheres may indirectly alter the value or relevance of the organization's product the availability of appropriate resources (be they persons, funds, symbols, or raw materials), or the effectiveness of the technology (Aldrich, 1979; Hall, 1977). Enviroments in which these external spheres are highly interconnected tend to be "turbulent," subject to rapid changes that are effeciively outside of the organization's control (Terreberry, 1968; Enery \& Trist, 1965; Aldrich, 1979). It is particularly important for an organization to have a structure that is capable of processing information about the environment and that can respond rapidly and effectively when it exists within a turbulent environment. The bureaucratic model, on the other hand, with its fixed roles and hierarchical communication patterns is deened most effective for dealing with a stable environment, whereas a less formal structure of roles and comminication is essential when dealing with a turbulent environment (Aldrich, 1979; Zaltman, Duncan, \& Holbek, 1973).

Organization-Set Enviroment. At the level of direct linkages to other organizations, an organization exchanges resources such as information, personnel and products (Evans, 1966). Within any set of organizations, there are variations in the relative status (i.e., 
daminance or dependency) of the organizations and in the strength of the tie that exists between any two of them (Weick, 1976; Aldrich, 1979). Weick (1976) found that loose coupling or weak connections between organizations permitted coordination of common activities while permitting each organization to vary independently. Loose coupling to other organizations also permits an organization to adapt the technology or activities of one internal unit to its specific enviroment, while maintaining the stability of technology and activities of other units. If this argument and evidence is accepted, then it seems reasonable to suppose that organizations which are tightly coupled to other organizations or which are tightly linked internally will find it difficult to adopt technology that is more appropriate to its environment; to be, in a sense, locked into a particular way of carrying out its activities. Loose coupling may also permit more self-determination and require more initiative fram organization members which contributes, in turn, to informal social relations among members (Aldrich, 1976).

When an organization is both highly dependent and tightly coupled to an external organization, such as funding body, it is particularly valnerable to environmental influence. In this situation it is likely that changes in practice will reflect the preferences of the daminant organization and that the rules and regulations and communication pattern will be adapted to the demands of that external source, rather than to less tightly coupled groups or organizations (Sieber, 1974; Aldrich, 1979). Human service organizations are among the most vulnerable to this type of influence (Hasenfeld \& English, 1974; 
Sarri \& Hasenfeld, 1978) and the social relations within them thus tend to be overly bureaucratized (Elgin \& Bushnell, 1977; Lenrow, 1976). Litwak (1978b) emphasizes that the survival and effectiveness of human service organizations require the development of a differentiated structure within an organization, which is bureaucratized only to the level appropriate to its specific technology and environment. He argues that the coupling of any organization to its enviroment should vary by unit and that each unit should be free to vary independently of other units to achieve a linkage that is appropriately balanced.

Implications of Organizational Influences on Social Relations

This discussion has reviewed several perspectives on the ways that organizational properties influence social relations and benaviors of organization members. From the structural perspective the variables of organization size, complexity, and formalization are major determinants of the form of social relations among members. Fran the performance perspective, the nature of the task or technology, the leadersinip style, and work group norms interact to shape behaviors and relations within the organization. From the enviromental (contextual, open-systens) perspective, the general enviromment and the organization-set (both in terms of levels of dependency and degree of coupling) influence an organization's goals and its internal structure of control and initiative.

While organizations may be internally hamogeneous on each of these dimensions, it is more likely that there will be variations among different functional units within the organization. In any event each of these dimensions can have an influence on the shape that social 
relations among organization members take. In turn, the social relations among staff can be expected to influence the behavior and norms of staff when they are given the task to work with informal helpers in the cormunity.

\section{PROGRAM ININONATIONS AND SOCIAL RETATIONS}

In the organizational literature, attention has been directed to observing and describing the impact of the adoption of changes or innovations on organizational behavior (Bennis, 1966; Burns \& Stalker, 1961; Havelock, 1970; Zaltman et al., 1973). This subject has been of increasing interest and concern as an open-systems perspective has taken hold because of the need for organizations to adopt new technologies that contribute to their survival. There have been several studies that have identified factors operating at the individual, organizational and environmental levels that either hinder or facilitate the adoption of innovations (P.A.C., 1976; Zaltman et al., 1973). However, in this section, the properties of the innovation itself are considered as factors that influence how easily and completely it is adopted.

Fram the perspective of organization members, changes may be viewed as major or minor, radical or non-radical (Knight, 1967). Thus there are some changes which alter the entire organization and the rules and role expectations for all members, while other changes may alter only the roles of a small portion of organization members (Rowe \& Roise, 1973). Changes may be minimal in effect in that they require modification or addition of only a few procedures; they may be moderate requiring modifications of many procedures, or addition of a complete set 
of new procedures; or they may be basic (or major) in effect, reaching the core goals and procedures of the total organization and all its members (Patti, 1971). The ability of an arganization to adopt a change in the way that it is initially intended and with the effect that was envisioned depends to a great extent on the perceived scope or magnitude of the proposed change. Organization members are likely to weigh the perceived riskiness of the change and the perceived relevance, that is, the advantages and disadvantages that the innovation poses for their own set of responsibilities and their roles (P.A.C., 1976; Zaltman et al., 1973). There are a number of potential advantages that are more likely to lead to support or camitment to a proposed innovation. Thus organization members are more likely to be supportive of a change that is seen as relatively advantageous, or superior to existing procedures; compatible with current practices and procedures; feasible, not too complex or costly; easily implemented in increments or stages; with results that are visibly observable; relevant to the situational needs or problens of the organization; low in real costs, both in terms of actual resources, social statuses, and existing assets of the organization; readily modified to make it more relevant, compatible, or advantageous; easily reversed if it proves to be unsuccessful or unsatisfactory (P.A.C., 1976, HIRI, 1973; It is often easier to gain the motivation and commitment of organization members when they have had a part in the design and decision-making regarding the change (Marrow, 1969; HIRI, 1973).

The structural and performance properties of the organization are significant influences on the ability of the members to adopt changed 
or new procedures and tasks. Whenever a change is in its initial stage, there are elements of uncertainty, a need for learning and becaning accustamed to the new elements. At such times the organization with low formalization of roles, open communication, supportive leaders, administrative and peer support, and high levels of mutual trust and morale has been found to be most effective in adopting changes. However, in later stages of implementation of a change, it may be feasible and in fact desirable to have a rore formalized structure of roles and responsibilities, including a more directive leadership style. This seems to be particularly true if the technology being adopted is well-developed and if the task involves problems that are fairly predictable and recurrent. If the technology is less welldeveloped, or the problems that arise are non-recurrent and non-routine, the change in structure toward a more impersonal routine set of rules and procedures may, in fact, reduce the ability of the organization to achieve its goals. Nevertheless, the stage of implementation of an innovation may well be a factor in determining the shape of social relations among organization members (Zaltman et al., 1973). Each organization will respond to a specific innovation in a manner that reflects its own properties and the perceptions of its members of the innovation's potential relevance and riskiness to their existing roles and relationships. The nature of the organizational response may vary as the process of implementing the innovation progresses. Thus, organization structures may evolve from very informal to very formal as the members' experience with the innovation increases their sense of certainty. 
Innovations are, thus, one more variable or factor that can affect the structure of social relations within an organization. However, they do this inoirectly through their influence on the technology and on the morale of the members. The intensity of their effect can be expected to vary with the relevance and scope of the innovation as perceived by organization members and with the stage to which the organization has progressed in implementing the change. The intensity of effect also tends to be greater in the specific unit of the organization that is directly involved in the change, in proportion to degree of difference or risk that the change is perceived to present from existing practices.

CONCEPTUAL MODEL

The major dimensions of the conceptual model (Figure 1) have now been reviewed and can be elaborated on in more detail, and a more fully developed model can now be presented (Figure 2).

Organizational Attributes as Predictor Variailes

This model includes the predictor variables which are the several dimensions of the organization itself that are presumed to have a prevailing and direct influence on the types of relationships that agency staff develop with informal helpers. Included here are three general types of organizational attributes: the structural, the work climate, and the environmental linkage dimensions (Table I).

Structure. The structural dimension is divided into some of its component elements: size, complexity, and formalization. It is 


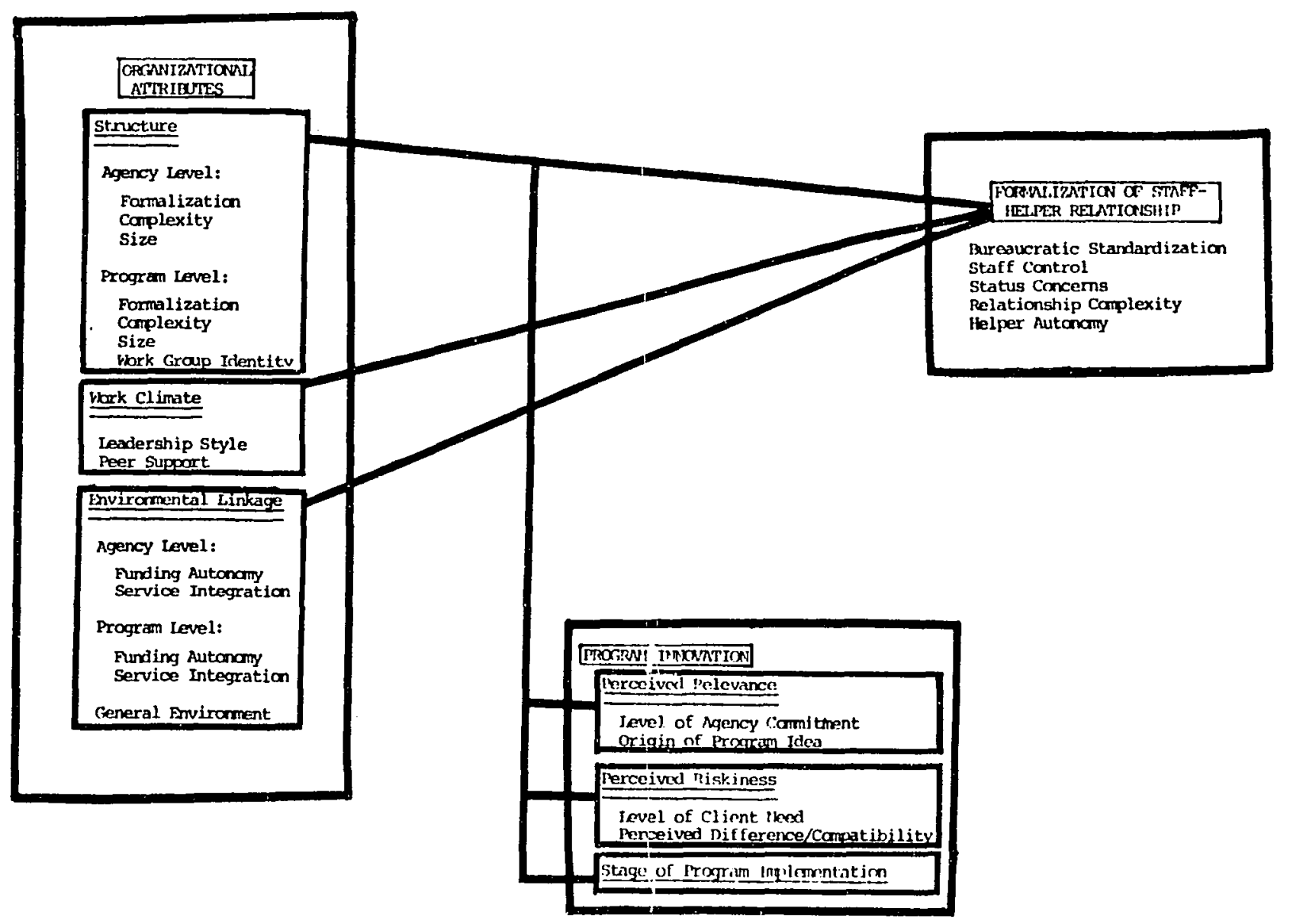

Figure 2. Conceptual model of predicted relationships between agency, innovation, and staff-helper relationship attributes. 
TABLE I

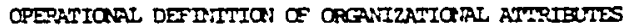

STRUCTRE

Agency Size

Agency Formalization

Agency Complexity

Program Size

porgram formalization

Program conplexity

hork Grow Identity

Agency; Structure

Progran Structure

overall stmicture

\section{HORK CITATE}

Leadership

Peer support

Qverall Wark Climate

ENIFCNMERAL ITRAAE

Ceneral Envirament

External Funding Autonany

Internal Funding Autonary

Agency Service Integration

Program Service Integration

Overall Progran-Enviranmental Linkage
Assesses budget and staff capacities of total agency.

Assesses specialization of roles, standardization of multiple aspects of work, hiring and performance, and centralization of decision-making within agency as a whole.

Assesses momber of different maxches, clients, and natural helper prograns.

Assesses budget and staff capacities in natural helper program.

Assesses specialization of roles, standardization of work procedures, hiring, performance appraisal, and reporting and centralization of decision-making in program unit.

Assesses number of branches, client types, funding sarres, and apsoaches within program unit.

Assesses degree to which natural helper program is freestanding unit within a larger agency context.

Is an overall measure combining size, fomalization and complexity.

Is an overall measure combining size and fomalization of progran urit.

Combines agency size, complexity, and formalization. program size, camplexity and fomalization and work graup identity.

Assesses the relative enphasis on participation and support or directions and control of program manager.

Assesses the morale and openness of exchange amang workers in program.

Cambines leadership and peer suport

Assesses level of urbanization, density and absolute physical size of service area.

Assesses the sources, stability, flexibility and adequacy of funding for the program.

Assesses degree to which ratural helper program funting is separate from general agency.

Assesses the role, reputation, and level of linkage of agency to other service arganizations.

Assesses the reputation, relative role in providing services and degree of connection to other agencies and to clients.

Combines program service integration and external funding autonany. 
also divided into measures of each of these elements at both the total agency level and at the program level. An additional structural dimension at the program level is the degree to which the program operates as an identifiable, distinct unit.

Work Climate. The work climate dimension is divided into the camponent elements of leadership style and peer support.

Enviromental Linkage. The enviromental linkage dimension is divided into its component elements of funding autonomy and service integration at both the total agency level and the program level and a measure of the total level of urbanization of the general environment. While the component elements of the structural and work climate dimensions are self-explanatory, those related to environmental linkage deserve some further explanation. The critical dimensions of environmental linkage have been described as the resource dependency continurm, the continurm of linkage to other organizations, as well as the level of stability of the general enviromment. In this study each of these dimensions is translated into an element used as a proxy for the more complex concept. Thus, the resource dependency element is operationalized using a funding autonomy measure; the organizational linkage element is measured through service integration; and the environmental stability dimension is measured using level of urbanization and density as proxies for stability.

\section{Program Innovation Attributes as Mediating Variables}

Also included in the model are mediating variables, which are several dimensions of the perception of the program innovation, 
expected to influence the organizational attributes and to exert an indirect influence on the types of relationships that develop between agency staff and informal helpers. Included here are three general types of program innovation attributes: the perceived relevance of the innovation to the agency/program overall mission; the perceived riskiness of the innovation in terms of scope of change and intensity of service needs of client population; and, finally, the stage to which the implementation of the innovation had progressed. Each of these attributes is an agency-specific assessment of the potentials offered by the program within tiat agency context (Table II). Perceived Relevance. This innovation dimension is divided into two component elements: type of agency camitment and level of omership by program staff of the innovation idea.

Perceived Riskiness. This dimension of the perception of the program innovation consists of two elements: the level of client need and stigma, an indicator of the importance of appropriate services to the target population; and the degree of perceived difference of compatibility of the program innovation in terms of its procedures, the tasks that staff must perform, and certainty of the technology. In combination high need and high difference levels constitute a proxy for program riskiness.

Stage of Program Implementation. This dimension cambines several elements that are indicators of the process stages in inplementing an innovation, one of which is the length of time since the program was instituted. 
TABTE II

OPERATIONAL DEFINITIONS OF PROGRAM INNOVATIONS

Agency Camitment

Origin/Emergence

Client Need/Stigma

Difference/Compatability

Stage of Program

Inplementation

Perceived Relevance

Perceived Risliness
Assesses overall view by agency administrators and staff of the general idea of natural helper program and its specific value to this agency.

Assesses the degree to which present program staff helped develop program idea.

Assesses the level of social stigma of problems of clients and the types of helping resources needed to meet them.

Assesses the number of dimensions on which staffing and practice in natural helper program differ from general agency practices.

Assesses the duration and point in program development process of the natural helper idea and/or program.

Combines the agency commitment and emergence dimensions.

Cambines the client need and program difference dimensions. 
Together these three dimensions of the program innovation can be taken either as exerting an indirect effect on the structure of the staff-helper relationship through their influence on the organizational attributes, or as exerting a direct, confounding influence on the relationship which exists between the organizational attributes and the staff-helper relationship. In the model direct influences are represented with a solid line, and indirect influences with a dotted line.

\section{Staff-Helper Relationship Attributes as Outcome Variable}

In this model the outcome variable is the structure of the relationship between the agency staff and the informal helpers. This is a single unitary concept which has certain component elements, reflecting in a staff-helper relationship certain of the dimensions used in the literature to describe the relationships between leaders and workers or between peers within an organizational context. These elements include: bureaucratic standardization (of roles, procedures, times and places of service, etc.), staff control (over the activities of helpers), status concerns, relationship complexity (a diversity of horizontal and geographic differentiations of the staff-helper activities), and helper autonany of norms and activities (Table III). 
TABLE III

OPERATIONAL DEFINITIONS OF STAFF-HEIPER REIATIONSHIP FORMALIZATION

Bureaucratic Standardization

Staff Control

Status Concerns

Relationship Conplexity

Helper Autonosily

Overall Relationship

Formalization
Assesses the degree to which staff use agency practices such as job titles, training, scheduling contacts, and agency-base for helpers.

Assesses the extent to which staff assign helpers specific tasks or persons to help, tell helpers how to help, use helpers only as assistants, and require reports from helpers.

Assesses the extent to which staff express beliefs in need for professional supervision and concerns about adequacy of informal helpers or informal helping.

Assesses the number of sites, the shifts of roles between staff persons and shifts in initiative between staff and helpers.

Assesses the level of helper initiative and connectedness among helpers.

Cambines all the above: bureaucratic standardization, staff control, status concerns, complexity and helper autonamy. 
RESEARCH GYPOTHESES

Based on the literature review and the conceptual model, the following research hypotheses were formulated:

1. Large organizational size will be associated with high formalization of the staff-helper relationship. Similarly, large size of a program unit will be associated with high formalization of the staff-helper relationship.

2. High organizational bureaucratization (cambining high camplexity and high formalization) will be associated with high formalization of the staff-helper relationship, at both an agency level and a program level.

3. A highly supportive work climate (where there is supportive, democratic, person-oriented leadership, and supportive work group norms) within the program unit responsible for the partnership program will be associated with low formalization of the staff-helper relationship.

4. An organization or program unit with an envirormental linkage that combines low autonamy in funding and tightly-coupled service integration will be associated with high formalization of the staff-helper relationship.

5. When organization members perceive the partnership program to be relevant to their agency's overall goals (that is, they know the agency is committed to the program and have had a part in developing the program), this perceived relevance vill be associated with low formalization of the staff-helper relationship and, when controlled for, the strength of association between the staff-helper relationship and the agency or program unit structure, work climate, and envirormental linkage will be reduced.

6. When organization members perceive the partnership program to be risky (for their clients, whose needs are high, and for thenselves, because the practices required by the program are different/incampatible with existing agency practice), this perceived riskiness will be associated with high formalization of the staff-helper relationship, and, when controlled for, the strength of the association between the staff-helper relationship structure and the agency or program unit structure, work climate, and enviranmental linkage will be reduced.

7. The further along the program has progressed in implementing the partnership program, the more highly formalized the staffhelper relationship will be. 
Each of these hypotheses was tested using appropriate statistical procedures after the scales measuring each of the elements were constructed. Following the testing of these hypotheses, which primarily involved the testing of pairs or triads of variables at one time, the larger research question of the overall relative significance of the measured attributes of the organization and the program innovation was posed for exploratory analysis. The results of these tests and exploratory analyses will be discussed in Chapter IV, after more complete description of the research methodology in Cluapter III. 
CHAPTER III

RESEARCH METHODOIOGY

A variety of strategies was used to answer the research questions of interest to the Networks project. The purpose and methods used were prinarily exploratory and descriptive. The procedures used in selecting the sample and in collecting the data reflected this pursuit of information to illustrate the range of possible partnership programs linking formal and informal systems, rather than a concern for statistical representativeness. This research study, as an integral part of the Networks project, shares the same sample, data base, data collection procelures and concerns, with all their attendant strengths and weaknesses. This chapter presents more cetailed information on the methods used in this research, including sampling procedures, data collection procedures, and methods of data reduction, scale-building, analysis and hypothesis testing.

\section{SAMPLING PROCEDURES}

\section{Inventory of Programs}

An inventory of social service agencies with natural helper partnership programs was compiled in response to several different methods of identification and recruitment. The methods used by the research staff to identify programs included: scenning the research and practice literature for descriptions of such programs, sending letters 
and announcements regarding the research project and its purpose to national, regional and state agencies or organizations serving one or more of the target populations, publishing announcements of the research project in newsletters and bulletins reaching a wide variety of human service professionals. In addition known experts and researchers in the areas of natural helping networks and/or partnerships between professionals and informal helpers were asked to nominate any programs known to them. In this way about 70 programs were identified. This inventory of programs served as the sampling frame from which the 30 sample programs were selected. Appendix A contains samples of the announcements, letters, the program description request form, and the project revieiv checklist.

\section{Sample Selection}

Normative Criteria. The actual sample of 30 programs was selected in two stages using a set of normative criteria derived from an intensive review by research staff of practice, theory, and expert opinion regarding the form that such programs should take. These nomative criteria are sumarized in Table IV.

First Stage. The first stage of the sample was selected after the nomative criteria were agreed upon. In the first stage 10 programs were studied in depth and used to evaluate the enpirical relevance of the normative criteria to determine what, if any, other criteria should be used to ensure a broad range of program types and experiences focusing on partnerships between agency staff and infomal helpers.

second stage. In the second stage of sample selection several considerations were weighed in addition to the normative criteria. 
TABLE IV

NORMATIVE CRITERIA FOR SAMPLE SETDCTION

Agency Characteristics

1. Agency operates with paid professianal staff. Professional as used here thed's irdividials for itom providing belping services is a principal cocupation (rather than simply having attained a certain level of training).

2. The agency has a program of direct service delivery or is involved in activities that have applications to hum service objectives.

3. The project must be currently" operational and expected to continue for the duration of the research study, 18 months.

\section{Characteristics of Staff-Helper Relationship}

1. The agency staff intend to develop a sustained zelationship with helpers in the retwork.

2. The agency seeks to establish links with individuals who are instrumental in providing help to others within their ow network.

*3. The agency staff views helpers as colleagues or as peers. The helpers are considered as equals, with a "clientele" of their ow. This excludes agencies working with paraprofessionals or volunteers who are considered junior partners to the agency.

4. The objective of the staff-helper relationship is to reach a broader group of individuals through the identified helpers, rather than to provide social services to the helpers anly.

5. The agency staff respects the cultural norms of the helpers and the network. The focus is on enhancing rather than changing the network.

\section{Network Characteristics}

1. Relational ties within the network are existing rather than created. Within the network indivichuals have a reason for getting together or having a relationship independent of the efforts of the agency. While an agency may initially foster the develognent of such a network, the intent should be to promote a "freestanding" network of relationships.

2. The predoninant element of exchange within the network is helping. The enphasis is on exchanges directed to pronoting positive functioning or ajjustment among members.

3. The exchange is based on mutuality, reciprocity and shared values. People are not interacting primarily because they are being paid to do so. The focus is on voluntary and equal participation.

*4. The retwork may have key figures or indivicuals who play central roles in exchanging information, advise, support or other helping resources within the network. This characteristic may alternatively be considered as a feature of a multiplier effect." This means that the network functions so as to diffuse, share or transfer helping resources across the entire network.

5. The exchange of help occurs in the indigenous setting of the network and does not deperd on a created envirament. 
Decisions were made to select programs representing the widest possible diversity in target populations, to include small "shoestring" programs that might otherwise be overlooked in a national survey, and to include programs using different prograrn approaches, from among the types identified in preliminary analyses of the first ten cases.

The research project was funded with a cross-cutting grant of funds fram several agencies within the federal Department of Health, Education, and Welfare, Office of thman Development Services. This office enconpasses agencies serving the elderly, children, youth and families, the developmentally-disabled, and Native Americans. One goal of the research staff was to ensure representation of programs serving each of these populations, as well as neighborhood service programs and mental health prevention services or community support programs for the chronic patient.

Small service projects, often operating on very small budgets, are ubiquitous in the field of human services. However, they may escape the attention of experts or of large govermmental bureaucracies, and may not have access to the media used to announce the Natural Helping Network project's goals and purposes. Many such small local programs were known to members of the research team through their involvement with the local cammities in Oregon. Several such local programs were deliberately included in this study to ensure fair representation to this cammon type of social service effort.

Program Approaches. Finally, staff sought to include programs using the five different strategies for working with informal helpers that were apparent in the first ten cases. These five approaches, 
described in more detail elsewhere (Froland, et al. 1980a, 1981), are presented briefly below:

Neighborhood networks: In these approaches agency staff worked with a locality-based network of local residents who were found to be natural helpers to agency clients, and/or they worked with local civic leaders and activities interested in assuring better social services for residents of their area. Two types of neighborhood network approaches were identified: the neighborhood helper approach in which local residents were providing services directly to other residents, and the community enpowerment approach in which the residents of interest to the agency were involved indirectly in serving individuals, with their primary efforts directed to benefiting the entire neighborhood or cammity.

Personal networks: In this approach agency staff worked with persons who were relatives, neighbors, or friends of specific individuals who were also clients or potential clients of the agency's direct service programs.

Volunteer-linkage: In this approach the agency recruited volunteers to work with individual clients or families. These volunteers were selected because they possessed skills that could be of value to the agency's clients, often including though not limited to their willingness and ability to socialize with and befriend clients.

Mutual aid: In this approach the agency staff played the role of catalyst and facilitator for informal groups or dyads 
of persons who came together around cammon concerns, problems, or life experiences, for sharing ideas, experiences, exchanging advice, and offering mutual support in coping with the focal concern.

Each of the programs in the study used one or more of these approaches to working with informal helpers or informal helping systems. Often different approaches were used with different populations within a single agency, in other cases several approaches were combined within a single program. Table $\mathrm{V}$ presents brief descriptions of the 30 programs in the study and includes information regarding the types of approaches used in each, the target populations, the agency auspices, and location. Appendix B includes more extensive case study sumaries.

\section{Issues Regarding Sampling Procedures}

There are two aspects of the study sample that deserve mention because they require some caution in regard to the interpretation of results. The first aspect that requires caution is that of the sample size; the second is the sample selection process itself.

Size. A sample of 30 programs constitutes a small sample for purposes of statistical and quantitative analysis, particularly when the number of variables measured begins to approach the number of cases in the study sample. However, it is not uncammon for studies in the field of organizational research to have small sizes. Two highly regarded studies in this field range in samn?e size from 16 agencies (Hage \& Aiken, 1970) to 52 (Pugh et al, 1968). This study sample is clearly in the middle of that range. The research design seeks to overcome the limitations of the small sample size by relying on a 
TABLE V

BRIEF CASE DESCRIPTIONS

Strategies

\begin{tabular}{|c|c|c|c|c|c|c|c|c|}
\hline Case & Target Population & Location & Agency & $\begin{array}{l}\text { Personal } \\
\text { Network }\end{array}$ & $\begin{array}{l}\text { Volunteer } \\
\text { Linking } \\
\end{array}$ & $\begin{array}{c}\text { Mutual } \\
\text { Aid } \\
\end{array}$ & $\begin{array}{l}\text { Neighbor- } \\
\text { nood } \\
\text { Helping }\end{array}$ & $\begin{array}{c}\text { Commenity } \\
\text { Enpowerment }\end{array}$ \\
\hline 1 & Elderly & small, midwestern town & gmall demonstration project & $x$ & & $\mathrm{x}$ & $\mathrm{x}$ & \\
\hline 2 & Elderly & medium-sized western city & small senior center & & & & $x^{x}$ & \\
\hline $\begin{array}{l}3 \\
4\end{array}$ & $\begin{array}{l}\text { Elderly } \\
\text { Elderly }\end{array}$ & $\begin{array}{l}\text { rural counties in northeast } \\
\text { large, eastern city }\end{array}$ & $\begin{array}{l}\text { caminity mental health center } \\
\text { large, private agency }\end{array}$ & $\mathbf{x}$ & & $x$ & $\mathbf{x}$ & \\
\hline 5 & Elderly & large, eastern city & large, private sectarian agency & $\mathrm{x}$ & $\mathbf{x}$ & & $\mathbf{x}$ & \\
\hline 6 & Elderly & eastern, suburban area & comminity mental health center & & & $\mathrm{x}$ & & \\
\hline 7 & Elderly & large, western city & private settlement house & $\mathrm{x}$ & & $\mathrm{x}$ & $\mathrm{x}$ & \\
\hline $\boldsymbol{\theta}$ & Elderly & large, western city & branch of large senior center & $\mathrm{x}$ & & $\mathrm{x}$ & & \\
\hline 9 & Elderly & large, southwestem city & middle-sized ethnic agency & & & & $\mathrm{x}$ & \\
\hline 10 & Fantlies & medium-sized westem city & mall demonstration project & & & $\mathbf{x}$ & & \\
\hline 11 & Families & large, westem city & amall demonstration project & & & $\mathrm{x}$ & & \\
\hline 12 & Families & medium-sized midwestern city & branch of statewide private program & & $\mathrm{x}$ & $\ddot{x}$ & & \\
\hline 13 & Families & large, westem city & mall private agency & & & $\ddot{x}$ & & \\
\hline 14 & Fanilies & eastem suburtian area & large, private child guidance agency & & $\mathrm{x}$ & $\ddot{x}$ & & \\
\hline 15 & Fhysically handicapped & large, southwestern city & large, private agency & & $\mathbf{x}$ & $\mathrm{x}$ & & \\
\hline 16 & Develogmentally disabled & medium-sized western city & middle-sized private agency & & $\mathbf{x}$ & $\mathrm{x}$ & & \\
\hline 18 & $\begin{array}{l}\text { Developmentally disabled } \\
\text { Developmentally disabled }\end{array}$ & $\begin{array}{l}\text { large, eastern city } \\
\text { large, wegtern city }\end{array}$ & $\begin{array}{l}\text { mall, private agency } \\
\text { one site of a 3-site, stateride }\end{array}$ & & $x$ & & & \\
\hline 19 & Develomentally disabled & large, eastem city & demanstration project & & $\mathbf{x}$ & $x$ & $x$ & \\
\hline 20 & Preventive mental health & small southwestern town & $\begin{array}{l}\text { aranch of comunity mental health } \\
\text { center }\end{array}$ & $\mathrm{x}$ & & & $x$ & \\
\hline $\begin{array}{l}21 \\
22\end{array}$ & $\begin{array}{l}\text { Chronically mentally ill } \\
\text { Preventive mental health }\end{array}$ & $\begin{array}{l}\text { large, southeastern city } \\
\text { nural eastern counties }\end{array}$ & $\begin{array}{l}\text { large, state agency' } \\
\text { demonstration project at state } \\
\text { university }\end{array}$ & & $\mathrm{x}$ & & $x$ & \\
\hline 23 & Mental health & urban and rural midwestern & oumitym mental health center & & & & & \\
\hline 24 & Chronically mentally ill & $\begin{array}{l}\text { county } \\
\text { four urban and rural, mid- }\end{array}$ & mall, private agency & & & $x$ & $\mathrm{x}$ & \\
\hline 35 & Promention montal honlth & Han & & & $\mathrm{x}$ & $\mathbf{x}$ & & \\
\hline 25 & Preventive mental health & lange midwestem city & $\begin{array}{l}\text { branch of large private settlement } \\
\text { house }\end{array}$ & & & $x$ & $x$ & \\
\hline $\begin{array}{l}26 \\
27 \\
28 \\
29\end{array}$ & $\begin{array}{l}\text { Neighborhood housing \& health } \\
\text { Community mental health } \\
\text { Commity mental health } \\
\text { Comminity health and mental } \\
\text { health }\end{array}$ & $\begin{array}{l}\text { modilum-sized southern city } \\
\text { gmall, western town } \\
\text { large, midwestern city } \\
\text { midwestern, rural Indian } \\
\text { reservation }\end{array}$ & $\begin{array}{l}\text { city goverment } \\
\text { small demonstration program } \\
\text { small demonstration program } \\
\text { demonstration project at college }\end{array}$ & $x$ & & $\mathrm{x}$ & $\begin{array}{l}x \\
x\end{array}$ & $\begin{array}{l}x \\
x\end{array}$ \\
\hline 30 & Ceneral community improvement & large, western city & large, private service agency & $\mathrm{x}$ & & $\mathrm{x}$ & $\begin{array}{l}x \\
x\end{array}$ & $\begin{array}{l}x \\
x\end{array}$ \\
\hline
\end{tabular}


combination of quantitative and qualitative analyses. The quantitative methods (correlations and multiple regressions) are complemented by analyses of the case materials.

Despite the limitations of the small sample size this study does move the understanding of professional collaboration with informal helpers from the primarily anecdotal level of single case studies to a more empirical level in which comparisons between programs can be made.

Selection process. The sample of 30 agencies was selected using a purposeful rather than a random selection process, as previously noted. This was due, in part, to the broad exploratory nature of the research. It was also due to the limited availability of information on such programs that drastically constrain the construction of a sampling frame fram which programs could be randomly selected. The result of this type of selection process is to linit the nature of conclusions that can be drawn from the resulting data and analyses. These conclusions cannot be generalized to all human service organizations, for example, or to all such organizations involved in working with informal helpers. However, the research does serve its purpose as an exploration into the types of issues and considerations that can occur when human service organizations attermt to adopt programs in which they work with non-professionals in partnership relationships.

\section{DATA COLLECTION PROCEDURES}

\section{Types of Data Collected}

The data gathered in this study were primarily qualitative in nature. Guided discussions, observations, and written materials were 
the primary data sources. The guided discussions were held by research staff with agency administrators, program managers and staff, and with natural helpers. These discussions were loosely structured around several major topics: characteristics of the community or neighborhood, program history and functioning, staff characteristics, agency characteristics, helper characteristics, staff-helper relationships, assessments of program strengths and weaknesses. Same topics were discussed only with agency administrators, others with line staff or helpers only (See Appendix C for the Discussion Guide) .

Data were collected during brief but intensive site visits to the agencies, in wich research staff met, talked with, and watched program staff in action with natural helpers. The average duration for site visits was 13 hours. During the visit the researcher met with many levels of staff and often also met natural helpers. Same discussions occurred in groups of staff and/or helpers, others with individuals.

\section{Discussion Guide Development}

A discussion guide was developed prior to the actual site visits. Questions included in the discussion guide were selected by the research staff by drawing on the questions originally posed in the research proposal and adding others of interest and relevance to these central issues. Specific questions were developed through review of prior research and joint review by staff and by expert consultants. For example, the questions regarding the influence of agency on program characteristics were developed out of literature reviews of organizational factors that affect the ability of organizations and their characteristics. These sources offered both theoretical and 
operational definitions of organizational characteristics. Many of the specific instruments were deemed to be either too narrow in focus (e.g., worker morale or leadership style) or too general (broad typologies, for example) to be used in the context provided by this research. The questions finally settled upon in the figency portion of the discussion guide were those which were intended to permit the research staff to reconstruct both a case history of the program within its agency context and to develop a case profile of the specific structure and context of the program at the time of the site visit. The discussion guide provided the framework for the site visits, each of which was conducted by one member of the research staff. The researcher took notes, taped conversations, gathered program and agency descriptions and/or other written conceptual or descriptive materials produced by agency or program staff relative to their partnership efforts. In several instances the researchers were given access to case materials on individual helpers or helping systems that were maintained by program staff.

In order to minimize the potential biases that could enter into the interpretations given to different programs due to individual differences among the researchers, special efforts were made to achieve and maintain common understandings. This was done through frequent, intensive sessions focused on clarifying the questions and their relevance to the research focus. This effort was doubly important, for not only did the research staff members differ in background and training, but tine agencies and programs visited were quite diverse. This diversity made it necessary for staff to probe responses, check 
perceptions, and to strive to master the vocabulary and nuances of each specific program in order to describe then within the research framework.

\section{Reliability Controls on Data Collection Procedures}

Given the potential for individual biases in rating programs, i.e., one researcher consistently rating his/her programs high or low on certain items, tests for biases were run. Included among similar potential "nuisance" influences on the reliability of the data were such factors as the length of time spent at the agency during the site visit, the number of administrators met, the amount of documentation available regarding the agency and/ar program. One-way analysis of variance procedures using the interviewer (length of site visit, amount of documentation and so on) as the treatment was used to test for systematic differences in the dependent variable, the structure of the staff-helper relationship. Using this method to test for bias revealed no "nuisance" factors that were associated with significant differences in the structure of staff-helper relationships. Appendix E presents the items used and the results.

DATA REDUCTION PROCEDURES

\section{Case Studies}

Each researcher was responsible for generating the two major types of descriptive data about the programs she/he visited. The first step in data reduction was the preparation of a narrative description or case study of each program, drawing on the notes, tapes, and other documentation obtained during the site visit. The first 10 programs' 
case studies ranged in length fram 15 to 30 pages. The other 20 case studies were less detailed, ranging in length fram 10 to 15 pages. Each case study was returned to the staff in the program described, who reviewed it for accuracy and for content validity.

\section{Content Analyses}

The second type of data generated by the researchers came after the completion of all of the site visits and case descriptions. The researchers jointly conducted a content or theme analysis of the programs in order to identify major dimensions along which they varied. once these major dimensions were detemined they were factored into camponent elements, for which item stems were written. Each item stem consisted of a descriptive statement which permitted each program to be rated (generally on a 4-point scale). For example, the degree to which the agency relied on written job descriptions and written job procedures could range fram very high to very low. The complete set of item-stem/descriptive statements on which each program was rated for this study is included in Appendix $D$.

The development of the themes, dimensions, and elements was a joint endeavor of the research staff in order to develop a cormon understanding of the complexities of the different situations they had observed and compare these situations. Each researcher was then responsible for rating those programs she/he had visited, again relying on all the available information and documentation. The ratings were then computerized for ease of analysis using the Statistical Package for the Social Sciences, Version 8. (Hull \& Nie, 1979), on the Honeywell $66 / 20$ computer located at Portland State University. 
MULTIPLE-ITEM SCALE CONSTRUCTION

The research reported here relies on a cambiration of quantitative and qualitative methods of data analysis. As previously noted, two methods of data reduction were the use of case descriptions and content rating scale analyses.

The primary step that this research adds is the construction of multi-item scales. These scales are fomed by adding together tine itens which theory suggests to be interrelated, yielding a single scale. The multi-item scale measures camplex constructs such as organizational or program size, complexity, or formalization; community type and density, program leadership style, and so on.

\section{Benefits of rultiple-Item Scales}

Nultiple-item scales are deemed to be an effective method of determining relationships between complex variables in social science research. Nunnally (1978) identified four strengths of such multipleitem scales: (1) they avoid the specificity and narrowness of operational definition of single items; (2) they permit finer differentiation between subjects than would single items; (3) they are more reliable than single items: (4) they include more information on the various aspects of the attribute being measured than do single items.

\section{Steps in Scale Construction}

To form the scales used in this research, a number of steps were followed: 
(1) The first step was to develop items deemed to be valid operational definitions of same aspect of the attributes of human service organizations and to identify all of those items which then were deemed to be conceptuallyrelated. For example, organizational size was one aspect of agency structure, and it was measured by items such as total buaget or funding level, total number of paid staff and so on. The complete list of variables with brief descriptions of the items used to operationally define and measure them were presented in Fables I-III. They are the same variables included in the research model in Chapter II. The actual items are included in Appendix D.

(2) All items were entered into a correlation matrix. Items conceptually linked to a common scale were rated for the number of other items in that scale with winich they correlated at a level of $r>.40$. Their correlations with items in other scales was also examined, primarily as a first rough assessment of the conceptual validity of the proposed scales. Also examined at this stage was the direction of the correlation to determine whether items were all reflected in the same direction. As necessary itens were reflected. (see Appendix F for more detail).

(3) The scores on all items were standardized into z-scores with a mean score of 0 , standard deviation of 1 . This step, carpleted using the SPSS Condescriptive subprogram, has necessary because the range of values on variahles included in each scale varied. Standardization permits addition. 
(4) The next step in the scale construction was to compute the reliabilities of the proposed scales through the use of the SPSS Reliability sub-program. Careful examination of the correlation matrix, the item-total correlations, the item-total correlation and alphas that would result by removing each item (one at a time) and the standardized alpha for the overall scale were the steps followed to finalize the selection of items to include in each scale. At times the choice was between a higher reliability level for the overall scale, but a lowered content or conceptual validity by removing an iten or items from the scale. These considerations were carefully weighed in deciding which items to include in the final version of each scale.

(5) The scales included in this study were of two types: First, subscales were constructed to measure different aspects of some larger concept. Thus, the larger concept of work climate was measured by two subscales, leadership style and peer support. The subscales each consisted of two or more items which reflected an operational definition of one aspect of the larger concept. Second, aggregate scales were constructed by cambining two or more subscales. These aggregate scales were formed by adding the subscale scores. Among the aggregate scales were agency structure, program structure, overall work climate and overall staff-helper 
relationship formalization. The same steps followed in subscale construction (particularly steps 2 and 4 above) were followed in constructing aggregate scales.

\section{Missing Data}

In the process of scale construction the problem of missing data had to be dealt with.

Two types of missing data were found in this data. In developing items on which programs were to be rated, some items wer's included that were of theoretical interest and relevance to certain programs and not others. This resulted in missing data on those cases for which those items were not relevant. For example, some programs were essentially autonamous and had no other agency to which they were directly accountable. In these instances items designed to measure agency-wide characteristics (e.g., to show the differences or similarities between agency structure and program structure) were deemed inappropriate, and these scales were not constructed. That is, missing data was not a problem.

A second type of missing data resulted when the rater failed to camplete an item due to lack of knowledge or certainty regarding the specific item. While this is a very appropriate response, it presented complications for the use of the SPSS Reliability sub-program which excludes any cases from the internal consistency analysis which has data missing on any item included in the scale. Rather than lose cases from the analysis on which most items were available, a decision was made to determine whether using mean scores on missing items would alter significantly the overall scores. 
This was determined using the multiple regression technique described by Cohen and coinen (1975, p. 265-290) for assessing whether the mean score was ohanged when overall mean replaced missing velues. This technique involved using two forms of the same scale in a multiple regression equation, then inspecting the beta weights to determine whether they differed significantly. The first form of the scale consisted of all appropriate cases, with the group mean score assigned for those items on which there was missing data. The second form used a dummy variable, with 0 for cases with no missing data, 1 for those with missing. The beta weights revealed no differences between the group mean approach and that in which the dummy variables were entered. The decision was then made to assign group mean scores to the items on which there was inappropriate missing data. This step was campleted prior to standardizing scores and scale construction.

\section{Constructing Weighted Scores}

In constructing scales to represent the predaminant structure of relationship between agency staff and informal helpers, it ras first necessary to construct a single score on each item. Rating of relationships between staff and helpers was done separately for each different approach used. Then the percent of total staff effort and program resources used in each approach were assessed. The scores on items were multiplied by the percentage of staff effort devoted to that approach, then added together and divided by 100 to obtain a single weighted score for each item. It was the weighted scores which were combined to form scales measuring different aspects of the staff- 
helper relationships but may, in fact, obscure same of the variation possible within agencies.

\section{Reliabilities of Scales}

Thirty-two scales were constructed to measure different aspects of the agency context, program context, and staff-helper relationship. Of these 32 scales, 24 were subscales consisting of two or more itemstems, rhile the other cight scales were aggregate scales formed by adding together scores on two or more subscales. Fourteen scales were predictor subscales measuring attributes of the agency, five subscales measured innovational nature of program, and five subscales measured staff-helper relationships. The internal consistency reliability of these scales was calculated through the use of Cronbach's alpha, using the SPSS Reliability sub-program (See Table VI). These coefficients ranged from a very low alpha of .28 to a high of .94 . Eighteen of the scales had high reliabilities, over .80 . Eight had moderate reliabilities, between .60 and .79. Four of the scales had low reliabilities, under .60 . Since reliabilities are affected by the number of items in the scale, scales with fewer itens tended to have lower reliabilities. Althougin construction of subscales served to partially reduce the comilexity and heterogeneity of the measures, even same concepts measured by the subscales were complex and multidimensional. This reduced their internal consistency. The aggregate scales generally proved to be much less reliable and internally consistent due in part to the fewer items they included and to the greater complexity of the concepts they represent. 
TABLE VI

DNERTAL CONSISTENCY REILABITIDS OF SCALES

Subscales

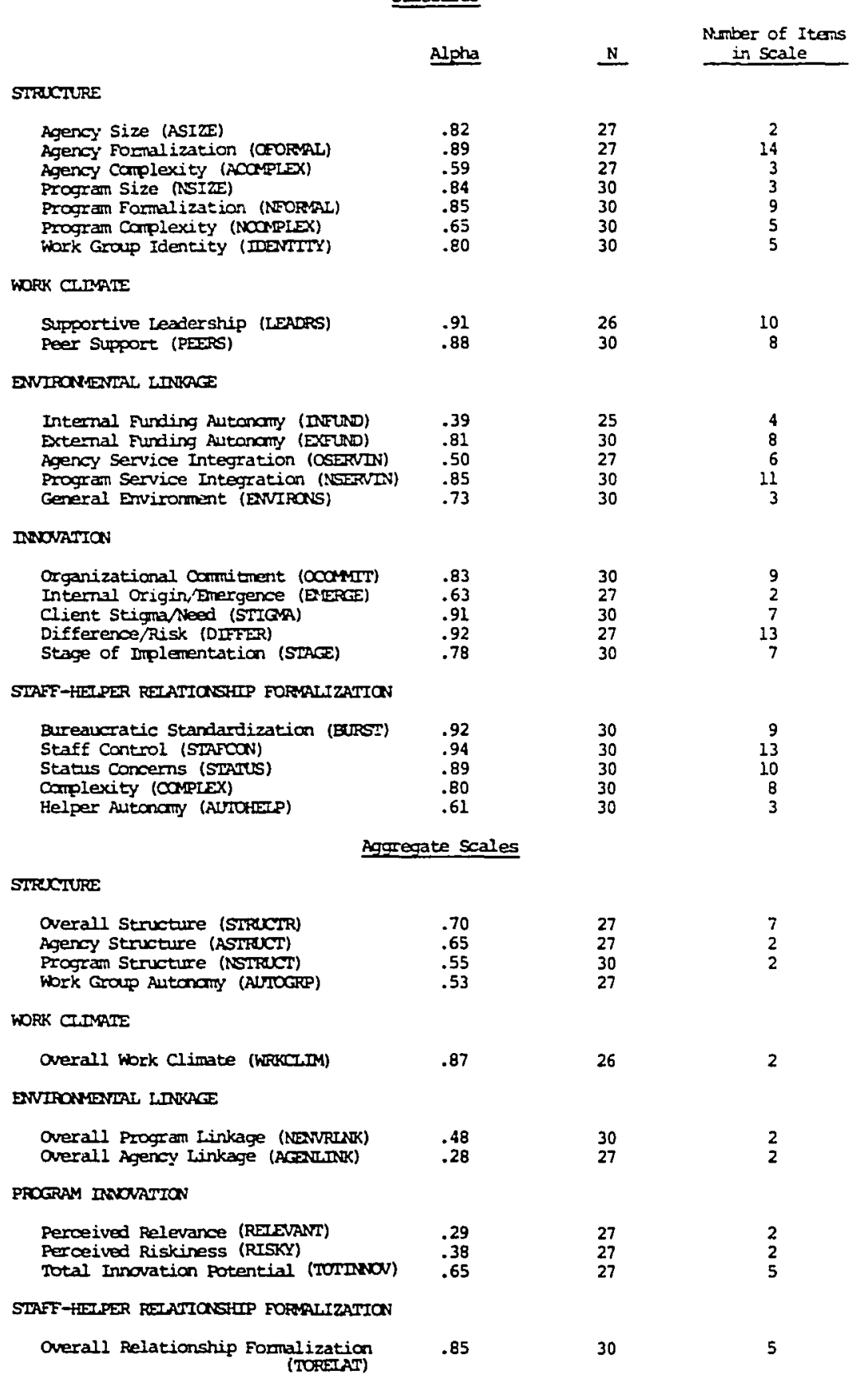


Although high reliabilities contribute to a higher level of confidence in the conclusions one draws from the data, the process of scale construction requires a fine balance between the theoretical or construct validity of the scale and its overall reliability. Removal of certain items could increase the alpha reliability of the resultant scale. However, remoral of such an item could decrease the overall validity by eliminating an item essential to the meaining of the concept.

Scales, once constructed, were used to generate single scores for each case on each variable. Subscale scores and aggregate scale sccres were developed for each major category of variables in keeping with the model of predicted relationships-the predictor variables, the mediating variables, and the dependent variable.

Once the scales were constructed, the next step in the research process was to test the relationships among these variables and to test the hypotheses.

HYPOTHESIS TESTING PROCEDURES

\section{Pearson Correlations}

Quantitative methods used to test the hypotheses included calculation of Pearson correlation ( $\underline{r}$ ) to measure the degree of association between each of the scores on predictor scales and the score on the dependent variable scale, and partial correlation procedures to determine the mediating effect of innovation on the associations between predictor and dependent variable. Also, due to the exploratory and qualitative nature of the research, multiple regressions were run and case materials used to increase the understanding of the complex social situations presented by these data. 
For purposes of this analysis correlations significant at the .01 level or greater were considered outright to be evidence for associations between variables. Due to the small sample size, correlations which the computer programs placed at the .05 level of significance were also tested using an analysis of variance test using the formula $F_{1, N-2}=\frac{r^{2}}{1-r^{2}}(N-2)$ (See Blalock, 1979, p. 417-418). This was done because of concern for the degree of significance of a relationship of about . 30 when the sample size is small. This more conservative test of significance reduces the liklihood of attributing undue significance to associations that occur as a result of small sample size.

\section{Partial Correlations}

Correlations permit generalizations about the degree to which two variables vary together. Partial correlations were used to test hypotheses suggesting that the relationship between two variables was an artifact of their relationship to a third variable. The magnitude of the direct relationships was expected to be larger than those of indirect relationships. If the relationshif ras spurious, controlling for the third variable nould reduce the correlation to zero; if the relationship was mediated through the third variable, controlling for the third variable will also reduce it to nearly zero. If the third variable is an independent variable affecting the dependent variable, controlling for it should increase the magnitude of the relationship between the first two. 


\section{Multiple Regression}

In this research there was interest in the explanatory power of the several predictor variables taken together, as well as that of the relationship between the dependent variable and the predictor variables taken separately. This led to the use of miltiple correlations. An effort is made to explain as much of the variance in the dependent variable as possible, while avoiding problems of multicollinearity of the predictor variables or spurious correlations due to the number of predictor variables approaching the number of cases.

To deal with problems of malticollinearity, each of the clusters of predictor variables that represent a larger construct ras first entered into a regression equation with the dependent variable. In this step highly intercorrelated variables were identified and the best of the two predictors was selected out for later use in a single regression equation to explain the dependent variable using the three or four best predictors as proxies for the larger constructs.

This step was also required in order to reduce the number of variables entered into any single multiple regression equation so that the number of variables did not approach the number of cases.

\section{Case Materials}

Finally, the introduction and analysis of case materials were used to give more depth to the quantitative results in hypothesis testing. Since the number of cases is small, it is possible to explore more fully the results of hypotheses that are either supported or refuted by drawing on specific examples and analyzing the factors at work within them. 
The case analysis for each hypothesis was accomplished using a cross-classification procedure in which programs with scores above the mean on any scale were classed as high on that dimension; those with scores below the mean then were classed as low. This resulted in a four-cell classification of the 30 cases in which two cells were expected to hold all the cases and two cells to be enpty. Those cases which fell into the cells that did not support the hypothesis were reviewed to determine whether they exhibited same cammon features that might account for their unexpected pattern of association with the dependent variable. Case examples were drawn from among these deviant cases for description and analysis to illustrate such other influences on the formalization of the staff-helper relationship. 


\section{CFAPIER IV}

\section{RESULTS}

Seven hypotheses were stated regarding the impact of the organizational context on the structure of the linkage between agency staff and natural hej mis. Four of these hypotheses are statements of ways that organizational attributes will be associated with the level of formalization of staff-helper relationships. The other three hypotheses are statements of ways that the program innovation affects the association between organizational and relationship attributes. In this chapter, the results of tests of these hypotheses are presented and discussed, using case illustrations to interpret ther. Also, in keeping with the exploratory nature of the research, the results of other procedures, used to gauge the relative and combined influence of the organizational attributes, are described and discussed.

\section{EF-ECTS OF PREDICTOR VARIIBLES}

Size

Hypothesis 1. Large organizational size will be associated with high formalization of the staff-helper relationship. Similarly, large size of the program unit will be associated with high formalization of the staff-helper relationship. Underlying this hypothesis is the assumption that the size of an agency has a direct influence on the degres to which staff will be inclined to use formal procedures and inpersonal approaches of interaction in their working relationship to natural helpers. This assumption is 
based on enpirical data that suggest that the larger an organization the more emphasis is put on control and coordination procedures within the organization and, consequently, staff will extend this norm into their relationships with informal helpers.

Size was measured at two levels, the total agency size and the program unit size, using a combination of two common indicators of size. First, the total budget of the agency and the total number of paid staff in the agency were combined into a measure of agency size. Second, the total burget of the program unit, the total number of paid staff in the program unit, and the total number of staff full-time equivalencies were cambined into a measure of program size.

Formalization of the staff-helper relationship was measured using a combination of five indicators: bureaucratic standardization, staff control, staff status concerns, complexity of the relationship, and autonony of helpers.

To test the hypothesis, correlations were calculated between the size scales and the relationship formalization scale, using the Pearson correlations procedure of the SPSS. As can te seen from rahle VII, neither agency size nor program size is significantly correlated with the formalization of the staff-helper relationship. The hypothesis is not supported by the data. Knowing the size of the agency or of the program does not allow one to predict the level of formalization of the staffhelper relationship.

Fron the Pearson correlations one can conclude that the relationship between size and relationship formalization is not a direct, linear relationship. However, there is a possibility of a curvilinear pattern 


\section{CORREIATIONS BETWEEN PREDICTOR MEASURES AND OVERATC STAFF-HEIPER REIATIONSHIP FORMAIIZATION}

\section{Subscales}

Pearson Correlation-r.r

STRUCTURE

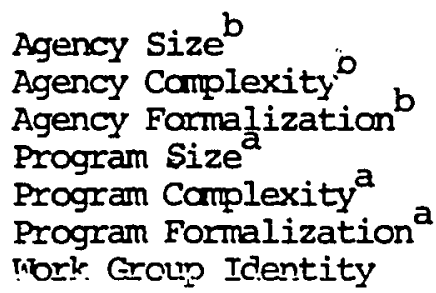

ns

ns

ns

ns

$-.40^{*}$

$.60 * * *$

ns

WORK CLIMATE

Leadership Style

Peer Support

$-.45^{\star \star}$

$-.36^{\star}$

ENVIRONRENIAI LINKAGE

Internal Funding Autonomy

External Funding Autonamy

Agency Service Integration

Program Service Integration ${ }^{2}$

General Enviroment ${ }^{2}$

\section{Aggregate Scales}

\section{STRUCTURE}

overall structure

Agency Siructure

Program Structure

wark Group Autonany

ns

ns

ns

ns

INORK CIIMATE

Overall Work Climate ${ }^{c}$

ENVIRONIENIAI IINKAGE

Overall Program Linkage

Overall Agency Linkage

ns

ns

Note: (a) $N=30$ cases; (b) $N=27$ cases; (c) $N=26$ cases

ns: not significant

${ }^{\star} \mathrm{p}<.05^{\star \star} \mathrm{p}<.01 \quad \star \star \star \mathrm{p}<0.001$ 
of association in which the very large and the very small programs or agencies are similar in the staff-helper relationship structure, with the medium-sized agencies at the other end of the continum of formalization. This possibility of curvilinearity was tested using the eta statistic. Again, this test revealed no significant pattern of association to support the existence of a curvilinear relationship between size and the formalization of staff-helper relationship.

The conclusion that can be drawn fram these results is that the level of formalization of the staff-helper relationship cannot be predicted solely on the rasis of either the size of the agency or of the program unit in which the staff are members. This conclusion leads to the question, what other factors may be influencing the pattern of association?

Case Illustrations. To answer this question, the case materials were reviewed with an eye to ways in which the size of an agency or program varied in its association with the formalization of the staff-helper relationship from what was predicted. Two cases are briefly presentizd to illustrate the issues that were discovered in the course of tinis analysis. These two cases illustrate examples in which the hypothesis did not hold, that is, where large agency or program size was not, or where small size ras, associated with highly formalized staff-helper relationships.

In the first case (\#14) a medium-sized agency with a primary focus on treating child and family prablems determined that it needed to also serve these populations in non-clinical ways. The agency was located in a large, densely-populated suburban county on the outskirts of New 
York City. It had a staff of clinicians located at several different sites within its service area. The partnership program that the agency had established to offer the non-clinical services was very small, both in its staff capacity (less than one full-time person) and its budget. There was one staff member who worked part-time as the coordinator of the program, and another who essentially volunteered her own time to get one part of the program underway. The coordinator worked on a separate strategy from the volunteer staff member, thus, within this very small program there rere tio separate sets of roles and relationships that developed between staff and helpers. In one approach the staff member sought to identify natural helpers fram the area served by the agency and to recruit them as volunteers to work with the agency clients providing non-clinical types of services, such as counseling families in financial management or tutoring adolescents.

The relationship between staff and helpers was highly structured. She recruited volunteers, trained them, assigned them to carry out certain tasks, had regular staff meetings with them, and generally dealt vith then in the same manner as one rould deal rith suhordinate paic' staff such as paraprofessionals. The types of roles they were expected to assume were very diverse, and in same ways each was a function of needs identified by the coordinator and the particular skills of the volunteer helper. Similarly the places where they were asked to work and the clients they were to assist were rarely from their own commuities so they were essentially helping strangers. This particular strategy had the coordinator trying to serve the entire agency service area and target population and supervising a set of helpers that were widely 
dispersed and each doing something different while working in a parttime capacity.

In the other approach a staff member voluntarily worked with a self-help group of single parents. She initially conducted forms that were used to recruit persons interested in participating in such a self-help group. Participants were recruited from throughout the entire service area. Among the helping activities that grew out of the self-help group effort, several were quite structured and formal. They included setting up an information and referral telephone service thich different parents took turns answering, putting together a monthly newsletter for single parents that some parents produced. The staff member also scheduled training sessions for interested group members in which she sought to teach them group process skills so that they could work as assistants to her in facilitating new groups.

Both of the approaches resulted in quite formalized relationships between the agency staff and the informal helpers. The staff functioned in roles that gave them considerable control and influence over the activities of the helpers. Also the relationships were canolex in that the program involved nearly parallel sets of activities that had little interaction or cormonality other than the fact that they stemmed from a single agency and were both non-clinical activities in a predominantly clinical setting. In each instance the amount of staff time available to reach the goals of the program were very limited so that the need for efficiency arose.

In the second case (\#25) a very large social work agency with a primary focus on serving the very poor, inner-city neighborhoods of 
Chicago had developed a moderate-sized program (with at least six fulltime positions) for working with natural helpers in one neighborhood within its service area. The agency had arranged funding for a research and demonstration program over a three-year period, in collaboration with professors at the University of Chicago. The staff selected for the program had to be able to carry out their service roles and to work in collaboration with the researchers as well, so that their salaries equaled or exceeded those of other staff in other agency programs. Although the agency service area ras very large and densely populated, the program service area was linited to a neighborhood area of about 50 blocks, and effectively about 25 to 30 blocks were served. The neighborhood was camprised primarily of two to three story flats and many of the homes originally in the area had been demolished so that the densities in the neighborhood were quite modest.

The guiding philosophy of this program was to learn more about how professionals could identify natural helpers and support their helping activities without controlling them. The target population vere all resicients of the neightorhood (seen as potential clients of the agency) as well as local business persons. This program was not offering specific services to specific categories of persons. Two broad approaches were used. One was to work with individuals nominated by other residents in the neighborhood as helpful, to get to know them, to offer to support their endeavors in certain ways. The second was to find different individuals with conmon concerns or an interest in doing samething about the same problem, to 1 ink them up, and to assist them in their efforts to solve the problem. Staff members met the 
residents in their homes, on the street, and often invited them into the rather home-like atmosphere of the program's storefront office. Helpers were not expected to perform any tasks for staff but to simply continue in their nomal range of helping activities, to discuss it with staff, and to call on staff if they thought that staff could help them with their activities in same way.

The relationship that developed between staff and helpers in this program was quite informal. Many neighborhood residents came to feel quite confortable calling upon staff of the program for acivice or for other types of assistance, such as transportation for a group of elderly neighbors who wanted to socialize together, or filing cabinets for a neighborhood resident who made an effort to familiarize herself with the many types of resources and services available to her friends and neighbors. Thus, despite a very generous budget and moderate staff size, this program was one of the least formalized in the study. These two cases illustrate some of the factors that contribute to lack of association between agency or program size and the level of formalization of the staff-helper relationship. The first issue that arises is the definition of size used in the study. Although the operational definition of size as number of paid personnel and budgetary resources is common in the organizational research (Hall, 1977), these cases illustrate that other dimensions could be labeled as size, which operate differently than budget and personnel in relation to the level of formalization of the staff-helper relationship. Same of these elements of size are the actual size or scale (geographic area) to be served or, perhaps more accurately, a ratio of size of the service area 
to the amount or scale of staff and budgetary resources available to carry out the program.

It seems then that the smaller the scale of the program (staff and budgetary resources) relative to the scale of the service area or persons to be served, the higher the formalization of the staff-helper relationship. This measure of size predicts a pattern of assoication between the two variables which is the opposite of the original hypothesis. This explanation appears to be relevant to all the cases with small program size and high formalization.

These cases also illustrate a difference between programs in their focus, i.e., the specificity of what is expected both in terms of who is to be helped and how that help will be offered. When the focus is narrow, e.g., working with single parents or providing specific services to specific clients, then it may seem more feasible and appropriate for the number of paid staff to remain small and for their time and involvement with helpers to be limited to the formally structured roles. Often the staff member is actually expanding the net:ork of a client ky creating linlss between helper and client. Thus, service goals that are specific and narrow are very lilely to lead to a small program in wich staff and helper roles are more formalized. On the other hand, a program in which the focus is rather broad or diffuse indicates the need for a larger staff and a larger budget and more time for informal relations with the helpers whose own activities are the primary direct outcame of the program. The staff member is primarily concerned with existing links between helper and potential client. This is particularly true when the service population 
is defined as a total neighborhood or community. Staff members will need to have time to get to know their commanity and to became known so that persons in the comminity will think of the agency/program staff as resources to help them with their own helping activities. The number of persons that any one individual can work with in this way is small, so staff and budget resources may need to be large and continuous. Litwak (1978a) makes reference to these two issues in his discussion regarding the different types of linkages that can be formed between an agency and a neighinortood:

There does seem to be same relationship between the demands for small scope and the demands for primary group intensity; and the more intense the linkage, the less the scope. (p. 79)

He is suggesting that when the staff member is involved in personal, informal relations with community members, the geographic scope of the program must be limited. When staff or budgetary resources are severely limited and a natural helper program is desired, the scope of the area to be served or the scope of the population to be served must be limited accordingly if the staff-helner relationship is to remain informal.

Sumary. The data revealed no clear pattern of association between the size of the agency or the program and the level of formalization of the staff-helper relationship. Review of same of the specific cases included in the study revealed other potential size-related factors that may be affecting the form of the staff-helper relationship. The first factor may be the choice of definition of size. These case materials suggest that the size of the service area or the number 
of clients to be served relative to the size of the staff and budgetary resources (that is, the scale of intended services to scale of resources) may be a more complex but accurate indicator of effective size. Surprisingly, in this case smaller size may be associated with higher formalization.

The cases also reveal that there may be other program decisions that will affect the size and the formalization of the staff-helper relationship. For example, the decision to serve a specific population with a particular set of services may preclude the use of an informal relationship, while the decision to serve a broad population in a large area with an informal helper approach will require a large staff size and resources because of the demands of informal relations for face-toface contacts and mutual trust. Certainly these data support the conclusion that neither large agency size nor large program size precludes the development of informal relations between the professional staff and lay helpers, and small size of program or of agency does not ensure a relationship that is less formalized.

\section{Formalization and Camplexity or Bureaucratization}

Hypothesis 2. High organizational bureaucratization (canbining hign complexity and high formalization) will be associated with high fomalization of the staff-helper relationship at both the agency and the program levels.

There are two assumptions underlying this hypothesis. The first assumption is that both dimensions of bureaucratization (i.e., complexity and formalization), when at the high end of the continuum, are associated directly with high formalization of the staff-helper relationship. The second assumption is that the two dimensions of formalization and 
complexity comprise a single dimension of organizational context, the structure of the organization (agency or program), making it reasonable to cambine the two measures into a single aggregate measure of agency structure or program structure.

In keeping with this hypothesis, bureaucratization or structure was measured at two levels, the agency level and the program level. Subscales were constructed to measure agency complexity, agency fonmalization, program complexity, program formalization, and work group identity. This last subscale sought to gauge the degree to which the natural helper partnerships actually functioned as a single unit within the agency in terms of staff and other resources or, in terms of the bureaucratic model, how specialized the unit was. Aggregate scales of agency structure and program structure were also constructed.

To test hypothesis 2, correlations were calculated to measure the degree of association between the measures of agency structure or program structure and the staff-helper relationship formalization. Also correlations were calculated between each of the bureaucratization subscales of acency formalization, acency ccoplexity, program formalization, program complexity, work group identity and the overall staff-helper relationship (See Table VII, P. 83).

The correlations between the aggregate scales of agency structure and program structure and the aggregate scale of staff-helper relationship formalization were not significant. Thus, the overall structure of the agency or program (as reflected in these scales rhich summed together the scores on formalization and camplexity) cannot be used to 
predict the type of relationship that will be developed between agency staff and informal helpers.

However, this is not conclusive evidence of an absence of association between the separate dimensions of structure and the form of the relationship. As noted earlier, Hall (1963) found in his research that the dimensions of complexity and formalization (as well as other dimensions of bureaucracy) often vary independently of each other. Thus, a single measure of bureaucratic structure may mask the independent effects of formalization and complexity on the staff-helper relationship.

In fact the pattern of correlations between the subscales of program structure and the relationship formalization scale lend support to this interpretation. There are high positive correlations between the level of program formalization and high formalization of the staffhelper relationship. Concurrently, there is a moderately high negative correlation or inverse relationship between the degree of program complexity and the level of formalization of the staff-helper relationsipip. These two suhscales, wher corininec. into a single reasure of program structure essentially cancelled out each other and resulted in a lack of clear patterns of association.

At the agency level, the pattern of association is similar, i.e., positive correlations between agency formalization and staff-helper relationship form and negative correlations between agency complexity and the relationship form. However, none of the correlations achieves the significant level. 
These data also raise questions regarding the different contexts in which complexity and formalization differ in their relationship to the staff-helper linkage, and the contexts in which the two share a common pattern of relationship. Given the strength of the two correlations, it seems complexity varies more in its association with relationship formalization than does program unit formalization. Case materials help in exploring this and similar issues regarding the pattern of association between kureaucratization and partnership programs.

Case Illustrations of Complexity and Formalization. Complexity and formalization are both multidimensional measures making the analysis of case materials slightly more difficult to manage. Complexity, for example, is a measure of internal differentiation. It includes the use of different sites or branch facilities (i.e., decentralization of service delivery), different functional units, target populations or levels of decision-making and control, and different types of funding sources at both the agency and the program levels. At the program unit level, it also includes the number of other types of service programs that rere comhiner into the sirgle progran unit, uncer the sare supervisor or manager as the natural helper partnership program. Three cases are briefly presented to illustrate differences in level of complexity.

In the first case (\#11), a very small free-standing program with two part-time staff members had been established by private agency funds to work with a working-class neighborhood in Portland (Or), to improve the child-care options available to worling parents. The program ras J.ow in carplexity; it operated out of a single office; served. a single 
neighborhood, had a single funding source, and, as noted, was freestanding so had no other programs or hierarchical controls to deal with. The staff had identified the family daycare providers in the neighborhood and had met and talked with many of them to identify the types of services that would enable providers to improve their services. One outcome was a mutual aid group of providers who met together occasionally to discuss their problems ard experiences, and who joined forces to obtain certain materials they could use in their daycare activities such as groceries, toys, and beds. Staff also worked with parents who called the information and referral number, providing them with guidelines for selecting a provider, and assisting others to start a play group. The staff roles in this program were very low in formalization. The two staff members shared basically the same responsibilities but alternated in the times they worked. There were no written rules, procedures, or guidelines; no hierarchy of roles; and no written formal evaluation of staff performance. Although a final written repart was required, the funding body gave great leeway to the staff. While there ras a local advisory boarc: of professionals and conmunity resicients, they functioned more as a sounding board for staff ideas and concerns than as a source of bureaucratic control.

The relationship between helpers and the staff was moderately low in formalization. Initially staff had canvassed the neighborhood to get to know the residents and their child-care concerns and to become known as a resource. However, in time the most cammon type of contact was by phone rather than face-to-face. Staff called providers from time to time to check on their infomation about availability of care, and they called 
back parents to check on their satisfaction with the referrals they had received. The staff came to be trusted by the members of the cammity who were users or providers of child-care and by other agencies in the city who used the staff as an information and referral source as well. This program was one which was low on both dimensions of structure, low program complexity and low program formalization, in combination with low staff-helper relationship formalization.

In the second case (\#24) program complexity was high. The agency ras small in size rith three different programs, to: of which involved working with informal helpers. Both were designed to provide socialization services to clients of the mental health system (both institutionalized and de-institutionalized clients) in a four county service area of southeastern Michigan. In one program the specific services offered were short-term mutual social groups, which brought together comminity volunteers fram churches, civic groups, and uriversity student bodies, and clients of the mental health system. In the other community, volunteers were matched one-to-one with longterr residents of the state hospital. Fach program r..s coorcinated: by a different staff person, both of wham reported directly to the executive director.

The funding for each of these programs came fram a different source. These two core staff members were paid out of the contract for services the agency had with a local community mental health center. In the first program, each group was led by a part-time, paid, staff facilitator. Each staff member was based in a different mental health center catchment area, fram which both clients and volunteer helpers 
came. These staff members were paid out of CETA monies. These positions could be only temporary and the CETA program as such encouraged all workers to seek other, more permanent positions, which resulted in high turnover in these positions. Staff in the hospital setting were volunteer members of the hospital paid staff.

Within the group program, relationships among the staff members were relatively formalized. In many cases the only staff member known by the facilitators was the staff coordinator, whose main base of operations was in the main office of the agency located at the state hospital. The contact between the coordinator and the facilitators was relatively infrequent and impersonal, although the coordinator sought to help staff with problems they might be experiencing. The facilitators were also supervised more directly by a designated staff member of the agency within which they were located, leading frequently to a divided sense of loyalties. Staff selection relied on formal procedures and criteria (such as professional training). Before staff were assigned to work with groups they underwent program-specific training. Fomal performance evaluations vere performed, in part, due to the CETA requirements.

Relationships between group facilitators and comminity volunteer were moderately formalized as well. The staff coordinator trained the volunteers before they were assigned to a specific group faciiitator. The facilitator then met with the volunteers before group sessions as a facilitator and role model, and conducted post-session performance evaluations for volunteers. The contact between the facilitator and community volunteers was generally relatively brief, 
structured and impersonal. The brevity resulted from the time-limited nature of the socialization groups (maximm ten weeks), the one-time involvement of most volunteers, and the high turnover in the staff positions. Overall this program represents one in which both program structure measures were high (complexity and formalization) and the staff-helper relationship was moderately formalized.

A third case (\#3), a small program for working with the elderly, was based in a cammunity mental health center serving two rural counties in lassachusetts. However, the program had its own independent funding for a research and demonstration project from the local Area Agency on Aging. Staff cooperated more closely with the AAA than with their own agency. The program had three staff members, one of whom was also project director. Staff members were each assigned to work with the elderly and service providers in a different nural town, selected on the basis of having an above average proportion of elderly residents and being in a transitional phase in terms of population composition. The staff person was to learn about their comminity, to become knom. and to act as consultant to the comminity on ratters related to the elderly. The program focus was on prevention of mental health problems, by supporting individual and cammity self-help efforts and by promoting better services to the elderly.

The camplexity of this program was in part due to the geographical dispersion of staff efforts and in part to the necessity for each of them to be sensitive and responsive to a different conmmity's cultural heritage, its natural helpers, and its own perspectives on its needs and resources. Camplexity also was derived fram the multiple 
roles of each staff menber: friendly visitor, facilitator, mental health resource person and consultant, and researcher.

The relationships among program staff were low in formalization. Staff roles were not functionally distinct, each person had the same basic assignment, although in a specific conmunity. The staff members all worked together collaboratively, sharing program ideas, problems, progress, and giving and taking advice. The program manager had certain added responsibilities. The time spent together was spent trying to describe, understand and imcrove their role perfomance. There were few specific written guidelines or procedures although the staff jointly developed their own guidelines and goals for working with natural helpers. The most formal aspect of their roles was imposed by the research component which required the daily logs and structured interviews with helpers and cormunity members.

The relationships between staff and helpers were personal and informal. Natural helpers were identified through agency contacts and informal canvassing. Once identified a friendship or informal relationship res slorly reveloped through visiting, shoring an interest in the activities, encouraging them and supporting them in their helping roles. Staff members also, in time, were able to link together different helpers with common concerns or interests. This program was high in program complexity but low in program formalization and in staff-helper relationship formalization and represents the pattern of association between complexity and relationship form most frequent in these data. 
These three cases illustrate the different patterns of association between program complexity and the formalization of the staffhelper relationship most frequently found in these data. A comparison of the first and third cases reveals several factors that may lead to different levels of progran corplexity in association with low program formalization. These two cases differed in the level of program camplexity and in the scale of the area to be served, although both established infonmal relations between staff and helpers. The large scale service area (three different rural towns) was associated with some specialization and variation in the specific activities carried out by the staff members and with relationships reflecting personal attachments, making it difficult for one staff member to take the place of the other. In the smaller scale program, staff roles were essentially interchangeable. On the other hand, both programs had a focus on working with helpers within their existing helping roles and relationships. Their focus was on the helpers and not on specific clients, permitting both programs to develop and maintain staff-helper relationships that were informal and personal.

Comparisons of the second and third cases illustrate the differences in level of staff-helper relationship formalization that can be associated with high program complexity. These two programs differed on several dimensions. One difference was the level of staff involvement in creating and structuring the relationship between helpers and clients. In the program where the staff-helper relationship formalization was high, the relationships had all been created by the program staff. The helper-client relationship was controlled by 
the staff's definition of roles, procedures, frequency of contact and duration of the relationship. In the other program, the helpers were helping persons who were members of their own personal social networks, so that the staff role was supportive rather than directive relative to the content, frequency, and other aspects of the helping role.

A second difference between high complexity programs that were high, versus those low in staff-helper relationship formalization was their status vis-a-vis other programs or agencies serving the same client population. The high fomalized staff-helper relationship programs were highly dependent on the active cooperation and collaboration of other agencies, which controlled both staff and resources and clients. Volunteers or helpers were also drawn from social organizations; places for the groups to meet in the community were the property of still other organizations. The program with an informal staffhelper relationship approached other organizations for information and for collaboration but was not dependent on their ongoing cooperation and involvement for the success of the program. Thus, the directness of access of the program to its resources (or its relative dependency on other organizations for resources) varied with the level of the staff-helper relationship formalization. In one instance the program relied on formal inter-organization agreements, in the other staff were permitted and encouraged to make informal connections and agreements as appropriate.

A third difference between the two programs and one that seems to hold across other programs in the sample is the real or implied reference group for staff. While the one program was serving chronic 
mental patients in which the professional role models were the highly formalized professions of psychiatry, psychotherapy, and medicine, the other program was serving the elderly from a prevention unit in a mental health center where the professional role models were more likely to work in the community and in collaboration with other professionals. Helpers do not fit the role-sets of either professional model; they are neither co-professionals, sub-professionals, nor clients. However, the dominant models of practice within the agency or with the target population seems to influence the level of formalization of staff-helper relationships.

Sumary. These data reveal that the structure of the program unit from which the partnership program operates can be used to predict the level of fomalization of the staff-helper relationship. Highly formalized relationships within the program unit are associated with a highly formalized relationship between line staff and natural helpers. High program complexity, however, was more frequently, though less intensely, associated with informal relationships between staff and helpers.

Review of cases identified several factors that could alter the association between level of program complexity and the form of the staff-helper relationship. Sometimes when relationships were low in formalization, high complexity reflected differences in the scale of the service area. When high complexity was associated with high formalization of the staff-helper relationship, it was most frequently a situation in which staff were seeking to create relationships between community helpers and specific clients, rather than supporting 
existing relationships. This pattern of association between the two variables often occurred when there was high reliance on other formal organizations for the primary resources (staff, space, helpers or clients) required to make the program succeed, or when the prevailing model of professional practice within the agency (or with the target population with which the program staff had to deal) were highly formalized, clinical or casework types of professional roles.

rork Climate

Hypothesis 3. A highly supportive work climate (where there is supportive, democratic, person-oriented leadership and supportive work group norms) in the program unit which is responsible for the partnership program will be associated with low formalization (or informality) of the staff-helper relationship.

Underlying this hypothesis are several related assumptions. The first is that in a work unit where the supervisor or program manager relies on open communication, joint decision-making, and positive feedback on staff performance, the adoption of an informal relationship with the lay helpers will be easier for staff to accomplish. Second, that if staff are encouraged to adopt norms that include asking for and giving advice and sharing experiences both positive and negative, the informal relationships with helpers will become the work group norm offsetting other tendencies or role models of the individual staff member or the larger agency. Third, the combination of supportive leadership and peer group support will result in an overall work climate that is conducive, and perhaps essential, to the development of relationships between staff and helpers that are low in formalization. 
In this study, leadership style and peer group support were measured only at the program unit level. The two subscales were added together to form an aggregate work climate scale.

Hypothesis 3 was tested by calculating the level of association between each work climate scale and subscale and the overall relationship formalization scale using Pearson correlations. The resulting correlations (see Table VII) were as predicted. Each work climate scale (high leadership supportiveness, high peer support, high overall work climate) is negatively correlated with the relationship formalization scale at significant levels of $p .04$. The strength of the association was greater for leader support $(r=-.45, \mathrm{p} .01)$ than for peer support $(\mathrm{r}=-.36, \mathrm{p} .05)$.

These data support the hypothesis that the work climate of the program unit is associated with the level of formalization of the staff helper relationship. The pattern of correlations suggests that each factor, leadership style and peer support, affects the level of formalization, although leadership style may be more important in its effect. Case Illustrations. The case materials were revieved to discover illustrations highlighting the effects of different leadership styles or peer group noms and to look at cases where the hypothesis or the underlying assumptions did not hold to determine possible confounding factors.

The cases which had low work climate scores encampassed several different types of situations. In Case 1, for example, there had been a change in frogram directors concurrent with a changeover from federal 
research and demonstration funding to state categorical funds. The first program director had conceptualized the program approach, had obtained the support and interest of community leaders to establish the agency and program, had selected staff she believed capable of working informally with their elderly population of helpers/clients, and had set up the agency and program for the community. At the end of the demonstration period, she returned to her academic post, and a new director was selected from among the staff trained by the original director. However, this new director had no formal social service training and no management training. Her administrative experience had primarily been in coordinating local fund-raising drives. Both her notions of management, her lower level of appreciation of the partnership program model, and the changeover to categorical funding with its rigid, time-consming reporting categories had altered what had once been a supportive work climate to a directive one. Yet, the staff-helper relationships still retained the informal character; perhaps two years' experience helped keep them on this level.

In a second case, the program director had come from a line staff position within the program to the director's position to replace the program's dynamic, charismatic creator upon her retirement. At the tire of the study, the second program director had held the position for several years; and she had basically routinized what had originally been a fairly creative, flexible strategy for working with the inner city elderly and their natural helpers within their networks. During this routinization, the helpers with whom the agency had worked (hotel managers, shop keepers, etc.) were gradually reduced in number and new 
ones not sought out. The outreach efforts were taken from professional staff and assigned to low paid, part-time non-professional senior citizens. Professional staff roles had became more formal and lines of authority and communication clearly drawn. No mid-level professionals were authorized to work with the senior outreach workers. Noms of confidentiality had developed which kept discussions among staff regarding small problems or concerns to a minimum. This represents an extreme case of routinization and bureaucratic inflexihility.

In several other cases directive, low supportive work climates were less extreme or drastic in extent. They seem to have resulted from structural elements of program design such as independent, specialized staff roles, dispersed program sites, short-term staff members (hired to do a specific task), concern about issues of liability or confidentiality, or dependence on other formal organizations for resources. In many of these cases it was the higher supervisory level of personnel who had designed the program and who sought to control its outcomes through a directive leadership style.

Cases where the work climate was supportive usually iuxluded elements of both an open, democratic leadership style and work group/ peer norms that supported the development of informal, personal, mutually-supportive relationships with non-professional, communitybased helpers. However, there were same programs which lacked either a supervisor or a peer group or both. One case (\# 10) involved four part-time staff members whose roles were nearly identical except for the separation of site or neighborhoods with which they worked. In 
this program, decisions were made democratically, and adninistrative/ clerical responsibilities rotated among staff members.

In same cases the staff roles were totally specialized and each individual worked autonamously without agency-based supervisory or peer support. In other cases, the staff members found support for their informal approach to helpers fram a local advisory group, from other professionals involved in similar endeavors, or from outside consultants.

A supportive rork climate was not always associated with informal relations between staff and helpers. Those programs having a more formalized staff-helper relationship in association with a supportive work climate generally premised their work group norms on factors other than the relationship between staff and helpers. In same cases this work group supportiveness stermed fram a shared perspective such as ethnic minority cultural values, feminism, rights of the physically handicapped or the importance of peer support for the chronic, deinstitutionalized patient. In these instances, the emphasis or focus of rork group norms was on the positively shared perspectives and not on issues of the structure of the relationship with nonprofessionals. As a result, high leader or peer support was sometines combined with rore formalized linjages between staff and helpers.

S.mmary. The data provide support for the hypothesis that the type of leadership style and work group noms that exist within a program unit are associated with the level of formalization of the relationships that the program staff have with informal helpers. The 
leadership style that relies on person-oriented supervision, open cammuication, and participatory decision-making and work group norms for giving and asking for advice, sharing ideas, experiences and mutual encouragement is more likely to be associated with less formalized staff-helper relationships. Case materials indicated that the work climate could be negatively affected by unskilled supervision, routinization of an approach without personal commitment, inflexible reporting requirements by funding sources, or simply by structural arrangements which preclude the spontaneous, face-to-face interactions required by the more supportive leadership and peer group norms. Finally, case materials also illustrated that a supportive work climate does not necessarily mandate an informal staff-helper type of relationship. In several cases, the supportiveness of the program work climate revolves around shared perspectives and goals that have little or nothing to do with the structure of the relationships between staff and helpers.

\section{Environmental Linkage}

Hypothesis 4. An organization or program unit with an environmental linkage that combines low autonomy in funding and tightly-coupled service integration will be associated with high formalization of the staff-helper relationship.

This hypothesis is based on assumptions regarding the influence of environmental linkages and interdependencies on the ability of any agency or program to maintain less fomalized relationships with lay helpers outside the agency boundaries. First, it is assumed that funding sources in the human services influence program development. Furthermore, when an agency or program depends on a single source of 
funds, that source will have more influence over program design than when the agency or program receives funds fram several sources. The single funding source places the agency/program in a position of resource dependency. Thus, multiple sources of funds will permit an agency or program greater flexibility in determining who to serve, what services to offer, and how to deliver the services. Second, it is assumed that the agency or program that is tightly coupled into a coordinated service system will find it more difficult to develop less formalized staff-helper relationships with lay helpers because of the norms for formal relationships with the service system. Third, the more urbanized or densely populated the service area, the more likely that staff will rely on formalized staff-helper relationships. This is due to the greater reliance in urban settings on formal, impersonal, secondary relationships. Finally, it is assumed that these elements of the agency or program's environmental linkage are positively correlated with each other so that they can cambine into a single, overall measure at the agency level and another at the program level. This measure cambines low funding autonamy, high service integration, and high urbanization as a measure of high environmental linkage which is predicted to be associated with high formalization of the staff-helper relationship.

In order to test this hypothesis several subscales were constructed: funding autonomy, measured at the agency level in regard to external sources of funds and at the program level in regard to internal sources or alternatives for funds; service integration or tightness of coupling of the agency or of the program to other service 
organizations, measured at both the agency and program levels; and community types, measuring the urbanization and density of the general environment. This resulted in five subscales of environmental linkage. Two aggregate scales were constructed: program environmental linkage combining external funding autonany and program service integration and agency envirommental linkage combining agency service integration and general environment. The subscales and aggregate scales constructed to measure environmental linkage proved to be low in reliability. Particularly important was the independence of the subscales; they were not highly intercorrelated. Thus, of the two aggregate scales only the program environmental linkage was sufficiently reliable to be used in testing the hypothesis. Low reliability of the agency environmental linkage scale fails to support the assumption regarding a single dimension underlying all three measures of environmental linkage. No single scale could reliably combine all three measures.

The hypothesis was tested through calculation of the degree of association between each of the enviromental linkage subscales, the aggregate program environmental linkage scale, and the staff-helper relationship formalization scale, with the Pearson correlations. None of the correlations was significant; the level of correlation is so low that the pattern may not be stable. Nevertheless, the correlations of the funding autonomy subscales and the general environment subscale with the staff-helper relationship fomalization is in the predicted direction while the correlation between the program service integration subscale is in the opposite direction. The highest correlation is between the general environment and relationship formalization ( $r=.24)$. 
The program environmental linkage scale is not significantly correlated with staff-helper relationship formalization. These data fail to lend support to the hypothesized association between program environmental linkage and the formalization of the relationship between staff and helpers.

Case Illustrations. The pattern of association between each of the subscales of envirommental linkage and the level of formalization was investigated at the case level. The associations between external funding autonamy and the formalization of the staff-helper relationship was the opposite from what was predicted. That is, low funding autonamy measured by counting the number of funding sources was predicted to result in high formalization. However, upon closer examination, six of the programs classified as low in external funding autonomy were actually research and demonstration or model projects which also allowed the program staff great flexibility and discretion in regard to the staff-helper relationship. If these cases are added to the cases in which the programs had multiple funding sources, the predicted association holds between high funding autonamy/low resource dependency and low formalization of the staff-helper relationship.

The predicted association in programs that had informal staffhelper relationships with level of program service integration was consistent with the hypothesis, that is, low service integration was associated with low formalization of the staff-helper relationship. However, the association does not hold in programs that exhibit high formalization of the staff-helper relationship. Among these programs other factors must influence the level of formalization. 
What factors may lead to low service integration in associaton with high formalization of the staff-helper relationship? Among the cases exhibiting this pattern several were programs that were part of a larger agency to and from which referrals could be made, reducing likelihood of external referrals. Others were programs which either preferred to work autonamously or parallel to the rest of the service system or felt that their methods should reduce the needs for service referrals (Case 22 ). Others were programs serving populations either ignored or ignorant of other types of services, which this program sought to serve well, thus limiting referrals and collaborative efforts (Case 9). One program (Case 18) sought to serve handicapped persons who were experiencing difficulties receiving the service they wanted or needed fran other agencies. The program was dependent on other agencies to refer these persons with problems to it. It then turned into an advocate to get the client what he wanted. This paradox of being simultaneously dependent on other agencies and their aciversary made the integration of this program into the service system critical to its success, yet problematic. Lack of referrals was a major dilerma for the program.

The fact that agencies or programs can choose to be integrated into the service system, or choose to offer alternative services is an essential part of the definition of service integration

Sumary. The data do not support the hypothesis that the level of envirommental linkage of a program or agency can be used to predict the level of formalization of the staff-helper relationship. Nor do they support the assumptions regarding the predicted associations 
between funding autonomy, service integration, or general urban level of the environment. However, review of the distribution of cases on each of the dimensions revealed same factors that seemed to explain the lack of significant patterns of association. For example, the measurement of funding autonomy included research and demonstration projects in the low autonamy group, although $\mathrm{R}$ and $\mathrm{D}$ monies often offer great autonamy or discretion in program design. The inclusion of these programs in the high autonamy category would shift the pattern of association in the predicted direction. Similarly, the definition of program service integration fails to give adequate weight to the choices made by agency or program staff to remain outside of or parallel to the rest of the service system; this is particularly true of several of the programs exhibiting high staff-helper relationship formalization. The level of urbanization and density of the commity is weakly correlated with level of formalization of the staff-helper relationship.

Given the lack of internal hamogeneity, the pattern of association between program service integration and staff-helper relationship formalization is not significant. It is possible that the suggested changes in measurement would increase the reliability of the scale and the strength of the predicted pattern of associations. It is also possible that the association is bak because it is sourious, reflecting only the indirect influences of environmental linkage on the structure of the staff-helper relationship. 


\section{EFFECTS OF MEDIATING VARIABLES}

Perceived Relevance

Hypothesis 5. When organization members perceive the partnership program to be relevant to their agency's overall goals (that is, they know the agency is comitted to the program and have had a part in developing the program idea), this will be associated with low formalization of the staff-helper relationship, and when controlled for, will reduce the strength of association between the relationship and the agency or program unit structure, work climate, and environmental linkage.

Underlying this hypothesis is the assumption that if a program is perceived by staff to be relevant it will affect the program structure, work climate, environmental linkage, and staff-helper relationship directly, so that the correlations between the predictor variables and the staff-helper relationship may, in fact, be spurious. When the effect of perceived relevance is statistically controlled, the association between the predictor and outcome variables may be expected to be reduced or disappear.

Perceived relevance was measured as an attribute of the program innovation in a specific organizational context. It cambined two subscales measuring the intensity and continuity of agency conmitment to the program and the staff involvement in developing the program idea, referred to as emergence. While the initial assumption was that high agency commitment would be positively correlated with high emergence to form a scale of high perceived relevance, in constructing the scale it was determined that staff involvement (emergence) and agency conmitment were negatively correlated with each other. As a result, the scale that was constructed might better be described as 
low perceived relevance, in which a high score on the scale is expected to be associated with a high score on the staff-helper relationship formalization scale. This constructed scale also is low in internal consistency (alpha=.29), so that the results are somewhat limited in their interpretability. Despite these problems the perceived relevance scale was used to test the hypothesis.

To test the hypothesis, two steps were followed. Step one involved calculation of the Pearson correlations (or zero-order concelations) hetreen the low perceived relevance scale and the formalization of the relationship. The correlations were also calculated for each of the subscales of perceived relevance (see Table VII). INone of the resulting correlations vas significant. However, the direction of the correlation between perceived relevance and relationship formalization was as predicted. Thus, low perceived relevance of the program was positively correlated with high formalization of the staff-helper relationship.

The next step was to review the individual cases to see what factors might explain other patterns of association than predicted. It was found that cases in which high perceived relevance was associated with high relationship formalization there was a conmon reliance on created linkages between helpers and clients, rather than on existing networks of relationships. These were programs that involved staff seeking out helpers for specific clients, matching the skills of the helper to the need of the client. It seems that when creating relationships between helpers and clients is seen as relevant 
TABIE VIII

CORREIATIONS BETVEENN MEDIATING MEASURES OF PROGRAM INROVATION AND OVERALI STAFF-HELPER RETATIONSHIP FORMALIZATION

Subscales

Client Need ${ }^{a}$

Difference ${ }^{b}$

Lor Agency Comitment ${ }^{b}$

Emergence $b$

Stage $^{a}$

Aggregate Scales

Perceived Riskiness ${ }^{b}$

Perceived Relevanceb
Pearson Correlation

.28

$-.17$

.10

.20

.15

.04

.21

Note: (a) $\mathrm{N}=30$, (b) $\mathrm{N}=27$

None of the correlations were significant 
to the agency's goals, then the relationships between staff and helpers may require more staff control and decision-making authority, resulting in more formalized relationships. Programs that combined low perceived relevance and low staff-helper relationship formalization, on the other hand, commonly had an agency policy to develop "giveavay" programs. They would work with commmity helpers to get a program established and then turn control of the program over to the helpers. Agency camitment in these types of programs was very short-term, but staff worked closely with and respected the strengths of the helpers.

The partial correlation procedure was used to determine whether, in fact, controlling for level of perceived relevance altered the pattern of association between the predictor variables and the staffhelper relationship (Fahle IT). How does perceiver relevance affect staff-helper relationship formalization, program structure, rork rlimate, program enviromental linkage? Does.it simply contrihute to spurious correlations?

These questions can be answered by examining the effect of controlling for perceived relevance on the associations between the major predictor variables and the outcome variable--staff-helper relationship formalization. The prediction is that the level of perceived relevance will he directly correlated with inth predictor variables and outcome variable creating a spurious correlation between them. When this effect is removed or controlled, the level of association between the two vill be reduced. This prediction was supported in regard to the level of association between program 
TABLE IX

PARTIAI CORRETATIONS BETWEEN PREDICTOR MEASURES AND REIATTIONSHIP FORMALIZATION CONIRGLIING FOR INDOVATION NEASURES

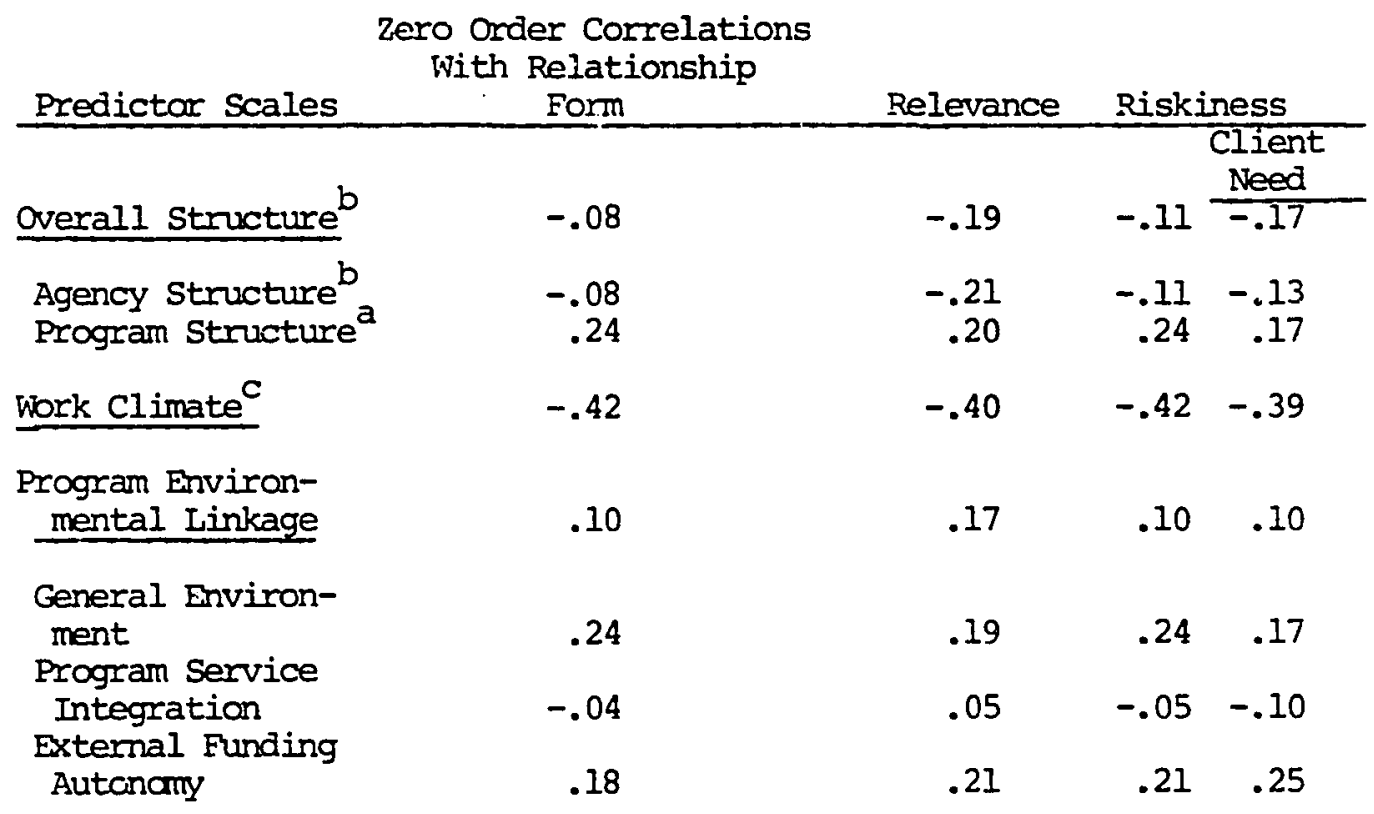

Note: (a) $\mathrm{N}=30$, (b) $\mathrm{N}=27$, (c) $\mathrm{N}=26$ 
structure and work climate and the level of relationship formalization, although the change is very slight. However, controlling for perceived relevance led to an increase in the level of association betreen agency structure and relationship formalization and between program environmental linkage and relationship formalization. This may suggest that perceived relevance suppresses these associations.

Summary. Although the perceived relevance scale is of low reliability and the resulting patterns of association are not significant, they are in the predicted direction. That is, low perceived relevance is associated with high staff-helper relationship formalization. The perceived relevance dimension seems to slightly suppress the association between program envirormental linkage and staff-helper relationship formalization and to contribute slightly to the assocation between relationship formalization and the program structure and work climate. Cases indicate that there are factors contributing to the low associations between level of perceived relevance and the staff-helper relationship formalization, including programs designed to create new relationships rather than to work with existing ones. Also affecting this pattern was the tendency of same agencies to develop programs as spin-offs designed to assist cammity helpers to get a program underway and then turn it back to them.

\section{Perceived Riskiness}

Hypothesis 6 . When organization members perceive the partnership program to be risky (for their clients whose needs are high, and for themselves, because the practices required by the program are different/incompatible with 
existing agency practice), this will be associated with high formalization of the staff-helper relationship and, when controlled for, vill reduce the strength of association between agency or program unit structure, work climate, and environmental linkage.

Underlying this hypothesis is the assumption that when a social service program involves a perceived risk (in that it requires major changes in the way services are delivered or in that it is directed to a population with very high levels of need and stigma who can't, therefore, afford to lose service) this element of riskiness may offset the positive effect of work climate and increase the emphasis on structure and standardization in the staff-helper relationship.

Perceived riskiness was constructed by cambining the measures of client need or stigma and of the difference of the program from its agency context. The two measures were added together to obtain a single score, the higher the score, the higher the perceived riskiness of the program innovation which is predicted to be associated with higher relationship formalization.

To test this hypothesis, two steps were followed. First, zero order correlations were calculated between the measure of perceived riskiness and its component subscales with staff-helper relationship formalization. Second, partial correlations were calculated between the major predictor variables and relationship formalization while controlling for perceived riskiness.

Examining the zero order correlations, it can be seen that the two subscales are not both positively correlated with high staffhelper relationship formalization. Client need or stigma is positively 
(though not significantly) correlated with formalized relationships. The level of difference between program and agency, however, is associated, though weakly, with informal relationships. As a result, there is no association at all between the constructed scale of perceived riskiness and the formalization of staff-helper relationships as the two component scales cancel out the effects of each other (see Tables VIII and IX).

The influence of the perceived riskiness of the program innovation on the association between measures of structure, work climate or environmental linkage and the staff-helper relationship was tested using partial correlation procedures (See Table IX). The first order correlations were conputed between the predictor variables and the relationship formalization while controlling for perceived riskiness. Because this perceived riskiness scale was very low in reliability, the same procedure was repeated using the client need subscale as a control variable (in lieu of the constructed scale). This subscale serves as a proxy for the perceived riskiness of the program for all the cases, whereas the difference/compatability scale applies only to programs located within a larger agency context. The effect of perceived riskiness was not supported. The strength of the associations between predictor and outcame measures was neither strengthened or weakened significantly by controlling for perceived riskiness. However, controlling for client need does have a slight effect on several of the correlations. The strength of association between relationship formalization and overall structure, agency structure, program service integration and external funding 
autonamy increases slightly while the association between relationship formalization and program structure, work climate, and general enviromment decreases slightly. This suggests that the perceived riskiness is not directly related either to the predictor variables or the relationship formalization. When the magnitude of the correlation increases, this suggests that riskiness (or its proxy, client need) is operating independently of the predictor variable (overall structure, agency structure) to cause variations in the level of formalization of the staff-helper relationship. When the magnitude decreases as with program structure, work climate, and external funding autonomy, it suggests that perceived riskiness may spuriously increase the relationship between these predictor variables and the formalization of the relationship; controlling this effect then weakens the association.

Both hypotheses (4 and 5) canprise two sets of findings. First, the scales proved to be unreliable or unstable in their internal consistency. The subscales camprising each of the dimensions of perceived relevance (agency camitment and emergence) and of perceived riskiness (client need and program difference/compatability) were not associated with each other in the predicted manner. Thus, low agency comitment was positively, though weakly, related with staff involvement in idea development (i.e., emergence). And the difference subscale was negatively, though weakly, correlated with high client need. Rather than tapping a single, underlying dimension, then, each of the constructed scales proved to be tapping divergent dimensions, leading to their low levels of reliability. Despite this they were used for further 
analysis because of their conceptual validity. When the effects of these measures were controlled and the resulting first order correlations between the major predictor scales and the overall relationship formalization scale were examined, no association changed significantly, although there was evidence of minor influences of the perception of the program innovation on the other predictor and outcame variables. It is not clear fram the data whether the limited effects reflect the actual limited influence of program innovation or whether they are due to the instability of the constructed scales.

\section{Stage of Progam Implementation}

Hypothesis 7. The further along the program has progressed in implementing the partnership program, the more highly formalized the staff-helper relationship will be.

Underlying this hypothesis is the assumption that while early stages in the implementation of an innovation may require an informal staff-helper relationship structure, time and experience may lead to more routinized and standardized relationships and activites. The longer the time since a program was initiated, then, the more highly formalized the staff-helper relationship is predicted to be.

The stage of program implementation was a subscale reflecting both age and stability of the program at the time of the site visit. To test this hypothesis, Pearson correlations were computed between scales of stage of program implementation and overall staff-helper relationship formalization. Though the resulting correlation is positive, it is not significant. Thus, the level of formalization of the staff-helper relationship cannot be predicted solely on the basis of the stage of program implementation. 
Sumary Regarding Effects of Program Innovation. Overall, the data have not revealed a significant mediating influence of program innovation dimensions on the staff-helper relationship or on the pattern of association between the staff-helper relationship and the major predictor variables. Thus, the organizational context has a greater influence on the staff-helper relationship than do the perceptions of the relevance or riskiness of the program or the actual stage in the implementation of the program.

\section{EYPLORATORY PROCEDURES}

Due to the exploratory nature of this research, several procedures were used to explore more fully the nature of the relationships between organizational attributes, innovational attributes, and the staff-helper relationship. These procedures are by nature more exploratory, and less constrained by theory and/or measurement limitations and must be viewed cautiously only as suggestions regarding the interrelationships among organizational and innovational attributes.

The purpose of these exploratory procectures was to increase the understanding of the interrelationships among the three major types of variables, i.e., the predictor, mediating, and outcome variables and, pariicularly, the degree of association among subscales of different major concepts or scales.

This led to a closer examination of the patterns of association among the subscales to determine whether, for example, there were significant correlations between program formalization and leadership 
style or between external funding autonamy and agency comitment. The intercorrelation matrix of all the subscales is presented in Table X.

It also led to the use of stepwise regression procedures to determine more accurately the relative contribution of different elements of the model to the level of formalization of the staff-helper relationship. This process encanpassed two broad steps. In the first steps, the best cambination of elements within each larger concept or category (e.g., program structure) were identified through regression procedure. In the second step, four of the best elements taken fram across major concepts (e.g., one subscale as a proxy for work climate, another for envirommental linkage, and so on) were entered into a combined multiple regression equation. This process was followed, rather than entering all the variables at the subscale level into a single stepwise regression procedure, because the small sample size makes the use of more than four or five variables totally unreliable.

\section{Intercorrelations Among Variables Across Scales}

As previously noted, the model suggests three major categories of organizational attributes: structure, work climate, and environmental linkage. Each of these major attributes is comprised of several elements, each of which is measured by a different subscale. There are seven structure subscales, two work climate subscales, five environmental linkage subscales. In addition, there are five program innovation subscales and five relationship formalization subscales. Among the seven structure subscales, there are twenty-one possible correlations; only eight actually achieve a significant level $(p<.05$, 
or greater). The two work climate subscales are highly intercorrelated $(p<.001)$. The five envirommental linkage subscales have only two significant intercorrelations. The five innovation subscales have three significant correlations, although same items are negatively related to each other. The five relationship formalization subscales are highly intercorrelated (see Table X

There is much intercorrelation across sets of subscales. For example, agency structure subscales tap same of the same underlying dimensions and sources of variance as the work climate subscales. It is interesting to note some of these intercorrelations in somewhat more detail. For example, program formalization is correlated with 11 of the other subscales; it is most highly correlated (inversely) with leadership style and with stage of program implementation. Programs that are highly formalized are further along in the process of implementation and tend to have directive styles of leadership. Thus, even though stage of implementation is not associated with relationship formalization, it is associated with the level of internal formalization. Programs that are low in complexity are likely to have external funding autonomy which, in turn, is correlated with supportive leadership and peer support.

\section{Pultiple Regressions with Predictor Categories}

The next step in the exploration of relationships among variables and across sets of variables involved the use of multiple regression procedures. This approach enables us to determine which variables were the best predictors, in the sense of accounting for different 
TABIE X

SIGIITICANI DNIERCOREDIATTONS AMONG SURSCNLS

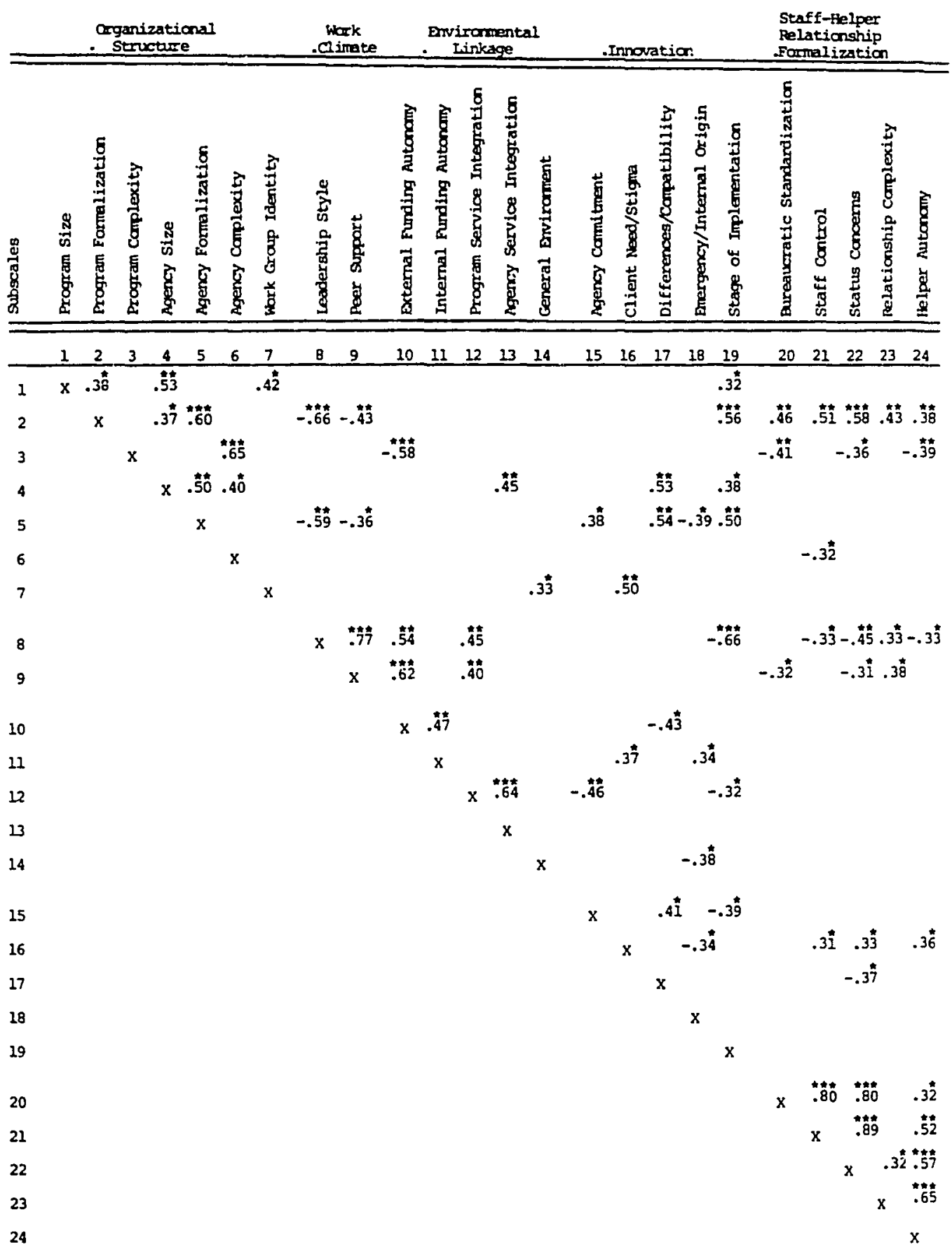

${ }^{*} p<.05 \quad * * p<01 \quad * * * p<.001$ 
sources of variance in the level of relationship formalization. To this point the only information available was the degree of association between single variables and the staff-helper relationship fomalization, or between other pairs of variables. In this exploratory analysis two steps were followed, in onder to avoid the statistical problems of entering all the predictor variables into a single multiple regression equation with this small sample size.

In the first step the variables comprising each major category or attribute of organizations (agency structure, program structure, work climate, and environmental linkage) were entered into four separate multiple regression procedures with the overall measure of staffhelper relationships formalization as the dependent variable. A fifth procedure using the variables camprising program innovation was also conducted, even though this set of factors were initially proposed to be mediating or intervening variabies. Table XI presents the results of these five procedures. Multiple regression procedures facilitate the identification of the most powerful predictors fram each category, and of those variables or correlations that are essentially spurious, in that they simply account for the same variance as another more powerful predictor variable. Multiple regression procedures, thus, permit the researcher to "assess unique variance" of several variables at one time (Cohen \& Cohen, 1975).

In the second step the most powerful predictors from each of the categories or attributes of organizations (program structure, work climate, and so on) were entered into a single multiple regression equation, to assess the best predictors of the staff-helper relationship. 
TABLE XI

\begin{tabular}{|c|c|c|c|c|c|c|c|c|}
\hline \multirow[b]{2}{*}{ Najor Category } & \multicolumn{6}{|c|}{$\begin{array}{l}\text { MUTIPLE RDGRESSIONS WITH SEPARATE PREDICTOR CATSOORIES NDD } \\
\text { STAFF-HIELPER RELATIONSHIP FORAFITZATION }\end{array}$} & \multirow[b]{2}{*}{ E } & \multirow[b]{2}{*}{$\begin{array}{l}\text { Degrees o } \\
\text { Frsedon }\end{array}$} \\
\hline & Predictor subscales & $\frac{\text { Multiple }}{R}$ & $R^{2}$ & $B$ & BEEA & $\begin{array}{l}\text { Standand } \\
\text { Exror of } B\end{array}$ & & \\
\hline \multirow[t]{3}{*}{ igency structureb } & Agency Complexity & .34 & .12 & -.41 & -.40 & .20 & $4.0^{*}$ & $(3,23)$ \\
\hline & Agency Formalization & .47 & .22 & .34 & .38 & .19 & $3.1 *$ & \\
\hline & Agency Size & .48 & .23 & -.07 & -.11 & .14 & 0.2 & \\
\hline
\end{tabular}

Total Variance Acocounted For: 238, F statistic of equation on 3rd step: 2.3

\begin{tabular}{lllllllll}
\hline Prograr. Structurea & Program Fomalization & .60 & .36 & .64 & .75 & .13 & $24.4 * * *$ & $(4,22)$ \\
& Progran Complexity & .71 & .50 & -.22 & -.26 & .12 & $3.3 *$ \\
& Program Size & .75 & .57 & -.27 & -.40 & .12 & $5.4 * *$ \\
& Work Group Identity & .78 & .60 & .16 & .21 & .12 & 1.9 &
\end{tabular}

Total Varianoe Accounted For: 608; F statistic of equation on 4th step: $8.3^{* * *}$

\begin{tabular}{llllllllll}
\hline Work Climate & Suportive Leadership & .45 & .21 & -.39 & -.43 & .26 & 2.2 & $(2.23)$ \\
& Peer support & .45 & .21 & -.00 & -.03 & .24 & .01 & &
\end{tabular}

Total Variance Accounted for: 218 ; F statistic of equation on 2nd step: 3.0

Note: If only ane variable is entered, Leadership, the $F$ statistic is $6.2 *$, which indicates the high multi-collinearity of these two variables.

\begin{tabular}{lllllllll}
\hline Enviranmental Linkagea & Ceneral Envirament \\
& $\begin{array}{l}\text { External Funding } \\
\text { Autoneny }\end{array}$ & .24 & .06 & .14 & .23 & .12 & 1.5 & $(3,26)$ \\
$\begin{array}{l}\text { Program Service } \\
\text { Integration }\end{array}$ & .29 & .08 & .17 & .20 & .17 & 1.0 & \\
& .31 & .10 & -.11 & -.12 & .19 & 0.3 &
\end{tabular}

Total Variance Acoounted for: 108; F statistic of equation on 3rd step: .92

\begin{tabular}{llllllllll}
\hline Program Innovationb & Client Need & .28 & .08 & .26 & .36 & .14 & $3.3 *$ & $(4,22)$ \\
& Difference/Compatibility & .37 & .13 & -.31 & -.38 & .18 & $3.1 *$ \\
& Agency Comitment & .44 & .19 & .19 & .22 & .20 & 1.0 & .0 \\
& Stage of Implenintation & .46 & .21 & .12 & .14 & .19 & .4
\end{tabular}

Total Variance Accounted for: 218: F statistic of equation on 4th step: 1.5

Note: a) $N=30$; b) $N=27$; c) $N=26$

$p<.05$

$\rightarrow p<.01$ 


\section{Agency Structure}

Three agency structure subscales were entered into a stepwise regression equation with relationship formalization as dependent variable. Agency complexity was the variable most highly associated with relationship formalization, entering on the first step and accounting for 12 percent of the variance. Agency formalization enters the equation on the second step and accounts for an additional 10 percent of the variance. Both of these individual variables are significant at the $p<.05$ level. However, agency size, which enters on the third step, adds only 1 percent to the total equation and is not significant in effect. This is understandable given the high level of intercorrelation between agency size and the other two variables as seen fram the intercorrelation matrix. These agency structure variables account for 23 percent of the variance in the relationship formalization; however, these results are not statistically significant. Thus, although both individual variables make statistically significant unique contributions to the overall explanatory power of agency structure, the overall results indicate that agency structure is not a good predictor of the level of formalization of the staff-helper relationship. It leaves 77 percent of the variance in the formalization unexplained.

\section{Program Structure}

Four program structure subscales were entered into a stepwise regression equation with the staff-helper relationship formalization as the dependent variable (Table XI). The program formalization scale 
entered on the first step, contributing 36 percent of the variance in the relationship formalization scale. Program complexity, which enters on the second step accounts for an additional 14 percent of the variance, and program size, entering on the third step contributes another 7 percent to the explanatory power of the program structure. Each of these variables is contributing significantly to the overall explanatory power of program structure. However, work group identity, which enters on the fourth step, adds only 3 percent to the overall variance and is not significant in its contribution. In fact, introducing work group identity pulled out same of the same variance as program complexity and reduced its level of significant unique variance. The overall equation using the four subscales of program structure as predictor variables accounts for 60 percent of the variance in the formalization of the staff-helper relationship and is significant in its explanatory power. Program structure, again, is revealed to be a very significant factor in determining the degree of formalization that was found in relationships between agency staff and informal helpers.

\section{Work Climate}

The two work climate subscales, leadership and peer support, were entered into the third regression equation. The first variable to enter the equation was leadership, which accounted for 21 percent of the variance in the fomalization of the staff-helper relationship. However, peer support, entering on the second step, added nothing to the explanatory power of the equation and, in effect, reduced the significance of the total equation. These two subscales are highly 
intercorrelated $(r=.77)$ so that this result reflects their high multicollinearity. They are both basically explaining the same variance in the staff-helper relationship formalization rather than contributing unique variance. If only one variable is entered, the explanatory power of work climate is greater than when both variables are entered. Although leadership is the first of the two variables to enter the equation, in later analysis, peer support will be used because it is essentially explaining the same variance and because it does not unnecessarily restrict the number of cases that are entered into the equation.

\section{Program Envirormental Linkage}

Only three of the envirommental linkage subscales were entered into the regression equation with relationship formalization. These were the subscales that in combination comprised the program environmental linkage scale. The general environment scale entered on the first step, accounting for 6 percent of the variance. In the next two steps, external funding autonomy entered, followed by program service integration. None of these individual factors contributed in a statistically significant way to the explanation of the variance in the level of formalization of the staff-helper relationship. And the total equation combining the three subscales explained only 10 percent of the variance, which was not statistically significant. Again, the data reveal that the program enviromental linkage dimension does little to explain the differences in levels of formalization of the staffhelper relationship. 
Multiple Regression with Program Innovation as Predictors

Although the program innovation variables were not predicted to function as predictors of relationship formalization, one step in the exploratory process was to determine just how useful this set of perceptions regarding the innovation were in explaining the formalization of the staff-helper relationship. The five program innovation subscales were entered into a multiple regression equation. Client need/stigma entered on the first step, accounting for 8 percent of the variance. Difference/compatibility entered on the second step, adding another 5 percent. Both of these variables offered a significant unique component of variance. Adding the other three variables: agency camitment, stage of program implementation, and emergence added nothing further of significance to the explanatory power of the equation. Overall the explanatory power of this equation was not significant, and the five variables accounted for only 21 percent of the variance in the dependent variable, the formalization of the staffhelper relationnship.

\section{Multiple Regression Using Cambination of Organizational Attributes}

The primary purpose of this exploratory section was to determine the relative influence of the different organizational attributes on the staff-helper relationship. The advantage of the multiple correlation analysis is that it permits one to assess the influence of several ixlependent variables sirultaneously and to identify those which are contributing to the explanation of the variance of the dependent variable or which are most useful in predicting the level of 
formalization of the staff-helper relationship. In this last step, those variables which were found to be the best predictors in the prior regression equations were selected as proxies for the major organizational attributes and entered sirultaneously into a multiple regression equation. Organizational structure was measured here with two variables, program formalization and program complexity, due to their high levels of unique variance. Work climate was measured using peer support as the proxy. Peer support was used in lieu of leadership style becuase the two were found to account for essentially the same variance and peer support had no missing data cases. Program environmental linkage was measured using the variable which entered on the first step in that equation, general environment (see Table XII). The resulting stepwise regression equation accounted for 55 percent of tine variance in the dependent variable, more than any one single-factor regression except program structure. Program formalization entered on the first step, accounting for 36 percent of the variance, program complexity on the second step, accounting for another 14 percent of the variance, peer support entered on the third step adding another 4 percent, and general environment adds only I percent unique variance to the equation's explanatory power. While the amount of unique variance provided by both the structural measures is significant $(p<.001)$, neither of the other two organizational dimensions adds significantly to the explanatory pover of the equation. While this is not suprising in regard to the enviromental linkage dimension, it is somewhat unexpected that work climate adds nothing to the equation. In order to understand this, the intercorrelations 
TABLE XII

MUTITPLE RBGRESSTON WTTH COMBINED ORGANIZATIONAL ATTRIBUTE AND STAFF-FEI PER REIATTONSFIIP FORAALIZATION

\begin{tabular}{|c|c|c|c|c|c|c|c|c|c|}
\hline $\begin{array}{c}\text { Major } \\
\text { Attribute } \\
\end{array}$ & Step & $\begin{array}{c}\text { Subscale(s) } \\
\text { Used as } \\
\text { Prosy } \\
\end{array}$ & $\begin{array}{c}\text { Multiple } \\
\mathrm{R}\end{array}$ & $\underline{R}^{2}$ & B & Beta & $\begin{array}{l}\text { Standard } \\
\text { Error }\end{array}$ & $\underline{E}$ & $\underline{D F}$ \\
\hline \multirow[t]{2}{*}{$\begin{array}{l}\text { Organizational } \\
\text { Structure }\end{array}$} & 1 & $\begin{array}{l}\text { Program Form } \\
\text { alization }\end{array}$ & .60 & .36 & .38 & .44 & .14 & $7.5^{\star \star \star \star}$ & $(4,25)$ \\
\hline & 2 & $\begin{array}{l}\text { Program Com- } \\
\text { plexity }\end{array}$ & .71 & .50 & -.36 & -.43 & .12 & $9.4^{\star \star \star}$ & \\
\hline Work Climate & 3 & Peer support & .74 & .54 & $-.2 i$ & -.26 & .13 & 2.6 & \\
\hline $\begin{array}{l}\text { Envirarmental } \\
\text { Linkage }\end{array}$ & 4 & $\begin{array}{l}\text { General Envi- } \\
\text { romment }\end{array}$ & .74 & .55 & .05 & .08 & .08 & 0.3 & \\
\hline
\end{tabular}

Total Variance Accounted for: 558; F statistic of equation con fourth step: $7.7^{\star \star \star}$

Note: $N=30$

a) Peer support is used as a prory for hork Climate for two reasans. It is highly intercorrelated with leadership style and has the added advantage of having no case data/missing data. 
between the work climate subscales and the program structure subscales were re-examined. There are high intercorrelations between these scales which suggest that, indeed, the possibility of some multicollinearity between peer support and program formalization. Thus, the added unique variance of peer support is low because it shared in the variance explained by program formalization.

\section{Multiple Regression with Program Strategies}

There is one final step that was taken to explore the interrelationships among the variables potentially influencing the structure of the staff-helper relationship. Up to this point, the dimensions that have been used as predictor variables have all been properties of the organization or properties of the innovation in its agency context. The decision was made to explore whether another aspect of the innovation, the primary program strategy or approach used, "as ar. effective predictor of the staff-helper relationship. The choice of program approach or approaches was a decision reached by agency staff prior to actual implementation of the program. It may thus be expected to have an influence on the relationship structure. The possibility of an interaction betieen program structure and the selected program approaches on the staff-helper relationship seens possible, although the causality of this model cannot be proved. These five different approaches ( $a$ typology developed by the Natural Helping Networks Project) may vary in the formalization of the staff-helper relationship with which they are associated. The five approaches were entered into a single regression equation with the 
staff-helper relationship as the dependent variable (Table XII) . Volunteer linking enters on the first step, accounting for 25 percent of the variance. The beta weights indicate that volunteer linking is positively associated with high formalization of the staff-helper relationship $(p<.01)$. On the second step, canturity enpowerment enters the equation, adding 7 percent to the variance explained. The other three variables, neighborhood helper, mutual aid, and personal network, togeiser add only 7 percent to the variance. Both community empowerment and neighborhood helper approaches are negatively correlated with formalization of the staff-helper relationship (see Table XIV). Altogether the subscales combined explain 36 percent of the variance in the staff-helper relationship.

This brief exploration into the associations between program approaches and the staff-helper relationship reveals that some strategies such as volunteer-linking are more frequently associated with formalized staff-helper relationships; others, such as cammunity empowerment and neighborhood helping are associated with informal relations between staff and helpers. The overall explanatory power of these program approaches is less than that of some of the organizational properties such as program structure but greater than that of others such as agency structure or environmental linkage.

In Table XV same of the basic differences between these program approaches are presented. It can be seen that the voluntary-linking approach relies most heavily on the creation of new relationships between skilled helpers or volunteers and specific clients; it is also the approach associated most directly with highly formalized 
TABIE XIII

MULTIPLE REGRESSION USING PROCRAM APPROACHES AS PREDICTORS OF STAFF-HET PER REIATIONSHIP FORMAIIZATION

\begin{tabular}{|c|c|c|c|c|c|c|c|}
\hline Program Strategies & $\begin{array}{c}\text { Multiple } \\
\mathbf{R}\end{array}$ & $\underline{R}^{2}$ & $\underline{B}$ & Beta & $\begin{array}{l}\text { Standard } \\
\text { Error }\end{array}$ & $\underline{F}$ & $\underline{D F}$ \\
\hline Volunteer Linking & .48 & .23 & .37 & .29 & .24 & 2.3 & $(5,24)$ \\
\hline Canmmity Enpowerment & .54 & .29 & -.50 & -.30 & .30 & $2.8^{*}$ & \\
\hline Neighborhood Helper & .57 & .33 & -.23 & -.25 & .17 & 1.8 & \\
\hline Mutual Aid & .60 & .36 & -.17 & -.17 & .17 & 1.0 & \\
\hline Personal Network & .60 & .36 & .02 & .02 & .19 & 0.0 & \\
\hline
\end{tabular}

Total variance explained: $368, \mathrm{~F}$ statistic, 5th step: 2.66*

a) Typology developed by Natural Helping Networks project. These are not treated elsewhere as predictors but are used here to explore 
TABLE XIV

CORREIATIONS AMONG PROGRAPI APPROACHES AND REIATIONSHIP FORMAIIZATION

\begin{tabular}{|c|c|c|c|c|c|}
\hline $\begin{array}{l}\text { Perscinal } \\
\text { Network }\end{array}$ & $\begin{array}{l}\text { Volunteer } \\
\text { Linking }\end{array}$ & $\begin{array}{l}\text { Mutual } \\
\text { Aid }\end{array}$ & $\begin{array}{c}4 \\
\text { Neighbor- } \\
\text { hood } \\
\text { Helper }\end{array}$ & $\begin{array}{c}5 \\
\text { Community } \\
\text { Empower- } \\
\text { ment }\end{array}$ & $\begin{array}{l}\quad 6 \\
\text { Relation- } \\
\text { ship } \\
\text { Formali- } \\
\text { zation }\end{array}$ \\
\hline \multirow[t]{5}{*}{1.00} & -.20 & -.30 & .20 & $.34^{*}$ & -.18 \\
\hline & 1.00 & -.08 & $0.43^{\star}$ & -.24 & $.47 * \star$ \\
\hline & & 1.00 & -.18 & -.13 & -.11 \\
\hline & & & 1.00 & .12 & $-.38 *$ \\
\hline & & & & 1.00 & $-.36^{\star}$ \\
\hline & & & & & 1.00 \\
\hline
\end{tabular}


JABIE XV

OVERNIEW OF PROGRAM APPBDACHES

\begin{tabular}{|c|c|c|c|c|}
\hline Approach & Coal & Actors & $\begin{array}{c}\text { Source of } \\
\text { Helper stelpoe } \\
\text { Formalization } \\
\end{array}$ & $\begin{array}{l}\text { Pelationship } \\
\text { Formalization }\end{array}$ \\
\hline Personal Network & $\begin{array}{l}\text { o consult with client's significant } \\
\text { others; support existing efforts } \\
\text { o canvene network of providers and } \\
\text { family, friends and others to } \\
\text { resolve problems } \\
\text { o expand client's range of social ties }\end{array}$ & $\begin{array}{l}\text { - fanily manbers, friends, neigtr } \\
\text { bors, service providers }\end{array}$ & $\begin{array}{l}\text { Existing } \\
\text { and } \\
\text { created }\end{array}$ & Informal \\
\hline Volunteer Linking & $\begin{array}{l}\text { o provide lay therapists for counseling } \\
\text { o establish companionate relationships } \\
\text { o recruit and link volunteer advocates } \\
\text { to client }\end{array}$ & $\begin{array}{l}\text { o citizen volunteers } \\
\text { o people with skills, interests } \\
\text { relevant to client's needs } \\
\text { o people with similar experienoes }\end{array}$ & Croated & Formal \\
\hline Mutual Aid Networks & $\begin{array}{l}\text { o establish peer support groups } \\
\text { o onnsult with existing groups and } \\
\text { support activities }\end{array}$ & $\begin{array}{l}\text { - local church associations } \\
\text { o clients with gimilar problens } \\
\text { o people with shaned concerns }\end{array}$ & $\begin{array}{l}\text { Created } \\
\text { and } \\
\text { Existing }\end{array}$ & $\begin{array}{l}\text { Moderately } \\
\text { Formal }\end{array}$ \\
\hline Neighbarhood Helpers & $\begin{array}{l}\text { o consult with neighbor to monitor } \\
\text { problems } \\
\text { o corvene neightbors to promote local } \\
\text { helping }\end{array}$ & $\begin{array}{l}\text { o neighbors } \\
\text { o clerks, managers in local busi- } \\
\text { nesses } \\
\text { o church leaders }\end{array}$ & $\begin{array}{l}\text { Exiating } \\
\text { and } \\
\text { created }\end{array}$ & $\begin{array}{l}\text { Moderately } \\
\text { Informal }\end{array}$ \\
\hline Community Enpowerment & $\begin{array}{l}\text { o Establigh local task forces for } \\
\text { meeting canmunity needs } \\
\text { o provide for community forums to have } \\
\text { input into local policies }\end{array}$ & $\begin{array}{l}\text { o opinion leaders in local } \\
\text { business, churches } \\
\text { o mentiers of local voluntary } \\
\text { assoclations } \\
\text { o neighborhood leaders }\end{array}$ & $\begin{array}{l}\text { Existing } \\
\text { and } \\
\text { Created }\end{array}$ & $\begin{array}{l}\text { Moderately } \\
\text { Formal }\end{array}$ \\
\hline
\end{tabular}


staff-helper relationships in which staff control and bureaucratic standardization are likely to occur. Community empowerment, on the other hand, essentially relies on the abilities, interests, and actions of the community residents to help thenselves. Together with the neighborhood helper approach, it relies primarily on existing relationships between helper and helpee for achievement of program goals.

The personal network and mutual aid approaches are more likely to rely on the less formalized staff-helper relationship, but the Iow correlations (Table XIV) suggest that both of these approaches can vary in formalization of the staff-helper relationship.

Overall summary

Hypotheses Tests. The first section of this chapter presented data to test the seven hypotheses. The results show that agency and program size are not good predictors of formalization in the staffhelper relationship. Other ways of measuring size were identified which may be better predictors. The bureaucratization of the agency and program levels differ in their relative influence on the staffhelper relationship. They vere found to consist of tr.o dimensions that were ridely divergent in their association with the structure of the staff-helper relationship. Program formalization was positively associated with staff-helper formalization, program complexity negatively associated with it. Other situational factors were associated with different levels of program carplexity associated rith staffhelper relationship formalization. 
Envirommental linkage was a weak scale with no significant predictive effect, although case reviews suggested alternative definitions which might strengthen the predictive capability of this scale. Its camponents of funding autonamy, service integration, and general environmental urbanization were not highly intercorrelated. The perceived relevance was not a significant predictor of formalization, although the pattern was in the predicted direction. This dimension of the program innovation was only slightly acting as a suppressor of correlations or creator of spurious effects, indicating that it does not function as a significant mediating factor in the formalization of the staff-helper relationship. Perceived riskiness proved to be a scale with little reliability, due to problems in its construction which cambined two elements, client need and the difference or compatibilility of the program relative to the agency. These two measures were not related in the predicted manner. As a result, perceived riskiness had no significant association with formalization and no significant mediating influence on the formalization. When client need alone was used as a proxy for perceived riskiness the effect was closer to what was medicted but still not significant.

Stage of program implementation had no significant association with formalization of the relationship although the direction of the relationship was predicted.

Exploratory Findings. Statistical procedures (Pearson correlations and multiple regressions) were used to assess the degree of interrelatedness of the scaled variables constructed in this research 
process and to determine which combination of variables was most effective in predicting the degree of formalization found in the staff-helper relationship. Entered into this process also, as a partial check on the conceptual model, were the five types of program approaches developed in earlier explorations of the data. The question raised by this last exploratory step was how well do these approaches "explain" the formalization of the staff-helper relationship compared to the conceptual model's predictor variables. Table XVI sumarizes the results of the multiple regression analyses.

The results of these procedures suggest that program structure is the single best major organizational dimension to be used in predicting the amount of fomalization in the staff-helper relationship. The three major dimensions of frogram structure offer unique explanatory power to this conclusion. Cambining the two first program structure dimensions with peer support and general enviroment reduces the overall predictive power but still explains 55 percent of the variance.

The third best predictor of formalization is the program approach typology which, though not part of the conceptual model, offers an alternative intervening step between program design and actual development of staff-helper relationships.

The other organizational attributes (work climate, agency structure and envirommental linkage) and the innovation attributes each offer same limited explanatory power.

Work climate, in particular, has significant explanatory power when only one variable is used to predict formalization, but the two 
TABLE XVI

SUMNARY OF REGRESSIONS TO EXPLATN FORMALIZATION OF STAFF-HEITPER REIATIONSHIPS

Ranking

Predictor

Variance Explained

Program Structure

578

2 Combined Organizational Attributes 558

3 Frogram Approaches 368

$4 \quad$ Agency Structure 238

5 Work Climate 218

6 Innovation Factors 218

7 Environmental Iinkage 108 
variables essentially account for exactly the same variance, so they add notining to each other from the statistical perspective. However, leadership style and peer support are also highly negatively correlated with program formalization. Thus, either could be used in lieu of program formalization with essentially the inverse pattern of association with formalization of the staff helper relationship. 
CHAPTER V

DISCUSSION

This research has explored the ways in which differences in agency context are associated with differences in the partnership programs that have been developed between social service agency staff and commity-based lay helpers. It has focused primarily on the effects of the organizational properties on the structure of the relationship between the paid staff and the informal helpers, and on the ability of staff to adopt an infonmal relationship style.

Both statistical and case analyses have been used to answer the questions and to explore the hypotheses regarding the patterns of association between the major dimensions of the formal agency context and level of formalization of relationships between the staff and the helpers. In the same way the questions regarding the perceptions by the program staff of the innovative potential of the erograms were examined, to determine the direct effects of this perception on the formalization of the relationships, and the indirect effects on the actual structure, work climate, and environmental linkages within the program unit.

Multiple-item scales vere constructed to measure the organizational, innovational, and staff-helper relationship attributes. This concluding chapter discusses the relevance of these findings to organizational theory and research and to social service policy and practice. 
THEORETICAL IMPLICATIONS OF THE RESEARCH

This research presents support for a muber of theories and conceptual models found in the literature on organizations and on innovations.

It confirms Hall's (1963) work, in which he notes that the dimensions of bureaucracy are not necessarily positively intercorrelated, and that they vary independently of each other in any given organization. The reseach data confirm the independence of several of the major structural dimensions usually associated with bureaucracy. Thus, although the size, camplexity, and formalization measures were all positively intercorrelated at both the agency level and the program unit level, they differed dramatically in their pattern of association with the formalization of the staff-helper relationship. These findings suggest that not only do structural dimensions vary among organizations, but that these differences are associated with differences in the behavior of organizational members and relationships among them. They also suggest that, at some point, increases in organizational size and complexity reduce the likelihood of uniformity in level of fomalization across the many units of such an organization. Thus, in this study size and complexity were not highly correlated with the structure of the staff-helper relationships while reliance on formalized procedures and standards within the program unit was positively associated with reliance on formal procedures and standards in working with helpers. Staff who felt they had to be accountable for every mimute and act sought to make helpers also accountable for their activities. 
The data in this study also lend empirical support to Litwak's (1978a) contention that hman service organizations seeking to work with individuals or groups in the community must develop linkages that find a balance between the formal structure of the agency (bureaucratic intensity) and the informal structure of the individual or group (primary group intensity). He also suggests that organizations must be designed with appropriate internal stracturing to permit each program unit to adopt a structure (or level of fomalization, leadership style, and work group norms) that are most suited for the types of tasks it must accomplish (Litwak, 1961; 1978b). The internal structure and external linkages of the program unit should both be adapted to the task structure, i.e., its predictability and routineness. In his model of the effectively functioning agency, then, he sees working with community groups to be a non-routine task, which requires internally low levels of formalization as well as infomal linkages between staff and the community.

Litwak's conceptual model is supported by the data in this study. This research has shown that the structure of the relationship between agency staff and informal helpers in the commity varies as the program unit varies in formalization. While this does not directly support Litwak's emphasis on informal linkages or that proposed by the conceptual model for this research, it does illustrate that the structure of the program unit is a key element in the way that staff relate to informal helpers. A highly formalized program unit may be inappropriate for the task of working with cammity helpers in an informal manner, as this model suggests. Formally structured units tend to develop more 
formalized approaches to working with informal helpers, such as the volunteer-linking approach. Such approaches rely on creation of ties between helper and "clients", which are then more subject to agency staff definition and control. Programs that are successful in adopting more informal staff-helper relationships are those that have fewer standardized procedures and roles, and which rely, as a result, on the ingenuity, initiative, and the professionalism of the staff, and on the existing social relations of the helpers.

These data support Litwak's theories in another way. They reveal that hman service organizations need not be monolithic, monocratic bureaucracies. They can adopt a structure which gives the members assigned to certain tasks discretion in the way that they structure their relationships and decision-making authority. The data also indicate that program structure is often correlated with agency structure, but that is not always true. Certain programs within Iarger organizations had managed to develop a supportive work climate cambined with an informal relationship structure between program staff and informal helpers. When this happened, however, that specific program unit was generally freestanding, such that coordination with other, more formalized program units in the agency was minimized.

There are contradictions in the organizational literature regarding the definition of size and its relevance as an indicator of bureaucratization. The work of Blau and associates (Blau, 1973; Blau \& Schoenherr, 1971; Blau \& Scott, 1962) suggests that size is a major predictor of organizational bureaucratization, that is, that it is highly correlated with complexity and formalization. Other researchers 
have suggested that size is a multi-faceted concept that can be defined in so many ways that its relationship to other structural dimensions can only be determined in a specific context (Kimberley, 1976). In such a situation different indicators need not be highly interchangeable, as Hall (1977) suggests the conventional measures of size, number of paid staff and total budgetary resources, can be. These data offer more support to Kimberley's perspective than to the others. In the present study, size of the agency or the program were not good predictors of the structure of the staff-helper relationships. Other factors than size were found to be more useful in accounting for the level of formalization within these programs. The case analyses also suggested other ways of operationally defining size, such as the proportional size of budgetary and staff resources relative to the size of the area or client population to be served, which might lead to very different predictions about the way that size and other structural dimensions of the staff-helper relationship would be related. These data add weight to the cautions of those who suggest that size not be lised as a proxy for overall bureaucratization.

The research also lends modest support to the work of the human-relations school of theorists and researchers who posit that leadership style and work group norms will be reflective of the type of structure of the organization in which they occur. Highly formalized organizations generally tend to have more directive, less personal types of leaders and work group norms that contravene rather than support the formal definitions of roles. These data showed that a supportive work climate was more likely to occur in an organization 
that was conplex in structure (often meaning decentralized in its rule-making and decision-making) than in one which was more structurally simple, relying on formal definitions of roles, rules, and hierarchical centralized authority. The data also underscored that leadership style was a critical factor in most of the programs that had developed informal relationships with the lay helpers. Ieadership was closely associated with supportive work group nonms, and both of them related to the structure of the program unit. Fiedler's (1965) contingency theory of leadership, which suggests that the type of leadership that is effective is contingent both on the task structure (the degree of uncertainty of the tasks to be carried out) and on the position of the leader in the hierarchy of the organization (the relative autonamy and decision-making authority delegated to the leader), is supported by these data. The programs in which the staff-helper relationships were least formalized required a great deal of flexibility of staff and prevented the routinization of staff roles and activities. It is in just such programs that the highly supportive leadership style and supportive work group norms were found. Similarly, these program units, often within larger agencies, had often accorded the program manager considerable authority and discretion to make decisions.

Although this research was not primarily methodological in focus, the results suggest a continued need for work on measurement issues within the field of organizational theory. The methods used in this study prove that a multi-method model of data collection and analysis can be an effective research strategy in this field. Combining interviews with staff at several levels within the organization, surveys, 
observations of staff in the course of their work with helpers, and document analysis as data collection techniques, and case studies, content analyses, and statistical procedures to analyze these data has been a productive and informative way of exploring organizational behavior.

Multi-item scales, experimented with in this study, permit the researcher to bridge the two more conventional methods used by organizational reserachers. In one approach, represented by the vork of Woodward (1970) and Pugh (et al, 1968), the researcher relies heavily on the viewpoints and descriptions of the organization of one or two higher level members (such as an executive director or administrator). In the other approach, represented by the work of Hall (1963) and Hage \& Aiken (1970), persons at many levels within the organization are asked to complete standardized questionnaires. From this a single description of the organization is drawn by weighting the responses based on levels of authority and other such criteria (Miller, 1977). The present research seens to offer an attractive alternative to each of the other approaches. It offers a broader perspective of the organization than is seen fram the executive level, and is a less complicated approach than the survey technique. Yet, it permits the synthesis of of differences between perspectives and vocabularies among organization members to be done in a face-to-face approach by the interviever, rather than relying on the construction of a questionnaire that assumes that all organization members share the same language, interests, and concerns.

This research raises one important concern for theory and research 
on innovational behavior in organizations. It suggests that more attention needs to be directed to the step of operationally-iefining the major concepts used in describing innovation and social change. Considering innovation to be a process and a step to be undertaken within a specific organizational context (since what is new to one organization may resemble standard practice in another) seen to be valid (Baldridge \& Bumham, 1979), as does the notion that the process can be divided into stages (Zaltman et al, 1973). However, these conceptual models are not integrated. Much of the empirical work relies on bipolar typologies to characterize innovations (e.g., major or minor) rather than on a continum with levels of similarity or difference, radicality of change, ease of adoption, and so on. This research sought to develop such continuous measures of the perceived relevance and riskiness and stage of development of the innovation, but without great success. These results indicate that further work is necessary to develop internally consistent measures of the innovative potential of any program change within an organization, and to assess its effects on the organization and its members.

In this same vein, it is desirable that research on innovations have baseline data on the organizational structure and work climate prior to the adoption of an innovation, so that the inferred causality of models (suggesting a mediating or intervening role for the innovation) can be more easily tested and interpreted.

$$
\text { IMPLICATIONS FOR SOCIAL SERVICE POLICY AND DRACTICE }
$$

Fram the standpoint of policymakers and practitioners in the 
field of hman services, this research can provide certain tentative answers to their questions regarding which organizations can effectively undertake such programs and what is required of the organization and its members if the program is to achieve its intended goals.

The data indicate that partnership program can ve developed in a diversity of organizational contexts. Neither the size of the agency or the urbanization of its locale are significant barriers to the development of informal relationships between agency staff and lay caregivers. From these data it also appears that such relationships can be developed in contexts involving funding dependency and highly integrated service systems.

Factors which are significant to the ability or inclination of staff to develop and maintain informal relationships with the lay helpers include: a program unit in which there is minimal standardization of roiles, rules, procedures, and so on; a program manager who is capable of exercising supportive and democratic leadership and engaging the program staff in mutually supportive relationships; and an uncerstanding or belief in the value of informal helping. Sametimes an individual staff member may be assigned to work with informal helpers. In this event the availability of peer group support, in the form of another member of the agency with whom he/she can discuss ideas and problems, may be critical to the ability of that staff member to remain committed to the informal type of relations'nips and to the agency's goals in working with informal helpers.

Similarly, a program manager must have adequate authority and status within the organization, and administrative sanction at a high 
enough level, to set up procedures and roles that differ from standard agency practice. Staff members must be permitted to give their relationships with informal helpers adequate time for trust and acceptance to develop and for the helpers to accpet them in the the role they seek to play. Every step taken to develop the relationships can be evaluated for its level of formalization and the potential consequences that will have for the type of helpers identified and the eventual degree of formalization that will ensue. Thus, advertising for natural helpers may lead to the identification of very different types of informal helping skills and activities than will asking residents of a neighborhood or clients who they turn to for help in specific types of situations.

Agencies which are highly bureaucratized may find that the idea of working with informal helpers in order to improve the accessibility or acceptability of services is very attractive. However, upon closer consideration they may determine that creation of a freestanding unit is not feasible, that none of their staff have the requisite skills or interest to manage such a program, or that funding and similar pressures require high levels of acountability (cost-reporting systems) that are not easily adapted to this type of program. Does this mean that such agencies are precluded fram working with informal helpers? The research data indicate that certain approaches for working with informal helpers are amenable to use by formalized agencies or prograrn units. They include the volunteer-linking approach, in which persons are recruited for their skills (much as a professional would be) and are matched to a needy client or group of clients with whom that skill can be vell 
used. A second approach that has been successfully implemented within more formalized program units is the mutual aid approach, in which the role of the staff person(s) is to bring together persons with a cormon concern or problens and to act as a group facilitator as these persons share their problems and solutions to them. Often a staff member who has the requisite professional skills in group leadership and yet shares the same problem or concern is an effective catalyst fo mutual aid groups.

This research did not deal with issues of cost analysis. Hovever, program in the study often had developed rudimentary evaluation techniques. Some of their greatest costs arose from : staff time to identify and recruit helpers and to coordinate their activities, changes in administrative procedures to support the staff activities, finding locations outside the agency context in which to meet with helpers, dealing with concerns of staff or hoard members about issues of liability and responsibility, deciding who was actually responsible for the care that helpers provided. The consequences of the work with informal helpers had also been described by some of the programs. They included: increases in local control over services, increases in the number of clients who remained in the community rather than in institutions, the greater efficiency in the use of funding resources because of the addition of helpers' activities to those of professional staff. These and other issues involving the costs and benefits of working with informal helpers are discussed in more detail elsewhere (Froland, Chapman, Pancoast, \& Kimboko, 1981: 85-108). Here it is fair to say that those agencies which need to exercise care in monitoring their costs 
and effectiveness can find ways to do so with partnership programs.

NEEEDS FOR FURIHER RESEARCH

A major limitation of this research is the small sample size. One area for further research would be to replicate the study with a larger sample, or with a more controlled sample serving only one type of client. In this latter event it would also be desirable to ratch agencies or programs with partnership programs to agencies or programs without them to determine how they differ on the many organizational attributes. Until such replication occurs the results of this study must be accepted with caution.

Another limitation of this research is its attention only on the organizational context in which agency staff must function, to analyze the barriers to an informally structured relationship betreen the staff and informal helpers. Of equal importance and interest are the properties of the informal helpers and the informal helping systems within which they function, and the potential barriers this context presents. It would be useful to develop a similar profile of the helping systems linked to the formal service system through partnership programs, if this study were to be replicated. In this event the structure of the informal helping system prior to and after the linkage to tine agency should be described, as well as the nature and frequency of helping exchanges that occured before and after, and the acceptability of the help to its recipients before and after the linkage to the agency. It would also be useful to know how the program innovation was perceived by the helpers: its relevance to their daily lives, its riskiness for their other personal relationships, and so on, since it is not clear 
whether this type of Iinkage is valued by the informal system or whether same within the informal system would prefer that the formal and informal systems vould continue to operate independently.

This research raises the issue of whether, by working with informal helpers in the manner suggested by the normative model, there is a reduction in the scope of the services offered by an agency to its target population. Such reductions could occur in the actual geographic extent of the area served (i.e., reauctions in the scope of the service area) or in the numbers of persons served, or in the types of clients served. The normative model proposes an effective way of serving populations who do not make mach use of formal services, or who do not know how to use those services appropriately. What effect does it have on populations who do use formal services? Does it alter the way they are served or their access to services? This is another issue for further research.

This research has not given explicit attention to the differences in professional bacgrounds and role models among the staff fram different programs in this sample, although they are known to range videly from cammity-based paraprofessionals to highly trained clinical psychologists. Yet one of the areas of agency procedure most likely to be standardized early in the history of an organization is the type of credentials required of staff, either for hiring or for promotion. It would add to the explanatory power of this type of research if future studies also sought to determine how closely associated levels of professional training or how specific professional models are associated with formalization of the relationships between agency staff and 
informal helpers. One of the further issues for consideration is the relative emphasis of a given profession on a hierarchical relationship between professional and client or a collaborative relationship.

The present research was exploratory both in terms of the questions asked and in the methods used to analyze the data. It would be desirable to have further methodological development in regard to the reliability and validity of the ratings used to measure the various properties of the agencies, programs, and relationships for this study. A logical next step would be to have more than one observer or rater to complete the content analyses, thereby permitting the calculation of the inter-rater reliabilities of the rating system and the scales. The content or face valiaity of the ratings could also be enhanced by having the agency staff members rate their own agency, program unit, and staff-helper relationships. It is possible that such cross-validation and reliability checks would strenthen the conclusions of this exploratory research, or alter the conclusions that could be crawn.

\section{SURPARY}

It is apparent from recent trends in social service funding and fram critiques of the social service system, that social service agencies are being confronted with the need to reassess their delivery systems and their reliance on highly-trained professionals to deliver those services. However, in the face of the continued needs of their client populations, these agencies are not likely to consent to totally abandon their camitment to serve those populations. Rather they will seek acceptable alternative modes of service delivery that permit them 
serve their clients at a reduced cost. The partnership program is one such alternative model of service delivery that offers at least a partial solution to policymakers and practitioners alike in their efforts to serve populations in the face of stable or declining resources.

In deciding to adopt such a program it is important that those involved (planners, adninistrators, and other professional staff) evaluate both the strengths and the drawbaclss of such programs for their specific purposes, and recognize those aspects of their own agency context that may either facilitate or impede the successful inplementation of such a program. Since the long-range purpose of such program is to aid, support, and foster informal helping behaviors that prevent the need for more costly formal services, and to pramote self-reliance and mutual aid among commuity residents or clients, then the agency staff must inevitably seek to maintain the integrity of the infomal relationships of those they work with. Staff must determine whether this integrity would be possible within their particular agency context.

This research demonstrates that agency context is a valid focus for concern in regard to partnership programs in at least two ways. If an agency relies heavily on formal procedures and standards, and enforces equally across all its program units, the partnership program unit will develop formalized relationships, in contrast to the nomative model calling for informal relationships between agency staff and helpers. Highly formalized agencies and programs units tend to have highly formalized staff-helper linkages, which emphasize staff control 
and on staff definition of helper roles and helping activities.

Partnership program also require an open, democratic, supportive leadership style that encourages the open exchange of ideas and advice among the program staff. Program units with such a work climate are likely to survive in a highly formalized agency only if they are freestanding, or are loosely couped to other, more-routinized units in the agency. Even highly fomalized agencies or those with strong legal obligations to provide services to a particularly needy population or in a time of crisis may find that there are feasible alternative approaches to articulating their professional services with the informal helping resources in their communities. Among the approaches there are same that capitalize on the values of informal helping while permitting higher levels of staff control and accountability. Underlying all these efforts to work with the informal, private sector lies a respect for the value of both formal and informal care. This is coupled with a recognition by both the professional and the lay caregiver that one can never replace the other, and that both are essential elements in a humane world seeking to provide all its members with avenues to effectively meet their basic physical and emotional needs and to pramote their health and well-being. 
REFERENCE BIBLIOGRAPHY

Abrams, P. Community care: Some research problems and priorities. In J. Barnes \& N. Connelly (Eds.), Social Care Research. London: Bedford Square Press, 1978.

Abrams, P. Social change, social networks and neighborhood care. Social tork Services, 1980, 22, 12-23.

Aiken, M. \& Hage, J. Organizational interdependence and intraorganizational structure. American Sociological Review, 1968, 33, 912-30.

Aldrich, H. An interorganization dependency perspective on relations between the employment service and its organization-set. In R. Kilmann, L. Pondy, \& D. Slevin (Eds.), The Managenent of Organization Design. Amsterdam: Elserier, 1976.

Aldrich, H. Organizations and Enviroments. Englewood Cliffs, N.J.: Prentice-Hall, 1979.

Aldrich, H. \& Pfeffer, J. Environments of organizations. In Inkeles, A. (Ea.), Annual Review of Sociology. Palo Alto: Annual Reviews, 1976.

Andersen, T. \& Warkov, S. Organizational size and functional compplexity. American Sociological Review, 1961, 26 , 1-25.

Anderson, R. \& Carter, I. Human Behavior in the Social Environment, a Social Systems Perspective. Chicago: Aldine, 1974.

Argyris, C. Personality and Organization. New York: Harper, 1957 .

Argyris, C. Organization and Innovation. Homewood, III.: Dorsey Press, 1965.

Argyris, C. Intervention Theory and Method. Reading, Ma.: AddisonViesley, 1970.

Baldridge, J. V. \& Bumham, R. A. Organizational innovation: Individual, organizational, and environmental impacts. Administrative Science Quarterly, 1979, 24, 48-64.

Bell, D. The Coming of Post-Industrial Society. New York: Basic Books, 1973. 
Bennis, W. Changing Organizations. New York: McGraw-Hill, 1966.

Berelson, B. \& Steiner, G. Human Behavior: An Inventory of Scientific Findings. New York: Harecourt, Brace \& World, 1964.

Beyer, J. M. \& Trice, H. M. A re-examination of the relations between size and various components of organizational complexity. Administrative Science Quarterly, 1979, 24, 48-64.

Biegel, D. \& Naperstek, A. Neighborhood and Family Services ProjectFirst Year Report. Washington, D.C.: Washington Public Affairs Center, 1979.

Blalock, H. M., Jr. Social Statistics (2nd rev. ed.). New York: McGraw-Hill, 1979.

Blau, P. The Dynamics of Bureaucracy (2nd rev. ed.). Chicago: University of Chicago Press, 1973.

Blau, P. \& Schoenherr, R. The Structure of Organizations. New York: Basic Books, 1971.

Blau, P. \& Scott, W. R. Formal Organizations. San Francisco: Chandler Publishing, 1962.

Booth, A. \& Babchuk, N. Seeking health care from new resources. Journal of Health and Social Behavior, 1972, 13, 90-99.

Bowers, D. \& Seashore, S. Predicting organization effectiveness with a four-factor theory of leadership. Administrative Science Quarterly, 1966, 11, 238-263.

Brocm, I. \& Selznick, P. Sociology, a Text With Adapted Readings (4th ed.). New York: Harper \& Row, 1968.

Brown, B. Social and psychological correlates of help-seeking behavior among urban adurts. American Joumal of Community Psychology, $1978, \underline{6}, 425-440$.

Burns, T. \& Stalker, G. The Management of Innovations. Iondon: Tavistock Publications, 1961.

Caplan, G. Support Systems and Community Mental Health. New York: Behavioral Publications, 1974.

Caplow, T. Organizational size. Administrative Science Quarterly, $1957,1,484-505$.

Cartwright, D. \& Zandner, A. (Eds.). Group Dynamics (3rd ed.). New York: Harper \& Row, 1968. 
Chase, G. Implementing a human service program: How hard will it be? public Policy, 1979, , 384-435.

Child, J. Strategies of control and organizational behavior. Administrative Science Quarterly, 1973, 18, 1-17.

Cohen, J. \& Cohen, P. Applied Multiple Regression/Correlation Analysis for the Behavioral Sciences. Hillsdale, N.J.: Lawrence Erlbaum Associates, 1975.

Collins, A. \& Pancoast, D. Natural Helping Networks. Washington, D.C.: National Association of Social Workers, 1976.

Cooley, C. H. Human Nature and the Social Order. New York: Scribners, 1902.

Cooley, C.H. Primary groups. In P. Hare, E. Borgatta, and R. Bales (Eds.), Small Groups. New York: Knopf, 1955.

Craven, P. \& Wellman, B. The network city. Sociological Inquiry, 1973, $43,57-88$.

Elgin, D. \& Bushness, R. The limits to complexity, are bureaucracies becaning unmanageable? The Futurist, 1977, 9, 337-349.

Enery, F. E. \& Trist, E. L. The causal texture of organizational enviromments. Human Relations, 1965 (Feb.), 21-31.

Etzioni, A. A Comparative Analysis of Complex Organizations (rev. ed.). New York: Free Press, 1975.

Evans, W. H. The organization-set: Toward a theory of interorganizational relations. In Thompson, J. D. (Ed.), Approaches to Organizational Design. Pittsburgh, Pa.: University of Pittsburgh, 1966.

Fiedler, Fred T. The contingericy model: A theory of leadership effectiveness. In H. Proshansky \& B. Seidenberg (Eds.), Basic Studies in Social Psychology. New York: Holt, Rinehart, 1965.

Filley, A. \& House, R. Managerial Processes and Organizational Behavior. Glenview, Ill.: Scott, Foreman, 1969.

Fischer, C. Networks and Places. New York: Free Press, 1979.

Froland, C. Fomal and informal care: Discontinuities in a continuum. Social Service Review, 1980, 54, 572-587. 
Froland, C., Pancoast, D., Chapman, N., \& Kimboko, P. Professional Partnerships With Informal Helpers: Lmerging Forms. Paper presented to the American Psychological Association, New York, September 1979 (a).

Froland, C., Pancoast, D., Chapman, N., \& Kimboko, P. Helping Networks and Service Delivery: A Sampler of Agency Experience. Portland: Regional Research Institute for Human Services, 1979(b).

Froland, C., Pancoast, D., Chapman, N., \& Kimboko, P. Project Reports. Natural Helping Networks and Service Delivery. \#2 Sample Design for Initial Site Visits, 1979 (c). \#3 Final Sample Plan, 1979(d).

Froland, C., Pancoast, D., Chapman, N., \& Kimboko, P. Expanding Human Services With Informal Helping Resources. Portland: Regional Research Institute for Human Services, 1980 (a).

Froland, C., Pancoast, D., Chapman, N., \& Kimboko, P. Natural Helping Networks and Service Delivery: Case Study Sumaries, Executive Summary. Portland: Regional Research Institute for Human Services, 1980 (b).

Froland, C., Pancoast, D., Chapman, N., \& Kimboko, P. Helping Networks and Human Services. Beverly Hills: Sage Publications, 1981.

Gershon, M. \& Biller, H. The Other Helpers. Iexington, Ma: Lexington Books, 1977.

Gottlieb, B. \& Schroter, C. Collaboration and resource exchange between professionals and natural support systems. Professional Psychology, 1978, November, 614-622.

Gouldner, A. W. The nom of reciprocity: A preliminary statement. American Sociological Review, 1960, 25, 161-179.

Gourash, N. Help seeking: A review of the literature. American Journal of Comminity Psychology, 1978, 6 , 413-425.

Hage, J. \& Aiken, M. Program change and organizational properties. American Journal of Sociology, 1967, 72, 503-518.

Hage, J. \& Aiken, M. Routine technology, social structure and organization goals. Administrative Science Quarterly, 1969, 14, 366-375.

Hage, J. \& Aiken, M. Social Change in Complex Organizations. New York: Randam House, 1970.

Hall, R. The concept of bureaucracy: An empirical assessment. American Journal of Sociology, 1963, 69, 32-40. 
Hall, R. Formal Organizations: Structure and Process (2nd ed.). Englewood Cliffs, IJ: Prentice-Hall, 1977.

Hasenfeld, Y. People-processing organizations: An exchange approach. In Hasenfeld, Y. \& English, R. (Bds), Human Service Organizations. Ann Arbor: University of Michigan Press, 1974.

Hasenfeld, Y. Client-organization relations: a systens perspective. In Sarri, R. \& Hasenfeld, Y. (Eds), the Management of Human Services, New York: Columbia University Press, 1978.

Hasenfeld, Y. \& English, R. (Eds). Hhman Service Organizations: A Book of Readings. Ann Arbor: University of Michigan Press, 1974.

Havelock, R. Planning for Innovation. Ann Arbor: Center for Research on Utilization of Scientific Knowledge, University of Michigan, 1970.

Hickson, D., Pugh, D, Hinings, C., et al. A conceptual scheme for organizational analysis. Administrative Science Quarterly, 1963, 8, 289-315.

HIRI (Human Interaction Research Institute). Planning for Creative Change in Mental Health Services: A Distillation of Principles on Research Utilization (Vol. 1). National Institute of :'ental Health, Health Services and Mental Health Administration (\#HSM-73-9148), 1973.

Hirschhorn, L. Toward a Political Econimy of the Service Society (Working Paper \#229). Berkeley: Institute of Urban and Regional Development, 1974.

Homans, G. The Human Group. New York: Harcourt, Brance \& Vorld, 1950.

Homans, G. Social Behavior: Its Elementary Forms. New York: Harcourt, Brace, Jovanovich, 1961.

Hull, C. \& Nie, N. SPSS Update: New Procedures and Facilities for Releases 7 and 8. New York: IrGraw-Hil1, 1979.

Kasl, S., Gore, S., \& Cobb, S. The experience of losing a job: Reported changes in health symptoms and illness behaviors. Psychosanatic Medicine, 1975, 37, 106-121.

Kast, F. \& Rosenzweig, J. Contingency Views of Organization and Management. Chicago: Science Research Associates, 1973.

Katz, D. \& Kahn, R. Social Psychology of Organizations. New York: John Wiley, 1966.

Kimberly, J. Organizational size and the structuralist perspective: A review, critique, and proposal. Administrative Science Quarterly, 1976, 21, 571-597. 
Knight, K. A descriptive model of the intra-firm innovation process. Joumal of Business, 1967, 40, 478-496.

Lauffer, A. Social Planning at the Community Level. Englewood Cliffs, NJ: Prentice-Hall, 1978.

Lawrence, P. \& Lorsch, J. Organization and Ervirorment. Cambridge, Ma: Harvard University Press, 1967.

Lazarfield, P. \& Thielens, W. The Academic Mind. New York: Free Press, 1958.

Lenrow, P. Dilemmas of professional helping. In L. Wispe (Ed.), Sympathy, Altruism, and Helping. Cambridge, Ma: Harvard University Press, 1976.

Ienrow, P. B. \& Burch, R. W. Mutual aid and professional services: Opposing or complementary? In B. Gottlieb (Ed.), Social Networks and Social support. Sage Studies in Commmity Mental Health (4). Beverly Hills: Sage Publications, 1981.

Leutz, W. N. The informal comminity caregiver: A link between the health care system and local residents. American journal of Orthopsychiatry, 1976, 46, 678-688.

Ievine, S. \& White, P. E. Exchange as a conceptual framework for the study of interorganizational relationships. Aministrative Science quarterly, 1961, 5, 583-610.

Lewin, K. Group decisions and social change. In G. Swanson, T. Newcomb, \& E. Hartley (Eds.), Readings in Social Psychology, (rev. ed.). New York: Holt, 1952 .

Likert, R. New Patterns of Management. New York: McGraw-Hill, 1961.

Lippitt, R. \& White, R. K. An experimental study of leadership and group life. In H. Proshansky \& B. Seidenberg (Eds.), Basic Studies in Social Psychology, New York: Holt, Rinehart, \& Winston, 1965.

Litwak, E. Models of organization which permit conflict. American Journal of Sociology, 1961, 76, 177-184.

Litwak, E. Agency and family linkages in providing neighborhood services. In D. Thursz \& J. Vigilante (Eds.), Reaching People: The Structure of Neighborhood Services. Beverly Hills: Sage Publications, 1978 (a).

Iitwak, E. Organizational constructs and mega bureaucracy. In R. Sarri $\&$ Y. Hasenfeld (Eds.), The Management of Human Services. New York: Columbia University Press, 1978(b). 
Iitwak, E. \& Hylton, L. F. Interorganizational analysis: A hypothesis on coordinating agencies. Administrative Science Quarterly, 1962,6 , 337-341.

Litwak, E., Shiroi, E., Zimmerman, L., \& Berstein, J. Community participation in bureaucratic organization principles and strategies. In Kramer \& Specht (Eds.), Readings in Comminity Organization Practice (2nd ed.). Englewood Cliffs, NJ: Prentice-Hall, 1975.

Litwak, E., \& Szelenyi, A. Primary group structures and their functions: Kin, neighbors and friends. American Sociological Review, 1969, 34, 465-481.

Lowenthal, M. The social econary of the working class. In G. Gappert \& H. Rose (Eds.), The Social Econamy of Cities. Sage Urban Affairs Arnual, Beverly Hills: Sage Publications, 1975.

MeCall, G. (Eds.). Social Relationships. Chicago: Aldine, 1970.

March, J. \& Simon, H. Organizations. New York: John Wiley, 1958.

Marrow, A. The Practical Theorist. New York: Basic Books, 1969.

Mayo, E. The Human Problems of an Industrial Civilization. New York: Macmillan, 1933.

Mayo, E. The Social Problem of an Industrial Civilization. Boston: Harvard University Press, 1945.

Merton, R. K. Social Theory and Social Structure (rev. ed.). New York: Free Press, 1957.

Michael, D. On Planning to Iearn and Leaming to Plan. San Francisco: Jossey-Bass, 1973.

Miller, D. Handbook of Research Design and Social Measurement (3rd ed.). New York: David McKay, 1977.

National Commission on Neighborhoods. People, Building Neighborhoods. Final Report to the President and the Congress of the United States. Washington, D. C.: U.S. Govermment Printing Office, 1979.

Newcomb, T. The study of consensus. In R. Merton, et. al. (Eds.), Sociology Today: Problems and Prospects. New York: Basic Books, 1959.

Nie, N., Hull, C. H., Jenkins, J. G., Steinbrenner, K., \& Bent, D. H., SPSS: Statistical Package for the Social Sciences (2nd ed.). New York: McGraw-Hill, 1975. 
Nunnally, J. C. Psychametric Theory (2nd ed.). New York: MoGraw-Hill, 1978.

Parsons, T. The Social System. New York: Free Press, 1951.

Parsons, T. Suggestions for a sociological approach to the theory of organizations. Administrative Science Quarterly, 1956, 1, $63-85: 225-239$.

Parsons, T. Structure and Process in Modern Society. New York: Free Press, 1960.

Patti, R. Organizational resistance and change: The view from below. Social Service Review, 1971, 14, 26-35.

Perrow, C. A framework for comparative organizational analysis. American Sociological Review, 1967, 32, 194-209.

Perrow, C. Camplex Organizations: A Critical Essay (2nd ed.). Glenview, IIl: Scott, Foreman, 1979.

President's Commission on Mental Health. Report of the Task Panel on Community Support Systems. (Vol. 2, Appendix). Washington, D. C.: U.S. Government Printing Office, 1978.

Public Affairs Counseling. Factors Involved in the Transfer of Innovations: A Sumary and Organization of the literature. Prepared for Office of Policy Development and Research, Department of Housing and Urban Development. HUD-PDR-157, August 1976.

Pugh, D. Modern organizational theory. Psychology Bulletin, 1966, 66, 235-251.

Pugh, D., Hickson, D., Hinings, C., \& Tumer, C. Dimensions of organization structure. Adninistrative Science Quarterly, $1968,13,65-105$.

Roethlisberger, F. \& Dickson, W. Management and the Worker. Cambridge, Ma: Harvard University Press, 1939.

Rowe, L. \& Boise, W. Organizational and Managerial Innovations. Pacific Palisades, Ca: Goodyear Publishing, 1973.

Rushing, W. \& Zald, M. (Eds.). Organizations and Beyond: Selected Essays of James P. Thampson. Iexington, Ma: D. C. Heath, 1976.

Sarri, R. C. \& Hasenfeld, Y. (Eds.). The management of Human Services. New York: Columbia University Press, 1978. 
Schon, D. Network-Related Intervention. Unpublished manuscript prepared for the Networking Conference, sponsored by the School Capacity for Problem Solving Group, National Institute of Education, Washington, D. C., August 1977.

Schreiber, S., \& Glidewell, J. Social norms and helping in a community of limited liability. American Journal of Comminity Psychology, $1978, \underline{6}, 441-453$.

Sieber, S. Toward a theory of role accumulation. American Sociological Review, 1974, 39, 567-578.

Simmel, G. The Sociology of Georg Simmel (K. H. Wolfe, Ed. and trans.). New York: Free Press of Glencoe, 1950.

Stogdill, R. \& Coons, A. (Eds.). Leader Behavior: Its Description and Measurement. Columbus, कrio: Bureau of Business Research, 1957.

Taguiri, R. \& Litwin, G. (Eds.). Organizational Clinate: Exploration of a Concept. Boston: Harvard University, 1968.

Terreberry, S. The evolution of organizational envirorments. Administrative Science Quarterly, 1968, 12, 590-613.

Thibaut, J. \& Kelley, $\mathrm{H}$. The Social Psychology of Groups. New York: John Wiley, 1959.

Thampson, J. Organizations in Action. New York: MCGraw-Hill, 1967.

Thompson, J. D. \& McEwen, W. J. Organizational goals and envirorment: Goal setting as an interaction process. American Sociological Review, 1958, 23, 23-30.

Thampson, V. Modern Organizations (2nd ed.). New York: Alfred A. Knopf, 1977.

Warner, P., Hutchison, E., \& Armstrong-Adams, D. Elder Support Project Final Report. Franklin/Hampshire Commity Mental Health Center, Northampton, Massachusetts (Agency on Aging Model Projects Grant \# 90-A-1834), n.d.

Weber, M. The Theory of Social and Economic Organizations (Henderson \& T. Parsons, trans.). New York: Free Press, 1947.

Weick, K. Educational organizations as loosely coupled systems. Administrative Science Quarterly, 1976, 21, 1-19.

Wellman, B. The community question: The intimate network of East Yonkers. American Journal of Sociology, 1979, 84, 1201-1231. 
Wellman, B. Applying network analysis to the study of support. In B. Gottlieb (Ed.), Social Networks and Social support. Sage Studies in Community Mental Health (4). Beverly Hills: Sage Publications, 1981.

Whyte, W. F. Human relations: A progress report. Harvand Business Review, 1956, 34, 125-32.

Wilensky, H. Human relations in the work place. In C. Arenberg, et. al. (Eds.), Research in Industrial Human Relations. New York: Harper \& Row, 1957.

Wingspread Report. Strengthening Families Through Informal Support Systems. Racine, Wi: The Johnson Foundation, 1978.

Wirth, L. Urbanism as a way of life. American Journal of Sociology, $1938,44,3-24$.

Wolfenden Report. The Future of Voluntary Organizations. London: Croan Helm, 1978 .

Woodward, J. (Ed.). Industrial Organization: Behavior and Control. Iondon: Oxford University Press, 1970.

Zaltman, G., Duncan, R. \& Holbek, J. Innovations and Organizations. New York: John Wiley, 1973. 
APPENDIX A

DOCUMENIATION OF SAMPLE IDENTIFICATION AND SEIFCTION PROCESS 
Announcing a New Research Project:

NATURAL HETPING NETWORKS AND SERVICE DETTVERY

Investigators at the Regional Research Institute for Human

Services at Portland State University have received a grant from the Office of Human Development Services to study natural helping networks and the effects of private and public agency efforts to strengthen and utilize them. The research team is presently attempting to identify agencies across the nation which are working with natural helpers.

Natural helping networks occur informally within nearly all communities and involve mutual exchange of support, advice, and other forms of assistance among families, friends, and neighbors. Several mothers sharing child care, friendship, and information form a helping network. Family and neighbors who provide assistance to an elderly person who might not otherwise be able to live alone is another example. These informal systems of help may be of significant benefit to families with young children, teenagers, the disabled, the elderly, and a wide range of other "at risk" target populations.

Many public and private agencies have begun to look for ways to identify and work with these systems of mutual and informal helping within the communities they serve. For example, a number of agencies have developed informal consultative relationships between their staffs and key individuals in a neighborhood to whom many turn for help or advice with everyday problens. Often these so-called "natural helpers" work independently of the agency but may regularly seek advice fron agency staff about the individuals in their networks. Other types of relationships having varying degrees of formality may be formed between 
agency staff and natural helpers that focus on community outreach, information and referral, training or different types of preventive activities. There are likely to be a good number of alternative approaches to working with natural helping networks that are being developed spontaneously by human service agency staffs throughout the country.

Over the course of the two-year study, research staff will be identifying agencies in a wide number of fields who have developed programs to work with natural helping networks and natural helpers. The study will be concerned with describing the chairacteristics of networks that are involved, the types of problems of the populations that are being assisted and the range of strategies that agency staff have developed to work with such networks. The study hopes to identify particularly useful models of practice and to suggest policy guidelines and implementation procedures for agencies who are interested in developing such programs.

The research staff are currently preparing a listing of projects across the nation and would like to hear from any agencies who are engaged in activities of this type or fram those who may know about such programs in their communities.

Please contact:

Charles Froland or
Diane Pancoast
Regional Research Institute for
Human Services
Portland State University
P. O. Box 751
Portland, Oregon 97207

(503) $229-4040$ 
SAMPLE LETTER \#1

We are currently conducting a research project to examine the efforts of public and private human service agencies to strengthen or utilize natural helping netuorks in formal services and have been referred to your agency in this connection. At present, we are trying to identify a variety of projects across the nation who may be engaged in activities of this type.

As this is a rather innovative and developing area within the $f: 2: d$, there is no comon definition of terws and a wide variety of worts say be used to describe what we are interested in studying; lay helpers, gatekeepers, indigenous workers, informal support systens, natural helping networks are perhaps some of the terms. Our particular interest is centered around how formal services way link up with naturally occurring helping networks in their commalties. This type of resource is largely an informal and unstructured set of relationships among people that occurs to engage in mutual support, advice and other forms of assistance. Several mothers who share day care, friendship, and information is a common example. Family and neighbors who provide assistance to an elderly person who might not otherwise be able to live alone is another. These informal systems of help occur in a side varlety of ways and may be of significant benefit to families with young children, youth peer groups, the disabled, the elderly, and a wide range of other potential "at risk" target populations.

We are becoming aware of many public and private agencies that have begun to look for ways to Identify and work with these systems of mutual and informal helping within the communities they serve. For example, a number of agencles have developed informal consultative relationships between their staffs and key Individuals in a neighborhood to whom many turn for help or advice with evaryday problens. Of ten 


\begin{abstract}
these so-called "natural helpers" work independently of the agency but may regularly seek advice from agency staff about the individuals they're attempting to help. The varlety of ways these "1inks" may be developed is potentially as diverse as the range of helping networks that may occur or the particular types of services, problems or target populations an agency is concerned with.
\end{abstract}

If your agency has developed a project or program that adopts this kind of strategy, we would like to hear from you. Fcr this purpose, we have enclosed a short project information sheet to help us get a better idea of what you may be doing.

Over the course of our study, we wlll be concerned with describing the characteristics of networks that are involved, the types of problems of the populations that are belng assisted and the various range of strategles that agency staff have developed to work with such networks. We hope to Identify particularly useful models of practice and to suggest policy guidelines and implementation procedures for agencies who are incerested in developing such programs.

Should you have any questions, or know of any projects that may be working in this area, please let us know. Thank you for your interest.

Sincerely,

Nancy J. Chapman

Co-Principal Investigator

Natural Helping Networks Project

$\mathrm{NJC} / \mathrm{vlm}$

Enc. 
SAMPLE LETTER \# 2

We are currently conducting a research project to examine the efforts of public and private human service agencies to strengthen or utilize natural helping networks in forwal services. More parrfcularly we are looking for a number of projects or programs serving the developmentally disabled that are engaged in activities of this type. We have

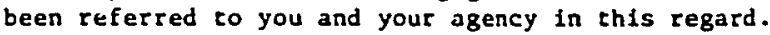

A brief announcement is enclosed which more fully describes the goals and purposes of our profect. If your agency has developed a project or program that adopts this kind of strategy we would like to hear iron you. We have enclosed a brief profect infornation sheet to help us get a better idea of what you are doing. We would also be appreciative of any more detailed written materials that you have available.

Over the course of our study we will be concerned with describing the characteristics of the networks involved, the types of problems of the target population(s), the range of strategles that agency staff have developed to work with such networks. We hope to identify useful models of practice and to suggest policy guidelines and implementation procedures for agencies interested in developing such programs.

We look forward to hearing from you about your own and any other such projects that you may know of. We would be happy to answer any questions you may have. Thank you for your interest and assistince.

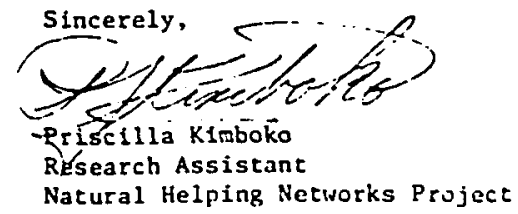

PK/vlw

Natural Helping Networks Project

Enc. 
NATURAL HELPINC NETWORKS AND SERVICE DELIVERY PROJECT:

PROJECT INFORMATION

Name of concact person

Agency nave

Address

Phone number

Please briefly describe the ways in which your profect is working with natural helpling networks, informal systems of support, indigenous helpers or other types of informal helping resources.

How so :Os identify or recruit natural helping resources?

What problems or target populations do you focus on?

How long has your project been in operation?

Please send any descriptive materials on your project if avaliable. If you know of any ocher projects we should contact, please provide their names and addresses on the back of this sheet. Thank you.

Please return to:

Charles Froland or

Diane Pancoast

Regional Research Insticute for Human Services

P.O. Box 751

Portland, Oregon 97207

(503) $229-4040$ 
Location

State

City

NATURAL HELPING NETWORKS

PROJECT REVIEW CHECKIIST

Yes No

Recelved by

Referral

Date

If yes, referted by

Agency Name

Program Name

Contact Person

Phone Number

Descriptive Materials Requested

Target Population

Is chis project one that should be included in our study?

Yes*(fits the model well)

Yes*, but $1 \mathrm{t}$ is not so close as others

Saybe, some elements that fit todel; target population needed.

No, unless noching else is identifled for this target population.

Not at all

*If checked, please follow up on all data and complete project information sheet; if direct contact is made request descriptive materials.

Follow-up

Date

By letter (attach copy)

By phone

Materials requested

Materials received

Project information sheet complete 
APPENDIX B

CASE STUDY DOCUMENTATION 


\section{CASE STUDY SUMMARIES}

Prepared for Natural Helping Networks and Service Delivery Project, (Office of Human Development Services Grant \#18-P-00088, 1980) 
Benton Neighborhood Program for the Elderly:

A Mutual Help Model

Benton, Illinois

Benton is the county seat of Franklin County in the southern part of Illiniois. It is a small town (about 8,000 ) in which coal mining, local governments, churches, and civic groups play significant roles. An unusually high proportion of the residents of Benton are elderly--the number of residents over 60 years of age is nearly 2500. The presence of such a high number of elderly and a lack of accessible services made this an ideal setting for trying out a new approach in serving the elderly.

The Benton Neighborhood Program for the Elderly began as a 2-year research and demonstration project, funded by the federal Department of Health, Education and Welfare through the Administration on Aging. The funds were awarded in July 1976 and actual program implementation begun in November 1976, ontinuing as a joint research/ demonostration effort for 18 months under the direction of Phyllis Ehrlich, a social worker and researcher at nearby Southern Illinois University at Carbondale. It was she who had developed the model program approach and applied for the demonstration monies.

The program model, developed and implemented by Phyllis Ehrlich, was drawn from her prior experience in administering programs for the elderly and fram gerontclogical research. Both sources pointed to the need for a decentralized service delivery system geared to a microscaie Iife space (i.e., a decreased mobility) among the elderly, and to a need for new or renewed social roles to reduce the sense of loss and isolation experienced by the elderly with the loss of spouse, friends and for social contacts. The resulting program is neighborhoodbased and encourages mutual-help among neighbors. The mutual help model prenises that people can and do help themselves and others, that people (including the elderly) can identify their own needs and can organize to meet those needs primarily through their own efforts. The neighbor-helping-neighbor approach opens up or revitalizes the roles of neighbor and friend, and potential roles as member of the neighborhood group and as cormunity actionist or consumer spokesperson. By providing this array of meaningful number of roles, the types and frequency of interactions with peers and participating elderly. The role of the community aide in this neighborhood-based service approach is to activate peer networks among the elderly by encouraging neighbors to help neighbors, to increase the visibility and accessibility of existing formal service programs for the elderly, and to act as advocates and educators within the elderly population, the comminity, and other service agencies for improving the formal services for the elderly.

The Benton Program now operates an extensive service program fram its new Center, located in a new building adjacent to the Benton Township offices. The agency is governed by a 13 member Boand of 
Directors, consisting of local leaders, professionals, and elderly consumers; and is staffed by a Director, three full-time, and one part-time canmunity workers. The agency currently operates on funds from the state $(\$ 30,000)$ and from local sources $(10,000)$. Many inkind resources have been made available by local organizations; particularly significant are the spaces donated by local churches and organizations for the biweekly neighborhood group meetings, and the Center Building, paid for by the Benton Township.

The community aides have outreach, case management, group work, and community organization responsibilities. Their efforts to reach and involve all the elderly in the community are supplemented by those of volunteers and by the elderly helping themselves. Fach community worker has three neighborhood groups assigned to her. The small town has been divided up into ten smaller areas or "neighborhoods." All the elderly in each of these neighborhoods has been identified by name and street-and all have beer invited to participate in the closest neighborhood group for the elderly. The groups meet twice a month, primarily for social and recreational activities with same added elements-blood pressures are taken, information about services and programs and special events, and information about other elderly individuals in the neighborhood are shared. The group participants are encouraged to reach out to hame-bound and hospitalized neighbors. A local newspaper column, the Senior Form, reports on the activities of each neighborhood group so that even non-participants can follow neighborhood happenings. While originally limited to the City of Benton, the neighborhood groups and related services have recently been extended to a small neighboring town and to a nearby rural area. The Center receives calls and makes referrals for elderly throughout Franklin County.

The Benton Program is designed to provide highly visible, accessible services to its elderly consituents. It also actively seeks coordination with other agencies serving the elderly and advocates for more community-wide resources for the areas where neighborhood groups exist. The Board intends to expand the service program to the entire county. The staff in the program and the Board also collaborate with the originator of the Program in her efforts to disseminate the Mutual Help liodel to a wider audience. 
Trude Kaufman Senior Center Eugene, Oregon

The Trude Kaufman Senior Center began operation in late 1972 in a large old house that was the family hame of the Kaufman family, donated to the city by Mrs. Kaufman in 1969 with the stipulation that it became a senior center. The goal of the Center is to meet the needs of all the elderly in the neighborhood, whether by providing a service directiy, by helping neighbors help each other, or by providing information and referral to the formal services provided elsewhere in the camminity. A number of the unique features of the Kaufman Center program originate in the fortunate combination of circumstances surrounding the donation of the house: the big rambling old home that the older neighbors proudly show off to friends and relations; a facilitity that had already been remodelled by the elderly Mrs. Kaufman and is particularly suited to older people; its funding and administration by the City Parks and Recreation Department rather than by a 'welfare agency;' and its location in a 170 block area adjacent to downtown housing 21 percent of the city's and 10 percent of the county's elderly population. The Center is staffed by a director, two assistant supervisors, an outreach worker and a maintenance person. In addition to the professional staff, there are two elderly persons funded by outside sources who do friendly visiting and coordinate the food programs. Older volunteers from the comminity and a stiudent intern are also integral to the program.

The Center is unusual both in its emphasis on outreach work and on relatively unstructured activities within the Center itself. The Center provides a hame-like atmosphere and drop-in activities, although there are also planned events such as mini-tours, a weekly produce market, a yearly yard sale and weekly transportation to the supermarket. The Center also provides a focal point for the outreach-a place, program and staff that can be identified with, and it provides a reason for maintaining contact with the neighbors. The outreach program allows the Center to serve the whole neighborhood, not just the few active and involved individuals who come to the Center itself. The strategy of the outreach program has been to contact all of the older persons in the neighborhood, and to maintain contact by providing monthly calendars that inform the elderly about activities at the Center and about other services available in the community. The calendars are delivered by block workers, and the role of the block worker is to get to know his/her neighbors and chat a little as well as deliver the calendar. In this way, the block worker can learn about their problems and service as a source of information or refer them to the Center staff. The block workers were recruited fram among the elderly on each block, with an emphasis on those who are able to relate well to others, and are enthusiastic about the role but not intrusive or judgmental.

Through their outreach work in the neighborhood and their contacts with block workers and with the elderly who use the center, the staff 
have discovered people who provide same kind of assistance on a regular or irregular basis to ane of the elderly residents of the neighborhood. They use this growing fund of knowledge about the helping system to find informal help for other elderly residents. They may encourage such helping by simply letting it be known that sameone has a problem-perhaps a need for lawn mowing or small services during an illness; a simple mention is usually enough to spark spontaneous offers to help or visit. In other cases, the staff may be able to suggest what an older person could offer in return for help, for many are reluctant to accept help if they cannot reciprocate. Their work with both block workers and the neighborhood helping system are aimed at making the resources of the center a part of the neighborhood and at making the helping system work better. 


\author{
Elder Support Project \\ Franklin Hampshire Camminity Mental Health Center \\ Northampton, Massachusetts
}

As route 9 threads its way through rural Hampshire County in western Massachusetts, it connects a number of small towns and villages to the largest city in the county, lorthampton. The connection provides a common thoroughfare but the towns retain their distinct identities and unique heritages, each steeped in several centuries of history. Farming has been a tradition for the area but is now overshadowed as a way of life by the concentration of institutions of higher learning. Within a 25 mile radius, one finds five major colleges-Amherst, University of Massachusetts, Smith College, Hampshire College and Mt. Holyoke-all contributing to an influx of students, a shortage of housing, new development, and a change in tradition.

Iocated in Northanpton, the Elder Support Project reaches out to three of the small towns along Route 9, each town having an above average proportion of senior residents and each in various stages of transition. Middleton, the smallest of the three towns with under 700 residents, is the furthest away fram Northampton and also has the highest proportion of elderly. Closer in, Russellville with a population of 3000 is experiencing change but still retains a spirit of community. Ashton is the third and largest town at 4000 population and is undergoing the greatest amount of transition as it is slowly being absorbed into nearby Amherst. Each of the three communities has been assigned an individual staff member of the Elder support Project who has responsibility for learning about the community, becoming known and accepted by residents, and acting broadly in the role of a community consultant. The project was formally funded in March of 1977 as part of the Consultation and Education Program of the Franklin/Hampshire Community Mental Health Center. Funding was provided by the local Area Agency on Aging and will continue for two years at approximately $\$ 100,000$ each year. The goals of the Elder Support Project emphasize prevertion. Supporting and pramoting the strengths of individuals, families and communities, promoting selfhelp and improving comminication among service delivery organizations in order to develop better policies for the elderly are the major elements of the projects' philosophy of prevention.

The strategy for addressing these goals is one that is of necessity and by design carried out on an informal and personal basis. As each of the three project staff have responsibility for a particular community, emphasis is given to identifying and developing relationships with each community's natural helpers as a way to became sensitive to community needs and to extend staff resources. The focus is on finding the key helping resources in each town and understanding the role they play both for elderly and in the community. This task is pursued on many levels. Representatives of formal service agencies such as the Visiting Nurses Association, or the Council on Aging, and religious and voluntary organizations are contacted as a 
way to understand what various organizations are doing, develop ties with agency staff, and identify possible referrals. Through such referrals, as well as a good deal of informal canvassing, staff learn of informal helpers who play key helping roles in the cammities. Another dimension of staff activities is concerned with understanding the cultural heritage of each town, as this has been recognized as being an important aspect of working with each community particularly in regard to the elderly.

While still in the early stages of implementation, staff have already made progress in identifying and working with comminity helpers. In one community, Middleton, where informal efforts had been made for a year prior to formal funding of the project, contacts have been made with a number of key helpers, group meetings are ongoing, consultation and referral relationships have been established, and a major camminity forum has been held. A cormon principle underlying work in all three conmunities has been the staff's belief in the importance of informal networks of support, and the need to develop a sensitivity to the interests, and incorporate the perspectives of such networks, in the direction the project takes. Thus, as the project develops further, it is likely that the shape of the project will emerge differently in each of the three towns as it cones to reflect the particular history and traditions of the separate communities. The cormon elements, however, will involve working with natural helpers, developing peer support groups, consulting with community agencies, and using educational efforts and the media to pramote a broader awareness within each comminity of the process of aging and the needs of the elderly.

Ultimately, the project intends to formulate and disseminate a model of prevention for working with the rural elderly. In line with this, the project includes a research and evaluation component that will study and document several aspects of project work. Staff maintain logs of daily activities and minutes are kept of meetings in order to provide a record of the process of implementing the project. Several surveys will be conducted including a pre/post survey of conmunity attitudes and understanding of elderly citizens and a survey of formal service providers. Natural helpers and other volunteers will also be interviewed to document their activities in the community and interactions with staff. Information obtained from research and evaluation studies will be melded with staff experience in developing a handbook for dissemination of project results.

While the development of a model of prevention will represent one outcome of the project, the project will perhaps have greater meaning to the camminity members with which staff are working. The commitment of staff members goes beyond project objectives and stems from a philosophy that sees a strength and dignity in the citizens of each town and a desire to reinforce patterns of everyday helping within the community. It is this cammitment and philosophy that will likely be at the base of the project's success and will ensure continuing efforts of the staff after the project is completed. 


\author{
Natural Supports Program, Cammity Service Society \\ New York, New York
}

The Comminity Service Society is one of the oldest and largest non-profit social agencies in the country. The Natural supports Program began as an extension of the services provided by the older Persons Service Program of the Cammunity Service Society. In contrast to existing programs, the purpose of the individual services camponent of this program is to work with the informal supports of the older person as well as with the older person him or herself to make decisions about formal service needs. The emphasis of the program is on supporting the caregivers of the elderly, so that they are able to continue in their role, keeping the older person out of an institution for as long as that is possible or reasonable. The program allows the caregivers rather than staff to make decisions about the services needed, and is able to provide counseling, housekeeping, hamecare and other services.

In addition to the individual services camponent, there is a group services effort which has been supported since October 1978 by a grant from the Administration on Aging. In this sector of the program the support for caregivers occurs in the context of groups. The groups operate according to a variety of models, and may offer social and emotional support, education in aging and the needs of the elderly, skills training, and group problem solving. The groups may be led either by a professional or as self-help groups, and choose a modei of group activity that fits their needs.

The Natural Supports program is staffed by nine professional workers, seven paraprofessionals (largely hane care workers), and four or five student intems. In the group program, the staff work through planning committees of social service professionals in each of the communities. The intent of the program is to enable the planning committees, or the community agencies, to continue the program on a permanent basis after the initial development and demonstration of the program by the Natural Supports Program staff.

While the individual services component of the program is available to anyone living within one-hour travelling distance from Midtown Manhattan, the groups are based in specific localities served by the program: Staten Island, Southeast queens, Clinton (midtown Manhattan), and the Upper East Side of Manhattan. The areas served are diverse in population, in service availability, and in size, and have become more diverse with the addition of two more areas, the Upper West Side and Harlem.

Major developments recently include the phasing out of the individual services camponent, although the group program will be able to provide services to 25 people, and, the growth of an advocacy group. The advocacy group, with 8 to 10 active members, has developed spontaneously among the caregivers to advocate at the local, state and 
and national levels for services and other forms of support for families caring for elderly parents. 


\section{In-Home Service Program, Philadelphia Geriatric Center Philadelphia, Pennsylvania}

The Philadelphia Geriatric Cunter was formed in 1865 as a Jewish Hame for the Aged, and has developed into a large private non-profit organization which provides intermediate and skilled nurisng care for Jewish elderly, provides apartments for seni-independent living, and conducts behavioral and biomedical research through its Gerontological Institute. Beginning in about 1973, it began for the first time to reach out into the community immediately surrounding the Center, offering new services to this population as well as making same of its existing services available to them. The In-Hame Service Program is one part of this development, funded in 1974 by a grant from the Administration on Aging and since 1976 by the local Area Agency on Aging.

The goal of the In-Home Service Program is to support the elderly in the community in order to prevent early or unnecessary institutionalization. The program relies on three sources of services to support the elderly in the community, in the following order of priority: the informal system made up of family, friends, and neighbors; the private and public system of formal services; and services provided by the staff of the program itself. Program staff include a director, a social work supervisor, four paraprofessional caseworkers, and a driver who provides transportation and delivers meals. The paraprofessionals meet with the elderly client, identify with them present and potentital sources of help within the client's personal network, and encouriage the older person to contact particular people to ask for help with specific tasks. If the personal network is not present or able to help, services from this agency and others are located. The aim of this part of the program is to build a support system for each person, relying as much as possible on his or her own informal system.

The program also has a community development component, which involves two major parts: (1) contacting businesses, hospitals, libraries, and banks in the community, to educate them about the needs and problems of the elderly, to ask them to refer those with problems to the program, and to encourage them to change their policies and procedures to benefit the elderly; (2) working with existing organizations in the community, particularly churches and civic groups, helping them develop volunteer programs to aid the elderly, which may include friendly visiting, transportation, or escort services. These resources can then be used by the staff in meeting the needs of their elderly clients.

The Geriatric Center is located in an area of Philadelphia which has traditionally been populated by white ethnic immigrant groups, particularly from Germany and Eastern Europe. It is about equally Protestant, Catholic, and Jewish. Since 1970, portions of the comminity have turned over very rapidly, becoming perhaps 60 to 80 percent nonwhite. In these sections almost all of the older people are white and 
almost all the young families are nonwhite. As the original white population left, the stores, doctors, churches and symagogues and related institutions that served them left also. Since both the personal and institutional supports that the elderly depended on have gone, the program has been challenged to rely on informal supports for this segment of their population. 


\author{
Elderly Services \\ Northwest Center for Community Mental Health \\ Reston, Virginia
}

Not far fram Dulles Airport, situated in Virginia's traditionally rural northwest Fairfax county, Reston has added a new dimension to East Coast urban living. As one of the "New Towns," the city is a totally planned community, mixing residential densities, shopping centers, industrial parks, recreational opportunities and open spacesan urban planner's dream cut from whole cloth. Begun in the $60^{\prime} s$, Reston will have same time to go before losing its feeling of newness, as development (same still on the drawing boards) expands to accomodate the influx of new business and population seeking proximity to the Nation's Capitol some 15 miles away.

Located in newly acquired office space in an industrial park within Reston, the Northwest Center for Community Mental Health was formally established in 1975 to serve the expanding population of more than 205,000 residents in Northwest Fairfax County. As an agency of the Fairfax County-Falls Church Camunity Services Board, the Center is funded by local, state, and federal governmental grants to provide a full complement of comprehensive comunity mental health services, including the 12 basic services mandated by PL 94-63. Major services include: psychiatric inpatient; adult, children and adolescent programs; emergency services; residential care; consultation education and prevention programs with a support system of administration and evaluation services. The center is based upon the Balanced service System model emphasizing integrated clinical service based on need and aimed toward greater functional autonomy for clients. When fully operational, the Center will have over 90 professional staff including psychiatrists, psychologists, nurses, and social workers. Since it began in 1975, the Center has grown from a staff of less than 10 to more than 80, adding 45 staff in the last year alone. The growth in program has not been without problems, as, even with recently acquired office space, the center is planning to rent additional facilities for staff.

One of the main guiding principles of the Center's services is to recognize the assets of the client's natural cammunity support networks defined as family, friends, neighbors, other community providers such as clergy, community groups, and other community agencies. This principle is translated into program objectives aimed at maximizing existing client resources and participation in the conmunity and conserving limited agency resources by complementing, rather than supplanting, the clients' support network.

Although still in the developing stages, the Elderly Services component of the Adult Service Section within the Center is a good illustration of how a program of services can incorporate an emphasis on natural carmunity support networks in their activities with elderly 
clients. With the expansion of staff within the last year, the Adult outpatient program hired a full-time professional to develop a program of both clinical and consultation and education services to the elderly population in the catchment area. With half-time devoted to clinical outpatient activities and the remainder oriented to community consultation and education, the elderly services coordinator is at present responsible for the primary effort directed to elderly, although plans are to add additional staff in the future. Although limited in time, she began to explore the informal resources of the elderly within the community and found nearly a half a dozen mutual aid groups for the elderly in the Reston area alone. She has made presentations or informal contacts with many of the informal leaders of the groups and is beginning to develop an ongoing relationship with same groups. As coordinator of elderly services, her goals are several, incorporating general educational and case finding objectives with consultative aims specific to each group. In general, her developing role is one oriented to identifying elderly needs and strengthening existing mutual aid efforts in the help they provide senior citizens. Plans include contacting other groups within the catchment area (there are nearly 80 identified groups within Fairfax County) and developing a supporting role with key helpers within the existing mutual aid networks of elderly. 


\section{Neighborhood House: support Systems for the Elderly Portland, Oregon}

Neighborhood House serves the metropolitan area of southwest Portland which is made up of a number of small neighborhood communities. The people who live here think in terms of "districts" and there are many neighborhood councils. These areas consist of pockets of older settlements now engulfed in the spread of suburban housing in the last 20 to 30 years. ilany of these neighborhoods are geographically insulated by traffic, hills, and other natural boundaries, as well as the less easily drawn influence of tradition.

In recent years, a number of these small comminities have faced a growth of population, in some instances threatening or destroying the cohesiveness of the neighborhood. Many neighborhood councils have taken up battle with encroaching developers. Other neighborhoods have been threatened more by new development rather than redevelopment. Overall, Southwest portland is typically considered to be an area where only those with above average incomes might live. The area is predaminantly white, single family, owner-occupied residences, with housing values generally above average. Compared to other sections of metropolitan Portland, the elderly population as a whole also appears to be in relatively favorable circumstances. Of the more than 7,500 person aged 60 and over (roughly 40 percent are over 75), 13 percent had income below the poverty line, substantially lower than the county average of 22 percent. Twenty-seven percent of the elderly live alone and are considered isolated. These statistics give perhaps a distorted picture of an area characterized by a diversity of insular neighborhoods and possessing a number of pockets of poverty. For example, within a long strip west of Barbur Boulevard between Cheltenhan and the Ross Island Bridge, nearly one-half of the elderly (65 and over) live in impoverishment.

Although changes have been made to suit shifting needs, Neighborhood House has been serving the southwest community of Portland since the turn of the century. Founded as a settlement house by the National Council of Jewish women, the agency has a long tradition having served variously as a school, medical center, recreational facility, Red cross and uso Centers, and provided for the needs of day camps, clubs for all ages, and programs for the physically and mentally handicapped. In 1975, Neingborhood House was designated and funded by the Aging Services Division of Portland Human Resources Bureau (the Area Agency on Aging) to provide for the needs of the elderly as indicated under the older American Act.

Neighborhood House is a private non-profit organization governed by a policy board of 25 individuals recruited fram the business community, other agencies, and citizens in the community. The board delegates the management of the agency to the Executive Director with 
the two major camponents of the agency (Aging Services and Children and Youth Services) being managed by assistant directors.

All told, the agency has 25 paid staff although not all are fulltime. The largest source of funding is The United Way which also supports several staff to provide aging services. 10st of the staff working with the elderly (a total of nine) are supported through the Aging services contract with the City of Portland.

The stated policies of the senior adult camponent of Neighborhood House stress neighborhood development by pramoting client independence, elderly support system, and cooperation with other agencies, outreach to elderly to improve access to services where needed, and; social contact and involvement, which enphasizes a balance between advocacy, education and recreation services to promote independence and volunteer involvement. Throughout, agency philosophy centers on increasing self-determination, recognition, and strengthening the elderly clients' own resaurces, and helping people to help thenselves, "live and help live," as the agency advertises. The program views itself as filling gaps that other people can't serve whether this be the informal support resources of the client or other formal services potentially available within the cormunity. The program is camitted to serving those in need and will not refuse services for reasons of incame. This is exemplified by the agency's policy to serve elderly who do not meet the eligibility criteria under the aging services grant from the city. Needy clients who fall outside of these incame rules are served using United Way funds.

The staffing of the elderly program is highly differentiated by task: one half-time assistant director; three full-time field counselors (one of whom serves as a counseling supervisor); one senior worker responsible for transportation services; two half-time information and referral workers; one community liaison; and one volunteer coordinator. The staff is roughly split between young and old, male and female, and professional (USWV) and non-professional. The program offers a full range of services including case management, information, referral and follow-up, telephone reassurance, friendly visiting, counseling, problem-solving, and educational and recreational opportunities.

Staff go about identifying informal helping resources in several ways. First, because most clients are referred by other agencies (roughly 5-10 percent are self-referred), clients are asked at intake who has helped them before, what help has been provided and who are the client's family, friends, and relations. A file sheet records potential contacts which individual staff follow up on to establish a relationship. Staff often first visit the "referrals"--sometimes neighbors, sametimes family members--to make contact, to let them know the agency is working with the client, and to set an expectation of cooperation in helping the elderly client. Fram time to time, usually every one to three months unless a crisis emerges, staff will phone the significant others to "check-in," monitor their relationship 
with the client, and to discuss what problems might be occurring. The relationship is informal, neighborly, but special and reserved between an individual staff member, a client, and their significant others. This means that although staff may exchange information between one another, only a crisis will provide cause for a field counselor who has not had contact with an elderly client's support system to contact a member of that system. This may not be so much a matter of confidentiality as it is a reflection of who knows whom, and who has established a basis for communication. In all, the process appears to be distinguished by informality and cooperation.

Another realm of resource goes beyond any single client and refers to the more general clusters of interrelationships that involve the elderly population in the southwest area. Some of these involve the churches and others such as the Golden Age Club are mutual aid groups. Here, the nature of helping is one of linking elderly clients into a broader resource network of activities, social involvement, and participation.

In the future staff plan to spend time contacting more neighborhood organizations, church groups, and to develop relationships with the business community. The process of tapping into support resources for the elderly is one that is dymamic. Continuing efforts need to be meie to establish new commuity ties and to maintain existing relationships in sustaining a network of infoimal support for the agency's clients. 


\section{Downtown Senior Center San Francisco, CA}

The "Tenderloin" is a central city district of old hotels and apartment buildings, porno shops and adult movies, and small shops and restaurants. It is situated amidst the affluence and pomp of San Francisco luxury hotels, central shopping district, and government buildings. Within the Tenderloin are same of San Francisco's most destitute residents--it is here that recent immigrants and refugees, addicts, prostitutes, and alcoholics, and many frail elderly have congregated due to the availability of low cost lodgings--typically the old hotels in this district have single-roam occupancy units. over 17,000 elderly San Franciscans reside here--many are in deteriorated physical condition, poor, and without close ties to family or friends.

In designing a program to serve all elderly San Franciscans the San Francisco Senior Center was located in one of the most prestigious, accessible areas of the city. It is housed in the Aquatic Park Maritime Museum Building on the elegant North Beach. Within this same vicinity are such attractions as Ghiradelli Square, Fisherman's Wharf, and Golden Gate Bridge. San Francisco Senior Center, established in 1946 , is the oldest private non-profit senior center in the country. Despite its goal to serve all the elderly in the city, however, the Center staff found that those poor, frail elderly from the Tenderloin, the largest concentration of elderly in the city, were not being well served. In an effort to reach out to these hard-to-reach elderly a small storefront Dowontown Branch Center was established in the heart of the Tenderloin in the mid-1960's. Today, several years later, this Downtown Senior Center is still in operation. Its $\$ 80,000$ annual budget cames from several sources--San Francisco Department of Public Health, federal AOA Title III and Title XX, and San Francisco Surplus Parking tax monies.

This Center is staffed by four professional social workers and six non-professional Senior Aides, or outreach workers. The Senior Aides are paid with DOL Senior Employment funds and, occasionally CEIA manpower funds. The Center also has an administrative asisistant, kitchen help and volunteers or paid staff who conduct classes and other program activities. The Center serves as an outpost for other agencies who provide individual services to this same elderly population. In the past year new outstations have been established away fram the Center to reach elderly not otherwise involved in Center programs and activities.

The Downtown Senior Center has its own regular schedule of activities for the central city elderly: it is an approved congregate meal site with nutritious hot lunches for up to 40 seniors; a weekly mini-market gives the members an opportunity to purchase low-priced fresh produce. The problems of the seniors who frequent the small storefront Center are initially attended to by professionals. They are then 
assigned to the Senior Aides who, under supervision of a social worker, each work with up to 30 clients. The Senior Aides visit the clients in their hames, and assist them in their efforts to stay in the cammanity.

The Center is an informal hospitable setting--a "hame away from home"-where many elderly spent time together, or in pleasant solitude with a book, craft or puzzle. The lounge is open from 9 to 4 weekdays; one or two regular participants sit near the door to greet those entering and to record their names. Same of the members meet weekly with staff to play the regular program and special events as well as the very popular special trips. Beyond these participatory roles little effort has been made to create a formal structure among the elderly members of the Center. The "members" of the Downtown Branch are also members of the Acquatic Park San Francisco Center and can participate in their programs and activities.

Having struggled along for some time with a cramped facility and minimal resources for space, staff, and innovating program endeavors, the Downtown Senior Center now looks to a bright future. Recent decisions in the North of Market Planning Area which encorpasses the Tenderloin, have provided the opportunity and auspices for the construction of a new, much larger downtown senior center in conjunction with the development of a small park and open space area adjacent to the new Airporter terminal. It is expected that when this new facility is available the Downtown Senior Center will plan a much greater role in serving all the elderly in this central city district. 
Thutual Aid and Self-Help Project, Centro del Barrio San Antonio, Texas

In the midst one of the poorest sections of San Antonio is located Centro del Barrio, whose intual Aid and Self-Help Project (MASH) serves the elderly of this langely Mexican-American neighborhood. Centro del Barrio was established in 1971 as a learning laboratory for social work students at our Lady of the Lake University, and receives funding from NIMH for the teaching-learning lab, from the city for a nutrition center and human services program, from the county for the youth program, and fram HUD for housing counseling. The MASH program is funded by a five-year grant (due to end in September 1980) from the Texas State Department of Human Resources to Centro del Barrio and to an evaluation research team from the University of Texas Health Sciences Center.

The :ASH program serves those who are 60 years old or older and live in two census tracts in San Antonio, with the aim of extending mutual aid and self-help among the elderly in the neighborhood. The program is staffed by a program coordinator, three social workers, a nurse, and a nurses aide in addition to the evaluation team. The major effort of the program has been to organizae elderly volunteers from the area into task forces to provide services to their neighbors. The home maintenance task force provides home repair, gardening and yard work, and housecleaning; the home health task force has groups which provide friendly visiting and telephone reassurance as well as self-help groups for those with arthritis, diabetes, and hypertension; and the social service task force provides information and assistance in acquiring social services; education, recreation and therapy classes; and programs to 'maintain and sustain' the volunteers.

Nuch of the mutual aid activity occurs in groups. For example, friendly visiting groups meet three times a week and go in pairs to visit people in the area. Hame repair and maintenance is also often carried out by a team. Volunteers also associate with each other regularly at the nearby nutrition center, at task force and advisory council meetings, and through activities planned for the volunteers as incentives. Over time, relationships among volunteers and with those they help often turn into friendship, increasing the network of ties and potential for additional matual aid within the neighborhood.

A major reason for the emphasis on direct service delivery in this program is the lack of public services due to low levels of human services funding within the city, county, and state. In addition, the elderly Mexican-American population is often unaware of available services, and prevented by the language barrier and lack of selfconfidence fram using those they do know about. Thus, a major service provided by MASH is information about services, help in filling out forms and an escort who will see the client through the process at the agency. 
If there is one lesson that this program teaches, it is the importance of allowing the program to develop slowly over a period of years. It has taken time for the elderly in the neighborhood to develop trust in the program through their contact with the IASH staff and with neighbors and friends who have received help from MASH. The elderly are now very active, they have developed their assertiveness and self-confidence, and through the body of the Advisory council appear to have developed to the point that they will be able to take a major role in continuing the program when the funding ceases or is reduced. 
Birth to Three

Eugene, Oregon

Eugene, Oregon is a small city situated near the southern tip of the Willamette Valley. Though the University of Oregon is a dominant force in the lifestyle and values of Eugene this area has long relied on agriculture and lumber for its economic base. Thus the Eugene metropolitan area has a diverse population ranging from those associated with the university faculty and student bodies to a working class of loggers and lumber mill workers. In social and public services Eugene has typically offered a full array of innovative programs.

Birth to Three is a private non-profit, grass-roots service organization in Eugene that was formed soley for the purpose of providing services to parents of infants and young children. It is staffed by four half-time workers who are all young women with the dual roles of service provider and mother of young children. The primary goal of Birth to Three is to pranote good parenting skills and positive attitudes toward child-rearing among parents of newborns and toddlers; conversely, it is to prevent child abuse or neglect and parental isolation, uncertainty, and exhaustion.

The agency meets this goal by offering a conprehensive array of support services to parents of newborns in Eugene and Springfield. These services include an informational poster detailing services and resources for parents of infants which is distributed through hospitals, birth clinics, and midwives to new mothers and posted in offices of pediatricians and other appropriate public places; outreach to new parents by B-3 staff through letters, phone calls, and hame visits; support groups for parents of newborns that are neighborhood based; peer counseling by the Birth to Three staff through phone and first person contacts, and parent education, through a newsletter and a series of special events on themes and topics of interest to parents.

Although Birth to Three is an independent organization whose sole function is to deliver these services, it receives its funding through an agency consortium or network which links it administratively and programatically to Family Counseling Services of Lane County. These two agencies, together with the Eugene Public Library, were funded by the National Center on Child Abuse and Neglect to develop a model program in child abuse prevention. The lead agency in this demonstration grant is Family Counseling which is thereby responsible for administration of the funds, monitoring the service program, and preparing reports and evaluations. Family counseling also has a program function in the overall network. A primary function is the assignment of one staff member to be Director of the New Parent Support Network Project, who is in turn responsible for providing professional consultation and support to the Birth to Three program. The Project Director meets biweekly with Birth to Three staff in this regard. Family counseling also provides direct services to parents of newborns 
and toddlers who have been referred by Birth to Three. The services provided range from hamemaker assistance with home management and child care training and assistance, to individual, couple, family or group therapy. The agency has used its grant funds to reduce or eliminate waiting time and reduce fees for the Birth to Three referrals. The Eugene Public Iibrary used its portions of the funds to develop an extensive collection of books and tapes on child development, parenting and other related topics.

In its efforts to fill the service gap for parents of young children, Birth to Three has drawn widely on the larger network serving children and families in Eugene. The organization now has linkages with the health services through hospitals, public health agencies, professionals (nurses, pediatricians, dentists), and with social service agencies (welfare, private organizations such as Catholic Charities, Laleche League), with schools and day care providers, and with local government bodies. Through its Board of Directors Birth to Three also taps the civic and business leaders of the cormunity.

Three different neighborhoods with high birth rates were selected for demonstration of the basic service--the new parent support groups. These neighborhoods vary on a number of dimensions such as demographic structure, income levels. In the first nine months of the program, 22 groups had been started by the staff. About 50 percent of the new mothers contacted participated in the groups which have an average size of 10-12 members. After 8 to 10 sessions under the guidance of a staff member, volunteers fram the group are sought to lead their own group, while staff then form groups with a new cohort of young parents.

The demonstration grant funding from HEW requires that local funding levels increase each year. For its second year, Birth to Three has succeeded in obtaining revenue sharing funds from Lane county, and has also approached local mental health agencies for funds. If possible, the staff would like to be able to obtain sufficient levels of funding to be able to add two additional full-time staff positions to permit more extensive outreach and follow-up for hard-to-reach and resistant parents. The staff also sees a need to concentrate on providing more support, training, and guidance to the volunteer group leaders. 
Neighborhood Options in Child Care
Portland, Oregon

Often when a need is identified the first response of social service planners is to look for outside resources which can be used to develop a new program. The Neighborhood options for Child Care Project. (NOCC) is an exarple of an altemative approach. In 1975, when the closure of same day care centers in Portland, Oregon pushed the chronic need for day care into the critical category, the Anerican Friends Service committee decided to look for a neighborhood which could be helped to meet its child care needs by using existing resources-chiefly the informal system of family day care and child care exchanges. While some external resources would be needed at first to help the cammity mobilize to provide child care, the aim of the project was to eventually withdraw these resources, leaving a self-sustaining day care system. AFSC's sponsorship of the project ended in June, 1979. The NOCC office was closed at this time but several of the programs continue to function.

A neighborhood was chosen which met same preselected criteria: racial and economic mix; demonstrated need for child care based on a large number of women in the labor force and a lack of child care services, and evidence of neighborhood stability and local resources. The area is a blue collar neigiborhood of modest, well-maintained, single family hames, 70 percent of which are owner-occupied. Ten percent of the residents are black and the percentage is increasing since this neighborhood is on the edge of the main concentration of blacks in the city. Originally the area was strongly Catholic, primarily German and Irish in ethnic backgrourd, but this is no longer as typical. The median income is below the city average. Forty-one percent of the neighborhood's women are in the workforce.

The Catholic Church and school and the public schools are major institutions for families in the neighborhood. "lany of the parents attended these same schools. In addition, there is a large park with a community center. There is an active neighborhood association with an interest in child care. The major social service agencies in the area are a Catholic residential treatment center for delinquent young women and a family counseling agency. The family counseling agency is located in an old house on a busy street and offered space to the NOCC project.

While this area continued to be the main target of NOCC's efforts, the boundaries for "elibibility" never needed to be clearly drawn and the program eventually extended its services into an entire quadrant of the city. The program was run by a steering canmittee composed of local AFSC representatives and some local day care professionals and experts in child care. Once the neighborhood was selected, local residents were added to the committee. As the project developed, the "outside" professionals were replaced by local peoplenany of whom are participants in the various child care options developed by the project. 
The NOCC project was originally staffed in 1975 by one professional and an assistant, both of whom were full-time. As funds were reduced, the staff was cut back to two half-time workers.

Fram the beginning, the project was more committed to a neighborhelping-neighbor approach than to any specific form of child care. Their initial activities therefore were intended to identify the types of child care activities already going on in the neighborhood, key figures in these activities and needs as perceived by local residents. A door-to-door canvass of part of the neighborhood was conducted to inform the neighborhood of the existence of the project and learn more about needs. A flyer which asked "CHIID CARE-can you give it, do you need it?" was posted in stores, laundramats, conmunity centers and distributed through school and church bulletins. Word of mouth leads were followed up and coffees were held in neighborhood homes to talk about child care. Hames which were known to be providing family day care were visited.

Visits to the day care providers showed that they were isolated and could benefit from association with other day care givers. They also had specific needs for clothing and equipment. Increasing visibility was bringing the project inquiries fram parents who were looking for child care. Several mothers were also interested in starting a play group. These became the major activities of the project: organization of a day care providers association; procurement and disbursement of resources for family day homes; information and referral for parents looking for day care and a variety of services aimed at families who were looking for occasional care and enrichment activities for their children.

In some instances the staff has organized local residents to provide various forms of child care, in others they have provided same services themselves. Both forms of intervention are based on an understanding of how all camponents of the neighborhood's child care system function and interrelate so that the interventions can enhance this system rather than duplicating or interfering with it. The Camittee has also intended originally to provide more indirect support to the central figures in the neighborhood day care system but decided that the approaches mentioned above were more conpatible with local needs and staff preferences. They handed over the direct service activities to local residents as they neared the end of their funding.

The most general function that NOCC served was as a rallying point, resource base and focus for child care concerns in this area. It was seen as "the place to go" with questions, concerns, or ideas about child care by local residents and outside agencies alike. Without this base, day care concerns may lose their visibility and saliency, new programs may not be generated and there is no one to provide a matchmaking function. 


\section{SCAN Volunteer Services} Arkansas

Arkansas is the site of an innovative approach to dealing with child abuse, SCAN (Suspected Child Abuse and Neglect) Volunteer Services, Inc. SCAN is a private, non-profit organization which contracts with Arkansas Social Services to handle all cases of abuse in families with children 12 years of age and under, in 12 counties in Arkansas. SCAN has grown from an initial informal volunteer service with six volunteers and six cases located in Pulaski County, to a 12-county program with over 50 staff persons, about 300 laytherapists (volunteers), and from no budget to one of over $\$ 700,000$ most of which is Title XX funding.

The program has a state central office which includes the Executive Director, Assistant Director, three Field Coordinators, and administrative staff. The three Field coordinators supervise and provide support to the staff of the 12 county programs. Each county has a small staff of paid professionals and a number of volunteers trained to be "lay therapists" to families suspected of child abuse. For purposes of this study we focused on the J. County program in a small city not far from Little Rock. The J. County SCAN program, opened in 1973, is located in donated office space in an old hospital. It had a budget in 1978-79 of $\$ 47,000$, which covered staff salaries and $\$ 50$ monthly reimbursements for the volunteer lay therapists. It has a small staff of paid professionals: a Director, an Assistant Director, an Evaluator (currently, part-time), and a secretary. There is a volunteer staff of about 15 persons, plus several student nurses who, as part of their training, each serve as lay therapists to one family. The program serves up to 60 families. The local program is assisted in its planning, administration, and evaluation efforts by one of the field coordinators from the state office. The state and local offices are closely linked by a WATS line, and by the availability of the field coordinator for support in decision-making.

The primary "treatment" approach of the SCAN program is the "lay therapists" who are the "primary caseworkers" in the homes of the abusive families. The entire paid staff of SCAN see their fundamental responsibility to be to provide the necessary support and supervision to the volunteers who are directly working with families.

The volunteers or lay therapists can expect to spend up to 20 hours a week working with these difficult families, to be on call 24 hours a day, and to make irmediate responses to emergency calls fram their families. Initially, daily contact is recommended with involvement in meeting all the obvious concrete needs of the family; at the second level, the lay therapist views the case as stabilized but continues to visit or call the family two or three times a week, at this point the family is expected to take more responsibility for 
meeting their own needs (i. e. to draw on community resources and services); at stage 3, a "case" is considered closed and the interaction between lay therapist and client is no longer required (but deep, personal bonds have normally developed and friendships persist).

The "lay therapist" approach is a hame-based intervention. It takes place in the hames of the clients. The therapist cames to the hame as a "friend" and focuses on positive interactions. Therapists are often accepted by the clients more readily than a professional because they have time to build up a relationship based on trust. The client soon learns that the therapist helps in concrete ways and does not force the client to make decisions or take initiatives that they are not ready for. The therapists do not represent authority; they rarely ever are used to present testimony regarding a client in court, and they can assure the clients that their involvement with them is totally voluntary.

SCAN uses Parents Anonymous as a strong parallel treatment. Other abusive parents act as a peer group who press the individual or couple to get involved in solving their parenting problems. P.A. can also provide a positive support system to individuals who have become very isolated or are tied into negative social relationships. In J. County the staff of SCAN serve as advisors and sponsors to the local P.A. chapter.

The SCAN Volunteer Services plans to continue to expand within the State of Arkansas, at least two counties a year and to "package" the SCAN program for a wider audience on a national level, acting as consultants to assist other localities in developing SCAN programs. SCAN staff also believe that the "lay therapist," or equal-partner role of volunteers in social service delivery can be used in other program areas and with other populations. 


\section{Abused Wanen's Network Seattle, Washington}

Seattle probably has a more camplete array of services for battered women than many other large metropolitan areas. Services include temporary shelters, legal aid, and a special prosecution unit in the City Attorney's office. There are also counseling agencies for long-term therapy, and the police and a Crisis Clinic for direct intervention in dangerous or violent situations. There was still a need, however, to provide an information and referral service with an outreach capacity to help women in crises link up with the available services and services aimed specifically at helping a woman build a new life for herself once she has decided to leave the abusive situation. It is common for wamen who do not have such support to return to the abusive relationship once the crisis period is over and more long-term problems such as loneliness and financial security set in.

The Abused Women's Network is sponsored by the Wamen's Institute, a non-profit, feminist-oriented center which offers individual and group counselling, workshops, and courses in assertiveness training and other topics of interest to women. The Institute also does research and evaluation projects on feminist topics. Tho of the directors of the Institute are also faculty members of the school of Social work, University of Washington.

The feminist orientation of the program leads them to view the problems of battered women as social ones, cased, in part, by sex role definitions. The feminist perspective also influences the way services are designed. They are intended to help battered women develop a sense of self-esteem and an independent lifestyle, and learn to trust and rely upon other women. "Women helping wanen" is the philosophy of the program.

Headquartered at the Institute, an old house near the University of Washington, the Network has been in existence since 1976. It employs a part-time director, a full-time assistant director, and two full-time outreach workers. Funding has been a continuous problem and funds (in the form of staff positions) have been provided by CETA, the Work Incentive Program of Public Assistance, private foundation money and donated time and overhead fram the Wamen's Institute.

Services consist of support groups led by trained group leaders, information and referral, crisis intervention, and individual casework. The staff has also been involved in training other professionals to work with this population and advocacy efforts on their behalf with other elements of the service system such as welfare and the police.

While battered women require an array of professional services, the program is finding it increasingly possible to involve battered wamen in matual helping activities. Some women who met in the group 
have set up cooperative living arrangements. Other wamen who were helped by the Network to establish new lives are now offering to help women in crisis. A survey of participants revealed that a number of them maintain supportive contacts with each other long after they have ceased to participate in the frogram. New group leaders have been trained and have begun to set up groups in various sections of the city. Eventually the program staff would like to see a city-wide, neighborhood based program sponsored by a "mainstream" agency such as the YWCA. 


\author{
Family life Center \\ North Shore Child Guidance Center \\ Manhassett, N.Y.
}

The North Shore Child Guidance Center with its various clinics and programs is located in Nassau County, on Long Island, just a few miles from the outer linits of New York City. Nassau County is one of the most affluent suburban areas in the country, including towns such as Port Washington, Great Neck, Sands Point, Roslyn, and old Westbury. Upon closer inspection, however, it becomes apparent that Nassau County is a patchwork of villages, townships, and neighborhoods of great diversity in terms of wealth, ethnicity, and values. Some areas are conservative white, blue-collar working-class suburbs. Others are suburban ghettoes with a large percentage of poor racial minorities, public housing projects and substandard housing. These are pockets within the larger service area of middle to upper class white communities. The North Shore Child Guidance Center serves children, youth, and families in seven Nassau County suburbs. It is a communitybased, non-profit mental health facility with a professional clinical staff, and a corps of volunteer supporters (North Shore Child Guidance Association), with offices in Manhassett, Roslyn Heights, and westbury. These offices are centrally located so as to serve several of the poor and working class neighborhoods. The agency's treatment programs are funded by Nassau County and New York State.

The Center has undergone a thorough reorganization and revitalization since 1975 under the guidance of a new Executive Director and its Board of Directors. While clinical services retain a primary role, the reorganization has led to greater emphasis on brief therapy, early intervention and assessments, and team approaches so that more people are being treated by the professional staff of psychiatrists, psychologists, and social workers. Other new developments involve expanded community education programs, advocacy projects to increase services to unserved and underserved children and families, and a nationally acclaimed non-clinical program with an emphasis on discovering and encouraging natural helping networks, and developing informal support or self-help networks for individuals and families with special needs, the Family Iife Center.

With a small grant from the North Henpsted Commuity Development Fund a part-time social worker was hired to coordinate the Family life Center (FLC) development. Since the programs rely heavily on a canbination of professional and volunteer skills to assist or launch groups designed to support families in special life situations and crises, the first tasks of the coordinator were to identify and train skilled volunteers to assist in the identification and activation of conmunity informal support systems, and in the provision of the FLC services. In the first full program year, Sept. 178 to June 179, she worked with 8-10 volunteers. They were given a rigorous orientation to the agency, 
to the Family Life Center concepts, and to basic social work skills, and were then given "work assignments" based on their own experiences, talents, and interests.

Initially volunteers were used primarily to provide non-clinical back-up services for clinical programs-tutoring adolescents in treatment who were also having problems keeping up in school, providing escort services to children of working parents needing transportation to clinic appointments, providing financial management counselling to individuals or couples that therapists felt needed this added assistance. Two hours each week were devoted to professional supervision and guidance.

The first year-and-a-half of the Family Life Center has been devoted to experimenting with the various camponents of the program: selection, training, and supervising volunteers, making contacts with, and presentations to, cormunity groups, developing specific programs (around single parents, and mother of infants, for example); defining appropriate relationships within the overall North Shore organization.

One of the full-time psychiatric social workers volunteered one year of her own time to developing a support system for suburban North Shore single parents. Under the auspices of Family Life Center the Single Parent Action Network (SPAN) seeks to provide a full range of non-clinical services to single parents. These 'services' rely heavily on the efforts of the single parents to help each other, with a professional available to provide technical support and agency tieins for the network. Parents are 'recruited' through comminity meetings and workshops on the dilemmas of single parents. The SPAN program also relies on volunteer single parents to act as peer problem managers and group facilitators, to edit the newsletter, and to participate in planning and coordinating the program. Those recruited to these vital roles are persons who throughout the workshops and discussion groups demonstrated their capability to reach out and be supportive to others, and who demonstrated positive problemsolving skills. The SPAN program represents the Family Life Center conmitment to value and support lay caregivers through a careful balance of professional and self-help elements. The SPAN program was funded to go into full operation in the fall of 1979.

As the non-clinical programs evolve, particularly the Family Life Center, the North Shore agency expects to have two parallel service organizations, one clinical, the other non-clinical. The Family life Center would house a number of non-clinical programs mach in the manner of consultation and education programs of a traditional community mental health center; it would reach out to those families in the community whose needs are for social support and resources rather than (or in addition to) individual therapy. The strengths of both the clinical and the non-clinical programs are expected to grow from their close ties and the eventual benefit to the client of receiving appropriate family services. 
New Opeions for the Disabled:

Independent Living in Houston

Houston has experienced unbridled growth in the last decade with population increasing an average of 20 percent per year. Now the fifth largest city in the United States, the city's 1.5 million residents are scattered over 500 square miles. Jobs are plentiful, the econany boaming and scme estimate that nearly 1600 people are moving into the area per week! iuch of the prosperity can be attributed to the oil business; Houston is a major world center for the oil tool trade.

Like any other major city, living in Houston is inviting to some and problematic for others. For the physically disabled, a housing market where demand outstrips supply and a transportation system which only poorly accamodates special needs for mobility are major obstacles to successful integration into an urban environment. A major force in promoting independent living opportunitites for the disabled is the New Options project which is affiliated with The Texas Institute for Rehabilitation and Research (TIRR).

The New Options program was a three year research and demonstration project focussing on helping severely disabled people bridge the gap into community living and into established housing clusters. New Options was initiated in June of 1976, relying in part on funds from TIRR for planning and initial operation. In October of 1976, the project was awarded a $R$ \& D grant from the Rehabilitation Services Administration. Other funding comes from fee-for-service payments through the Texas Rehabilitation Commission. The Program provides an intensive leaming experience directed to integrating the severely disabled into the community. Goals of project participants include establishing independent living arrangements, exploring educational and vocational opportunities, enhancing skills of daily living and expanding social participation in the mainstream of society.

To carry out these goals, the program is designed as a six-week, live-in training experience for approximately 8-10 medically staile, severely disabled individuals. In the earller stages of the project, individuals with spinal cord injuries were more often served; now the client population is roughly split between spinal cord and developmental disabilities. Clients may be of all ages (youngest was 18, oldest 53) and the program is co-educational.

New Options staff includes a project director, research director, a social worker, a functional skills advisor, a part-time vocational counselor, staff associate coordinator, secretary and research assistant and includes a mix of both disabled and able bodied persons. Although the project director has overall responsiblity for the program, management is informal and decentralized. Staff coordination is achieved through informal day to day contacts and weekly meetings devoted to case review. Relationships with the TIRR, of which the New 
Options project is one arm, are along departmental lines although staff serve on various committees within the Institute. New Options is, however, perceived as being separate and spart from other TIRR programs and this has allowed staff the flexibility to innovate and change as the project progresses.

Clients are moved directly into the training aspects of the program and group interaction is encouraged. Weekly counseling sessions during the six weeks provide an opportunity to work on individual problem solving and planning for the future. The training component is the core of the program and involves a series of 11 modules centering on independent living skills, including: a) living arrangements; b) educational/vocational training and employment;

c) transportation; d) functional skills; e) meeting medical needs; f) sexual relationships; g) managing financial affairs; h) managing attendants and budgeting energy; i) developing social skills and assertiveness; j) consumer affairs; and $k$ ) use of leisure time. Modules run concurrently meeting once per week for a total of about 30 hours of planned activities. Training methods include classroom instruction and group discussions, field trips and use of outside resource persons called staff associates. The training component is designed to increase awareness of available options in the comminity, to offer practical skills in personal matters and to informally link up clients with individuals in the community through the use of staff associates.

\section{Staff Associates - Links to the Comminity}

A central part of pramoting conmunity integration of clients involves the use of non-professional resource persons in the community. These individuals, usually disabled, are selectively recruited and paid for their special skill in one or more areas within the series of training modules. The job of identification and recruitment falls on the staff associate coordinator, herself a disabled individual with a wide range of contacts within the handicapped community. The coordinator goes about identifying individuals in several ways: a roster is kept of people who have served in the past, they are contacted to see whether they are interested in doing a training module or if they know of sameone else; sometimes the "grapevine" is set in motion by numerous phone calls; announcements are advertised; sametimes the coordinator knows of sameone through her network. Individuals are recruited because they have a special knowledge or skills in one of the training areas of independent living. For example, one individual was recruited for the module on living arrangements because he had experienced the gamut of possible living situations. He had lived with family members, in nursing homes, apartment clusters and had ultimately set up his own cooperative living arrangement. As a result, he had unique insights into the problems and possibilities associated with each type of arrangement. Another individual was recruited for a session on performance of physical tasks. She was a quadraplegic with severe limitations in physical mobility but had successfully managed a law practice by learning how to run several office machines 
specially modified for her abilities. Not only do staff associates have concrete skills they are able to teach disabled clients, but they also serve as role models demonstrating a life-style and an approach to living independently. They also serve as informal contact brokers for clients suggesting individuals or agencies in the community that may be helpful to clients.

Staff associates are expected to make a comittment for at least one six week cycle of clients. This usually involves around five or six training sessions. Staff associates are utilized to teach seven of the training modules and thus provide the majority of independent living training clients receive. Associates who play a major role in leading a training module are paid $\$ 25$ per session; others who act as co-facilitators are paid less. The project made a deliberate choice to pay associates. On the one hand, the payment was a statement about the important contribution associates were making. On the other hand, by paying associates, project staff could establish clear expectations about what they wanted associates to do: if associates were doing training as a favor, the project felt they would have to take what was offered. The average time that associates continue is about six montins. Same stay "forever" and really enjoy the process. Others just want to try it out and see what training is like. sanetimes associates want to drop out for awhile as personal business may have created new demands but later return.

\section{Community Networks}

To a large extent, the New Options program works closely with several networks among the disabled in Houston. Same of these networks are very informal, as, for example, those that grow up around the process of finding or living within barrier-free living arrangements or nursing hames. Many also stem fram cammon attendance in service programs or the University of Houston. Other networks are more formalized. The rajor example here is the Coalition for Barrier Free living which serves as a link to the politically active and vocal segment of the disabled comminity as well as providing a point of association for those less politically inclined.

These networks serve an important function not only in pramoting broader social participation but in aiding the adjustment of individual disabled persons. The day to day operations and the ultimate success of the New Options Program involves a process of both fostering and drawing from such networks to pramote opportunities for clients to became integrated into the community. 


\section{Soncma County Citizen Advocacy Santa Rosa, Calif.}

Within the last decade, Santa Rosa has had to absorb an influx of population brought in by the developient of mobile home parks, and adult and retirement communities. The largest city in Sonama county and only an hour and a half drive north of San Francisco, Santa Rosa is surrounded by orchards, vineyards and sprawling ranchiands. Just east of Santa Rosa lies Sonoma State Hospital, housing nearly 2000 mentally retarded residents served by almost an equal number of staff. Beginning in the lat 1960 's, the progressive closing of Sonama State and nearby Napa and Mendocino hospitals moved a significant number of developmentally disabled individuals into the community. Now nearly 12,000 disabled individuals live in Sonama county whether in group care hames, with families, or indedpendently.

In 1973 a small volunteer advocacy project was initiated by parents, professionals, and special education faculty at the Foundation for Educational Development at Sonoma State College in Santa Rosa. The project was inspired by the citizen advocate model pioneered by Wolf wolfensberger who proposed that citizens in the community could be matched with developmentally disabled individuals to form a companionship in which citizens would provide support and advocacy for the disabled individual to aid them in the everyday tasks of living in the community. A year later, the project had grown and incoroporated as a separate agency with a cammunity board of directors; Sonoma County Citizen Advocacy. In the beginning, the agency's focus was on finding and training individuals in the conmunity, developing one-to-ane relationships between "advocates" and "proteges," and providing community education to foster awareness of the program's aims.

Over the next three years, the agency grew in scope of services as various sources of funding were found to hire full-time staff. In 1977, the basis for a comprehensive personal advocacy system was in place. Funding came fram diversified sources and usualiy in limited amounts now the agency has five different sources to fund a staff of 11 including United Way, County Revenue Sharing, State Protection and Advocacy monies, CEIA and the federal Developmental Disabilities office in HEw. The agency has grown in complexity now operating from three different offices, two in Santa Rose and one at Sonama State Hospital.

The personal advocacy system is camprised of four major parts: citizen advocacy, consumer rights, self-advocacy and parent-advocacy. The citizen advocacy component retains its earlier objectives of providing for the personal and advocacy needs of disabled individuals through one-to-ane matches between citizen volunteers and developmentally disabled persons but has grown in size, coverage, and sophistication. Now with more than a hundred active volunteers, the component functions in the community and in Sonama State Hospital to 
link disabled individuals with personal advocates. As the longest standing service of the agency, the process of making successful matches has been refined from experience and has pointed to the need for other advocacy services. The consumer rights camponent was added later to deal with the need to inform disabled individuals, their families and other service providers of the legal, educational and service rights that have been established by law. A representative provides paralegal counseling and advocacy often working with other agencies to ensure the appropriateness and accessibility of mandated services. The Self Advocacy program provides counseling, assertiveness training and group meetings to assist disabled persons to advocate for themselves. The program operates in conjunction with People First of Sonama County and has several groups involving about 20 to 30 individuals living in the camminity and about 50 who reside in the state hospital. Beginning in 1977, the Parent Advocacy camponent was started. The program was originally conceived as a pilot parent program in which parents of recently identified children with a developmental disability would be matched with other parents who had gone through a similar experience and were willing and able to provide support and counsel to new parents in adjusting to new demands. The concept has been since expanded to include a more comprehensive view of parent advocacy incorparating both an emphasis on parents helping parents as well as parent's role in advocating in the community for the larger needs of the developmentally disabled population in Sonama County. This led to the creation of a Parents Advocacy Council which grew out of the existing networks among parents in the community and has come to create and embody other networks of mutual aid and advocacy.

The four camponents of the personal advocacy system provide separate and complimentary services in promoting the rights of the disabled and assuring their support in the community. While separately staffed, the programs are conceptually and operationally integrated with informal referrals and information flow augmenting the ability of each to provide services. The agency also gives emphasis to community education activities to provide the awareness and understanding of the wider population about the needs and rights of developmentally disabled individuals in Sonoma County. overall, Citizen's Advocacy has effectively articulated an integrated system of services which incorporates clients and cormunity in the concept of advocacy. 


\author{
Pilot Parents Project \\ inlltonomah County, Oregon
}

Finding out that your child is mentally retarded can be a lonely experience. Whether the diagnosis is made at birth or dawns more slowly as the child grows, many parents report feelings of isolation, as well as shock, grief, and denial. Few parents are likely to have other families who have a retarded child in their immediate circle of friends and relatives.

When parents of retarded childred to get together, often as a result of participation in programs for their children, they find a special kind of support in sharing their experiences with others who have "been there" too. They wish that they could have had this support earlier when they were dealing with the initial emotional reactions to their retarded child and needed more information about daily care and available services.

Out of these concerns, a group of parents in ihltnomah County, Oregon, who met when they enrolled their children in a special preschool program, decided to organize a parents' group. As one activity of the group, they decided to offer themselves to new parents as friends and guides. In 1975, they approached the Multnomah Association for Retarded Citizens (MARC) for sponsorship and developed a program called Pilot Parents.

As the program developed with the input from the professional staff at MARC, the parents became aware of similar programs in other parts of the country and adopted aspects of these programs. While the parents' experiences, the basis of what they have to offer to new parents, are influenced by the specific services available in this county, there is very little about the program that is specific to the locality. What seems to be much more important for its success is an enthusiastic group of parents willing to form the core of the group.

The Pilot Parent Program in Multnomah County is run by a group of approximately 16 fathers and mothers of retarded children. A halftime social worker in the MARC office provides assistance to the group in organizing the program, recruiting and training new Pilot Parents, and managing the service. Same parents learn of the program through publicity in the media, or friends and acquaintances, but the main source of referrals is doctors, nurses, and professionais wio mignt came in contact with families with retarded children. Requests for services are handled by the social worker who matches the new parents with a Pilot Parent. It is up to the Pilot Parent to make the initial contact with a new parent and to decide what is needed. Most contacts are relatively brief (1-3 visits or phone calls) and deal with new parents' needs for emotional support and information about services. 
One Pilot Parent described a "typical" contact as going through three phases. "Uppermost is talking about the child. They want to know all about my child and then they talk about theirs. The second thing is the emotional. What they went through when they were told. Then they finally get to services, the future."

Currently there are approximately 10 active Pilot Parents and referrals average 1-3 per month. The challenge facing the program is to continue to recruit new Pilot Parents, and to make the program more widely known in the community in order to be sure that all parents who might want to make use of the service hear of it, while maintaining the parent-run nature of the program. 


\title{
REP Project \\ Portland, Oregon
}

\begin{abstract}
"I have called a service agency on three different occasions with the same problem and gotten three different answers. On one occasion they'll say, 'Yes, we work with that.' On another, 'No.' And a third time, 'I'll have to check.' You have to sit down and ask yourself, 'We have handicapped people being integrated into the community and if anybody needs these services, they do. How the hell are they going to sort out the ambiguities, the inconsistencies and learn to utilize these services?' Right now anyway, that's basically what the volunteer does." (Jim Staats, REP Project Coordinator)
\end{abstract}

This is a succinct statement of the problem the REP Project was intended to address. The enphasis on community living for mentally and physically handicapped people has led to a plethora of services intended to make this adjustment easier. But the handicapped person may not always be able to gain access to them. There may also be instances when the handicapped person perceived his/her interests to be contrary to the actions being taken on his/her behalf. The REP Project made personal REPresentatives availble to handicapped persons to help them negotiate with this system and protect their interests.

Funded as a demonstration in June 1978, by ACTION, which had sponsored a similar program in Harrisburg, Pa., the Oregon REP program was channeled through People First, a state-wide peer support and advocacy program for mentally retarded adults. The program was terminated in September, 1979, midway through its 3-year demonstration period.

The program had a state-wide director and three coordinators serving the three areas with the largest concentrations of handicapped persons in the state-Salem, Eugene and Portland. The Portland office had a part-time assistant.

While this project was based on the use of volunteers, it is important to understand the ways in which it departed from more traditional volunteer services for the handicapped. In the first place, handicapped persons were volunteers as well as users, reflecting the philosophy of People First. Secondly, it was neither a friendship nor citizen advocacy program. The volunteers, called REPs, were expected to have specific skills which they used to help the users of the service solve a specific problem. The relationship was terminated when the problem was solved. If the user called back with a new problem, he/she would most likely be assigned to a different volunteer, depending on the expertise required. Finally, the REP Project had a commitment to changing the service system as well as to meeting the specific needs of users of the service. The staff saw 
the individual problems brought to them by the handicapped as illuminative of difficulties in the system and took action at the system level as well as the individual level. Part of the goal of the project was to show where the community is failing to provide the necessary services to allow the handicapped to live independently. 


\section{Coping Skills Program, Transitional Living Services Syracuse, New York}

Transitional Living Services (TIS) was founded in 1974 to provide group and apartment housing, training in daily living skills, and follow-up support for mentally and developmentally disabled clients in transition from institutions to the cormunity. The voluntary, nonprofit agency is located in Syracuse, New York and funded by United Way and by federal, state, and local grants and contracts. The agency originated through the cooperation and planning of a number of agencies, including the Onondaga County Department of Mental Health, Hutchings Psychiatric Center, and United Way, and continues to work closely with them. The staff includes four administrators, two social workers, a housing staff of 30, two follow-up workers and two in the coping skills program.

While the program began as a residential program centered in six apartment complexes and large houses providing training that would allow clients to move out into the community on their own within a reasonably short time, it has developed into a broader psycho-social rehabilitation program which also involves a mobile team of staff working in the community. The team includes follow-up workers who work with the clients on a one-to-one basis while they are in TLS housing, help them find housing in the community when they are ready to move on, and continue to help them cope with problems and retain what they learned at TLS after they leave.

The second part of the mobile team consists of two staff who provide opportunities for the clients to take part in activities in the surrounding community and to develop social networks. This carmonent, known as the coping skills program, is the focus of our study. The coping skills staff try in a variety of ways to make connections between the clients and infomal helping resources in the comminity. This may involve developing situations where clients mingle with community people; for example, one of the staff and same of the clients have begun to volunteer to cook dinner one night a week at a local cafe run entirely by volunteers, where clients and cafe 'regulars' from the conmunity mingle at dinner. In addition to helping clients feel comfortable in existing cammanity settings, they create new situations where clients and community can meet, such as sponsoring a dance with music by a local wamen's band and organizing a softball team that plays other teams in the community. They also encourage the clients to develop relationships with other clients, and to take part individually or in small groups in ongoing activities in the comminity.

Since our visit in June 1979, the coping skills program has received more support both within the agency and from the funding source. Two new staff have been added, and the two follow-up workers are being integrated into the program. With the support of the agency, the coping skills staff are moving out into the community to deal with 
former mental patients in general, not just with TIS clients. The program has received recognition from New York State as a model for community support and the staff have been involved in training throughout the state. 
Ajo Program

La Frontera Inc., Pima County, Arizona

The mental health program in Ajo, a small, company-owned mining town in Pima County, 127 miles from Tucson, Arizona is within the catchment area of La Frontera Inc., the outpatient arm of the Tucson Southern Counties Mental Health Services, Inc. Ajo has a population of about 6500. Only two small towns lie between it and Tucson. It is surrounded by hot, arid desert country, much of it part of the Papago Indian reservation and the U.S. Air Force bambing range. Its location acts to give residents a sense of isolation but also brings about a high degree of interaction and interdependence. Approximately half of the residents belong to minority ethnic groups, of which about 40 percent are Mexican-American. There is an extensive network of clubs, associations, and many churches. Since the men at all socio-econamic levels work very long hours at the mine, the women orm and manage most of the small businesses and are prominent in the leisure time activities. The Phelps Dodge Copper Mining Carpany owns most of the land in the town, operates the hospital and the local tavern and owns the housing with it allocates according to position in the mine hierarchy. It tolerates the mental health service but has not been active in promoting it.

The major program of La Frontera centers in South Tucson. Established in 1967, it has a total budget of about $\$ 2$ million derived from federal (NIMH) state, local, and private sources. Dr. Neliba Chavez, the director, is nationally known for her work in mental health with Mexican-Americans who, with other minorities, are of special concern to the organization. In order to provide them with the mental health services they need, extensive use is made of paraprofessionals in all its programs, and professional staff are chosen for their sensitivity and ability to reach out, as well as for their training. The agency offers a range of services in and outside its offices. It has provided mental health services in Ajo since 1975.

Ia Frontera initiated the mental health service after a study, carmissioned by the head of Nursing Service of Pima County, which sought to find ways in which the resident public health nurse might improve mental health services in the community. At that time anyone who evidenced problems of non-conformity was referred either to the judicial system or to the mental hospital and clinic facilities in Tucson. The Nursing Service study was conducted by a member of a private Nurse Consultant firm, who initially spent some time in Ajo, observing the life of the town as it flowed through the central square, and reading the local paper, noting the recurring names of the store owners, and the leaders of the numberous clubs and associations that made up the social networks. Insofar as possible, she included the public health nurse in her studies and gradually assisted her in discovering what kinds of services were needed which she might provide 
and how she could make use of the extensive and activie networks which already existed.

Working with community leadership several programs were started such as a drop-in day-care center and a listening clinic which provides counselling by telephone. When the consultant's work was campleted, La Frontera began to offer service to Ajo as part of its expansion into the wider catchment area.

A resident of the Mexican American Cammunity is now the mental health worker, located in the same building as other health and welfare services. She has worked here since the inception of the program in 1975. She sees some patients herself but works largely to assure them the support of the community networks. A psychiatrist and psychologist visit every three weeks to see patients and to confer with her on their management.

An alcoholism program was initiated about two years ago by Ia Frontera as an added mental health service. The staff of that program consists of a man with an MSW and one with a BA in Anthropology. They have spent most of their time to date sensitizing the entire commuity to the problem of alcoholism and providing an educational program for influential citizens and professional people. 
Comminity Network Development Project

Florida Mental Health Inst., Tampa, Florida

Along with St. Petersburg and Clearwater, Tampa is part of a two county metropolis on the central west coast of Florida. In many ways a natural garden spot, the area has an abundance of water whether from the Tampa Bay, the Gulf of Mexico, the many rivers and small lakes, the summer thunderstoms or the general high humidity. Tampa spreads north and east of the Bay Area with the downtown business district now situated to the south of the new suburiban developments that have reached North in the last several decades.

The Florida Mental Health Institute (FMHI) is located in the northern part of Tampa near several large state insitutions, notably the campus of Florida State University. As part of Florida's Department of Health and Rehabilitation Services, the Institute serves as the central research and program development arm for the state's mental health services and also provides statewide consultation and training services to agencies. Innovative clinical treatment projects are undertaken in three major sections of FMHI and include Adult, Gerontology and Children's programs. Each section has a number of distinct projects serving specific populations that comprise as a whole a generally more difficult type of clientele with more severe problems.

As one of four projects within the Adult program section tocusing on ex-mental hospital patients, the Community Network Development Project is perhaps unique among all the treatment programs at FMHI in stressing peer support, self-help and community based services as the primary focus of treatment. In contrast to other projects which generally emphasize structured residential or day treatment with an intensive program of clinical services, the CND project serves a population in the comminity, incorporates a committment to peer versus professional support, and structures opportunities for project participants to assume responsiblitites for helping each other. A core element of this shift in philosophy and practice is a respect for the abilities of project members to take responsibility both for the direction of the program as well as for helping other members as problems arise.

The CND project knits together several key themes in creating a structure of organization and procedures for involving participants in project activities. The project is founded on the recognition that when most people experience stress they look to family, friends, relatives or neighbors for support in coping and making adjustments. Such a support system is critical to mental health and is based on the personal network each individual has available. This is no less true for those with mental or emotional disturbances but the important difference lies in the general finding that such individuals have rather more limited personal networks and thus do not have well 
functioning support systems. Realizing the values of support provided by peers who have experienced similar circumstances, the project also incorporates the principles of self-help as a means to pramote the support systems of members.

The basis of the CND project's efforts centers on a network of mutual aid and self-help among nearly 100 ex-mental patients living within the Tampa and St. Petersburg areas. The overall network has been subdivided into four local networks based on geographical clustering of members so as to increase the accessibility of members to regularly scheduled network activities. Sub-networks are based in North, South and East Tampa and the St. Petersburg area and range in size fron about 10 to 40 active members. The CND project engages members in several different types of activities to pramote social interaction and develop supportive relationships. Regularly scheduled area meetings provide an opportunity for members within a particular area to get to know each other on an informal basis to plan activities and to participate in social and recreational activities. Periodic general network meetings, a newsletter and a membership directory provide vehicles for keeping in touch with the whole network. Member organized fundraising activities such as car washes, dances and bake sales provide ways to finance more expensive outings and events. The project also provides educational activities through skill training materials and programs. Cammunity Living Skill training modules are made available to members and include such topics as job hunting, problem solving and others. Project services also include crisis support, advocacy, infonmation and referral to community resources. The CND project has also assisted members to develop and run a cooperative living facility in cooperation with a halfway house, Boley Manor in St. Petersburg.

Staffing to help organize and maintain the network follows a pattern that places an emphasis on peer helping roles, called Community Area Managers (CAM), in providing counseling, activities, organization and maintaing liaison between members and professional staff in each geographical area. Each CAM is supervised and provided training, consultation and support by a Staff Area Manager (SAI4) who is a full time professional with experience in counseling. CAM's are hired from among members within each area network and are paid to take major responsiblity for organizing and convening weekly area meetings, planning actitivies, and sustaining membership involvement and interaction. A SAM and CAM responsible for a given area membership will meet regularly to discuss how members are doing, jointly plan future activities, and talk over any difficulties that may occur. The SAM is a consultant and resource person to the CAM but may directly intervene when a particular member may need help that the CAM is not able to provide.

In order to have a form for the entire four area networks, a similar pattern of peer-professional staffing exists to arrange for and coordinate periodic activities involving all network members. A 
Network Director is hired fran among CND members by a Network Coordinator who is a full-time clinical staff member. Because of the greater conplexity involved in planning and conducting Network wide meetings, circulating a newsletter and holding activities, other opportunities for member roles are created. Member Ieaders, who are paid, and llember Volunteers, who are not, perform various tasks as needed in assisting the Network Director to carry out organizing responsibilities.

Research activities cover several aspects of the project with a major amount of effort centering on the examination of project effectiveness in reducing recidivism among members. Preliminary data fram a 10 month follow-up amorg 40 members indicate significant reduction in required mental health treatment, total days of hospitalization, and total hours of out-patient contact when compared to similar data obtained from 40 controls.

More data is currently being collected to substantiate these findings, but the response of members and the interest of other agencies augur well for the project's success. Perhaps the most significant factor in this success has been a philosophical carmittment to self-help principles and an interest and organizational capacity for program innovation. These factors have involved project staff in a continued process of refining the existing program as well as looking fo: new areas to explore. Already, the project is involved in attempting to develop an independent "client corporation" which would serve as a vehicle for a comminity-based, client-controlled venture in program developrent. As the project's experience is examined and replicated in other agencies, it will likely serve as a model for promoting selfhelp and peer support among those with mental and emotional impairments. 


\author{
Camminity Helpers Project \\ Pennsylvania State University \\ State College, Pennsylvania
}

The Community Helpers Program is a three-year project funded by the National Institute of Mental Health, sponsored by Pennsylvania State University and the Mental Health/Mental Retardation Program of four counties in central Pennsylvania. The purpose of the program is to enhance the ability of nonprofessionals in rural communities to provide preventive mental health services within their own social networks.

The major focus of the program is on developing and evaluating the effectiveness of a training program for lay persons in the community, training them in basic helping skills, life development skills, and (prospectively) crisis intervention skills. The basic helping skills training outlines specific behavioral objectives for the helper, particularly good listening skills, and teaches them through modelling and role playing. The role of those receiving the training from project staff, called 'trainers,' is to in turn train other groups of laypersons, called 'trainees,' from the community, passing the skills down in a pyramiding fashion.

The program operates from two cities: a town of 12,000 and the western section of a rural county, where the largest town is about 1300. The areas differ greatly in the availability of formal services. The region is very stable, settled largely by Germans, English, Scottish, and Welsh; most are employed in small factories, although most of the land is farm land.

Contact with the two rural areas included in the project was begun by recruiting people to form volunteer Advisory Boards in each. The Advisory Boards and project staff then recruited trainers. Because those involved in the program at the outset were professionals who recruited from their own networks, both Advisory Boards and trainers tend to be more professional and human services related than expected. The trainees, however, are closer to representing a cross-section of the community. Both groups are expected to employ their skills in their everyday lives, helping those that seek them out, but doing so more effectively than before. In an area where people already rely strongly on informal systems for help, the long-term aim of the program is to make that help more effective and to prevent ordinary life development crises fram becaning mental health problems.

Since the funding of the program was largely a research and demonstration grant fram NIMH which ended in June 1980, the continuance of the program is uncertain. During the period of the grant, the staff consisted of four faculty members from the college of Human Development at the University who directed the project and its 
evaluation, four graduate students who carried out the training and assisted with the evaluation, and a half-time field coordinator who lived in the project area. The field coordinator continues with 10 percent support from the cormunity mental health center. 
Washtenaw County Conmunity Mental Health Center Ann Arbor, Michigan

Washtenaw County encompasses a heterogeneous population--the major cities, Ann Arbor an Ypsilanti, are quite different in their physical layout and social composition. Ann Arbor is dominated by the University of Michigan campuses, with its studerits and faculties, and by quiet, exclusive neighborhoods, lovely tree-lined streets, and light, clean industries such as research and warehouse/distributive firms. Many long time local residents are upper level managers of Detroitbased fims. Ypsilanti, on the other hand, is primarily a working class community. Eastern Michigan University and the Ford plant dominate the town. Many other workers cammute to Detroit's auto plants. The residents of both communities are predaninately white, but blacks and other ethnic minorities are also present. The Black cormunities have a long history in this area dating back to the preCivil War days of the "underground railroad." The outlying Washtenaw County has several small towns ranging from satellites of Ann Arbor and Detroit, university and industrial towns, to foarm communities.

To serve this diverse area, the Washtenaw County Community Mental Health Center is subdivided into three "catchment areas:" Ann Arbor, Ypsilanti, and "Out-County." This subdividison permits the programs and services of the overall agency to be responsive to each carmunity and to reflect the perceptions of need of each host locale.

Washtenaw CMIC has grown in its 12 year history from a small organization with a budget of around $\$ 50,000$ to a complex bureaucracy operating on a $\$ 5$ million budget. Its funds come primarily from the State of Michigan Department of Mental Health, as well as fram fees for services, and from grants and contracts. The structure of the agency has changed through the years from a very flat organization where everyone knew everyone and teamwork and individual initiative were highly valued. Despite the pressures toward bureaucratization the staff from the top level to the line level continue to pursue the goal of providing services that "make sense" relative to the community in which they are offered. The resulting catchment areas are further divided into adult and child clinical, pre- and after-care, and conmunity services (or direct and indirect services). Parallel to the catchments are county-wide services provided by the Child Guidance Center, the Development Center, and C.E.R. (Court, Emergency and Residential) Services. Within the agency the executive director is responsible for external linkages to the Mental Health Boand and County Commissioners, the state and regional Mental Health offices, the State legislature, and to directors of other public service gencies. The associate director is responsible for internal coordination and operations. Each catchment level has a program manager who supervises the clinical, pre- and after-care, and community services staffs. There are agency-wide coordinators for consultation and Education, Aging, and Community Support programs (the latter program specifically for after-care clients). 
It has been the agency's policy to use mental health generalists for a variety of its services, and to provide intensive supervision and in-service training programs to enhance staff skills. Persons are assigned their responsibilities based on personal skills and competence rather than credentials. This has led to an interdisciplinary staff where control and decision-making is not in the hands of any particular profession.

The primary mandate of the Washtenaw CMHC is to provide treatment to individuals suffering fram emotional difficulties, or related problems such as substance abuse, problems in interpersonal realtionships, or exhibiting psychotic behaviors. The agency also is mandated by Michigan law to provide 'aftercare' treatment services for the deinstitutionalized population, often chronic mental patients. These direct service programs absorb the bulk of the agency's resources-both funds and personnel. Community mental health centers are also mandated to provide primary prevention programs through their consultation and education (C \& E) services. This is a mandate which receives increasingly miniscule funding allocations relative to the overall mental health system financing. Despite the loss of a sure funding base for prevention, Washtenaw CMHC remains fimly camitted to $C \& E$ programing as of equal importance and validity as the clinical services. C \& $E$ is seen as pro-active mental health treatment, assisting individuals in the comminity to avoid mental health crises by educating them to better mental health practices and by strengthening the informal support systems within a cammunity.

Each catchment agency has its own $C \& E$ programs whereby it provides a variety of services to other formal agencies and organizations and to informal community groups. Among the more conventional $C \&$ E relationships are those with schools, law enforcement agencies, social services agencies, daycare programs and churches. The staff in the $C \& E$ programs work in teams; their relationships with a consultee are regarded as confidential. The consultation, or infonmation about the consultee gained through it, is never discussed with persons outside the agency without the written consent of the consultee. Many of these programs are "giveaways," where mental health professionals use their expertise to assist another agency, group, or neighborhood to put together a service program which it will eventually deliver on its own. Some consultations evolve into collaborative efforts with ongoing involvement of the mental health staff. The C\&E staff generally rely on the lay referral system combined with same outreach efforts to identify and establish new consultation service efforts.

It is in the context of the consultation function of its prevention programing that Washtenaw CIIC has worked with informal helping networks, mutual aid groups, and natural helpers or lay caregivers. Several instances of such efforts have occurred. One major effort drew together the Selected Neighborhood team for a five-year consultation relationship. There is an ongoing liaison/consultation with a 'natural caregiver' in a local S.R.o. hotel. Behavioral 
Science Study Groups among teachers and staff were fonmed in several schools. In efforts to reach the more informal helping sector of the community, the agency has also drawn volunteers (lay persons) from the local commuities into the agency, to give them an exposure to mental health services and programs, rotating then among the divisions. One outcome of this effort has been to improve information referrals from the cormunities. Same of these community recruits returned to the comminity, others have stayed with the agency as volunteers or as para-professional mental health technicians. 
Project Transition, Inc. Ann Arbor, MI.

Project Transition is a 12-year old program in southeastern Michigan which provides resocialization opportunities to mental health system clients through the use of community volunteers. It is a private non-profit organization which for the first decade operated solely through volunteer participation and membership.

In 1977 the Board of Project Transition added paid staff to ensure coordination of activities and proper administration of organizational resources and grants. The program is staffed by an Executive Director, a volunteer coordinator, a resources coordinator, a special program coordinator, and a secretary. The Executive Director and secretary positions are funded by a contractual agreement with Washtenaw County Community Iental Health Center. Other staff positions are paid for with public manpower funds--CEIA and VISTA.

The basic service provided by Project Transition is (re) socialization for mental health system clients; it involves community volunteers (coming from churches, civic groups, and student groups) who meet with clients (fram the Regional Psychiatric Hospital, or from mental health agencies in Washtenaw, Lenawee, and Jackson counties), as well as one or more mental health professionals and/or institutional staff (nurses, ward attendants). These groups meet weekly for ten weeks for social and recreational activities that they all plan and participate in. The program is based on the premise that friendly, caring community volunteers serve as a critical bridge to normalization for institutionalized persons and other mental health system clients. The volunteers form relationships with clients that facilitate their leaming comminication and other social skills, and the volunteers do so without pay which enhances their trustworthiness to clients.

In order to provide services to the clients of the psychiatric hospital and mental health agencies Project Transition has worked out cooperative agreements with these organizations. Project Transition contracts with these mental health system organizations to provide socialization services-to recently admitted patients, to short-term patients, to long-term patients, to patients scheduled for release, to "after-care" clients of the community mental health centers, and to clients of such centers who may never have been hospitalized but whan professionals feel could benefit from participation in Project Transition socialization programs. In their contractual arrangements the agencies are expected in turn to provide a staff liaison with Project Transition, who works with the Project Transition Volunteer Coordinator and supervises Project Transition staff-leaders of volunteer-client groups within that catchment; the Project Transition staff leaders are often shared staff--that is, they work part-time in their PT leader role and in supervision of volunteers, and parttime in other mental health staff capacities within the sponsoring agency. 
The clients participating in Project Transition activities are selected by mental health professionals. The Hospital, in its PT groups, releases in-patients for weekly meetings, provides transportation for the patients, and sends a staff member with the patients. Thus maintaining good working relationships with the mental health organizations is critical for successful functioning of Project Transition groups. 
Neighborhood Self-Help Project Chicago, Illinios

The Neighborhood Self-Help Project is a research and demonstration project jointly sponsored by the Chicago cormons (a large, canplex social service organization), the Taylor Institute (a private policy studies firm), and the University of Chicago School of Social Services Administration. The Project also has three major components: (1) a service program, (2) research program, (3) policy program. It is primarily the service or intervention camponent which is of concern to this study.

The Chicago neighborhood selected for the demonstration project is an inner southwest area of about 60 square blocks, not far from the University of Chicago. Although once a thriving European immigrant working class community, it has shifted rapidly in the last decade to one that is predominantly Black and Hispanic. Only a few pockets of whites remain in the area--they are poor and elderly and thus locked into the neighborhood despite its decline. The neighborhood is blighted by vacant lots, abandoned and decaying housing, and rubble, and the lack of effective city services--street cleaning and maintenance, garbage pick-up, rat control, fire and police protection, and so on. This poor service reflects the poor "connections" of the new residents to the political system, a very important aspect in Chicago life.

In 1976, in cooperation with the other organizations, the Chicago Cammons administration selected this neighborhood for a Project in which it sought to gain a better understanding of how informal systems of support in such a neighborhood affect the residents' needs for and/or use of formal services. The funding for the selfHelp Service Project cames fram Chicago Commons and is limited to a three-year domonstration program. The Project has four professional staff, and two clerical assistants; the staff members are all either Black or Hispanic, as are most of the residents of the neighiborhood. Although sponsored by the Chicago Commons, the Self-Help Project is fairly unique in its approach and thus operates in a more autonamous manner than other "Chicago Cammons" neighborhood-level offices. It is housed in a two-story apartment building, with a storefront office, two larger flats converted to meeting space and offices, and a small flat used by a volunteer caretaker and "natural helper." To residents of the neighborhood this building is known as the self-Help Center.

The "service" camponent of the Neighborhood Self-Help Project is designed to be as non-intrusive as possible. The goal is to understand the natural helping system and the community resources: natural helpers, special skills, and local concerns. The self-Help staff role is to became an added resource to help the local residents accomplish what they feel is important. Where the standard social service agency 
"does things for" people, the Self-help Project asks "What do you want to do, and hoN can we help you?"

The basic goals for the program staff are to:

- identify natural caregivers and their networks, and other neighborhood resources;

- strengthen, expand, and support self-help practices in the neighborhood;

- as appropriate, link neighborhood residents and groups to formal human service organizations within and outside the target area.

Two staff members are referred to as 'natural helper' facilitators. They are responsible for identifying and working with natural helpers, particularly those who provide direct personal assistance to their own circle of neighbors and friends-as advisors, "good neighbors," "play ladies," and so on. The natural helper facilitators follow the "good neighbor" strategy-they stop by to visit, call occasionally, listen, share information, act as consultants. They are also responsible for finding out how the natural helpers' efforts can be enhanced by the addition of tangible resources.

There is one staff member, a Network Developer, who is responsible for increasing the size of the local resource base by encouraging linkages between natural helpers with common service concerns-recreation for kids, crime, neighborhood maintenance, and jobs. This is a coordinating/mobilizing/facilitation role that requires sensitivity to what works and what will most meet what the comminity wants.

The Project has met and talked to over 200 persons that others in the neighborhood described as helpful. Of these they have found about 20 persons that are central figures, with an ongoing involvement in helping others. Most of these 'natural helpers' are wamen, although same men are incluaed. Most provide help to neighbors and friends directly; some are also concerned with more indirect services such as neighborhood irmproverent.

There are two basic service strategies that have been adopted by staff in the Project:

A. Strengthening natural helping networks-a variety of techniques designed to match local resources to local needs are used. Sametimes meetings are held bringing together helpers with those in need, sometimes referrals are made to natural caregivers, or persons with a cammon problem are referred to each other. In their interactions with natural helpers, staff provide information, assistance, 
or advice on handling problems (whether for another individual or for themselves).

B. Linking the neighborhood residents to formal human service agencies. Often in this impoverished neighborhood the resources necessary to provide adequate assistance are lacking in the informal system. Project staff refer residents to formal service agencies, but they go beyond the referral-they seek to help the individual, family, or camminity group to understand how the agency operates, what will be expected of them, and how they can best utilize the available services.

The long range goal of Chicago Cammons is for the Neighborhood Self-Help Project staff to leave this neighborhood and move on to other inner-city Chicago neighborhoods with a similar approach. 
Commanity Development Program Durham, N.C.

Seasoned urbanites might be somewhat surpriseo when hearing Durham being called a city. Although recent population counts number its inhabitants at 140,000 , Durham has many features of a small town atmosphere or even a suburban environment. The downtown area covers not mach more than a half a dozen blocks, residential areas are spread out, and open fields are not an infrequent part of the landscape. The city is growing, but the surrounding county is groving faster. Some of the county growth may be due to people moving out of Durham to find other housing, but the majority of it can probably be attributed to residents who work in other areas such as Chapel Hill, Raleigh and the Research Triangle Park-all within comuting distance.

Same of the urban fringe of Durham still engages in farming. For example, about a quarter of the Rougemont/Bahama population still farms small tobacco allotments. Poverty and dilapidated housing are not hard to find in and around Durham; Bragtown to the northeast of Durham had more than a quarter of its families earning less than \$2000 in 1972. To the north and east, one finds the old established neighborhoods of Durham, many now in decline or transition, same trying to redevelop. To the south and west one encounters Duke University, carpus housing and new development, although just beyond one runs into rural farms. Neighborhood decline and substandard housing are major problems for many of Durham's residents.

In Durham, the general strategy of the city's Cammunity Development Agency (CDA) has been to designate general community development areas on the basis of need, annually select target neighborhoods for development, and to offer financial assistance to qualifying hame owners for the purpose of bringing their houses up to code. Neighborhoods must have a certain amount of owner-oocupied dwellings. Renters cannot receive rehabilitation funds; landlords may be eligible for a loan to repair rental units but there is little incentive to exercise this option. Grants are small, usually less than $\$ 5000$.

The Housing Counselor camponent of the Durham CDA has the front line responsibility of working with local residents, organizing neighborhoods to consider special projects and assuring that needy residents obtain necessary services. Potential clients are identified by a housing inspector who checks for code violations. Sometimes this may involve a request by the resident for a determination of eligibility or a word of mouth referral by neighbors. Housing counselors go over what the program offers, check an applicant's financial eligibility, and refer eligible hameowners to the Redevelopment Commission. The CDA has taken the charge of not just rehabilitating the physical neighborhood but improving the life of the people who live in them. Cammity development does not simply mean code enforcement, the concept is taken to be much broader in scope. To them, this means identifying the strengths of a neighborhood area and building upon these or developing 
new resources in order to make a lasting impact on the lives of its citizens. In essence, the idea is to put the "neighbor" back into neighborhood.

The agency's approach to articulating this philosophy has been to seek out and develop a relationship witr. a comminity's "natural facilitators." Called "housing facilitators," these are people who informally play key roles in a neighborhood-others turn to them for advice or help, they have an active concern for what happens in a neighborhood or they may be central figures in neighborhood self-help activity. The tasks they perform are instrmental in sustaining or developing the informal social organizations within a community, and, as such, they became the channels through which one can best understand and work with a cammity.

The Durham Housing Facilitator project was begun in July of 1977 within the housing counselor section of the Durham CDA, utilizing existing staff. The counseling section is one of three arms of the CDA; planning and administration being the other two. The CDA Director is responsible to the City Executive, and lines of authority are delegated to supervisors for each of the three sections. The housing counseling staff include two counselors and a facilitator trainer. community aides have been hired for five neighborhoods.

As mentioned earlier, the CDA's general strategy involves identifying target neighborhoods each year within an overall CD designated area. A surbey is conducted initially which incorporates questionnaire items designed to obtain listings of potential facilitators.

Housing counselors are responsible for hiring community aides and identifying facilitators. Aside from the survey method, other methods are employed, the major one being a canvass of cammunity organizations, especially churches. Counselors refer the facilitators to a staff trainer who is responsible for arranging and conducting training workshops, coordination with the facilitators, conducting periodic community workshops, and evaluating the Housing Facilitator training program.

Once facilitators are recruited, a process of training is carried out. Training topics are developed on the basis of the housing counselor's needs assessment, resident input, essential CD program information, and material describing the scope and purpose of other service programs available to residents. An illustrative range of topics include Social Security, Senior Citizen programs, Tenants' Councils, Public Housing, Hameowner rights, Landlord-Tenant Bill, programs of the Department of Social Services, Homemaker Services and various health related issues. Training is rather informally arranged and includes use of resource persons in the cammunity. Descriptive information packets supplement the training and are intended to serve as reference materials for facilitators in making referrals to service programs or advising their clients. 
The general idea of training is to refine the facilitators' preexisting skills, not to alter them. Staff view facilitators as serving a vital need, and the status of the relationship between staff and facilitators is equal-"they have as much to offer us as we have to offer them." Community aides work most closely with facilitators outside of training; often housing counselors are a part of this when a client they are working with may be helped by a nearby facilitator. sometimes facilitators are clients themselves, receiving financial assistance for repairs or other services. Staff feel this often helps the facilitator's skill in advising others, as "after they've been through the process, they are better able to tell others what its like."

The intended outcome of the facilitator approach is to increase the accessibility of formal services to a cormunity by making key helpers more knowledgeable about existing resources and when referrals are appropriate. In some ways, the approach achieves this objective, as data irdicates that, although facilitators help about the same number of people as before, they make more referrals to formal agencies after being trained. Some evidence indicates that facilitators may play a larger role in providing input to agencies related to conmunity needs either informally or by serving on advisory comittees. 


\section{Galt Natural Helping Networks Project Galt, California}

Located not far from the cooling towers of the Rancho seco Nuclear Plant, Galt is a rural community of about 7,500 southeast of Sacramento, the state zapitol of Califomia. In Nugibes of 1978, the Galt Natural Helping lletworks project commenced operation through a two-year denonstration project grant funded through 314-D special project monies from the state. The goal of the project is to develop a community support system to meet the mental health needs of Galt residents in a way that recognizes and reinforces the existing resources of the comminity. The principal objectives of the project are to: identify and organize natural helping resources in the Galt community including professional providers, civic and business organization volunteer efforts, and informal helping networks; to test the effectiveness of a natural helping team approach to serving persons with mental health problems; to work with the chronic mentally disturbed population to expand their support systems, and to develop ties with the helping resources of the Galt Mexican-American community.

The grant, administered by the Department of Mental Health of Sacramento County, supports two paid positions and the project has also been fortunate to recruit two student volunteers from nearby universities. During the first six months, the project has had office space donated by the Galt Concillo Clinic, a community health clinic but has since moved to a storefront office in the business section of Galt provided by the city. The new office space reveals the progress staff have made in developing formal support for their work in the Galt conmunity.

Project staff have been engaged in a two-pronged effort since beginning operation focussing on overall community development as well as on individual client-oriented services. The major thrust of the project so far has been to work with the community, helievirig that until the community's existing resources are able to be mobilized, individual client needs cannot be effectively addressed by the cammunity. Additionally, the project is concerned to develop an angoing capacity within the community to respond to its problem, a capacity that will remain when funds for the project run out. Activities such as canvassing the neighborhoods of Galt, talking with citizens, the business cormunity, church and civic organizations, identifying and recruiting key opinion leaders within local government, meeting with other formal service providers, and organizing special interest carmittees to articulate and discuss comminity needs have been carried out. These efforts have developed support for the project within the community and helped to identify and enlist the natural resources of Galt to meet the needs of its residents. Beginning in April of 1979, the project began to move more in the direction of working with individual clients, receiving referrals and requests for services, doing individual and family counseling, and referring individuals to 
volunteer helpers in the community.

At present, the project staff have made progress toward identifying and mobilizing a community support system for residents and plan to expand this effort and to direct more attention to the needs of the chronically mentally disabled and to the Mexican-American conmunity. 
South Community Organization

The Neighborhood and Family Services Project Milwaukee, Wisconsin

The South Community Organization developed from the 4-year research and demonstration project for Neighborhood and Family Services of the hashingtion Public Affairs Center, funded by the National Institute of Mental Health. The overall project involves two demonstration sites one in Baltimore, MD. and the other in Milwaukee, Wisconsin. This study focuses on the Milwaukee site. Underlying the overall project are some assumptions about the type of mental health service delivery that is appropriate for urban white ethnic working class populations:

1. Social class and ethnicity affect attitudes towards and use of mental health services. Yet class and ethnicity are frequently ignored by mental health professionals.

2. Neighborhoods are a source of attachment for individuals, contributing positive identities; neighborhoods have many strengths and helping resources which should be strengthened and augmented by professional services.

3. Professional services should be designed to enhance the campetence and power of the community.

4. The community needs to be responsible for its own mental health. Professional services should supplement not replace the informal sector.

The overall goal of the Neighborhood and Family Services Project is to develop a conceptual framework, program and policy model for human service delivery leading to:

1. Reduction of negative attitudes toward mental health services among ethnic working class populations;

2. Development of a service delivery system congruent with the lifestyle of ethnic working class populations;

3. Determination of rearrangements of the formal delivery system necessary to remove obstacles to help seeking and receiving;

4. Development of policies in support of neighborhood-based mental health services.

Milwaukee, Wisconsin, a city of over 600,000 that still retains a small-town flavor, was settled by several waves of European immigrants, mostly Germans but including some east and south Europeans. Different 
parts of the city still are daminated by their ethnic traditions and values. One such neighborhood-a tight-woven, Polish Catholic working class area-was selected for this project. Values of ethnic pride, self-help, family, and church prevail. Working through an organization representing the varied sectors of the neighborhood, the Neighborhood and Family Services Project identified the strengths and resources used by area residents to solve mental health problerns, and same of the needs that residents still felt were unmet by the local helping network and the professional service system. Pilot projects were developed to meet these needs. The pilot projects involve volunteers from the community, in consultation with professionals from local agencies, planning a program or project. Each pilot project camittee is structured in a manner which leaves the community residents in control of activities and agendas. One representative fram each project conmittee sits on the SCO Steering Conmittee. In Milwaukee the first pilot project involved the preparation of a single page Referral Directory listing helping agencies and groups serving the neighborhood. A second major problem area identified was family communications for which a series of workshops and skits were developed. Currently SCO has 10 pilot project comittees: Referral Directories, Family Communications, Widowed Persons with Dependent Children (scow'ers), Widowed Persons, Southside Younth Camittee, Clergy/Agency Cammittee, Southside Wellness Project, Senior Citizens, Separated/ Divorced and Agoraphobia Groups.

The project funded two full-time staff positions--a Coordinator and an Assigtent Coordinator. The Coordinator has worked with the Project since its initial contacts with the Milwaukee residents. He functions as a cammunity organizer, technical advisor, and facilitator. He acts as a liaison between the commity groups and agency-based professionals. The role and responsibilities of the Assistant Coordinator have varied at several points in the project but in each instance the assistant has had responsibilities similar to those of the coordinator, under his supervision.

The 5c0 offices are located on the second floor of one of the local Catholic rectories in space donated by the parish. The office has accamodations for three private offices, and a very small conference room. Most of the meetings and activities occur in other places-in church halls, parish schools, and sametimes in the homes of the volunteer leaders of the various committees. In working with informal helping networks the Neighborhood and Family Services Project includes churches; ethnic, fraternal and social organizations; and natural helpers or "gatekeepers." A prime objective of this demonstration project is to refocus the previously fragmented helping system into a partnership of the professional and informal helping networks mediated through a neighborhood organization.

The clients of the Project include all residents of the neighborhood. Several self-help groups serve their participants--persons sharing conmon problems, or experiencing a similar life-situation-Widows, Widows with Dependent Children, Divorced, Agoraphobics. In 
other instances the volunteers present educational skills and workshops to other residents of their neighborhood.

SCO is now a vital part of the adaptive lifestyle of this ethnic neighborhood in Milwaukee. Cammity residents wish to continue the programs that are currently underway. They are also busily involved in the expansion of services. In order to do this they have successfully sought new sources of funds: United Way of Milwaukee has provided $\$ 75,000$ per year for the 3-year Southside Wellness Project-which is to create outreach and prevention capabilities in three local multiservice agencies. The SCO seniors comittee obtained funding for a three-year project from the federal Administration on Aging to expand the availability of low-cost lunches and other services required by many low-incame elderly residents of the neighborhood.

When the demonstration funding from NDM ends in 1980 this urban ethnic neighborhood will have an ongoing mental health program that meets needs in a manner that is compatible with the local lifestyles and values. 
Tiyospaye Project-

Rosebud, South Dakota

The leaders of the Tiyospaye Project say that their goal is the survival of the Indian people. While the poverty and misery of many people on the Reservation indicate that survival may be spelled out in very basic terms, the leaders of the Project are not talking just about bare existence. They are also talking about the survival of human dignity and self-worth and of the inportance of meaningful existence. The point is that, to the leaders of the project, survival means all of these things taken together. Without a sense of meaning, people die, as surely as they do without food. "Tiyospaye" is a term which connotes a traditional way of life based on extended families, cormunal economic/survival activities (e.g., gardening, ranching, hunting), and a leadership structure for problem-solving and religious rituals--all located on an identified land base on the reservation.

A 3-year research grant was awarded by NIMH in 1978 to Sinte Gleska College for a project to determine the extent to which traditional practices and beliefs had survived on the Reservation, whether or not there was any relationship between adherence to tradition and individual or collective well-being, and, finally, whether reinstituting traditional practices could imerove individual functioning and community life.

The Reservation is located on rolling grasslands in South Dakota. Federal boundaries for the Reservation coincide with those of one county but members of the tribe also live in the communities in three contiguous counties. Approximately 10,000 Indian people live in this 6,000 square mile area. Statistics regarding this population show the high rates of infant and adult mortality, disease, and unermloyment that are, unfortunately, typical of Indian Reservations. Services consist of hospital, Bureau of Indian Affairs social services, schcois and missions. Weather conditions and distances are major factors limiting access to services.

The staff of the Tiyospaye Project consists of a director and co-principal investigator, who is also the chairman of the Medicine Men's Association, research assistants, and data gatherers. The principal investigator is a psychologist and faculty member at Sinte Gleska. The project has collected data about traditional beliefs and practices, documented the use of medicine men and other healers and natural helpers, and helped to develop services and comminity development projects among members of the Reservation interested in reviving the traditional way of life. One cammunity was targeted for intensive intervention.

The Tiyospaye Project is nearing the end of its demonstration period. The research portion of the project will soon be campleted. The project has found that there is a positive relationship between a 
traditional lifestyle and physical and mental well being. A number of the community development activities (e.g., a mobile T.V. station, camunity gardens, a quilting cooperative and comminity rituals) will continue. The staff of the project will continue to be involved with the College, the Medicine Men's Association and mental health services for the Reservation, and will be looking for new ways to adapt traditional practices to a modern context. 


\section{Neighborhood Outreach Program San Diego, Calif.}

Formally established in 1887, the Golden Hill neighborhood of San Diego was dubbed Diplamat's Hill at the turn of the century, with large and elegant mansions reflecting an architecture as diversified as the political and social elite who lived there. As with many central urban neighborhoods, the last 50 years have seen a slow decline with the old hames divided into multifamily dwellings, urban communes, retirement and board-and-care homes. Even so, Golden Hill still retains a unique flavor with a varied juxtaposition of class and etruric backgrounds among its residents.

In the late 60's, an era which generated a growth in alternative camminity-based services, the Neighborhood Outreach Program was spawned in one of Golden Hill's large old homes as part of what was to became San Diego Youth Services (SDYS). Beginning as a youth dropin center, SDYS expanded until it became the administrative umbrella for three established service agencies-the Bridge, Family Care Resource Center, and the Neighborhood Outreach Program-now with a total budget in excess of $\$ 750,000$. The three member agencies share a common tradition as well as a board of directors, and SDYS has grown to reflect the needs of youth, families and children, and the community of Golden Hill.

As part of the SDYS, the Neighborhood Outreach Program is the only multi-service center serving Golden Hill and displays in detail a tradition of innovative development in response to an increasingly broader conception of problems and solutions relevant to Golden Hill. Established formally in 1972, the program was originally directed to youth outreach and gang work but as the problems of families, seniors, and, ultimately, the community, were seen to be interrelated, NOP moved to add new programs and develop a more comprehensive array of services. Now, the program's overall goal is to develop a "well integrated, self-sufficient neighborhood which effectively meets the needs of a maximum number of canmunity members by collective selfdetermination." Underlying all services of NOP is a philosophy which emphasizes self-reliance, self-help and the promotion of "networks of social interaction" and opportunities for social participation.

With a paid staff of almost 30 (14 full-time, 13 part-time) and a volunteer group of fram 10-20 individuals, NOP operates programs in four service areas: Senior Program, Social Services, Youth and Teen Services, and Community Development. The senior program incorporates a peer model of helping, exploying five senior citizens to provide counseling, information and advocacy, and emergency assistance to the isolated or needy elderly as well as promoting social activities and self-help networks among seniors in the community. The social services program provides services to families with more severe problems including individual and family counseling, employment assistance, 
emergency assistance, and information and referral along with group work with single parent families. The Youth and Teen program is divided into two parts, one serving youth 6 to 13 and the other 14 to 18. For those 6 to 13, after school and sumer programs include social and recreational activities, counseling, and a Parent's Advisory Board. Older youth have available peer counselors, counseling, training and several self-help groups as well as a diversion program for juvenile offenders. Finally, the conmunity development ccmponent, through a multifaceted strategy, directs its attention to the kroader needs of the community. The program was instrumental in organizing an independent Planning Association to oversee development in Golden Hill and has also developed a community newspaper, a "block watch" neighborhood awareness program, an artists' cooperative, a tenantlandlord council, comminity forums, and is now funded to offer a self-help housing rehabilitation program which will include a skillsand tools bank.

The diverse array of services that represents NOP today indicates the staff's committment to both listen and respond to grassroots issues and needs as well as the creativity and energy that individuals have brought to the program since its development. Owing to a shared philosophy, and an ability to attract individuals who can add to its articulation, there is a consistency and integration across the four components revealed both in methods of operation and the linking of clients and cammity in the outcames they achieve. The principle of self-help and self-determination pervade all programs and show themselves in the way the program emphasizes the recognition of existing helping resources and the need to support or create networks of helping to strengthen or erpower an individual and the neighborhood of Golden Hill. 


\section{CASE STUDY OUTLINE *}

I. Neighborhood/Community Features

Population characteristics

Physical characteristics

Stability/growth

Bounderies/subdivisions

II. Agency Overview

Target population

Development

Goals

Organization/affiliation/management

Staffing

Services/activities

Plans

Community relations

III. Description of Agency's Work with Helping Network

Development

Identification, recruitment (training)

Staff characteristics

Staff/helper relationship

Staff/nelper interaction

IV. Description of Helpers and Helping Network

Helper characteristics

Helper activities

Interactions among helpers

Characteristics of helping network

Network's development

Network's connection to community service system

Network's function in neighborhoods

V. Program Implications

Evaluation

Outcomes

Mediating factors

Replicability

Future plans

*Brief outline of case studies, ranging in length fram 12 to 30 pages, see also Froland et al, 1979b, 1980a. 
PROJECT REACTION SHEET *

1. To what extent do you think this case study captures (or distorts) your program goals, objectives, and Interests?

2. Which programs do you think are most simflar to yours?

3. Which programs are least similar to yours?

4. Did the site visit benefit you? e.g., lead to new insights, or provide opportunities for you to clarlfy your goals and objectives, and/or your evaluations of your program?

5. Please cozent on the issues raised in the introduction. Which ones seem ros: important to you?

6. Do you have any suggestions about how we might improve our site visits? The case studies? Our generalizations?

7. What comon subjects or 1ssues would seem valuable or interesting to discuss at a conference with the other projects' staff members?

Who filled o:1t this form?

* Submitted with each case study to project staff for their review and camments. 
Project Recontact Sheet

PROJECT

CONTACT PERSON PHONE

CONFERENCE

Project (does) (does not) plan on attending. Attending Coments :

FOLLOWUP:

Date of Site visit

A. Milestones (List major events since site visit)

B. Significant chanzes (Note changes in organizations, staff, funding, helpers)

c. Future Plans (New projects, funding, etc.)

D. Materials (Studies, reports, etc. avaflable for review) 
APPENDIX C

DISCUSSION GUIDE 
DISCUSSION GUDE FOR AGANCY STTE VISITS

The are studying the ways in which formally arganized human service agencies sche sith non-professional helpers. We are particularly interested in exinining wrether professional staff have identified and established relationships with people in the comminity who provide help to others in need on a more or less spontaneous and natural basis. We have developed questions for a muber of topic areas which will help us better understand what kinds of activities you are doing in this area. We will be asking about the type of neighborhoods or cammity you work in, characteristics of your agency and the kinds of services you offer. Then we'd like to particularly focus on the kinds of interactions agency staff have with indigenous or natural helpers, what those helpers do and the characteristics of those they help. Finally, we'd like to ask you about what you've learned from working in this area. Before we start, do you have any questions?"

CODING: Who to ank each question of

A. Supervisor

B. Staff

C. "Helpers" in contact with agency - regular

D. Natural helpers. 


\section{Neighborhood Factors/Communtey Character1st1cs}

A. 1. What are the demographic characteristics of the communtey/neighborhood you work in?

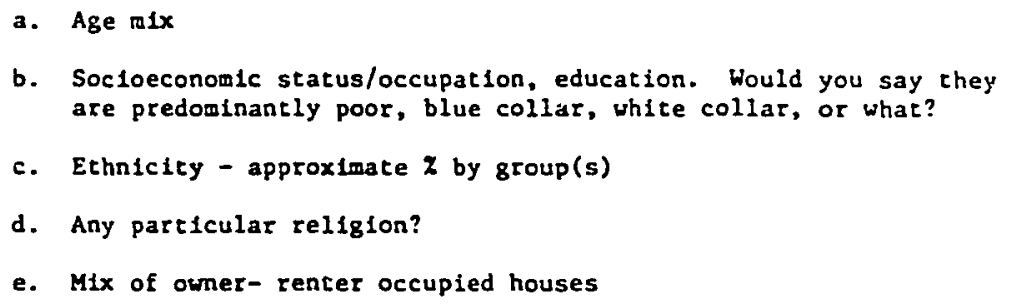

(Note: census data can be used for much of this if we can identify the census tracts.)

A. 2. What are the physical characteristics of these neighborhoods?
a. Mix of housing types
b. Resldentlal/comerctal mix: Kind of comercial (neighborhood oriented?)
c. Quality of housing and nelghborhood condition
d. Major trafflcways - is it divided severely?
e. Density of neighborhood? (average lot size)
f. How is this area related to the city as a whole: core, fringe, ecc.
8. City size

A. 3. how stable are these neighborhoods?

a. How high is residential turnover?
b. What accounts for most of the turnover? Is it due to the death of older residents, transient renters, a popultion mobile due to occupation?

c. What is the growth stage of the comunity? Is it new and still building, declining, or rebuilding?

A. 4. How much do people feel they belong to a neighborhood, that there is B. a neighborhood identity?

C.
a. Does the neighborhood have clear boundaries? What are they?
b. Does it have an agreed-upon name? c. Are there any physical features that rake it particularly unique
and imageable? 
d. How well do the nelghborhood boundaries coincide with those of the area you serve?

A. 5. What organizations are there in the community that provide a focal

B. point for social integration? For example, active church groups, voluntary organtzations, block clubs, self-help groups.

A. 6. Do you have any statistics on the soctal problems in this area that you can compare with the rest of the city--e.g., crime rate, mental hospitalization rate, child abuse rate, ecc.?

II. Characteristics of the Agency

A. 1. What group or area is the focus of your service efforts?

a. Target population defined-by problem, by locality, by both?

b. Elfgibility citeria (1f any)

A. 2. Briefly describe the agencles programs (whole agency, or if very complex, sector in which program is located).

"Program descriptions" -- number of staff devoted to each, levels of staff devoted to each, funding for each; elfgibllity criteria; recent statistics on program; evaluations (ete.). Any descriptive materials.

A. 3. Describe the organizational structure of your agency? (Obtain chart If available)

a. Levels of responstbllity: staff persons at each level--who supervises whom--from program to top levels.

b. Boards (if any), relationship to staff

c. Affiliations: private, independent; private voluntarg association; semf-public; public; ethnic, religlous, for profit, non-profit.

A. 4. What is the size of the budget for the whole agency?

a. Sources of funds

- federal

- stare

- local

- private foundation

- private Unfted Way

b. What about the program's budget

- size

- source 
A. 5. Would you say that your agency is vell-known combuntry-wide (in the service area defined)?

a. Which segments of the comsunity know of your services, how well accepted is your agency/program by the community?

b. What types of ties do you have to the local polltical structure?

c. To the voluntary organizations, churches, etc., within the comunity?

d. To other professlonals?

e. To the business communtity?

A. 6. What are some of the other service agencles in the comruntey who serve

B. the same population (or area)? In general, how available are services to this population?

a. What are your working relationships with other agencles? How auch do you coordinate with other agencies, and particularly large public agencies?

b. Is there any conflict (competition) between you and other agencies over funding, cllents, or other resources, or over gcals and objectives?

A. 7. How does your agency relate to the general community?

a. Do you have an advisory board? What kind of people are on that? Or a Board of Directors?

b. What type of publicity regarding programs?

c. Do you have a c1tizen involvement process? What is it?

A. 8. Tell we briefly about the developmental history of this agency?

a. When was it founded?

b. Why did the agency locate in this area? Select this target population? etc. Is there anything in the development of the agenzy over the years that moved 15 in the direction of natural helpers?

\section{Program Characteristics}

A. 1. Please brfefly describe the overall approach agency staft have taken

B. In working with the indigenous or non-professional helpers.

a. What are the goals or objectives of the program? 
b. What is the general philosophy or ortentation to service -dfrect agency advocacy -direct service delivery -education and sk1l1 development -improve access to formal services -community capacity bullding (enabling, facilitating, organizing) -strengthen (and expand) Informal services

c. What are the general strategfes employed to meet the goals?

d. What is spectal or unique about this approach?

e. Who are the 'natural helpers' in terms of your project--the ones you have contact with?

A. 2. How did you get involved in this area? What led your agency to adopt this approach?

a. When did you first start? (funding, program started)

b. Was it a consciously developed progran? Did the "network" ever come to the agency to ask for changes in operations to fit the community?

c. Was formal approval needed?

d. Who was involved?

e. Was it related to earlier activities?

f. Have your ideas about the purpose of this approach changed since you started?

8. Did you draw on the Ideas of others outside the agency in developing the philosophy or activities? (implanted or emergent)

h. Was it adapted for financial reasons--did funding change fust before adapting.

3. How many persons work for the program?
a. Administrators, supervisors
b. Professionals (what professions)
c. Paraprofessionals (what skill areas)
d. Volunteers
e. Others

Describe the cypes of roles or fobs within the program, at each level. Title and descriptions of task. (Ask each to describe our roles and those below.) 
A. 4. What are the general characteristics of the program staff? Please describe general background of staff including age, sex, where they live in community, length of service in agency, time lived in community, experfence, professional training (UG, C), common culcure w/target population.

a. Administrators

b. Professionals

c. Paraprofessionals

d. Volunteers

A. 5. How do you select your staff? What criteria do you use? What do

B. you look for?

A. 6. How are policy decisions relating to the program made?

B.

a. Who makes decistons about policy? Are all staff lavolved?

b. What about the helpers?

c. Is there a single final decision-maker?

Now I'd like to focus on the work you're doing with indigenous or non-professional helpers. We have already discussed the general idea of what your approach has been.

\section{Staff-Helper Interaction}

A. 1. When the program began, what specific steps did you take to begin

B. working with this network?

A. 2. What kinds of changes inside your agency were needed to allow yourself

B. this?

A. 3. What kind of internal conflicts, if any, were precipitated by this mode

B. of service delivery?

A. 4. How do (did) you Initially 1dentify the helpers?

B.

a. What procedures were used? What sources did you contact?

Did you: -contact organizations, agencies

- canvass the community, survey

-have referrals from other helpers

- contact key individuals

-advertise, have public hearings

-rely on staff knowledge

-rely on self referral

b. Why did you use this procedure? 
c. Did you use any criterla to screen potentlal helpers?

d. Did you try to identify central flgures in the network?

A. S. How are (were) helpers recruitcd?

B.

a. Who gets selected? Do you use formal, especial criterla or informal ones?

b. What intervieu processes do they go through?

c. Have you had any proulems in recrulting helpers to work with you? Can you describe them?

A. 6. How do you orlent helpers to their role? Have you thought about B. training them?

a. What is the purpose of training?

b. Please descrlbe training

- formal/informal

- content

- group/individual sessions

- time-limited/continuous

B. 7. What kirds of interactions occur between staff and helpers?

that do you expect of each other? How equal are staff and helpers?

a. What are the major types of activities (e.g., consultation)?

b. Please describe the frequency, duration, and arount of contact between staff and helpers. Where does it occur?

c. Overall, how wuch time do staff spend with helpers?

d. How many helpers does each staff work with on the average?

e. Do you ever see helpers in other contacts? (grocery store, church, etc.)

E. What would you consider the usual process of interaction?

8. Are there any examples of helpers who perform leadership roles concerning other helpers? (Please describe)

h. Have any difficulties between staff and helpers occured since you started?

1. Why do the helpers get Involved? Are they paid? 
B. 8. What is the purpose of interaction between staff and helpers--is 1t:
a. Directly client orfented
- information/referral
- support
- resource assistance
- consultation
- advocacy

b. Indirectly client orfented

c. Comunity ortented

- education/auareness

- program developwent

- community organizatiod

- Interorganizational

B. 9. I am interested in understanding your roles as a professional within this program. Could you tell me how you spend your time?

a. Describe a typical day or week.

b. How much do you interact with the other staff (both within this specific program and outside it)?

c. Can the staff that work with the natural helpers step in for each other--or do you consider your relatfonships with specific heipers to be special?

d. Are there skills, attributes or training that are particularly helpful for your work with helpers?

B. 10. Are there things that are frustrating about your fob?
a. Did your training prepare you for it?
b. Do you have adequate support and supervision?
c. Do you have enough autonomy and freedom?

11. How would you improve your job?

\section{v. Helper Characteristics}

B. 1. What is the "natural helper" expected to do--how do you/they detine C. your/their role?

a. Does the role involve giving: information, emotional support, skill training, watarial assistance, providing services.

b. How many other are they working with? 
c. What kind of networks are the helpers working with? (e.g., person centered, locality based, etc.)

d. Were these relationships created since they've been involved with your agency or were they pre-existing?

e. What do they get in return for thelr helping? Do they receive any direct return; do they expect those they help to help others in turn?

f. Do the helpers have a mutual relationship with those they help?

8. Where does the helping occur? (e.g., In the home or tertitory of the helper, helpee, or agency)

h. Is there ever a conflict between the way they define their role and the way you define it?

B. 2. How do the helpers function with the agency? Are there:
a. Coumittees
b. Forms to fill out
c. Spectalization of functions
d. Centralization

B. 3. What are the characteristics of the helpers?

a. How many are there?

b. What are their general denographic characteristics (age, sex, ethnicity, etc.)?

c. What part of the community do they live in?

d. Are they considered key figures in their own networks in terms of helping?

e. Are they similar to the people they help? Do they share the same problems? If so, have they been successful in dealing with theit problems? How?

f. What other volunteer activities are they involved in? How central is this role in their $11 \mathrm{fe}$ ?

8. Is their helping related to a role or situation they occupy?

B. 4. In relating to different helpers in your program, have you found that sone work out very well whlle others do not? If so, are there any particular characteristics that seen to predict how well the individual will work out? 
B. 5. How much interaction takes place between helpers you work with?

a. How does this occur?

b. Where does this occur?

c. Does the agency promote these interactions?

d. What would be different if there vere more interaction? Less interaction?

B. 6. What are the characteristics of the networks the helpers work uthin? C.

a. How big are they? Are these people who are involved in a rather large network in general?

b. Do the people in the network tend to know each other? Do they have a comnon basts for relating?

c. How well-supported are those who need help? Do they also use formal services? If not, why not?

d. What are the local norms regarding mutuality and reciprocity in everyday helping?

f. How are the helpers percelved by the network? What is thelr role?

8. Are there central figures in the networks that you don't work with?

B. 7. What are the linkages to the larger community? Are there people who

C. have memberships in outside groups or bring news about the larger

D. community back into the neighborhood?

8. How of ten and with what number of neighbors do people interact on the average during the year?

a. Meet in organizations of social groups--not necessarily in the nelghborhood, but with neighbors?

b. See others in the neighborhood as getting together of ten even if that's not theit own pattern?

B. 9. Has(ve) the network(s) of the helpers changed in some way since

C. you first became aware of them? Have they becore more or less organized?

B. 10. How do the helpers or the1r networks function in different neighborhoods?

a. Have you had more problems developing the program in some areas than in others?

b. Does 1t seem to be related to the social class, ethniclty, transiency, housing structure, etc.?

c. Please 1dentify which neighborhoods seen to have active networks, which do not. 
The final area I'd like to discuss concerns the lessons you've learned frow working with helpers, changes that may have come from this, and how useful you think your approach would be for other agencles.

\section{Program Implications}

B. 1. How do you evaluate your work with helpers?

a. What do you focus on? (e.8., cllent, helper, network)

b. What procedures have you used?

c. (If no evaluation) Why? that would you do?

A. 2. What changes can you attribute to working with the helpers?

C. a. Have any changes been noticeable in:

- staff activities or atcitudes?

- agency policy or expectations?

- clients?

- helper activities or attitudes?

- the helping network?

A. 3. What factors would you say facilitate your work with helpers? that

B. factors hinder your work?

C. a. Comminity circumstances?

b. Agency philosophy? Funding?

c. Legal? Political? Economlc?

d. Cultural?

e. Target population?

f. Clients you serve?

A. 4. To what do you attribute your success? Do you attribute success to

B. qualities of a particular worker or to the intensity with which you did field work in the commity.

A. 5. What do you see, looking back on your experience, as the factors that

B. were most related to your success in this enterprise and what do you see as the factors that were most resistant to continued work or elaboration of your work with the network? 
A. 6. Do you think what you are dolng is applicable elsewhere?

B.
a. What kinds of problems? situations?
b. What agencles might be able to adopt your strategy? What about large public agencies?
c. What modifications would be requited?
d. What are factors and problews to consider?

A. 7. What future plang do you have for working with helpers?

B.
a. Formalize relationships
b. Seek new funding
c. Training
d. Recruit new helpers
e. Orher

A. 8. If you had any advice to give other agencies interested in working with B. natural support systems what would it be?

ALL

9. Looking back on what we've discussed, do you feel there is something important for us to know about your work with helpers that we haven't couched upon?

Thank you for your help. 
APPENDIX D

CONIENT ANALYSIS ITEM STEMS 
ITRES FOR COTROR ANALYSIS WITH IARLABEE NATS

11

Agenet,

LEEIS

IUAPP?

APPROACHES liIST)

IMAPE

ranto

ITRVR.

Round of Site Visit: | IFirst, I ISecend

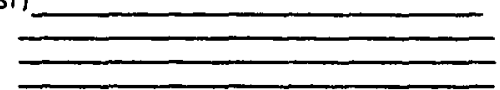

LTRV?

TOEm

Initivicu'cr: I Charles, 1 / Dianc/Alice

1 Nancy. 1 | Priscilla

Timi/Duracion: How much total time did you spend with pecple from the agency. program, or natutal helpers on the site visit?

ATIT

Whism. tid you mect in the agency, progran unit, on commitu?

111. Administrator lagency ditectc?, progran or divisicn marage:, Those whose primaris function is supervision or managcment Hou' invy?

STARIT

RIPIET

1 12. Progrem Staj6 These whose primrey function related to west witl helpers on similar direct "client/helpc:" contact)

1 13. Helpers HOL' MANY?

ROTALK

TAPTI

HIPTX

ATRASP

SCASP

Did you talk to these pecple alone on in groups?

1. Administrators I INone, I Group I IBcth. I Not applicable

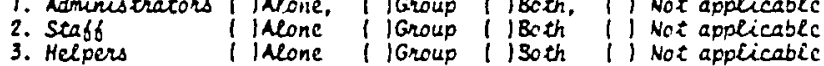

3. Helpers I ilone IGroup I isoth

Do you feel that these pecple had a goct grasp of the concepts las re sec theml of working with natural helping networks?

$\begin{array}{lllllllllll}\text { 1. Administratons } & N . A \text {. } & \text { Hig.i } & & & & & & & & \\ \text { 2. Stafb } & 10 & 9 & 8 & 7 & 6 & 5 & 4 & 3 & 2 & 1\end{array}$

Coments

$A C D O C$

How much written descriptive material on documentation did you obtain relative to the agency? I 11. NONE,

1 12. Very linited anount

13. Hoderate amount

NinמDOC

1. Extersive anount

How much written descriptive material on documentation did you obtain relative to the natural helping networks programing?

i Ii. NONE

12. Very linited anount

1 13. Moderate anount

1 14. Extensive anount

NOTE: In the fallowing peges the items rated by each resenrcher for this stary

are presented. The rame given to an itan for computer analysis precedes

in , Itens which were reflected are marked witi an ansterisk (").

ippondix $F$ presents further information on the scale construction process. 
21

TOSRA

(ASIZE)

1.

1. What was the total budget for the total agency in 1979-89 fiscat year?

(to the best of your knowledge. best estimate)

s

( ) 1. no fixed budget (may have sponsored workers, VISTA, CETA,ETC.)

() 2. under $\$ 50,000$ annual budget

) 3. \$50-100,000 annual budget

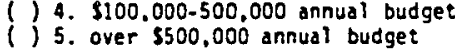

$\operatorname{rax}$ (RSIZE)

2. What was the budget for the NHN program in the 1979-80 fiscal year?

s

( ) 1. no fixed budget (may have sponsored workers: VISTA, CETA,etc:

() 2. under $\$ 25,000$ annual budget

() 3. \$25-50,000 annual budget

$\left\{\begin{array}{l}4 . \$ 50-100,000 \text { annual budget } \\ 5, \text { over } 5100,000 \text { annual budget }\end{array}\right.$

3. How many paid staff are there in the total agency? (total employees)

( ) 1. Less than five persons

1. Between 5 and 25 persons

() 3. Between 25 and 50 persons

4. Between 50 and 100 persons

() 5. Over 100 persons

FRSTAF

(NSIZE)

4. How many paid staff are there in the program unit (if different than the agency AND different than the NHN program)?

(j) 1 . Tess than five persons

( 2. Detween 5 and 25 persons

3. between 25 and 50 persons

( 4 . between 50 and 100 persons

() 5. over 100 persons

( ). Not Applicable

() 9. don't know

NATSLAF

(NSIZE)

5. How many paid staff work in the Natural Helping Networks (NHN) program?

() 1.2 or less

2. 3 to 5

$\left\{\begin{array}{l}3.6 \text { to } 10 \\ 4.11 \text { to } 15\end{array}\right.$

() 5. over 15

FIE

(NSIZE) actual staff effort (F.T.E.) in the HHN program?

6. What is the actual staff effort (F

( ) 2. 2 to 5 FTE

$\left\{\begin{array}{l}2.2 \text { to } 5 \text { FTE } \\ 3.5 \text { to } 10 \text { FTE }\end{array}\right.$

() 4. over 10 FTE

COMENTS ON STAFFING SIZE: 
3/

CLIENT TYPE

Sometimes the client tyoe is generally the same, but hroater or narrower in some way at each "level"; please note is this is true. (Example: the "el Jerly" may be general elderly population at agency level. Jewish elderiy

7. Which of the following client types does the total agency serve?

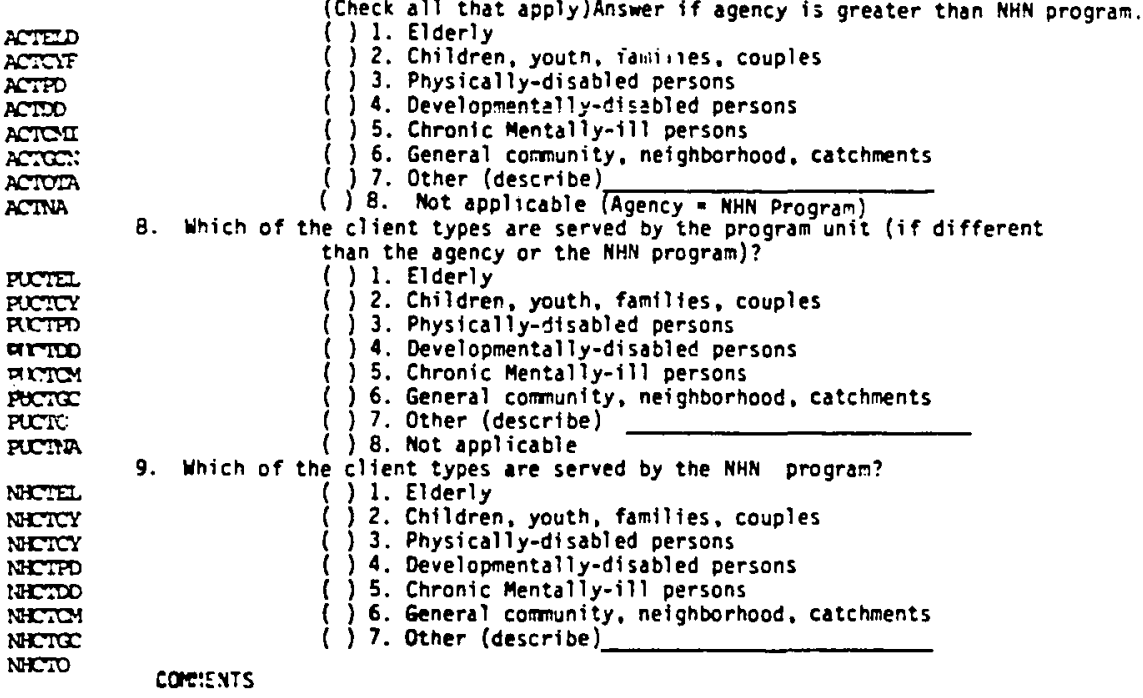


4/

POtsz

(ASIZE)

(NSIZE)

NTPOPS

(NSIZE)

$\operatorname{comen}$ (GANERAL

10. How large a population base is encompassed by the service area of the agency? (answer if agency is greater than NHN program) 1. under 10,000 people

$\{$ 2. between 10 and 20,000 people

3. between 20 and 50,000 people

4. between 50 and 100,000 people

5. between 100,000 and 250,000 people

) 6. over 250,000 people

11. How large a population base is encompassed by the service area of

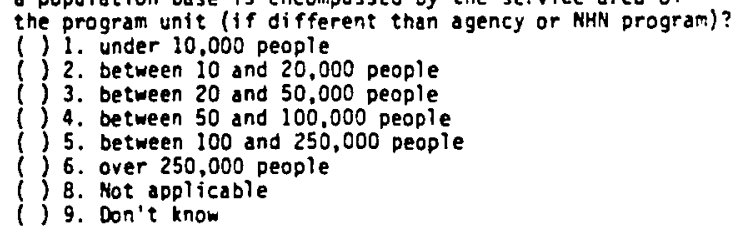

12. How large a population base is encompassed by the service area of

the NHN program?

() 1. under 10,000 people

2. betweer 10-20,000 people

3. between $20-50,000$ peopl

$\left\{\begin{array}{l}\text { 4. between } 50,000-100,000 \text { people } \\ 5 \text {. between } 100,000-250,000 \text { peopie }\end{array}\right.$

5. between $100,000-250,000$ people

f. over 250,000 people

COMENTS :

() 9. Don't know

13. What type of comunity or locale does this agency serve?

( ) 1. RURAL (no community over 20,000, extensive undeveloped

( ) 2. RURAL/URBAN MIX (some cominnities over 20,000 , but under
(1) 200,000 , with extensive undeveloped areas)

( ) 3. SUBURBan (Comunities of varying size, adjacent to urban

(1) 4. URBAN (communities over 200,000 that are centers of

(1) 4. ORBAN (comunities over 200,000 that are centers of ( ) 5. OTHER (DESCRIBE:

COMENTS: 
5.

\begin{tabular}{|c|c|c|}
\hline $\begin{array}{l}\text { ASITES } \\
\text { (ACSNCY } \\
\text { COAPLEXITY) }\end{array}$ & 4. & 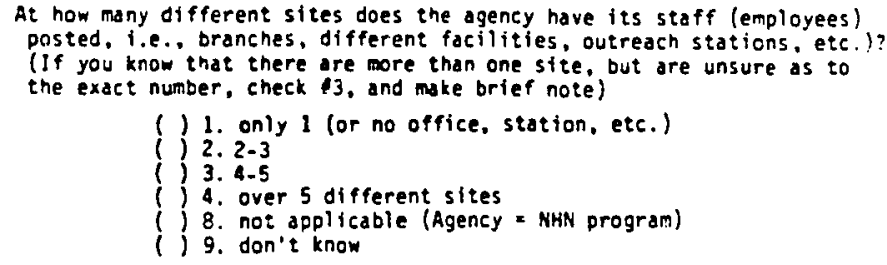 \\
\hline $\begin{array}{l}\text { NSTTES } \\
\text { (PFDORHM } \\
\text { CO PLENTTY) }\end{array}$ & 15 & 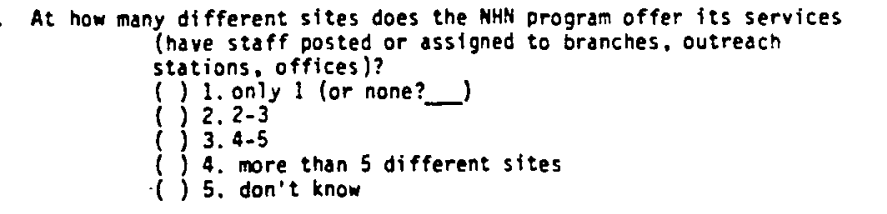 \\
\hline $\begin{array}{l}\text { PISPCT } \\
\text { (PROCRAM } \\
\text { COMPLEMTY) }\end{array}$ & 16 & $\begin{array}{l}\text { How many other sections or programs are there within the program } \\
\text { unit (if applicable)? } \\
\text { (1) none } \\
\text { 2. oniy } 1 \\
3.2 \text { or more } \\
\text { ( } 8 \text { not applicable (NHN program = agency or program unit) } \\
\text { (). don't know }\end{array}$ \\
\hline
\end{tabular}

COMMENTS:

(STAE)

17. How old is this egency? (Estoblished approxtmately what year?

( ) 1. Tess than 5 years old

3 . between 10 and 20 years old

() 4. Over 20 years old

() 8. not applicable (Agency = MHN program)

ACENFN

18. How long had it been since the flrst WHN program was initiated in this agency or setting (at time of the site visit)?

(STAGE)

(1) 1. less than ? year

() 2. between 1 and 2 years

() 3. between 2 and 3 years

(; 4. between 3 and 6 years

5. over 6 years

8. not applicable

( ) 9. don't know 
61

AUSPIC

FUNPBO

FUNOL

FUNOS

Tunar

FUNPRD

FURRDL

Fineos

Fundof

FunPC

FURTDF

FUNPSP

FUNFE:

Funo

19. Is this program (or nost agency):

() 1. public

2. private, non-profit

3. other?

8. not applicable?

() 9. don't know

20. How was the NHN program funded? (Check all that apply, and, if multiple, indicate relative significance, l.e. Ist or major. etc.)

()

1. Public funds (ongoing. legislated programs)

Local or Regional (includes ARA)

State

Federa?

( ) 2. Public, Research/Denonstration funds or special projects (CETA, etc.)

Local or Regional (includes AAA)

State

(1) 3rivate contributions/ grants (one-time, nonrenewable, including in-kind)

( )_4. Private donations/ funds (renewable)

( ) 5. Private, Research/Demonstration or special

( ) 6rojects

( ) 7. Other (describe)

COMHENTS? 


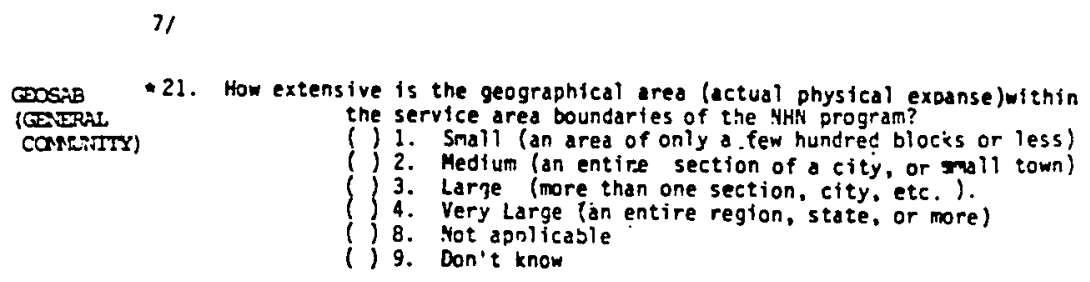

DESAg

22. What is the density of the development within the service area of the NHN progran? Answer for area :hers efforts are CORISITTY) concentrated, or for where most helpers are found.

( ) 1. Low density (e.g., mainiy single-level, single-family)

(1). Medium density (Mix of single-level, multi-level anc

() 3. High density (nainly

(3. High density (mainly multi-ievel. multi-family)

() 9. don't know

FORMALIZATION

23. Answer the following questions, by ratina the MHN program and then the Program unit (if larger than NHN progran) OP. agency (if program unit $=$ NHil program). Indicate to what extent each statement is true in this organization. On the second set, let me know i.s true in this organization. 0.7 the second
which level you are rating. e.g.. PIJ or A.

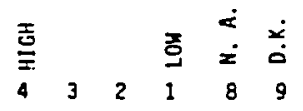

NORARI OFOPMALI

NTOFALS OFORATI2

NFORAL3

CFORATIS a. The activities and responsibilities of each staff

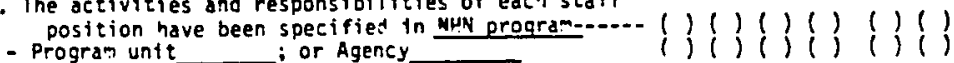

b. Written job descriptions and procedures are

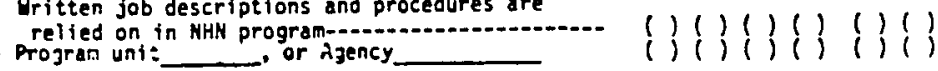

c. When hiring staff it is necessary to follow predetermined procedures and critería (c.g... education. experience, professional erofantials, etc.)...... IN NHW Program

-IN Program unit : or Agency

()) () $(1)(3)$

(NTORAPL = PROGRAM UNTT FORPAIIZATITON) (OFORAL, = ACENCY FORALIZATION ) 


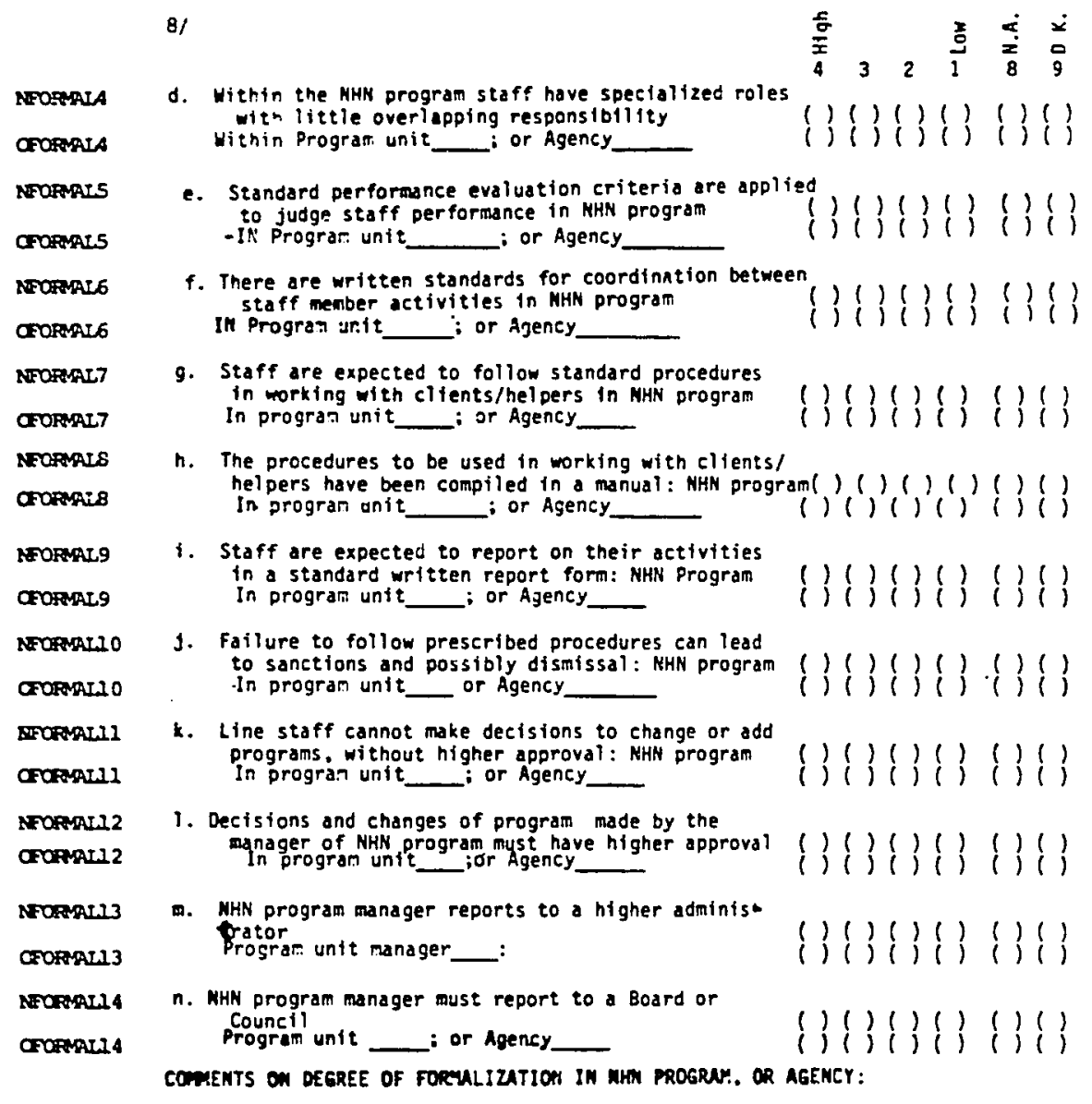


9/

MGRY. GROUF IDE:II:TY

24. Answer the following questions for the level or unit specified.

GRPIDI

GRPID2

GRPID3

GRPIDA

GRPID5

CPPID6

GRPID7 COMENTS :

a. The HHN program is odministered through a

b. The program unit is part of a larger agency c. The manager of the MHN program is responstbie for
other programs as well

- d. The NHN program has a separate facility from

e. The NHN programs or divisions has its own funding, separate from that of other programs in agency/unit

f. Staff that work in NHN program also work on other activitizs or programs of agency
The NHN program staff constitute a clearly

- g. The NHN program staff constitute a clearly

distinguishable group within the program unit

GPDI $=($ IIDNTITY $)$ scale

$\begin{array}{lll}\text { YES } & \text { (NO } & \text { Na } \\ (1) & (1) & (1)(1) \\ (1) & (1) & (1)(1) \\ (1) & (1) & (1)(1) \\ (1) & (1) & (1)(1) \\ (1) & (1) & (1)(1) \\ (1) & (1) & (1)(1)\end{array}$

, DK 
$10 \%$

26. Answer the following questions for the MHM program level. Noie that several questlons reiate to the relationship between the NHN program and the overali unit or agency. Answer only if NHN program $\neq$ Agency or

PEERI PEERS The NHN staff get together to discuss their work

(problems and suecesses) regularly

(problems and successes) regularly

b. The NHW staff work together as teams

PERR2

- c. The MHN staff work independently on special tasks, populations, areas, or problems

PEIRA

d. The NHN staff substitute/fill in for each other

e. The NHN staff commonly ask for and give help or advice to each other

PEER6

f. NHW staff indicate that support from co-workers coneributes to satisfaction and high morale

PEER7 contributes to satisfaction and high morale
NGW staff have found like-minded individuals

9. NGN staff have found
within their agency

within their agency
NHW staff have found like-minded persons outside of the agency context

$\begin{array}{llllll}4 & 3 & 1 & 8 & 9\end{array}$

PSEPR

PERPE

-1. NHN staff feel that non-NHM staff within their agency cannot understand their activities

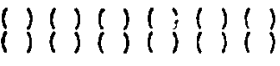

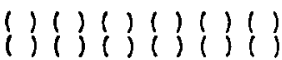

()()()()()()

(1)()( ) (1)(1)

() () () () () (1)

( ) (1)(1)(1)

()()()()()$(1)$

POXRIO

PEIRII

j. NHN staff seem to share a sense of common interest and purpose relative to MHN programing

k. Other staff in the program unit seem to understand the interdependenctes of their work and the NHN staff $(1)(1)(1)$

PEDRI2

-1. The activities of NHA staff are viewed by other staff with suspicion or indifference

()( ) ( ) ( ) ( )

- NHN staff identify more with their program than with overall agency program

(1)( )(1)(1)(1)

Farea 3

PEEPR 4

n. NHN staff feel that their efforts contribute and complement overall agency program COMENTS: 
111

27. Answer the following questions for the NHN program: These questions relate to the relationship between program and funding or regulatory bodies.

(TNON)

FUNR2

FUNOR3

(ENTR:D)

Funops

(EDRUND)

(EXTND)

FUND7

(EXPUND)

FUNR9

(EXFND)

FUNDRO

(ExFu:D

(INTURD)

FUNRI2

(ENTN)

FUNR13

(INTND)

FuNORI4

(EXTUN)

FUNOR15

(INTUD) $\begin{array}{llllll}4 & 3 & 2 & 1 & 8 & 9\end{array}$

a. NHW program funding is from a different source than rest of program unit. or agency

MHN program has at least one stable, ongoing source

of funding (ongoingarenewable, or 2+ years)

() () () () () ()

$(1)()()()()$

c. WHN funding source is flexible in its requirements for program activities

d. MHli funding seurce is flexible in its requirements for target populations

(1)( ) () (1) (1)

-e. MHN funding source exercises tight regulations and accountability procedures

- $f$. Funding source's reporting requirements and categor-

tes seem inadequate or inappropriate for NHN program

$(1)()()()()$

()()()()()()

$(1)(1)(1)(1)$

"g. NHN staff feel that time spent on paperwork and reporting functions detracts from NHN program effort( ) ( ) () () () ()

$h$. Funding source has accepted NHK program staff report-

ing categories as al ternatives to direct service () ( ) ( ) ( ) (1) (1)

1. Personnel within funding body are sensitive to special issues/demands of NHN programing

9. Relationships between NHK program and funding body are positive

()()()()()()

$(1)(1)(1)(1)$

- There are pressures on MHM program staff from other parts of agency to conform to accountability

*1. There are local or regional coordinating bodies that press NHN program to use standard reporting categories (e.g., AAA, United Hay)

$m$. The MHN staff have considerable autonomy in the use

and distribution of funds

$n$. The MHM program has sufficient funding to carry out it primary program goals

$(1)(1)(1)(1)$

()()()()()()

()( )( ) () ()

o. There is some $(1)(1)(1)(1)$ agency programs/units for the same funds $(1)(1)(1)(1)$

(EXIND) = Bxternal Funding Autonomy (INuN) = Internal Funding Autonany 
28. Answer the following questions for the Program Unit, OP Agency if deemed nore agpropriate.

@ERTLV

To what extent are the following statements true for this program unit?(OR Agency ,check here tf rating latter)

OSERII

OSFRVR

CSER'

oservi4

OSERVS

CSTRN6

Costrit

CSERVB

CSERV9

NSERV2

NGERN3

NERRV4

NSERS

NSERV

NERT/

NSERB

NSERV

NERMIO

NSTRII

NSTR12

NEERN3

NSTR24

NSRM15 a. The program unit is well known in the service ared

The reputation of the program unit is positive

c. This program unit is a major provider of services

to the target population in this service area

d. This community has a broad array of other service

agencies accessible to the target population

e. The program unit has a legal mandate to coordinate

The progran unit has a legal mandace co coordinate ()()()()()()

f. The program unit voluntarily coordinates its services with other agenctes

g. The program unit get referrals from other units within the larger ageney

$n$. The program unit get referrals from other agencies

in the community, service area

1. The program unit gives information and referrals

to other aqencies

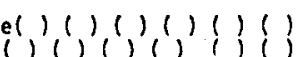

$(1)(1)(1)(1)$

(1)( ) (1) (1)

$(1)()()(1)$

$(1)(1)(1)(1)$

$(1)(1)()(1)(1)$

Answer same questigns for WH:A nmgran ftself:

a. The NHN program is well known in the service ared

by the public, other agencies: it is highly visible( ) ( )( )( )( ) ( )

bb. The reputation of the NHK program is positfve

cc. This NHN program is a major provider of services to the target population in this service area

dd. This NHN program has a legal mandate to coordinate

Its services with other social service agencies

ee. The NHN progran voluntarily coordinates its services

with other social service agencies

$(1)(1)(1)(1)$

The NHN program get referrals form other units wtthin

the larger agency

99. The NHN program get referrals from other agencies

hh. The whin the community, service area. other agencies

() () () () () ()

()()()()()()

ii. The MHN progran is backed up by other direct services

in the larger agency

- jj. The NHN program unit operates largely outstde of the

established service delivery system

- kk. The NHN program unit serves that portion of the tar-

$4(1)(1)(1)$

() $(1)(1)(1)$

-kk. Get population not well served by other agencies ()()()$(1)(1)$

11 . Other agencies in the service area rely on the NHN program unit as an effective intermediary with the

program unit as an effective intermediary with the
target population/comunity target population/comunity

m. The NHK program unit offers elients better access

to avallabie existing services

$\mathrm{nn}$. The MHM program unit offers clients an alternative

to the extablished services

00. The HHW progran unit acts an an advocate for more

oppropriate services for the client population

$(2,1)(1)(2)(0)$

() 1$)(1)(1)(1)$

() 111$)(1)(1)$

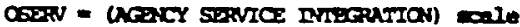

NSERV = (PROGRAM SENICE IMIDARATION) scale 
13/

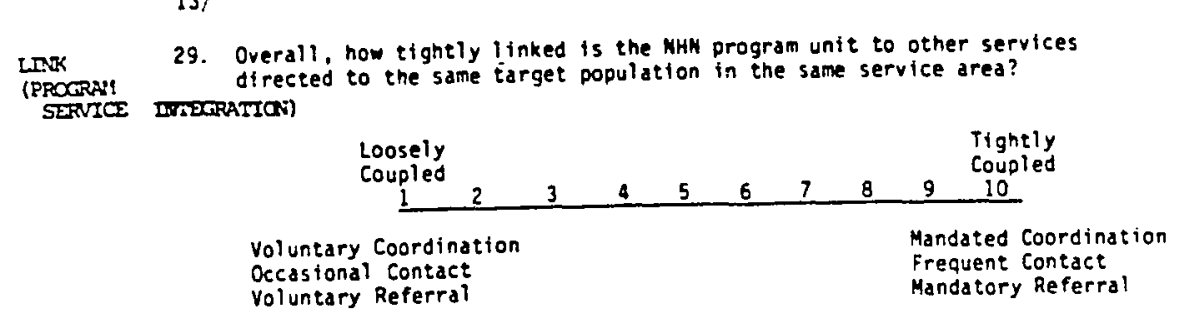

COAHEiTS

30. Rate the client/target population of the NHK program effort:

Nख्D 1

IIIED2

तDIDS

NIDOSA

NESD 6

NED?

NMTOSO

:20009

Noxis

a. The client population has a problem that is social?y stigmatizing

b. The problent of the client population is chronic,

and likely to continue despite services

c. The clients pose a severe burden on the existing

caregivers

(1)( ) (1) (1) (1)

d. The clients frequently have more than one problem $(1,1\})\{\}\{, 1\}$

( ) 1$)(1)(1)(1)$

e. The clients' needs include basic material survival

f. The elients needs include basic social survival $(1)(1)(1)(1)$

skills (befrierding. asking and giving help.etc.)( )( )( ) (1)() ()

9. The clients of this program resist help due to

personal or cultural traditions of self-relfance $(1)(1)(1)(1)$

h. It is particularly difficult to find or retain

informal helping resources for these clients

1. The NHN program staff do not expect this program

The NHN program staff do not expect this program

$(1)(1)(1)(1)$

3. The MHM program staff find te difficult to integrate

this program into the established service system

for these clients

$1)(1)(1)$

$(1)(1)(1)(1)$

COMMENTS:

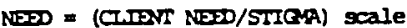


14:

31. Answer the following questions for the program unit, in regard to the way that this program developed.

(BNEREE)

DEVI2

(EMERCE)

DEVRP3

(IMPLART)

DEVIP4

(IIFLAT)

DEVTP5

(INPLANT)

DEVLF6

(EMEPGE)

DEVP7

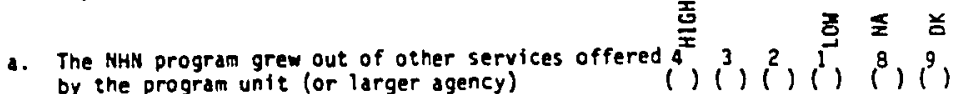

b. The present NHN program staff helped in developing

the program and the approaches

()()$(1)(1)$

-c. Though conceived within the agency, outside staff

were selected to implement the program

() () (1)(1) (1)

d. The program was initiated and developed in response

to comunity or client input/ideas

* e. The program was developed in response to an exter-

nal model of practice (RFP. consultant, etc.)

f. The program was a carefulty planned response to a

clearly identified need
g. The program grew and took on new dimensions through

(1)(1)(1)1)

$1111)(1$

the program grew and took on new diner

$11(1) 111)$

$(1)(1) 1) 1$

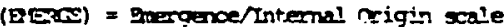
(IIPAir) = Implantedvatermal arigin scale

32. Answer the following questions for the program unit, in regard to the general view or committment to NHN programing:

$\infty$ arm

corrit2

$\cos 1 \mathrm{~T} 3$

$\infty$ orrts

conris

cartis

$\infty$ arrm

$\infty$ ant8

$\operatorname{cosing}$

$\infty \cos 110$

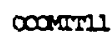

$\infty \cos 2$

$\infty 00 \mathrm{mI}$

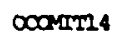

a. NHN program activities are highly relevant, have

b. NHN program is viewed as an adjunct (complementary) to the basic services/mission of this program unit ()$(1)(1)(1)$

c. MHM program is seen is filling gap in the preexisting service system/as essential

- d. The NHW progran is seen priartly as a cost-cutting

measure

(1)( ) () () (1)

e. The NHK program is seen as a way to maintain level of service desplte cutbacks in funding

$(1)(1)(1)(1)$

f. The NHA program was seen primarily as a pragram that

- g. The NHN program was seen as a way to promote local

control, through give-dways, spin-offs

$(1)(1)(1)(1)$

$h$. The Program unit is comitied to the continuation of the present level of NHN program effort

() () () () () (1)

1. The NHN program effort is expected to expand within this "agency"/unit

J. Other similar NHW programs are in the planning or early development stages within this untt

-k. MHN program efforts are seen as temporary, shortterm, and time-limited

() () () () () ()

$(1)(1)(1)(1)$

1. term.

The agency views this program as innovative and

$(1)(1)(1)(1)$

$(1)(1)(1)(1)$

creative but potentially expendable

-10. The agency is likely to abandon the NHN programing

n. Ot fundina is not forthcoming other factor
JESC?IBE

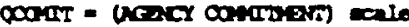


151

cangy 33. Overall how mould you rate the agency level of comitment and

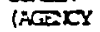
Corrtizer: investment in the hHN programing?

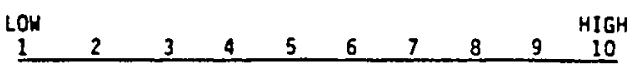

ALTVE

(STAE)

34. To the best of your knowledge had the AHN program effort been abandoned at the time the research project ended (Hovember 1980)?

_res (little sign of revival)

Yes, but.... some indication of possible revival or new funding Partially...some "pleces" have been lost

No. program still going

35. At the time of the site visit what was the state of the NHN program?

STATES

(STACE)

$\operatorname{sTATF}$

(STACE)

STATRH

(STPGE) a. The number of NHN program staff was:

11. Expanding (FTE was being added)

12. Stable (No change in past 6 months, none anticipated)

13. Declining (FTE lost. dropped)

b. The funding for the MHN program was:

(11. Expanding (actual dollar amount increasing)

12. Stable (in $\$$ ), may involve change in source

( )3. Decining (losing \$)

c. The number of helpers (and/or elfents) of the

program was:

() Expanding

2. Stable

i) 3. Decreasing 
161

36. Overall, which of the following statements best describes the stage of program development at the time of your site visit?

( ) 1. Very early idea stage

1). Early initation. first steps taken to implement, planning

() 3. Program underway, with early idenitification, entry occurring

(14. Program underway, developing routine staff and helper

contacts, activities, still open to ideas

() 5. Program fairly routinized, little indication of willingness to try new roles. activities

() 6. Program drifting into more conventionai service approaches. or staff losing interest/commitment

( ) 7. Program either inactive, staffing problems, funding probiems or similar hiatus

(1) 8. Program spun-off, given away to another organization; agency role ended, or available on call basis only

CONENTS:

PULDK

NaIDK
37. How closely is the program unit linked to the agency? (_Not applicable)

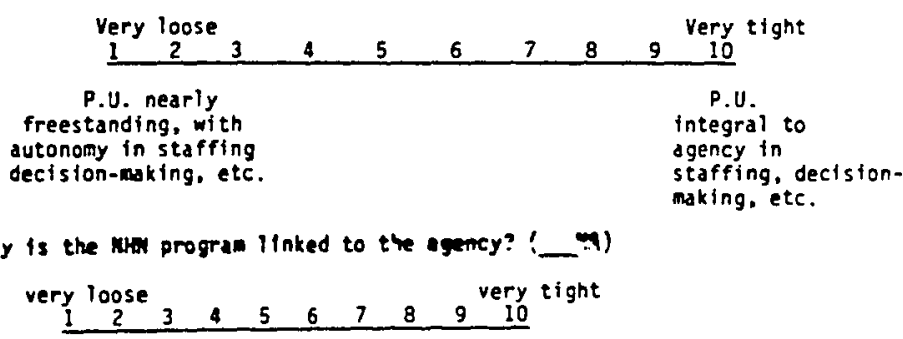


171

(_RIST)

$\cos 5$

('RISK)

( RIST)

Secte

(RISK)

38. Is the structure of the MHN program (use of rules, procedures, staff selection and supervision, etc.) like that of the program unit? (If rating agency, check here

\begin{tabular}{|c|c|c|c|c|c|c|c|}
\hline${ }_{10} \operatorname{Simfiar}$ & & 8 & & 3 & 2 & $\begin{array}{c}\text { Very } \\
3\end{array}$ & ${ }_{2}^{0} i$ fferent \\
\hline
\end{tabular}

39. Is the leadership style in the NHN program (type of supervision. flexibility of job procedures, dectsion-making process) like that of the program unit? (Agency rated.

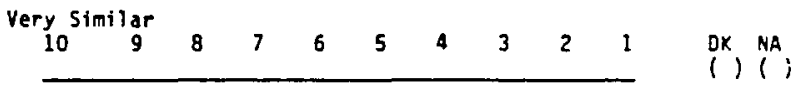

40. At what level has the MHN program been integrated into the host agency?

() 1. primarily at a ifne staff, procedural level, with modest changes in the rules and procedures that staff in the unit follow in their dally routine

( ) 2. primarily at the unit level. in which an entire program or unit has undergone a change in focus, or has been added to the services offered in the agency

() 3. At an agency level, the core objectives of the entire agency have been changed $O R$ a new agency with these objectives has been created.

( ) 8. Not applifable

( ) 9. Don't know

41. To what extent are members of the organization affected by the MHN progran effort?

() 1. Only the activities of one small group of staff have been affected, MINIMAL in effect

( ) 2. The activities of a majority of staff members have been affected, MODERATE in effect

(1) 3. The activities of all members of the agency are affected, MAJOR in effect

( ) 8. Not applicable

( ) 9. Don't know 
181

42. To what extent does the NHN Drogram effort differ from its surroundings (progra: unit or agency on each of the dimenstons below:

DIFERI

DIFFR2

DIFFR3

DIFFR4

DIFFRS

DIFFR6

DIFF? DIFFF9

DIFFR9

DIFTRIO a. Values and noms of staff regarding ways to deliver services

b. Values and noms of staff regarding the relative status of tasks (pricrities)

c. Ways in which decisions are made regarding programs and activities

d. Ways in which supervision and leadership roles are assigned/executed

e. Actual role or function of progran manager

f. Emphasis placed on staff coordination and

communication

9. Allocation or use of physical facilities

h. Allocation or use of support staff. Such as

t. The secretaries, clerks, etc.

f. The anount of time spent by professional staff in the field. community

j. The amount of discretion that staff have over the use of their own time DIRTR $=($ ITIS) Ecale

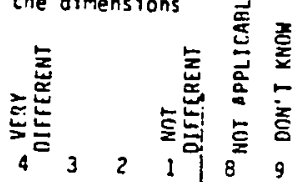

(1)( ) () (1) (1)

(1)(1)(1) 111

(1)( ) () (1) 1 ()

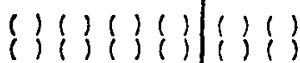

()\})( $)(1)(9\})$

() 1$)(1)(1)(1)$

$(1)(1)(1)(1)$

$(1)(1)(1)(1)$

List below the approaches you rated on the original "Microcomunity" Scale.

Indicate specific target group for each approach, and then note what percent of total staff effort (in the NHN program) is devoted to this particular

approach with this spectfic population. All FTE's together should sum
to 100\% (1.0). BE SURE TO LIST SAME APPROACHES, ND MORE, NO LESS. EXAMPLE:

Project Transition (AGENCY)

Approach I = Mutual Aid, Resocfalization Groups, $70 \%$

Approach II = Volunteer iinking, Hospitalized ilatches, 30\% 


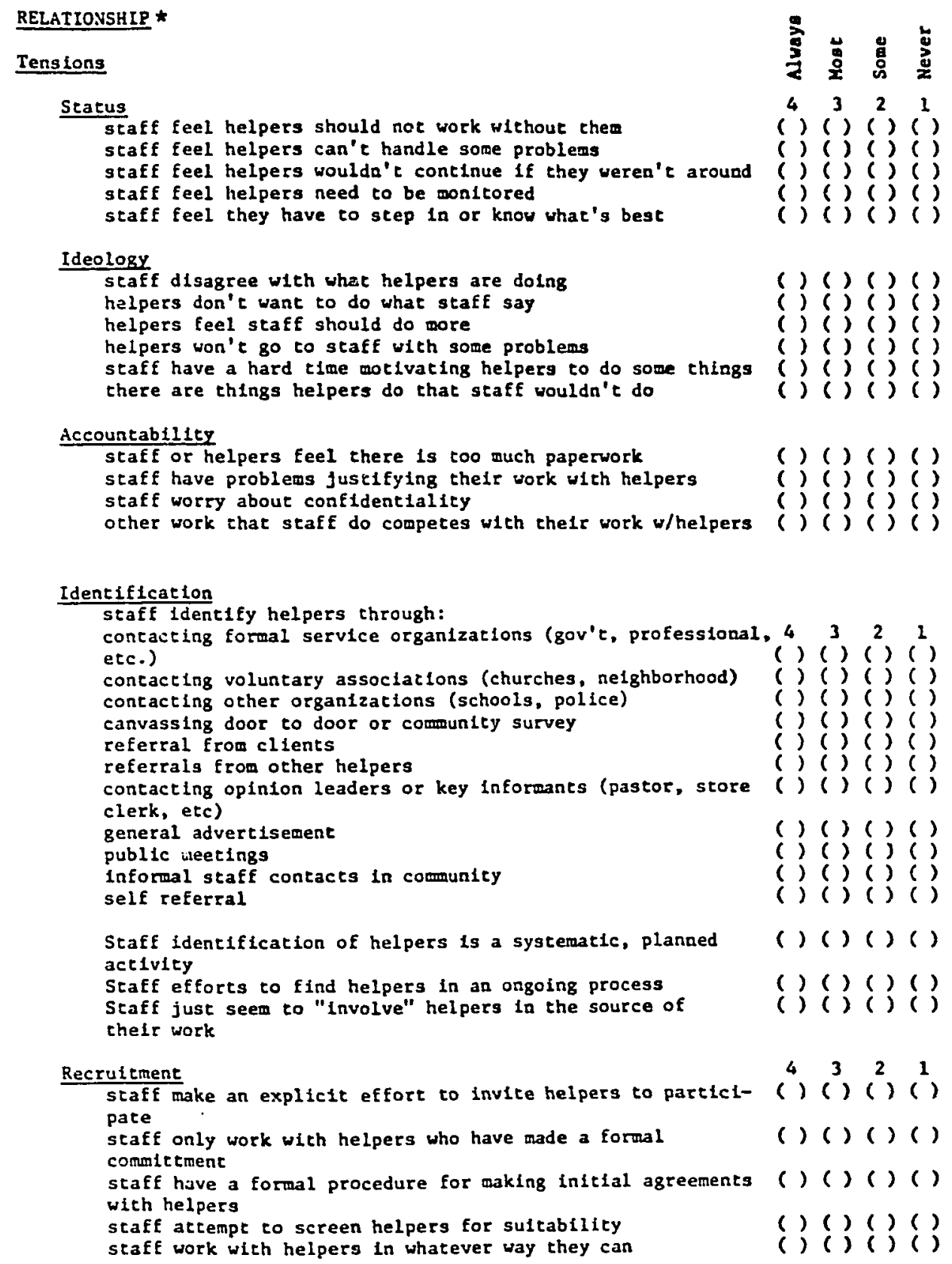

* Rated separately for each approach found in program 
RELATIONSHIP

\section{Balance of control}

Staff

staff define or set expectations for what helpers w11l work on

staff take charge if problems arise with helpers work stafe have authority if conflict arise staff supervise helpers

helpers are paid or relmbursed for their efforts

staff work in helpers' environment (e.g., home, street)

staff assign tasks or clients to helpers

scaff emphasis is on identifying problems that they will work on

helpers see staff as "In charge"

staff ultimacely "hire or fire" helpers

()()()()

()()()()

()()()()

()()()()

( ) ( ) ( () ( )

( ) ( ) ( ) ( )

()()()()

( ) ( ) ( ) ( )

Helper

helpers inltiate tasks or activities

helpers are left to "do their own thing"

helpers take responsibllity for that happens

helpers get staff to do things for them

helper seek staff out for help

helpers get together without staff to make decisions

helpers keep things going by themselves

helpers are expected to report on what they' re doing

helpers are seen as assistants by staff

helpers continue what they're doing without staff

( ) ( ) ( ) ( )

( ) ( ) ( ) ( )

() () () ()

() ( ) ( ) ( )

( ) ( ) ( ) ( )

( ) ( ) ( ) ( )

( ) ( ) ( ) ( )

( ) ( ) ( ) ( )

() ( ) ( ) ( )

()()()

\section{Investment}

StafE

staff live in communtey or target area

staff share cultural references with client/helpers

staff have background experiences in common with helpers

staff seem to identify with helpers

staff would work with this problem/population if they

weren't part of agency

staff see work as a model of practice that can be exported

$\begin{array}{llll}4 & 3 & 2 & 1\end{array}$

() ( ) ( ) ( )

( ) ( ) ( ) ( ) ( )

( ) ( ) ( ) ( )

( ) ( ) ( ) ( )

()()()()

( ) () ( ) ( )

Helpers

helpers share problems/circumstances with those they help

helpers live in comunicy or carget areas

()()()()

helpers are not interested in becoming professionals

( ) ( ) ( ) ( )

the help provided by helpers is part of existing relationship ( ) ( ) ( ) ()

helpers are identified as having been key members of ()()()$($ )

networks

helpers will probably continue what they're doing if $\quad()()$ () ()

program ends

helpers are asked to make comittment to agency (e.g.6 mos) ( ) ( ) ( ) ( )

Overall, please rate the following:

staff identity with agency

staff investment in helpers

helpers Identity with agency

helpers investment in clients/community

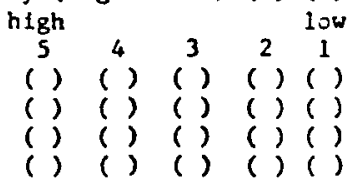




\section{RELATIONSRIP}

Complexley

staff and helpers may work in different settings

staff and helpers work on many differene things

$s t . a f f$ and helpers discuss personal feellngs/experlences

about each other

staff and helper roles may change at different times

staff work with helpers on a one-to-one basis

staff and helpers may see each other outslde of program

activities

\section{Formalley}

helpers recelve expliclt training in helping skills

helpers receive expllctt training/info regarding services helpers are given names such as "protege", "associate", etc. helpers are asked to keep track of what they're doing staff and helper contact is explicitly scheduled

helpers rake on speclalized helping roles

staff bring together many helpers to work on same task

helpers are segregated by task or activity

Density

different staff substitute for each other in their work with helpers

helpers get together with each other on thelr own

helpers crosscut or participate in different types of assoctation

staff/helpers live in same nelghborhoods as client/target population

helpers are sought out for thelr connections

the same helpers are included in other approaches

helpers are also clients

( ) ( ) ( ) ( )

()()()()

()()()()

$\begin{array}{llll}4 & 3 & 2\end{array}$

() ( ) ( ) ( )

() ( ) ( ) ( )

( ) $(5)(3)$

( ) ( ) ( ) ( )

() () ( ) ( )

( ) ( ) ( ) ( )

( ) ( ) ( ) ( )

()()()()

4321

( ) () () (.)

( ) ( ) ( ) ( )

()()()()

()()()()

( ) ( ) ( ) ( )

( ) ( ) ( ) ( )

()()()()

\section{Responsibilicy}

Client Related

individual helpers work with individual cllents

helpers determine what's "best" for clients

helpers have prevlous relationships with those they help helpers find their own clients

helpers spend more cime wich clients than do staff

helprs take charge of special tasks or activities

helpers are the major part of what happens to cllents

$\begin{array}{llll}4 & 3 & 2 & 1\end{array}$

()()()()

( ) ( ) ( ) ( )

( ) ( ) ( ) ( )

() ()()()

() () ( ) ( )

( ) ( ) ( ) ( )

()()()()

Non-client Related

helpers deterwine what will be worked on helpers have an equal vote in what is done nothing would happen if helpers weren't involved

helpers are seen as continuing when program ends

( ) ( ) ( ) ()

( ) ( ) ( ) ( ) ( )

() () () ()

()()()() 


\section{Bureaveratic Standardization}

QUPST2

BUTST2

BCRST3

BURST4

BUPSTS

BCR5T6

BT:ST

BTRST

BRST9

ERSTIO

BRSTH

Binsin

STAFCOI

$5 \mathrm{sicc02}$

STAFCO3

$5 \mathrm{SAFCO}$

STARCOS

STAFCOG

$5 \mathrm{SAFCO}$

STAFCOO

STAFCOS

STAFCOIO

STAFCOII

STAFCOI2

STroOl3

STPICO14

STPEDO15

STATUS1

STATUS2

STATUS3

STATUSA

STATUSS

STATUS6

STATUS

STATUS:

STATS

TTATUS10

SATIUSL

STATUS12

5 STATSI3

STATUSi4

STAUUS15

SIATUSI

STATUS17

Helper are paid for their efforts

Helpers are reimbursed for their efforts

Helpers are asked to make camiument to agency

Helpers identify with agency

Staff and helpers discuss persconal feelings/experiences with each other

Staff ad helpers see each other outside of program activities

Helpers receive explicit training in helping skills

Helpers receive arientation regarding services/acency

helpers are given titles such as "protege". "associate"

Helpers are asked to keep track of what the do

Staff and helper contact is explicitly scheinled

Helpers are segregrated by task or activity (i.e., specialized)

helpers work in agercy facilities

\section{Staff Control}

Staff define or set expectations for what helpers do

Staff take charge if problens arise with helpers' wark

Staff assign tasks or client to helpers

Staff enphasis is on identifying problems for helpers to work on Helpers see staff as "in charge"

- Helpers initiate tasks or activities

- Helpers get staff to do things for them

- Helpers seek staff ast for help

Helpers are expected to repart to staff on their activities

Helpers are seen as assistants by staff

- Helpers detemine what's best for clients

- Helpers have priar relationships with those they help

- Helpers find their own "clients"

- Helpers determine what will be worked on

- Helpers have an equal say in what is done

Statas Concerns

Staff supervise helpers

Helpers are left to do their onn thing

kelpers take responsibility for what happens

staff seem to identify with helpers

Staff seem to identify with helpers

if waild want to weik with this problem or population even if they were not part of the agency

Staff are developing a model of practice to export

telpers are not interested in beconing professionals

Helpers spend more tine with clients than do staff

Helpers are the major part of what happens to clients

Helpers take charge of special tasks or activities

Staff feel helpers should not work without them

Staff feel helpers cannot handle some pooblems

Staff feel helpers would not contimse if staff were not arourd Staff feel helpers need to be monitored

Staff feel they have to step in, that they know what's best

Staff disagree with what helpers are doing

There are things helper do that staff woild not do

NOrE: The itens an this page and the next page are included here, in this form to facilitate identification of items selected from those included on the revious three peges, and to present the compiter names for the itens used to measure the staff-helper relation to prip. 
Complexity

anple

$\operatorname{cospix}$

compuso

campixs

Comp $x 5$

Contro

$\infty \mathrm{MP}, x]$

$\cos 1 \times 8$

Compleg

COMpixo

Complal

Covp: XI2

Staff work in helper's emviroment (hanes, street, neighborhood)

Staff share custural references with client Melpers

Staft have background experiences in common with helpers

Staff and helpers work in different settings together

Staff and helper roles may change at different times

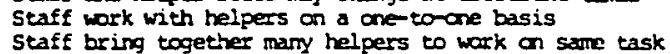

Staff bring together many helpers to wark on same task
Different staff substitute for ench other in their work with

fferent staf

Helpers get together with each other on their own

The same helpers are included in other approsches

Helpers are also clients

other work that staff do conpetes with their work with heipers 
APPENDIX E

RESULTS OF TESTS FOR BIAS WITH NUISANCE VARIABLES 
TABLE XVII

RANDOMI EFFECIS ANALYSIS OF VARIANCE FOR BIAS OR NUISAIYCE EFFECTS

Variables Tested:

Interviewer

Number of work days on site visit

Number of staff met by interviewer

Number of administrators met by interviewer

Amount of written documentation obtained regarding agency

Amount of written documentation obtained regarding program

Round of site visit $(1,2)$

Age of agency (years)

Age of natural helper program (years)

Continuity of funding* (1)

Auspices (private vs. public)

${ }^{*} \mathrm{p} \quad .05$

1. Continuity of Funding: measures were Research and Development (or short-term funding) and Legislated Funding (ongoing or long-term) 
APPENDIX F

SCATE COISTRUCTIOII PROCESSES

$>$ 
SUMAARY OF SCALE CONSTRUCTION PROCESS

Several steps were followed in the process of constructing scales to measure the major constructs included in this study. Initially items were developed and proposed for certain scales on the basis of theoreticai or conceptual issues, as discussed in Chapter II. Once the data had been camputerized for analysis purposes there were two major steps followed prior to computation of the final scale scores.

The first step involved the careful inspection of the intercorrelation matrix. Among the items proposed for any scale this inspection permitted the determination of how many of the other items each one was correlated with at a significant level $(p \leq .05)$. The rule of thumb that was applied at this stage was to drop an item if it was correlated with less than 258 of the other items in the scale. Thus, in the event of a 10-item scale an item was dropped if it was correlated with two or less items. For any item dropped fram its scale at this step a second inspection of the correlation matrix was carried out to determine whether, in fact, the item was highly correlated with another of the proposed scales. If so the item itself was checked to see whether, in fact, there was any theoretical or conceptual support for its inclusion in the other scale. The decision to include an iten in another scale was made very infrequently.

The second step in the scale construction involved the use of 
SPSS Reliability program to analyze the actual properties of the proposed scale. All of the items proposed for an single scale were entered into a reliability analysis. This program produced the correlation matrix for the named items, scale statistics (mean, variance, standard deviation, item mean, minimm, maximm, range, and variance), item-total statistics (scale mean if item deleted, corrected itemtotal correlation, squared miltiple correlation, alpha if item deleted), and the overall scale reliability (alpha, and standardized item alpha). All items entered into the reliability analysis were equally weighted. Using this reliability information the itens which reduced the overall scale reliability could be identified, and a determination made regarding the value of deleting or retaining the item. Also at this step items which contributed highly to the overall reliability but reduced the number of cases under consideration (because of missing data due to lack of information rather than conceptually appropriately missing) were examined for the effect on the scale reliability if they were deleted. Thus items were deleted at this step either if they pulled the reliability of the scale down significantly or if they involved missing data.

In same cases versions of the scale were samewtat less reliable with items removed, but this was warranted by the need for a scale applicable to the full sample. Some scales were split into two at this step to measure a construct as accurately as possible for all the cases while retaining those items that measured only for certain cases. This was done with the Funaing Autonomy measure, which was split into Internal Funding Autonamy for programs located in larger 
agencies, and External Funding Autonomy, for all the programs.

once the reliabilities of the scales were determined, each of the scale scores was canputed by adding the values for the appropriate items retained in the final form of the scale. The items were all equally weighted. The sum then was divided by the mumber of items in the scale to return it to the standardized range, of a mean value of 0 , standard deviation of \pm 1 . The values for all the variables had previously been standardized using the SPSS Condescriptive program to permit their addition.

It should be noted that the steps followed in this process have been conservative in their effort to retain itens of reasonably sure significance, and delete those which confound the results by introducing missing cases, potentially making the results more difficult to interpret. However, among the 1,382 correlations predicted among the items in the scales, at least 1,062 were in the predicted direction, or over $77 \%$ of the predicted correlations. This result suggests, that despite the limitations of the sample size, the resulting correlations could hardly be attributed totally to chance.

Table XVIII presents infomation on the scale fomation process, including the number of items proposed for each scale, the number of items deleted at step one (analysis of the intercorrelation matrix), the number of items deleted at step two (reliabilities and missing case analysis), and the number of items included in the computation of the final scale score. The other tables in this Appendix present the actual items in each scale, by computer name and by item stem. All the data used for these analyses are available from the author upon request. 


\section{TABLE XVIII \\ NTMBER OF ITEMS IN SCALES, PROPOSED TO FIMAL FORY, \\ BY STEP}

SCALE NANE

$\begin{array}{clll}\text { PROPOSED } & \text { DEIETIPD } & \text { DETETED } & \text { FIVAI } \\ \text { SCALE } & \text { STEP } 1 & \text { STEP } 2 & \text { SCAIE }\end{array}$

AGENCY SIZE

AGENCY FORALIZATION

AGENCY COMPLEXITY

PROGRAM SIZE

PROGRAM FORMAIIZATION

PROGRAM CONPLEXITY

WORK GROUP IDENITTY

LEADERSHIP STYLE

PEER SUPPORT

FUNDING AUTONOMY

IVIERNAL FUNDING AUTONONY

EXIERRNAL FURDING AUTCNONY

AGENCY SERVICE INITGRATION

PROGRAY SERVICE INIDGRATION

GENERAL ENVIRCANENT

AGENCY COR.PITIENT

STAGE OF DILITINATION

CIITET :IEED/STIGA

DIFFEREXCE/CO PATIBIIITY

ORIGIN

ENERGENCE

D.PLANIED

BUREAUCRATIC STANDAFDIZATION

STAIUS CONCERNS

STAFF CONIROL

REIATIOISHIP COIPLEXITY

(HETLER ALTONOMI)

$\begin{array}{rr}3 & 0 \\ 16 & 2 \\ 3 & 0 \\ 4 & 0 \\ 16 & 4 \\ 7 & 0 \\ 7 & 1 \\ 15 & 4 \\ 14 & 4\end{array}$

172

$\begin{array}{rr}10 & 1 \\ 16 & 4 \\ 3 & 0\end{array}$

$\begin{array}{lr}1 & 2 \\ 0 & 14 \\ 0 & 3 \\ 1 & 3 \\ 3 & 9 \\ 2 & 5 \\ 1 & 5\end{array}$

$1^{\mathrm{a}} \quad 10$

$-b$

11

$3 \quad 6$

0

$\begin{array}{lll}14 & 5 & 0\end{array}$

$\begin{array}{llll}7 & 0 & 0 & 7\end{array}$

10

17

8 1

(4)

$I_{b}$

(3)

2
0

$\begin{array}{cccc}14 & 3 & 2 & 9 \\ 16 & 6 & 0 & 10 \\ 16 & 3 & 0 & 13 \\ 13 & 5 & 0 & 8 \\ & & & \end{array}$

a) Deleted due to undesirable missing cases

b) Split due to missing cases on some items

c) Created with items determined to be highly intercorrelated, fram those deleted fram Status Concerns and Staff Control scales at step I. 
TABLE .XIY

\section{AGENCY STRUCTURE SUBSCALES}

\section{Agency Size}

TOBUDA - Total agency budget

AGSTAF - Paid staff in total agency

Agency Complexity

NUMAPP - Number of network approaches used by agency

NIMACT - Number of client types served by agency

ASITES - Number of different sites at which agency had branches

\section{Agency Formalization}

OFORMI - Activities and responsibilities of each staff position specified

OFORM2 - Agency relies on written job descriptions and written job procedures

OFORM3 - Agency follows predetermined criteria and procedures in hiring staff for NHN program

OFORM4 - Within the agency staff have specialized roles with little overlapping responsibility

OFORM5 - Standardized performance evaluation criteria are used to judge staff performance in agency

OFOPM16 - Agency has written standards and rules for coordination of staff activities

OFORM7 - In working with clients agency staff are required to follow standard procedures

OFORM8 - The agency has a manual of precedures for working with clients

OFORM9 - Staff must report on their activities in writing using a standard report form

OFORMI0 - In the Agency failure to follow prescribed procedures is the basis for sanctions or dismissal

OFORMII - Line staff in this agency cannot make decisions to change or add programs without higher approval

OFORM12 - Decisions and changes of program made by program managers require higher approval

OFORMI4 - Agency director reports to a Board or Council of Directors

STRUCT - Overall rating of degree to which agency structure and program structure (use of rules, procedures, staff selection, supervision) are similar. 
TABIE XX

PROGRAM STRUCTURE SUBSCALES

Program Size

NHNSTAF - Paid staff working in NHN program

NHBUD - Total budget for the NHN program

FTE - Actual staff effort (FTE) in NEN program

\section{Program Camplexity}

NUMNCT - Number of NHN program client types

NLMAPP - Number of approaches in NHN program

FUNDIV - Number of different funding sources

NSITES - Number of sites at which NHN program has branches

PUSECT - Number of programs in same unit as NHN program

\section{Program Formalization}

NFORMI - In NHN program the activities and responsibilities of each staff position have been specified

NFOR12 - Written job description and procedures are relied on in NHN program

NFORM3 - When hiring staff it is necessary for NHN staff to follow predetermined procedures and criteria

NFORM5 - Standard performance evaluation criteria are used to judge staff performance in NHN program

NFORM7 - Staff are required to follow standard procedures in working with clients/helpers in NHN program

NFORN9 - Staff are required to report on their activities in writing on standard reporting forms

NFORMIO - Failure to follow prescribed procedures leads to sanctions and possibly dismissal

NFORMl2 - Program decisions and changes made by manager must have higher approval

NFORMI3 - Program manager reports to a higher administrator

Work Group Identity

GRPID3 - The manager of the NFIN program is responsible for other programs as well

GRPID4 - The NHN program does not have a separate facility from other programs or divisions

GRPID5 - The NHN program does not have its own funding, separate from that of other programs in the agency/unit

GRPID6 - Staff that work in the NHN program also work on other activities or in other programs in the agency

GRPID7 - The NHN program staff do not constitute a clearly distinguishable group within their program unit 
TABIE XXI

WORK CLTMATE SUBSCALES

\section{Ieadership Style}

LEADRI - Supervisory and program roles within the NHN program are clearly defined and separate

LEADR2 - The program manager does not emphasize giving directions or coordinating actions of subordinates

LEADR3 - The program manager does emphasize sharing ideas, giving advice, and supporting subordinates' efforts

LEADR5 - Staff are expected to work on their own with only limited supervision

LEADR7 - Program manager calls staff meetings whenever a problem or decision requires it

LEADR8 - Program manager keeps staff posted about relevant agency plans, activities, and problems

LEADR9 - Program manager understands what staff in NHN program must do to succeed and how to do it

LEADRIl - Program manager and staff decide jointly on work procedures and activities

IEADR12 - Program staff freely discuss job-related matters, ideas, and problems with the program manager

LEADRI3 - Program staff view the manager's decisions and views with confidence and trust

\section{Peer Support}

PEERI - The NHN stäff get together to discuss their work (problems and successes) regularly

PEER2 - The NHN staff work together as teams

PEER4 - The INHN staff fill in or substitute for each other.

PEER5 - The NHN staff commoly ask for and give help or advice to each other

PEER7 - NHN staff have found like-minded persons within their agency context

PEER3 - NFN staff have found like-minded persons outside of the agency context

PEERIO - NHN staff seem to share a sense of conmon interest and purpose relative to NHN programing

PEERI 4 - NHN staff feel that their efforts contribute and complement overall agency mission and programs 
TABLE XXII

ENIROMDIIAL LINUAGE SUBSCALES

Progran Service Integration

NSER2 - The reputation of the NFN program is positive

NSERN3 - The Neputation of the Naj prograider of services to the target population in this service area

NSERV3 - The NWN program is a major provider of services to the target population in this service
NSERV4 - The NHN program has a legal mandate to coordinate its services with other public agencies

NSERVS - The NWN program voluntarily coondinates its services with other social service programs

NSERV - The NHN program gets referrals from other agencies within its cammity or service area

NSERV - The NNN program gives infomation and referrais to other agencies

NGERVI1 - The NIN program unit serves that portion of the target population not well served by othes agencies

NSERN12 - Other agencies in the service area rely on the NN prorram as an intemidiary with the target population/ommunity

NSERV 3 - The NAN program unit offers elients better acoess to available existing services

NSERVI5 - The NN program unit acts as an advocate for more appropriate services for the target population

LINK - Overall how tightly linked is NHN program to others in service area serving same target population (s)

Agengy Service Integration

OSERV2 - The reputation of the agency is positive

OSERV3 - The agency is a major provider of services to the target populaticn in this servioe area

OSERVs - The agency has a legal mandate to coordinate its services with other social and public agencies

OSERV 5 - The agency has a legal mandate to coordinate its services with other
OSterV6 - The agency valuntarily coordinates its services with other agencies

OSERV - The agency gets referrals frum other agexies in the service area or cammity

OSERV - The agency gives infomation and referrals to other agencies

General Camminity

ComuN - What type of commity or locale does this agency serve? Rural, Rural/Urban Mix Subrbar, Urban

DENSAB - What is the density of the service area of the NHN program? Low, Medium, High Density

External Funaing Autanamy

FUNDR3 - NFN funding source is flexible in its requirements for progran activities

FUNDR5 - NEN funding source does not exercise tight reoulations and acoountability procedures

FUNDR6 - Runding souroe's reporting requirements and categories seen adequate or appropriate for NHN program

FUNDR7 - NNN staff do not feel that time spent on paperwork and reporting detracts from Nin program effort

FUNDR9 - Persomel within funding body are sensitive to special issues/demands of NmN programing

FUNDRIO - Relationships betwen NNN program and funding body are positive

FUNDRI2 - There are no local or regiomal coordinating bodies that press NN program to use standard reporting categories

FUNDR14 - The NFN program has sufficient funding to carry out its primary progran goals

\section{Internal Funding Autoramy}

FUNDRI - NHN program funding is fram different source than rest of program unit or agency

FUNDRI1 - There are few pressures on NFN program staff fram other parts of agency to conform to general accountability procochres

FUNDR13 - The NHN staff have considerable autonany in the use and distribution of funds

FUNDI5 - There is little competition between NNN program and other agency programs/units for the same

funds 


\title{
TABIE XXIII
}

\author{
INONATION SUBSCAIES
}

Acenc: Comitnent

00012 - The NEN program is not viewed as an adjunet to the basie services/mission of the agency

OCX:3 - The INN program is seen as filling a gap in the pre-existing sevice system. . . is seen as essential

oco:16 - The NHN program is seen as a program that is more acoessible and acoeptable to clients $\infty$ oxis - The agency is comitted to the continuation of the present level of NN program effort ocows - The NHN program effort is expected to expand within the agency

$\infty_{0 N 1}$ - NFN program efforts are not seen as temporary, short-term or time-limited

ocoil2 - The agency does not view this program as expendable, although potentially innovative and creative COMLEV - Overall level of agency comitment and investment in the NHN program

Emergence

DEUPI - The N-N program grew out of other services of fered by the agency

DEVLP6 - The program was not carefully planned in response to a clearly identified need

Stiema (Client Need)

NESDI - The client population has a problem that is socially stignatizing

NEed 2 - The problem of the client population is chranic, and likely to continue despite services

NEED3 - The clients pose a severe.burden on the existing caregivers

VEest - The clients frequently have more thar one problem

NLso5 - The clients' needs include basic material survival resources (money, jobs, food, shelter, ete.)

NErad6 - The clients' needs include basic social survival skills (befriending, asking and giving help, etc.)

NEEDS - It is particularly difficult to find or retain informal helping resources for these clients

Stage of Program Inplementation

ALIVE - State of the program effort 18 months after first contact fram NHN Research Project

STAIES - State of the program staff size at the time of site visit

STIEF - State of the program funding level at time of site visit

STATE - State of mumber of helpers/clients for NAN program at time of site visit

ACrFin - Age of NiN program at time of site visit

AGEA - Age of agency at time of site visit

STAGE - Overall stage of program develogment at time of site visit

$\underline{\text { Risk }}$

DIFFI - Extent to which values and noms of program staff differ from larger agency on ways to deliver services

DIFF2 - Extent to which values and noms of staff regarding the priorities differ between NHN program and agency

DIFFR 3 - Extent to which ways in which decisions are made regarding programs and activities differ between program and agency

DIFrR4 - Extent to which ways in which supervision and leadership roles are assigned/executed differ between program and agency

DIFFR5 - Extent to which actual role or function of program manager differs from NHN program to - Extent to which

DIFFr6 - Extent to which the enphasis is placed on staff coardination and commication differs from N-N program to agency

DIFFR - Extent to which allocation or use of support staff differs between SiNN program and agency DIFFR - Extent to which the amount of time spent by professional staff in the field differs fram NNN program to agency as a whole

DIFFRIO - Dxtent to which the amount of discretion that staff have over the use of their own time differs between NWN program and agency as a whole

STRUCT - Overall similarity of NRN program structure to agency structure

ITIEV - Level at which Nov progran was integrated into agency

SCOPE - Dxtent to which organization members affected by NWN program effort

IEADSI - Overall sinilarity between leadership style in NWN Frogram and agency as a whole 


\section{Bureaucratic Standardization}

BURST3 - Helpers are asked to make a time comitment to the agency

BURTA - Helpers identify with the agency perspectives

BRST7 - Helpers receive training in helping skills

BURST8 - Helpers receive orientation regarding agency services

BURST9 - Helpers are given titles such as protege, associate, therapist

EURST10 - Helpers are asked to keep track of what they are doing

BURSTII - Staff and helper contact is explicitly scheduled

EURST12 - Helpers take on routine helping roles that are specialized by task

BURST13 - Helpers are segregated by task or activity (i.e., specialized)

Staff control

SLAFCOI - Staff define or set expectations for helpers' tasks

SIAFCO2 - Staff take charge if problems arise with helpers' work perfomance

STAFCO3 - Staff assign tasks and client to helpers

STAFCO4 - Stafí identify problems that helpers can work on

SIAFCOS - Helpers see staff as "in charge"

STAFCO6 - Staff ultimately 'hire and fire' helpers

STAFCO7 - Helpers do not initiate tasks or activities

STAFCO10 - Helpers are expected to report to staff on what they are doing

IIAFCOIl - Helpers are seen as assistants by staff

STAFCO13 - Helpers do not have pre-existing relationships with those they help STAFCO14 - Helpers do not find their own "clients"

STAFCOI5 - Helpers do not determine what will be worked on

STAFCOI6 - Helpers do not have an equal say in what is done

Status Concerns

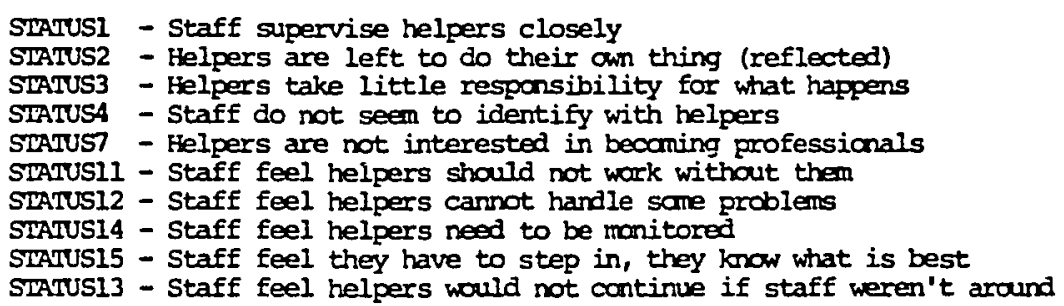

Complexity

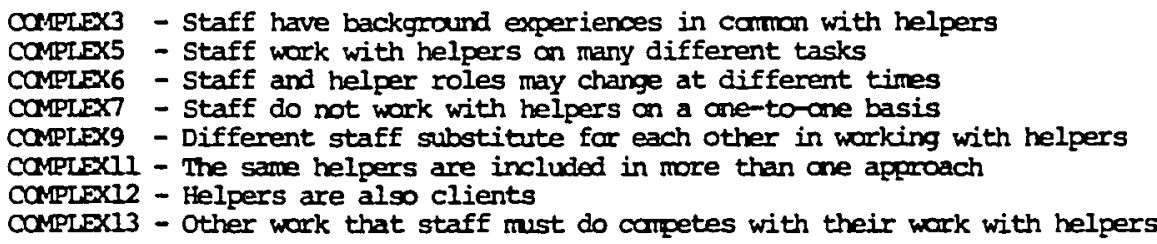

Helper Autanany

AUTOHETPI - Helpers get staff to do things for them AUTOHEDP2 - Helpers have an equal say in what is done AUTOHETP3 - Helpers take charge of special tasks or activities 